THAIS MARIA AIMOLA RONCA DALE VEDOVE

AMIDO TERMOPLÁSTICO COM POTENCIAL INDICADOR DE MUDANÇA DE PH PARA EMBALAGENS DE ALIMENTOS

São Paulo

2019 
THAIS MARIA AIMOLA RONCA DALE VEDOVE

\section{AMIDO TERMOPLÁSTICO COM POTENCIAL INDICADOR DE MUDANÇA DE PH PARA EMBALAGENS DE ALIMENTOS}

Dissertação apresentada à

Escola Politécnica da Universidade de São Paulo para obtenção do Título de Mestre em Ciências.

São Paulo 


\section{AMIDO TERMOPLÁSTICO COM POTENCIAL INDICADOR DE MUDANÇA DE PH PARA EMBALAGENS DE ALIMENTOS}

Dissertação apresentada à Escola Politécnica da Universidade de São Paulo para obtenção do Título de Mestre em Ciências.

Área de Concentração:

Engenharia Química

Orientadora:

Prof ${ }^{a}$. Titular Carmen C. Tadini Co-Oriendadora:

Dra. Bianca Chieregato Maniglia 
Autorizo a reproduçāo e divulgaçăo total ou parcial deste trabalho, por qualquer meio convencional ou eletrônico, para fins de estudo e pesquisa, desde que citada a fonte.

Este exemplar foi revisado e corrigido em relaçăo à versăo original, sob responsabilidade única do autor e com a anuência de seu orientador.
São Paulo, 18 de Setembro de 2019
Assinatura do autor: L hoú maria fimoia R, v vudare
Assinatura do orientador:

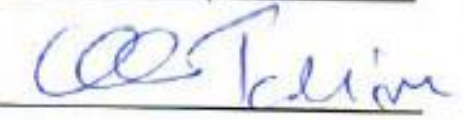

Catalogação-na-publicação

\section{VEDOVE, THAIS M.A.R.D}

AMIDO TERMOPLÁSTICO COM POTENCIAL INDICADOR DE

MUDANÇA DE PH PARA EMBALAGENS DE ALIMENTOS / T. M. VEDOVE,

B. C. MANIGLIA, C. C. TADINI -- versão corr. -- São Paulo, 2019. $146 \mathrm{p}$.

Dissertação (Mestrado) - Escola Politécnica da Universidade de São Paulo. Poli-Integra.

1.Amido termoplástico 2.Antocianina 3.Extrusão 4.Filme biodegradável 5.Indicador de pH I.Universidade de São Paulo. Escola Politécnica. Poli Integra II.t. III.MANIGLIA, BIANCA C. IV.TADINI, CARMEN C. 
Vedove, Thaís Maria Aímola Ronca Dale. Amido termoplástico com potencial indicador de mudança de pH para embalagens de alimentos. 2019. 147 p. Dissertação (Mestrado) - Escola Politécnica, Universidade São Paulo, São Paulo, Brasil.

Aprovado em:

Banca Examinadora

Prof. Dr.

Instituição:

Julgamento:

Prof. Dr.

Instituição:

Julgamento:

Prof. Dr.

Instituição:

Julgamento: 


\section{DEDICATÓRIA}

Dedico este trabalho a minha mãe Fátima, pelo exemplo de pessoa, apoio infinito e amor incondicional.

A minha irmã Tamara, que não mediu esforços para que eu chegasse até aqui, minha companheira da vida.

À memória de minha avó Isaura, que sua luz ainda ilumina meu caminho e me protege. 


\section{AGRADECIMENTOS}

Primeiramente agradeço a Deus, por ter me dado saúde, além de ser minha fonte de força para superar as dificuldades e me auxiliar no caminho da vida.

A minha mãe Fátima, que sempre se empenhou para que eu tivesse uma educação exemplar, e não mediu esforços para que eu chegasse até aqui. E a minha irmã Tamara, pelo apoio, risadas, por me financiar. Vocês são minha vida, sem vocês não seria possível realizar esse sonho e todos os demais. Eu as amo incondicionalmente.

Em especial à Dra. Bianca Chieregato Maniglia e a professora Carmen Cecília Tadini pela dedicação, confiança e orientação durante esses anos de trabalho.

A todos meus amigos do laboratório dessa Universidade, pela amizade e convívio diário e momentos de descontração.

À Fapesp, processo, 2013/07914-8, pelo apoio financeiro nas análises.

$\mathrm{E}$ a todas as pessoas que de forma direta ou indireta auxiliaram na execução deste trabalho.

Muito obrigada. 
"Por vezes, sentimos que aquilo que fazemos não é senão uma gota de água no mar. Mas o mar seria menor se lhe faltasse uma gota".

Madre Teresa de Calcutá 
Vedove, Thaís Maria Aímola Ronca Dale. Amido termoplástico com potencial indicador de mudança de pH para embalagens de alimentos. 2019. 147 p. Dissertação (Mestrado) - Escola Politécnica, Universidade São Paulo, São Paulo, Brasil.

\section{RESUMO}

Seguindo o desenvolvimento sustentável, empresas e pesquisadores da área de embalagens estão em busca de desenvolver materiais biodegradáveis provenientes de recursos renováveis. Este trabalho propôs, primeiramente, a produção de filmes biodegradáveis a base de amido de mandioca elaborados por extrusão, avaliando diferentes aditivos: glicerol e água como plastificantes, ácidos como modificadores químicos e celulose microfibrilada (CMF) como reforçador. Os filmes foram avaliados quanto às suas propriedades mecânicas (espessura, resistência máxima à tração, porcentagem de elongação na ruptura e módulo de Young), e de superfície (umidade, solubilidade, ângulo de contato, diferença de cor e opacidade). Obteve-se filmes com características diversificadas e promissoras. A partir do resultado obtido foi escolhido o filme com as melhores propriedades para aplicação como embalagem para alimentos. Em uma segunda etapa, filmes com adição de antocianina foram desenvolvidos para potencial aplicação como embalagem inteligente. Além das propriedades descritas para avaliar os filmes elaborados na primeira etapa do trabalho, microestrutura e cristalinidade também foram avaliadas. A atividade indicadora de mudança do $\mathrm{pH}$ foi verificada para dois tipos de carne (bovina e de peixe), em que três diferentes concentrações de antocianina (5, 10 e 20) mg de antocianina/100 $\mathrm{g}$ de filme, em duas condições de armazenamento (ambiente e sob refrigeração) foram testadas. Por meio da medida da cor do filme foi possível correlacionar a alteração do pH dos alimentos testados. Os resultados obtidos foram promissores, indicando que os filmes se mostraram bons indicadores de alteração do $\mathrm{pH}$, pela alteração da cor perceptível à olho nu, sendo essa mudança mais acentuada em filmes com menor conteúdo de antocianina.

Palavras-chave: amido termoplástico, antocianina, extrusão, filme biodegradável, indicador de $\mathrm{pH}$. 
Vedove, Thaís Maria Aímola Ronca Dale. Thermoplastic starch with potential pH change indicator for food packaging 2019. 147 p. Dissertation (Master's degree) Escola Politécnica, University of São Paulo, São Paulo, Brazil.

\begin{abstract}
Following sustainable development, companies and researchers of the packaging area are developing biodegradable materials from renewable resources. This work proposed the production of biodegradable cassava starch films by extrusion, evaluating different additives: glycerol and water as plasticizers, acids as chemical modifiers and microfibrillated cellulose (CMF) as reinforcer. The films were evaluated by their mechanical properties (thickness, tensile strength, percentage of elongation at break and Young's modulus), and surface (moisture, solubility, contact angle, color difference and opacity). It was obtained films with diversified and promising characteristics. From the obtained results the optimal film was chosen, that is, with the best properties for application as food packaging. After that, films were elaborated with anthocyanin for potential use as smart package. Beyond the characterization already described for films produced in the first step of this work, morphology and crystallinity were also evaluated. $\mathrm{pH}$ indicator activity was verified for two kinds of meat (beef and fish), at three different concentrations of anthocyanin (5, 10 and 20) $\mathrm{mg}$ of anthocyanin/100 $\mathrm{g}$ of film, at two different storage conditions (ambient and under refrigeration). By the color change measurement of the film, it was possible to correlate the $\mathrm{pH}$ change of the foods tested. The obtained results were promising, since the films performed as good $\mathrm{pH}$ indicators, as the color changes was noticeable to the naked eye, and this change was more pronounced in films with lower anthocyanin content.
\end{abstract}

Keywords: thermoplastic starch, anthocyanin, extrusion, biodegradable film, $\mathrm{pH}$ indicator. 


\section{LISTA DE FIGURAS}

Figura 1 - Mandioca in natura (a); Amido de mandioca (b) ……..........................29

Figura 2 - Representação estrutural da amilose e respectiva forma helicoidal .........30

Figura 3 - Representação estrutural da amilopectina e seu respectivo formato de ramificações..... 30

Figura 4 - Representação esquemática dos três tipos de cadeias presentes na estrutura ramificada da amilopectina. Cadeia $A$ em vermelho, cadeia $B$ em azul, ambas sem grupos redutores, e cadeia $\mathrm{C}$ em preto, com grupo redutor .31

Figura 6 - Estrutura química das antocianinas .46

Figura 7 - Estruturas moleculares encontradas em solução aquosa com diferentes valores de $\mathrm{pH}$. Cátion flavilium $\left(\mathrm{AH}^{+}\right)$, base quinoidal $(\mathrm{A})$; pseudobase incolor ou carbinol (B) e chalcona (C) e sua ampla variaçãoes de cores. 47

Figura 8 - Esquema do processo de obtenção do amido termoplástico (TPS) ..........53

Figura 9 - Processo de produção dos filmes de amido termoplástico (TPS) na extrusora .55

Figura 10 - Analisador de textura com probe A/TGT (Stable Micro Systems) .57

Figura 11 - llustração do ângulo de contato formado pela gota depositada sobre a superfície do filme .58

Figura 12 - Diagrama CIELab para os parâmetros de cor $L^{*}, a^{*} e b^{*}$. 59

Figura 13 - Curva de passagem granulométrica da celulose microfibrilada (CMF) ...63 Figura 14 - Distribuição do tamanho de partícula de celulose microfibrilada (CMF). 64 Figura 15 - Microscopia eletrônica (MEV) da celulose microfibrilada (CMF), com aproximação de $15.000 \times$ (a), (b) e (c), $30.000 \times$ (d) e (e) e de 60.000x (f) 66

Figura 16 - Difratograma de raios-X da CMF, com o respectivo índice de cristalinidade (I.C. \%) .67

Figura 17 - Fotos dos filmes extrudados de amido termoplástico (TPS) 69

Figura 18 - Espessura $(\mathrm{mm})$ e Tensão (MPa) dos filmes extrudados de amido termoplástico (TPS) sem e com celulose microfibrilada (CMF) .77 Figura 19 - Elongação (\%) e Módulo de Young (\%) dos filmes extrudados de amido termoplástico (TPS) sem e com celulose microfibrilada (CMF) .78 Figura 20 - Umidade $(\mathrm{g} / 100 \mathrm{~g})$ e Solubilidade (\%) dos filmes extrudados de amido termoplástico (TPS) sem e com a incorporação de celulose microfibrilada (CMF) ...86 
Figura 21 - Ângulo de contato $\left({ }^{\circ}\right)$ dos filmes extrudados de amido termoplástico (TPS) sem e com a incorporação de celulose microfibrilada (CMF)

Figura 22 - Diferença total de cor $\left(\Delta E^{*}\right)$ dos filmes extrudados de amido termoplástico (TPS) sem e com a incorporação de celulose microfibrilada (CMF) .92 Figura 23 - Opacidade dos filmes extrudados de amido termoplástico (TPS) sem e com a incorporação de celulose microfibrilada (CMF) .93 Figura 24 - Microscopia eletrônica (MEV), (a. e b.) se refere as micrografias dos filmes ATH_0,005, (c. e d.) dos filmes ATH_0,010, e (e. e f.) dos filmes ATH_0,020. Superfície com aproximação de 400 x, e da área transversal com aproximação de 200 $\mathrm{x}$.

Figura 25 - Difratograma de raios - $X$ dos filmes de amido termoplástico controle e com concentrações diferentes de ATH

Figura 26 - Espessura (mm), tensão (MPa), elongação (\%) e módulo de Young (MPa) dos filmes de amido termoplástico (TPS) controle e com diferentes concentrações de antocianina 101

Figura 27 - Umidade $(\mathrm{g} / 100 \mathrm{~g})$, solubilidade $(\%)$ e ângulo de contato $\left(^{\circ}\right)$ dos filmes de amido termoplástico (TPS) controle e com diferentes concentrações de antocianina 103

Figura 28 - Diferença total de $\operatorname{cor}\left(\Delta \mathrm{E}^{*}\right)$ e opacidade $(\%)$ dos filmes de amido termoplástico (TPS) controle e com diferentes concentrações de antocianina 105 Figura 29 - Imagens dos filmes de amido termoplástico incorporados com antocianina, durante sua estocagem sob refrigeração $\left(6^{\circ} \mathrm{C}\right)$, propostos como embalagem de carne bovina e de peixe

Figura 30 - Imagens dos filmes de amido termoplástico incorporados com antocianina, durante sua estocagem em temperatura ambiente $\left(22{ }^{\circ} \mathrm{C}\right)$, propostos como embalagem de carne bovina e de peixe. 108

Figura 31 - Variação da diferença total de cor $\Delta \mathrm{E}^{*}$, dos filmes de amido de mandioca sem (controle) e com a presença de antocianina (ATH) na presença de carne bovina

Figura 32 - Variação da diferença total de cor $\Delta \mathrm{E}^{*}$, dos filmes de amido de mandioca sem (controle) e com a presença de antocianina (ATH) na presença de peixe 113 Figura 33 - pH dos filmes de amido de mandioca sem (controle) e com a presença de antocianina (ATH) na presença de carne bovina 114 
Figura 34 - pH dos filmes de amido de mandioca sem (controle) e com a presença de antocianina (ATH) na presença de peixe 115

Figura 35 - Luminosidade $\left(L^{*}\right)$ dos filmes de amido termoplástico com ATH, ao longo do armazenamento na presença de carne bovina

Figura 36 - Parâmetro $a^{*}$ dos filmes de amido termoplástico com ATH, ao londo do armazenamento na presença de carne bovina 119

Figura 37 - Parâmetro $b^{*}$ dos filmes de amido termoplástico com ATH, ao longo do armazenamento na presença de carne bovina 120

Figura 38 - Luminosidade $L^{*}$ dos filmes de amido termoplástico com ATH, ao longo do armazemanteo na presença de peixe 121 Figura 39 - Parâmetro $a^{*}$ dos filmes de amido termoplástico com ATH, ao londo do armazenamento na presença de peixe 124 Figura 40 - Parâmetro $b^{*}$ dos filmes de amido termoplástico com ATH, ao longo do armazenamento na presença de peixe 125 


\section{LISTA DE TABELAS}

Tabela 1 - Tempo de degradação de alguns materiais quando descartados em lixões 25

Tabela 2 - Nomenclaturas para nanoceluloses á partir de principais fontes e obtenção

Tabela 3 - Propriedades físico-químicas dos ácidos carboxílicos com temperatura de fusão $T_{m}$ e temperatura de ebulição $T_{b}$ de decomposição. 43

Tabela 4 - Descrição das formulações para obtenção do amido termoplástico .52 Tabela 5 - Propriedades mecânicas e de superfície dos filmes extrudados de amido termoplástico (TPS) .72

Tabela 6 - Propriedades mecânicas e de superfície dos filmes extrudados de amido termoplástico (TPS), incorporados com $2 \mathrm{~g} / 100 \mathrm{~g}$ de celulose microfibrilada (CMF)

Tabela 7 - Umidade $(\mathrm{g} / 100 \mathrm{~g})$, solubulidade (\%) e ângulo de contao $\left(^{\circ}\right)$ dos filmes extrudados de amido termolástico (TPS)

Tabela 8 - Umidade $(\mathrm{g} / 100 \mathrm{~g})$, solubulidade (\%) e ângulo de contato $\left(^{\circ}\right)$ dos filmes extrudados de amido termolástico (TPS), incorporados com $2 \mathrm{~g} / 100 \mathrm{~g}$ de celulose microfibrilada (CMF)

Tabela 9 - Diferença total de cor $\left(\Delta E^{*}\right)$ e opacidade dos filmes extrudados de amido termolástico (TPS)

Tabela 10 - Diferença total de cor $\left(\Delta E^{*}\right)$ e opacidade dos filmes extrudados de amido termolástico (TPS), incorporados com $2 \mathrm{~g} / 100 \mathrm{~g}$ de celulose microfibrilada (CMF) .90 Tabela 11 - Propriedades mecânicas e de superfície dos filmes de amido termoplástico (TPS) sem (controle) e com a presença de antocianina (ATH) armazenados a (25 \pm 2$)$ ${ }^{\circ} \mathrm{C}$ e $75 \%$ UR

Tabela 12 - Propriedades de superfície dos filmes de amido termoplástico (TPS) sem (controle) e com a presença de antocianina (ATH) armazenados a (25 \pm 2$)^{\circ} \mathrm{C}$ e $75 \%$ UR

Tabela 13 - Propriedades de diferença total de cor $\left(\Delta \mathrm{E}^{*}\right)$ e opacidade (\%) dos filmes de amido termoplástico (TPS) sem (controle) e com a presença de antocianina (ATH) armazenados a $(25 \pm 2) \stackrel{\circ}{\circ}$ e $75 \%$ UR 104 
Tabela 14 - Diferença total de cor $\left(\Delta E^{*}\right)$, opacidade (\%) e pH dos filmes de amido de mandioca sem (controle) e com a presença de antocianina (ATH) na presença de carne bovina.

Tabela 15 - Diferença total de cor $\left(\Delta E^{\star}\right)$, opacidade (\%) e pH dos filmes de amido de mandioca sem (controle) e com a presença de antocianina (ATH) na presença de peixe.

Tabela 16- Parâmetros de cor $L^{*}, a^{*}, b^{*}$ dos filmes de amido termoplástico incorporados com antocianina, durante sua estocagem sob refrigeração $\left(6{ }^{\circ} \mathrm{C}\right)$, utilizados como embalagem de carne bovina.

Tabela 17 - Parâmetros de cor $L^{*}, a^{*}, b^{*}$ dos filmes de amido termoplástico incorporados com antocianina, durante sua estocagem em temperatura ambiente (22 ${ }^{\circ} \mathrm{C}$ ), utilizados como embalagem de carne bovina 118

Tabela 18- Parâmetros de cor $L^{*}, a^{*}, b^{*}$ dos filmes de amido termoplástico incorporados com antocianina, durante sua estocagem sob refrigeração $\left(6{ }^{\circ} \mathrm{C}\right)$, utilizados como embalagem de peixe 122 Tabela 19 - Parâmetros de cor $L^{*}, a^{*}, b^{*}$ dos filmes de amido termoplástico incorporados com antocianina, durante sua estocagem em temperatura ambiente (22 ${ }^{\circ} \mathrm{C}$ ), utilizados como embalagem de peixe 123 


\section{LISTA DE SIGLAS}

$3 \mathrm{D}$

3 Dimensões

ABRE Associação Brasileira de Embalagem

AN $\quad$ Amido de milho granular

AOAC International Association of Official Analytical Chemists

ASTM American Society for Testing and Materials

ATH Antocianina

DMA Dimetilmanina

DRX Difração de raios - $\mathrm{X}$

CA Ácido cítrico

CMF Celulose Microfibrilada

DSC Differential Scanning Calorimetry

FAOSTAT Food and Agriculture Organization of the United Nations

FMC Agricultural Solutions

GLY Glicerol

GMMT Montmorilonita modificada com glicerol

HNT Nanotubo de heloisite modificado

IBÁ Indútria Brasileira de Árvores

IUPAC Internation Union of Pure and Applied Chemistry

LEA Laboratório de Engenharia de Alimentos

LCT Laboratório de Caracterização Tecnológica

MCC Celulose microlistalina comercial

MEV Microscopia eletrônica de varredura

MMT Montmorilonita

NCC Celulose nanocristalina

NFB Nanofibras de bambu 
NFC Nanofibras de celulose

P.A - A.C.S Para Análise - American chemical society

PE Polietileno

$\mathrm{pH} \quad$ Potencial hidrogeniônico

PHB Polihidroxialcanoatos

PIB Produto Interno Bruto

PLA Ácido polilático

PP Polipropileno

PVA Álcool polivinil

PVC Policloreto de polivinila

QR Code Quick Response Code

RDC Resolução da diretoria colegiada

REX Extrusão reativa

RIISPOA Regulamento de inspeção industrial e sanitária de produtos de origem animal

SA Ácido esteárico

SPVA Álcool polivinílico

TMA Trimetilamina

TPS Amido termoplástico

TVB-N Nitrogênio básico volátil total

UR Umidade relativa

USP $\quad$ Universidade de São Paulo

Wt Água 


\section{LISTA DE SÍMBOLOS}

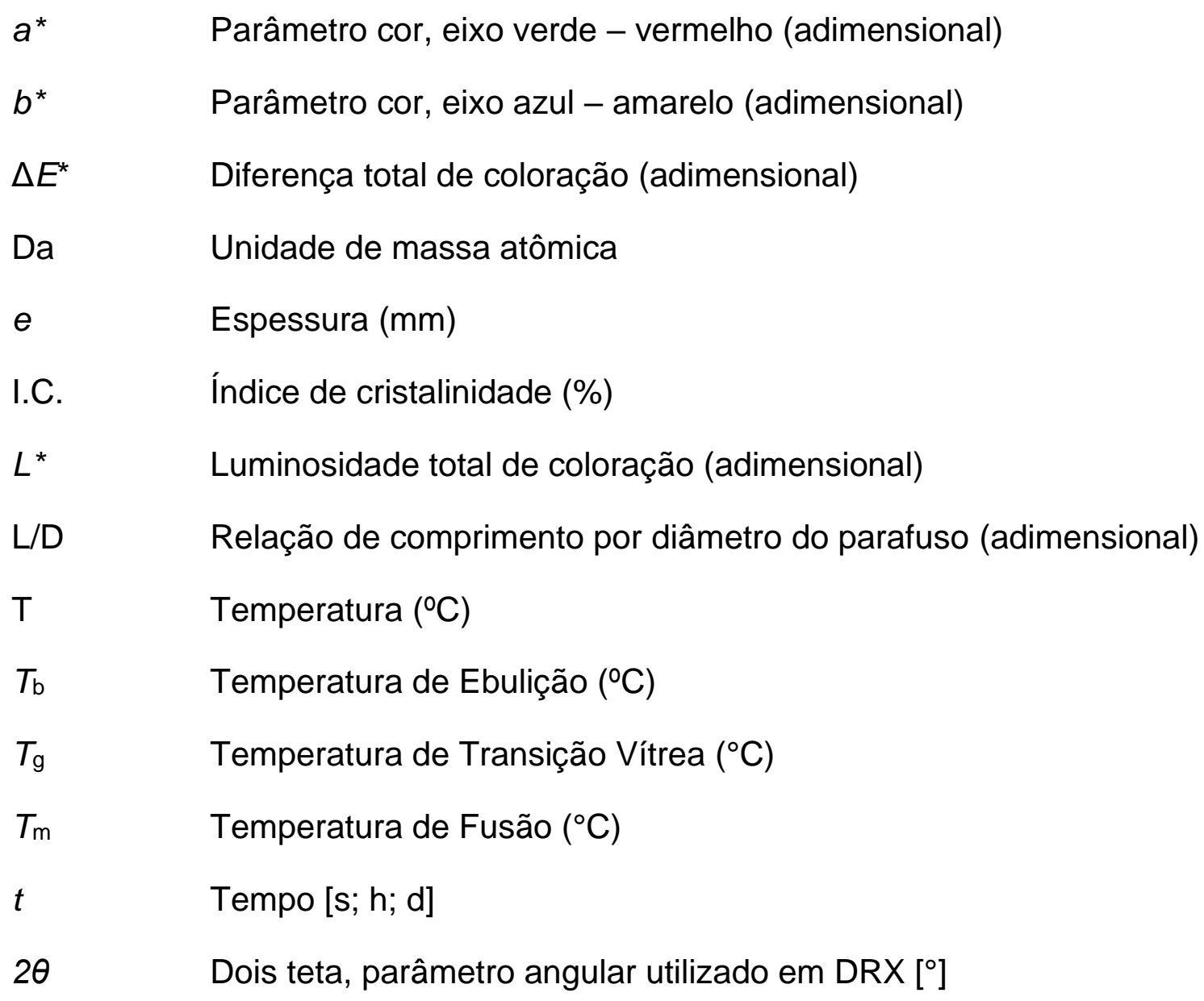




\section{SUMÁRIO}

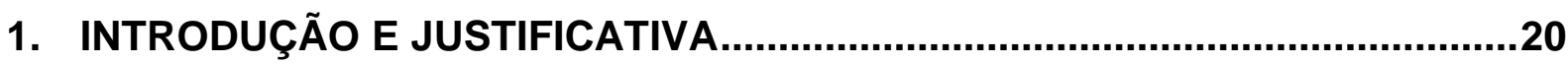

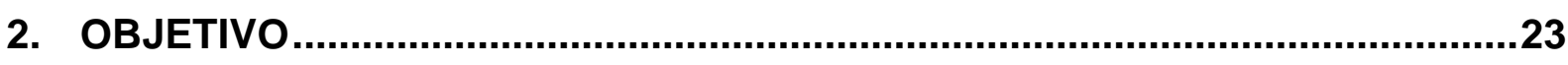

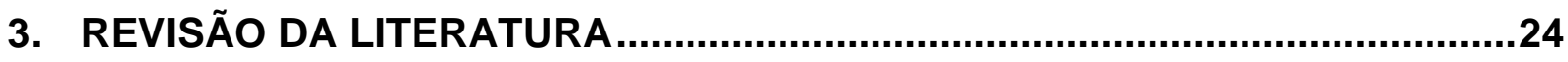

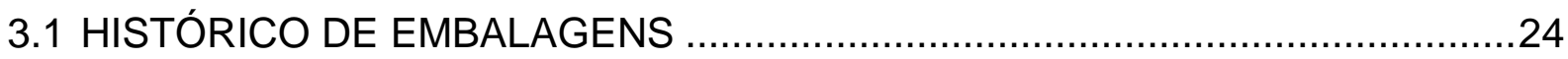

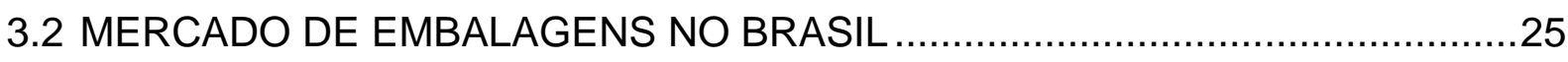

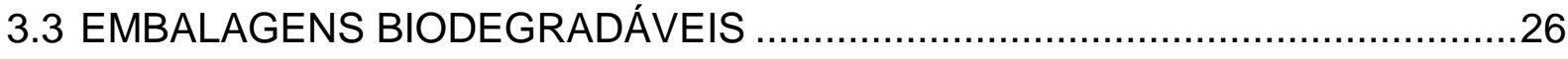

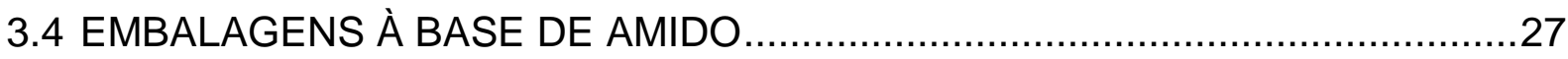

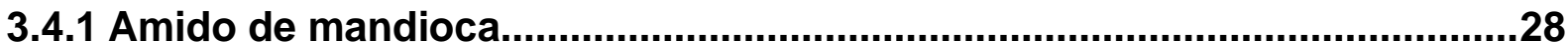

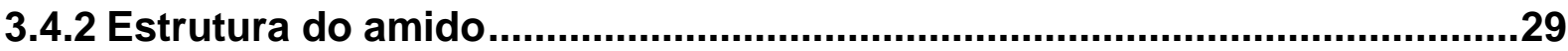

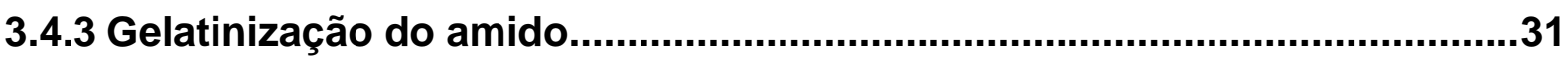

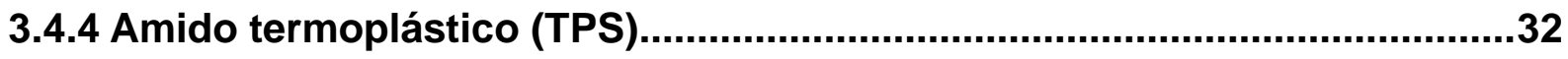

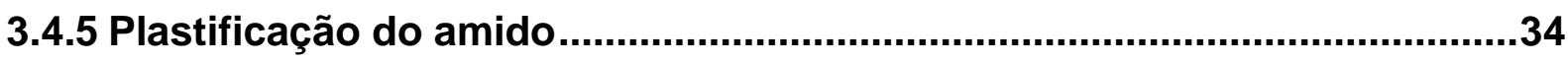

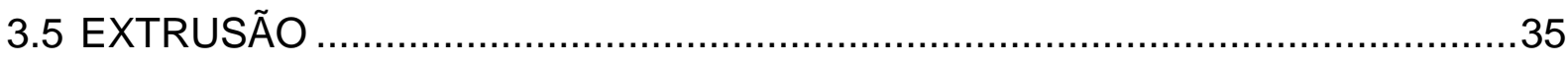

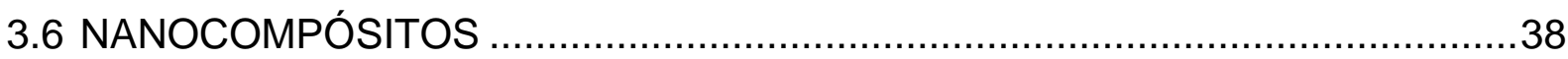

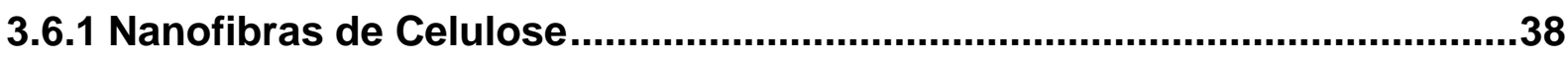

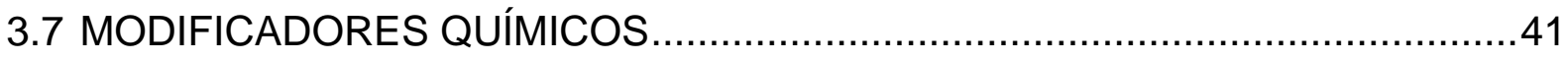

3.7.1 Ácido cítrico e ácido esteárico ........................................................................

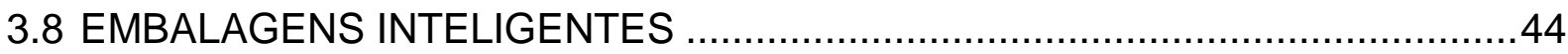

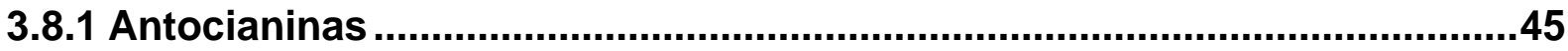

3.8.2 Mudança de cor da antocianina e influência do $\mathrm{pH}$...................................46

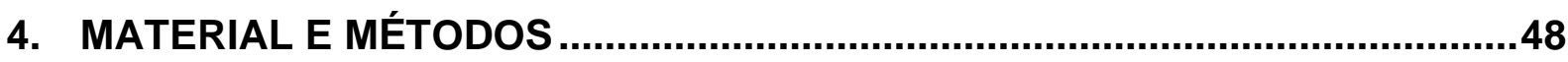

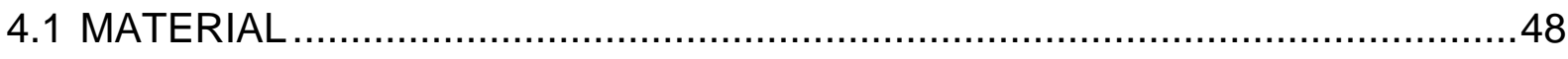

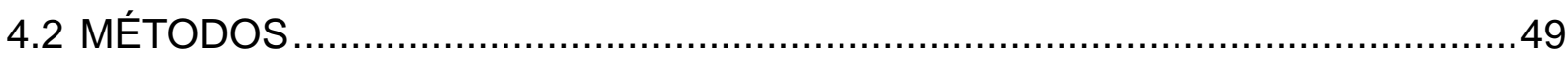

4.2.1 Caracterização da celulose microfibrilada (CMF) .....................................49

4.2.1.1 Tamanho e dispersão de partícula........................................................49 


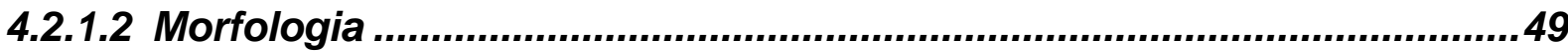

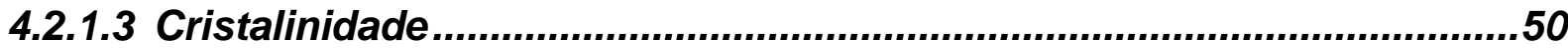

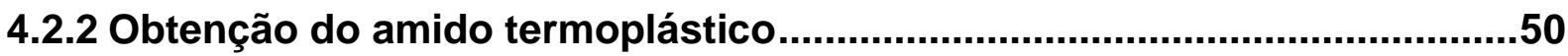

4.2.2.1 Formulações das pré-misturas............................................................50

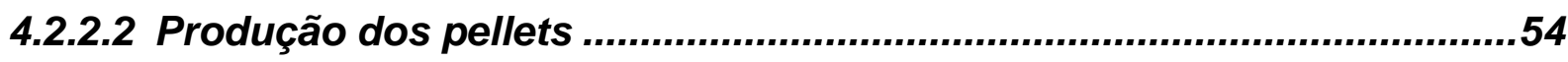

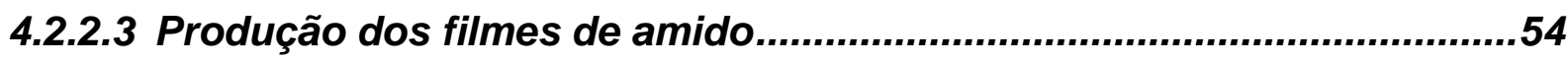

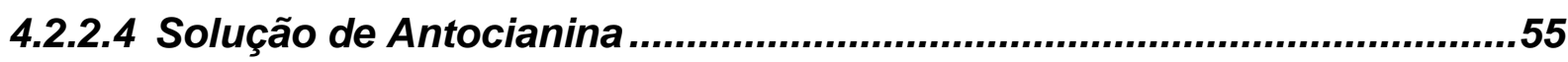

4.2.2.5 Produção dos filmes de amido com antocianina (ATH)........................55

4.2.3 Caracterização dos filmes de amido............................................................56

4.2.3.1 Propriedades mecânicas e de superfície .............................................56

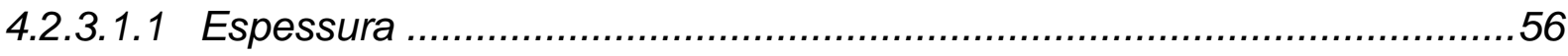

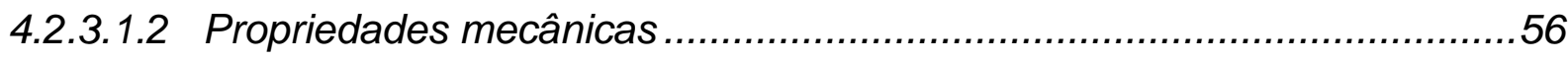

4.2.3.1.3 Solubilidade e conteúdo de umidade .................................................57

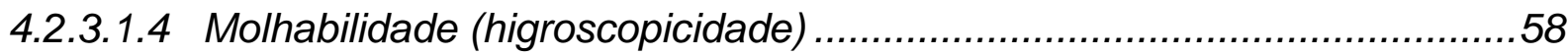

4.2.3.2 Propriedades ópticas (Cor e Opacidade) ...............................................59

4.2.4 Caracterização dos filmes de amido com antocianina (ATH) .....................60

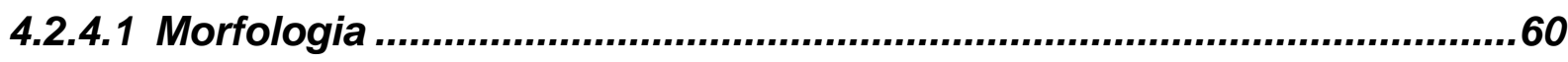

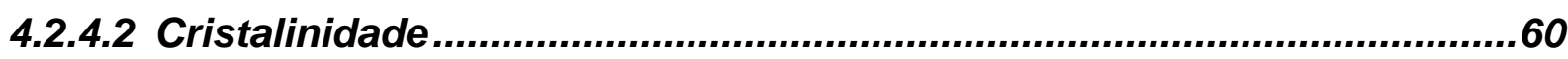

4.2.5 Avaliação da atividade indicadora de mudança de pH dos filmes de

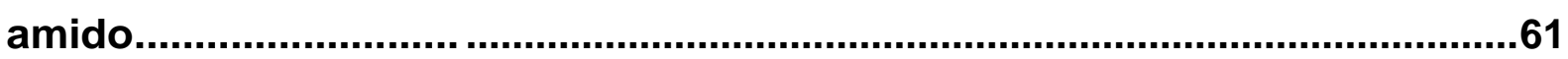

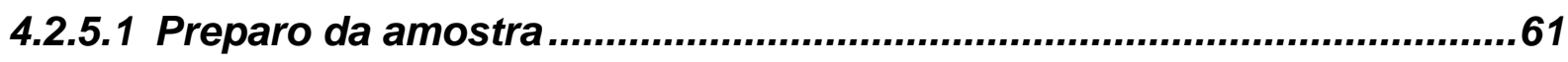

4.2.5.2 Determinação da alteração de cor dos filmes biodegradáveis

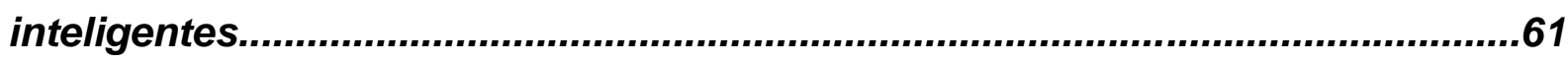

4.2.5.3 Determinação do $\mathrm{pH}$ das amostras de carne bovina e peixe .................61

4.2.6 Análise estatística - tratamento de dados ..................................................62

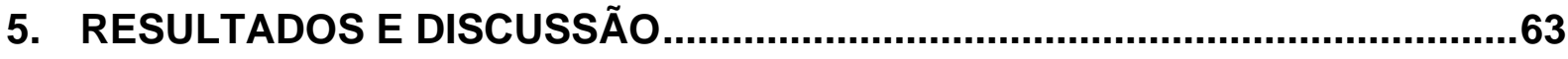

5.1 CARACTERIZAÇÃO DA CELULOSE MICROFIBRILADA (CMF) .....................63 


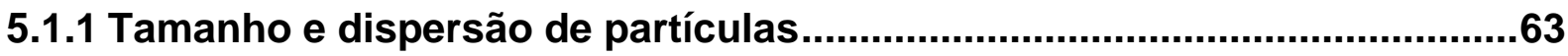

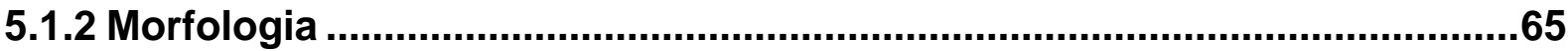

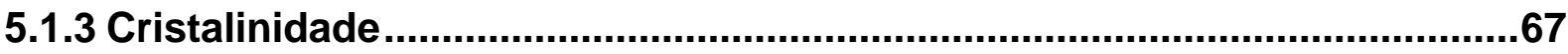

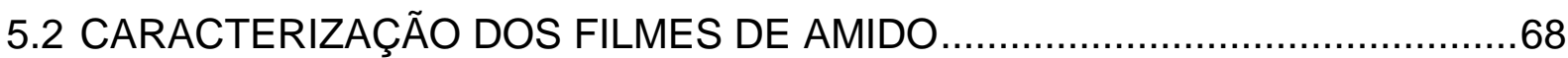

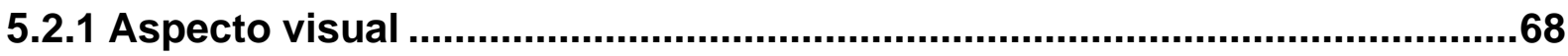

5.2.2 Propriedades mecânicas e de superfície ......................................................70

5.3 Caracterização dos filmes de amido com antocianina (ATH)............................94

5.3.1 Morfologia por microscopia eletrônica de varredura (MEV) .......................94

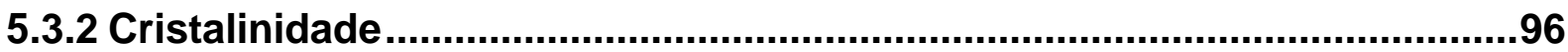

5.3.3 Propriedades mecânicas e de superfície ...................................................98

5.3.4 Avaliação da atividade indicadora de mudança de $\mathrm{pH}$ dos filmes de amido

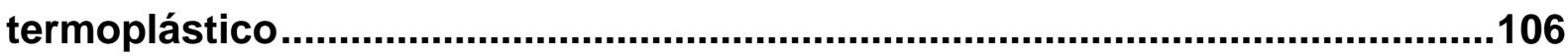

6. CONCLUSÃO

7. SUGESTÃO PARA TRABALHOS FUTUROS …...........................................129

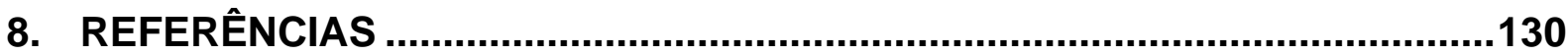




\section{INTRODUÇÃO E JUSTIFICATIVA}

$\mathrm{Na}$ expectativa de atender às exigências do mercado consumidor cada vez mais preocupado com a qualidade e inocuidade dos produtos alimentícios e também acompanhar o desenvolvimento sustentável, as empresas e pesquisadores da área de embalagens têm sido constantemente incitados a desenvolver materiais biodegradáveis provenientes de recursos renováveis aplicáveis neste âmbito. Em contrapartida, atualmente, tem-se como predominante o uso de polímeros derivados de petróleo e de caráter não renovável. Considerando o longo prazo requerido para degradação destes polímeros sintéticos derivados do petróleo e suas consequências sobre o meio ambiente, se torna essencial o desenvolvimento de materiais biodegradáveis que reduzam seu consumo.

Neste contexto, o desenvolvimento de filmes biodegradáveis tem ganho cada vez mais notoriedade. Este tipo de embalagem apresenta grande facilidade de se degradar por ação biológica, não gerando acúmulo na natureza, o que contribui para a diminuição da poluição do meio ambiente (SOUZA, 2011).

Além das preocupações ambientais, a contínua escassez de recursos fósseis também contribui para aumentar o interesse em polímeros fabricados a partir de materiais de fonte renovável (GHANBARZADEH et al.,2010; LOROTONDA et al., 2005; MALI et al., 2005). O amido se destaca entre as fontes renováveis, sendo possível sua compostagem sem produzir resíduos tóxicos e ser de relativa fácil obtenção, o que o torna um material de boa relação custo-benefício (MONTERO et al., 2016).

O amido é um polissacarídeo completamente biodegradável e amplamente produzido por plantas como armazenamento de energia durante o processo da fotossíntese (GHANBARZADEH et al., 2010). Está presente na forma granular em muitas das partes constituintes da planta: sementes, frutos ou tubérculos (MONTERO et al., 2016; SOUZA; ANDRADE, 2000).

Na presença de um plastificante (exemplo: água, polióis ou amida), sob calor e/ou cisalhamento, os grânulos de amido podem sofrer uma ruptura levando a uma fusão homogênea dando origem ao amido termoplástico (TPS). A substância plastificante tem a capacidade de penetrar nos grânulos do amido, rompendo a sua estrutura cristalina e induzindo a formação de uma estrutura amorfa quando 
submetida a altas temperaturas e tensão de cisalhamento durante o processo de fusão. Portanto, o amido amorfo, após a adição de um plastificante, comporta-se como um polímero termoplástico durante a fusão (JANTANASAKULWONG et al., 2016). O TPS é completamente renovável e pode ser processado com tecnologias utilizadas no fabrico de polímeros sintéticos (MONTERO et al., 2016).

Em geral, os filmes de amido têm tendência em serem transparentes além de fácil processamento, podem fornecer boa barreira contra oxigênio e dióxido de carbono, são biodegradáveis e compatíveis com outros materiais, o que facilita sua elaboração. Dessa forma, este material tem sido frequentemente utilizado para o desenvolvimento de polímeros biodegradáveis (SOUZA; ANDRADE, 2000).

No entanto, filmes a base de amido apresentam baixa resistência mecânica, alta permeabilidade ao vapor de água, alta solubilidade em água e são muito higroscópicos, frágeis e quebradiços quando comparados com polímeros sintéticos convencionais não biodegradáveis (ACOSTA et al., 2013; ALVES et al., 2006; GHANBARZADEH et al., 2010; SOUZA, 2011; SOUZA; DITCHFIELD; TADINI, 2009). O teor de umidade dos filmes de amido também pode afetar significativamente as propriedades físicas e de barreira devido à sua natureza hidrofílica inerente, pois filmes de amido tendem a absorver grandes quantidades de água (MALI et al., 2005).

Recentemente, aditivos têm sido incorporados para melhorar as propriedades físico-químicas dos filmes, podendo alcançar desempenho comparável ao de origem sintética (CROISIER; JÉRÔME, 2013).

Um plastificante é um aditivo incorporado a um material (usualmente plástico) que serve para aumentar a flexibilidade, o alongamento, a facilidade de processamento do polímero ou material (VIEIRA et al., 2011b). Reforçadores podem aumentar a resistência do TPS e diminuir a sua hidrofilicidade, sendo as nanofibras de celulose (NFC) e/ou celulose microfibrilada (CMF), excelentes aditivos para este fim, devido a sua boa funcionalidade, seu baixo custo e disponibilidade (MONTERO et al., 2016). Os ácidos carboxílicos também tem sido estudados como aditivos pois são capazes de causar uma modificação química nas cadeias de amido, reduzindo sua massa molar, resultando em materiais com menor viscosidade e melhores propriedades de fluxo (WANG et al., 2009). 
No setor de embalagens, se destacam as inteligentes, que são capazes de fornecer informações e alertar sobre possíveis alterações do produto armazenado (YAM; TAKHISTOV \& MILTZ, 2005).

Entre os diversos tipos de materiais inteligentes, os indicadores de $\mathrm{pH}$ fornecem uma correlação entre o alimento e o seu pH através de sensores associados à embalagem. Esse tipo de material é uma alternativa interessante para a indústria de alimentos, especialmente para as de carnes e frutos do mar, pois existe um interesse em desenvolver métodos para a avaliação da frescura e do armazenamento correto dos seus produtos, possibilitando que o consumidor avalie as condições de consumo mediante a indicação de alteração do pH do alimento (ARENAS, 2012).

Um sistema de embalagem que muda de cor com a alteração do pH do alimento embalado poderá permitir ao consumidor avaliar seu frescor e qualidade sem a necessidade de abrir a embalagem. Os indicadores de $\mathrm{pH}$ apresentam uma segurança adicional para os fabricantes e consumidores, pois podem detectar a deterioração do produto ainda dentro do prazo de validade (ARENAS, 2012).

Os estudos sobre os materiais indicadores de $\mathrm{pH}$ abordam a utilização de compostos naturais (AHVENAINEN et al., 1997; ARENAS, 2012; DITCHFIELD; TADINI, 2009; HONEYBOURNE, 1993; MILLERS; WILKES; CONTE, 1999; QUAN; STEVENS, 1998), como as antocianinas que são pigmentos derivados de sais flavílicos, solúveis em água, responsáveis pela ampla gama de cores. As antocianinas compõem o maior grupo de pigmentos solúveis em água do reino vegetal e são largamente encontradas em uvas, jabuticabas, amoras, romãs, cerejas, berinjelas, repolho roxo, entre outros (ARENAS, 2012).

Os estudos de embalagens inteligentes existentes na atualidade envolvem, em sua maioria, polímeros e corantes químicos sintéticos de uso limitado na indústria de alimentos (ARENAS, 2012; SOUZA, 2011). Dessa forma, o emprego de embalagens produzidas a partir de um polímero natural, como o amido, e de um indicador natural de mudança de $\mathrm{pH}$, como as antocianinas, permite a elaboração de embalagens inteligentes mais sustentáveis, além de agregar valor ao amido de mandioca. 


\section{OBJETIVO}

Em face do grande potencial do emprego de embalagens inteligentes em alimentos, este trabalho teve como objetivo desenvolver por extrusão filmes inteligentes de amido de mandioca incorporados com antocianina que atua como indicadora de mudança de $\mathrm{pH}$.

Para alcançar esse objetivo, o trabalho foi desenvolvido nas seguintes etapas:

- Elaboração por extrusão de filmes de amido de mandioca com diferentes aditivos (agentes plastificantes, de reforço e modificadores químicos);

- Caracterização (propriedades mecânicas e de superfície) dos filmes produzidos e determinação do filme ótimo para posterior adição das antocianinas;

- Elaboração por extrusão e caracterização (microscopia, cristalinidade e propriedades mecânicas e de superfície) de filmes de amido de mandioca com a adição de diferentes teores de antocianina;

- Avaliação da eficiência do TPS inteligente produzido por extrusão em relação à mudança de cor expressa mediante a mudança de $\mathrm{pH}$. 


\section{REVISÃO DA LITERATURA}

\subsection{HISTÓRICO DE EMBALAGENS}

A embalagem foi criada para atender à necessidade humana, e desde os primórdios da civilização vem evoluindo, se transformando e incorporando novos materiais e tecnologias de produção para além de cumprir seu objetivo fundamental que é proteger, possibilitar o transporte de seu conteúdo permitindo que ele chegue a seu destino em perfeito estado de conservação dentro da cadeia logística.

De acordo com a Associação Brasileira de Embalagem (ABRE, 2017), a embalagem tem como objetivo armazenar produtos por um determinado período de tempo, com a principal função de protegê-lo e estender o seu shelf life, viabilizando sua distribuição, identificação e consumo. A embalagem tem como intenção oferecer segurança e informação para 0 bem-estar das pessoas, possibilitando a acessibilidade a produtos perecíveis, de alto ou baixo valor agregado.

Frente ao mercado atual, a embalagem tornou-se uma tática para a competitividade dos negócios, no que diz respeito à eficiência de processo. Pensando no crescimento populacional do planeta, a embalagem é efetiva para otimizar o desperdício global. (ABRE, 2017).

Para o desenvolvimento da embalagem é dever observar alguns aspectos como: os técnicos, os de produção e funcionalidade; aspectos regulatórios, legislação e certificações, aspectos estéticos, aspectos ambientais, entre outros (ABRE, 2017).

As mudanças no setor de embalagem, explicou Hamilton Terni, podem acontecer por pontos macroeconômicos e demográficos. "O crescimento do poder econômico e de consumo da população, notadamente da classe média, traz o aumento do uso de embalagens. Outro direcionador de mudança é a ação da indústria em inovação tecnológica, a urgência em ser sustentável e de baixar custos" (TERNI, 2018).

No cenário que enfrentamos as embalagens ficam mais integradas com tecnologias, desde um $Q R$ Code até embalagens inteligentes, que apresentam as condições do produto - se este está próprio para uso, temperatura, etc. O objetivo é transformar a embalagem cada vez mais em uma utilidade iterativa verde (TERNI, 2018). 
O estudo de Terni (2018) é finalizado com conselhos à indústria: buscar valor ao longo da cadeia de suprimentos e estar ciente das tendências e tecnologias.

O consumidor, conforme pesquisa realizada pela ABRE (2017), é vigorosamente influenciado no momento da compra pela embalagem por possuir o diferencial de cativar o consumidor. São apenas três segundos para identificar a qualidade do produto para pegá-lo em sua mão e colocá-lo em seu carrinho de compras.

\subsection{MERCADO DE EMBALAGENS NO BRASIL}

No Brasil, em 2014, a indústria de embalagem atingiu US\$ 35 bilhões (10,8 milhões de toneladas), o equivalente a $1,5 \%$ do Produto Interno Bruto (PIB) (DATAMARK, 2015). Sendo que no setor nacional de embalagens, o papel ondulado corresponde ao volume de 31,6 \% em segundo lugar os plásticos com 22,6 \% em volume, respectivamente. Já os materiais flexíveis correspondem a um volume reduzido de 3,3 \% (DATAMARK, 2015).

Os plásticos representam a maior produção de embalagens, correspondente a $38,85 \%$, seguido pelo setor de embalagens celulósicas com 34,09\% metálicas com $18,15 \%$, vidro com $4,43 \%$, têxteis para embalagens com 2,53 \% e madeira com 1,95 $\%$ (ABRE, 2017).

Uma informação importante é o tempo de degradação desses materiais como embalagens quando descartados em lixões, que é apresentado na Tabela 1.

Tabela 1 - Tempo de degradação de alguns materiais quando descartados em lixões

\begin{tabular}{cc}
\hline Material & Tempo de degradação \\
\hline Aço (latas) & 100 anos \\
Alumínio & 200 a 500 anos \\
Isopor & Indeterminado \\
Madeira & 6 meses \\
Madeira Pintada & 13 anos \\
Papel & 1 a 6 meses \\
Plásticos & 200 a 450 anos \\
Plásticos (PET) & 100 anos \\
Longa Vida & 100 anos \\
Vidro & Indeterminado \\
\hline
\end{tabular}

Fonte: Arenas (2012); Magalhães (2012). 
Frente à preocupação da população, empresas brasileiras já estão produzindo e utilizando materiais biodegradáveis ou de fonte renováveis, no mercado de embalagens, como os exemplos da Tetra Pack e FMC.

Tetra Pack (2011) lançou as primeiras tampas do setor feitas de polímeros de fontes renováveis. Derivadas do etanol de cana-de-açúcar brasileiro, elas têm exatamente a mesma aparência das tampas convencionais, e apresentam uma pegada de carbono consideravelmente menor. Em 2014, criaram a primeira embalagem cartonada totalmente renovável para alimentos líquidos do mundo, a Tetra Rex® Bio-Based, feita com tampa, corpo e filme de fontes renováveis. No mesmo ano, também lançaram a Tetra Brik ${ }^{\circledR}$ Aseptic 1000 Edge com LightCap ${ }^{\mathrm{TM}} 30$ de fontes renováveis, sendo a primeira embalagem asséptica a ter a tampa e o filme feitos de plástico à base de cana de açúcar. Combinados com o papel-cartão, isso aumenta a porcentagem de materiais de fontes renováveis na embalagem acima de $80 \%$.

"A FMC Agricultural Solutions é a primeira empresa do setor a utilizar embalagens rígidas (bombonas) produzidas com matéria-prima de fonte renovável, utilizando como matéria-prima o polietileno proveniente da cana-de-açúcar em substituição a uma parte do petróleo empregado na sua composição. As embalagens Green são feitas de material renovável e contém, no mínimo, 51 \% de polietileno a base de cana-de-açúcar em sua composição e podem ser identificadas pelo selo "I'm green". A FMC acredita que até 2018 podem chegar a 100 \% das aquisições de embalagens rígidas de fontes sustentáveis no Brasil” (FMC, 2017).

\subsection{EMBALAGENS BIODEGRADÁVEIS}

É intuitivo que os materiais utilizados para produzir embalagens têm sido produzidos para serem barreiras inertes no sentido de ter a mínima interação com o alimento, trazendo ao mercado a função de proteger o produto. Entretanto, na última década, diversos estudos têm desenvolvido sistemas de embalagens com o objetivo de interagir com o alimento, utilizando matrizes biodegradáveis e aditivos naturais, para agregar valor, sendo chamadas de embalagens biodegradáveis ativas (MACHADO et al., 2010; SILVA, 2009; SOUZA 2011; SOUZA et al., 2012; SOUZA et al., 2013; SOUZA et al., 2014). 
Entre as vantagens da utilização de embalagens biodegradáveis quando comparadas às não-biodegradáveis, destacam-se: o processo de fabricação envolvendo somente a utilização de substâncias atóxicas; a utilização de matériasprimas provenientes de fontes renováveis; alta biodegradabilidade e, adicionalmente, a biomassa resultante da biodegradação da embalagem poder agir como fertilizante (THARANATHAN, 2003).

Nos últimos anos, o interesse em materiais biodegradáveis tem crescido, já que esses materiais podem ser facilmente degradados por bactérias ou outros organismos vivos sob condições ambientais bem definidas, diferentemente do plástico convencional derivado de recursos fósseis, cujo acúmulo é a principal causa de poluição ambiental (CURVELO et al., 2001; KAMPANGKAEW et al., 2014).

Os filmes biodegradáveis podem ser produzidos a partir de polissacarídeos (celulose e derivados, carboidratos e derivados, goma, etc.) e proteínas (gelatina, zeína, glúten, etc.) capazes de gerar matrizes contínuas. No entanto, estas matériasprimas renováveis têm de ser vantajosas em relação aos plásticos sintéticos em termos de custo e funcionalidade (AZEREDO et al., 2009; JACOMETTI et al., 2015; KAYA; MASKAN, 2003; MANIGLIA et al., 2014, 2015). Uma das matérias-primas mais promissoras para a produção de plásticos biodegradáveis é o amido, que é naturalmente abundante, renovável, barato, não-tóxico e biodegradável (KAMPANGKAEW et al., 2014).

\subsection{EMBALAGENS À BASE DE AMIDO}

Os filmes à base de amido como dito anteriormente, na maioria dos casos são transparentes, fornecem boa barreira contra oxigênio e dióxido de carbono, são facilmente biodegradáveis e compatíveis com a maioria dos materiais. Suas principais desvantagens em comparação aos plásticos convencionais derivados do petróleo são a alta permeabilidade ao vapor de água, solubilidade em água, resistência mecânica baixa e dificuldade de processamento (SOUZA; DITCHFIELD; TADINI, 2010).

No Brasil, a utilização de amido de mandioca para a produção de material biodegradável vem ganhando destaque no ranking dos maiores produtores mundiais de mandioca, dado que o país ocupa o terceiro lugar há mais de uma década, segundo relatórios anuais apresentados pela Food and Agriculture Organization of the United Nations (FAOSTAT, 2017). Além disso, o amido de mandioca possui vantagens frente 
a outras fontes de amido como: facilidade de extração, taxa de retrogradação menor em relação ao amido de outras fontes, resultando em materiais mais estáveis ao longo do tempo, baixo custo, baixa temperatura de gelatinização e boa estabilidade do gel (SOUZA; DITCHFIELD; TADINI, 2010). Relatos da literatura têm mostrado que o amido de mandioca é fonte promissora na elaboração de filmes biodegradáveis (BELIBI et al., 2013; BELIBI et al., 2014; MORAES et al., 2013; SOUZA, 2011; SOUZA et al., 2012; SOUZA et al., 2013; SOUZA et al., 2014; TEODORO et al., 2015; VEIGA-SANTOS; DITCHFIELD; TADINI, 2011).

\subsubsection{Amido de mandioca}

"Amido é o produto amiláceo extraído de partes comestíveis de cereais, tubérculos, raízes e rizomas segundo a RDC no 263 de setembro de 2005, que regulamenta os produtos de cereais, amidos, farinhas e farelos e fixa o padrão de umidade para o amido de mandioca em um valor limite de $18 \mathrm{~g} / 100 \mathrm{~g}$ ".

A mandioca (Manihot esculenta Crantz) (Figura 1a) é uma planta perene, cultivada em muitas regiões da Ásia, África e América do Sul, além de ser uma das mais tradicionais culturas agrícolas brasileiras, sendo cultivada em grande parte do território nacional. $\mathrm{Na}$ região Sul concentram-se as indústrias que processam de farinha e amido (APLEVICZ; DEMIATE, 2007; WOSIACKI; CEREDA, 2002).

"Segundo a Embrapa (2007), a colheita da mandioca é feita após o seu ciclo dos cultivares, que se classificam em: precoce (10 a 12 meses); semi-precoce (14 a 16 meses) e tardia (18 a 20 meses)" (TININI et al., 2009).

O amido de mandioca (Figura 1b) apresenta características físico-químicas de grande interesse industrial e mundial, por ser capaz de gerar massas que, quandosão submetidas à altas temperaturas com o intuito de assar, se expandem sem a necessidade de adição de fermento ou de processo de extrusão (DEMIATE et al., 1998; DEMIATE, CEREDA, 2000). O amido de mandioca tem baixa temperatura de gelatinização, o que facilita o processo de cozimento (DíAZ, 2018).

O rendimento industrial das raízes e os teores de amido sofrem interferências da época de colheita, da variedade da mandioca, dos danos causados por pragas e doenças, e pelos tratos culturais, dentre outros (BEZERRA, 2000; TININI et al., 2009). Em geral, na pós-colheita das raízes de mandioca, observa-se aumento do amido que está relacionado com o aumento do peso seco ou a evaporação de água das raízes 
durante o armazenamento (CAMPOS, 1987; TININI et al., 2009). Além disso, a variação dos teores de amido nas raízes pode ocorrer devido a fatores de ordem bioquímica, associando que seu acréscimo e decréscimo durante o armazenamento são decorrentes da desidratação amilásica (BEZERRA, 2000).

Figura 1 - Mandioca in natura (a); Amido de mandioca (b)

a)

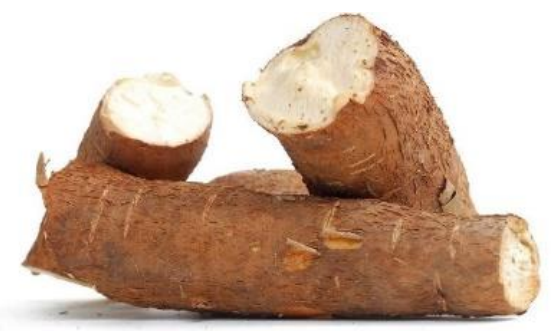

Fonte: Revista Saúde (2018). b)

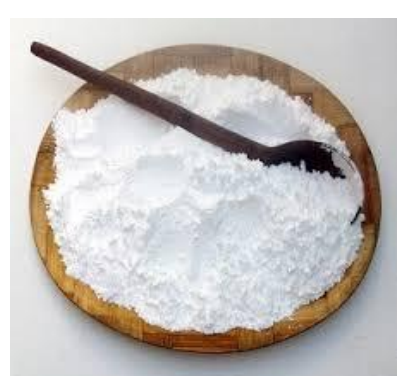

\subsubsection{Estrutura do amido}

O amido é o polissacarídeo de reserva de energia dos vegetais e está presente nos plastídios de vegetais superiores. Está disponível em abundância na natureza e pode ser obtido de diversas fontes vegetais, como cereais, raízes e tubérculos, assim como de frutas e legumes. No entanto, a extração em nível comercial de amido se restringe aos cereais, como milho, trigo e arroz, de tubérculos como batata e de raízes tuberculares como a mandioca (CHIVRAC; POLLET; AVÉROUS, 2009).

O amido nativo é um polímero natural que exibe a estrutura granular semicristalina, com grânulos constituídos por duas macromoléculas denominadas amilose e amilopectina. A amilose é formada por cadeias lineares de glicose (1500 unidades de glicose) com massa molar na ordem de 250.000 Da, e a amilopectina, formada por cadeias ramificadas de glicose (2.000 a 200.000 unidades de glicose), com massa molar entre (50 a 500) ×106 Da (BULEÓN et al.,1998; CORRADINI et al., 2005; LOROTONDA et al., 2005; VANDEPUTTE; DELCOUR, 2004; WHISTLER; PASCHALL, 1984). Nas Figuras 2 e 3 estão ilustradas as estruturas químicas das macromoléculas de amilose e amilopectina. 
Figura 2 - Representação estrutural da amilose e respectiva forma helicoidal
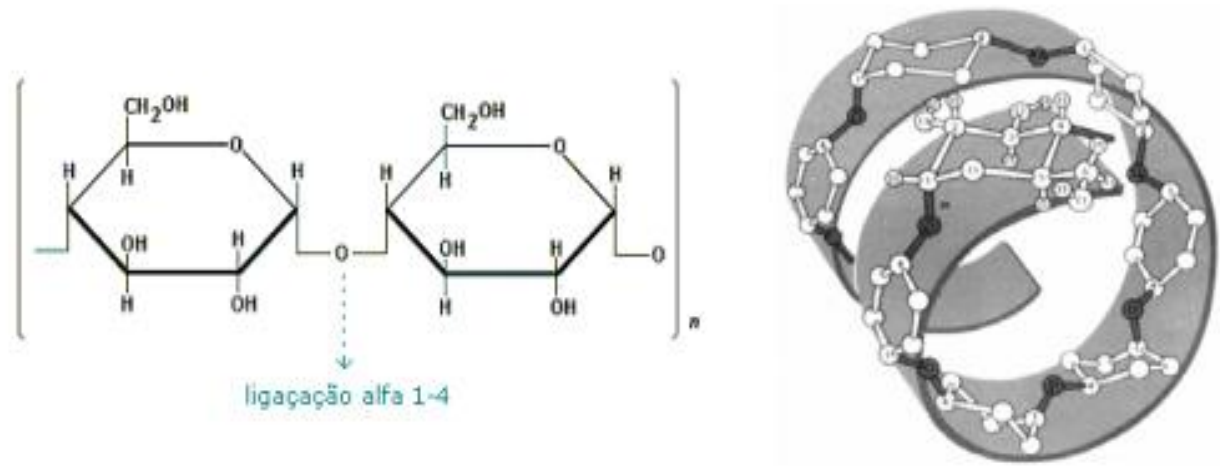

Fonte: REIS (2011).

Figura 3 - Representação estrutural da amilopectina e seu respectivo formato de ramificações
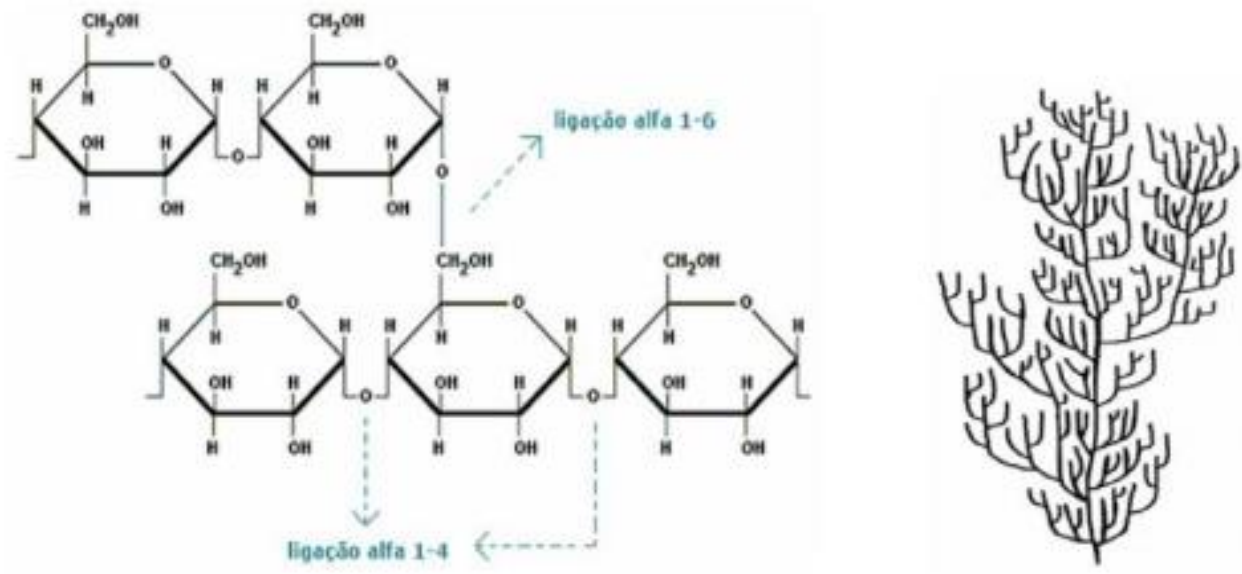

Fonte: REIS (2011).

O amido está organizado em uma estrutura macroscópica em que camadas de amilose e amilopectina são depositadas radialmente em torno de um ponto central, chamado hilo. A deposição continuada faz crescer a estrutura e dá origem ao grânulo semicristalino (ARENAS, 2012).

A molécula de amilopectina (Figura 4) consiste de uma cadeia principal, que carrega o grupo redutor da molécula, denominada $C$, e numerosas cadeias ramificadas denominadas $\mathrm{A}$ e $\mathrm{B}$, com grupos não-redutores (PERONI, 2003; SOUZA, 2011).

"O tipo A é composto de uma cadeia não-redutora de glicoses unidas por ligações $\alpha-1,4$ sem ramificações, que é unida à cadeia do tipo B por meio de ligações $\alpha-1,6$. As cadeias do tipo $B$, por sua vez, são formadas por glicoses ligadas em $\alpha-1,4$ e $\alpha-1,6$, contendo uma ou várias cadeias tipo $A$ e podem conter cadeias tipo B unidas 
por meio de um grupo hidroxila primário. Já a cadeia $C$ é única em uma molécula de amilopectina, sendo composta por ligações $\alpha-1,4$ e $\alpha-1,6$ com agrupamento terminal redutor" (FAO/WHO, 1998).

Figura 4 - Representação esquemática dos três tipos de cadeias presentes na estrutura ramificada da amilopectina. Cadeia A em vermelho, cadeia B em azul, ambas sem grupos redutores, e cadeia $\mathrm{C}$ em preto, com grupo redutor

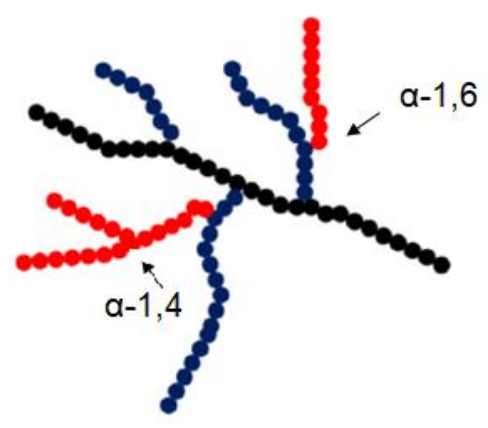

Fonte: SOUZA (2011).

Os grânulos de amido são formados por camadas escuras e claras, que podem ser observados por microscopia óptica, quando tratados termicamente em meio aquoso, essas camadas se distanciam devido à absorção de água. "Cerca de dois terços do grânulo de amido não está arranjado de maneira cristalina, ficando evidente que nessas regiões amorfas as moléculas estão parcialmente hidratadas, ou seja, os grânulos estão pouco inchados. A separação radial das camadas após tratamento térmico ou ácido mostra que as camadas escuras são degradadas primeiramente, pois são amorfas" (FRANCO et al., 2002; SOUZA, 2011).

\subsubsection{Gelatinização do amido}

Sabe-se que com a combinação de amido, água e calor, uma transição irreversível denominada gelatinização é alcançada, que pode ser caracterizada por uma endoterma obtida através de calorimetria diferencial de varredura (DSC, do inglês Differential Scanning Calorimetry), pela perda da birrefringência observada usando-se microscopia de luz polarizada (perda da cruz de malta) e pelo desaparecimento da cristalinidade evidenciada pela difração de raios - X (DRX). O inchamento dos grânulos e a concomitante solubilização da amilose e da amilopectina induzem a uma 
gradual perda da integridade granular com a geração de uma pasta viscosa e destruição da maioria das ligações de hidrogênio (FRANCO et al., 2002; SOUZA, 2011).

De acordo com Parker e Ring (2001), os grânulos de amido estão organizados em regiões cristalinas e amorfas. Estudos mostram que a amilopectina é a responsável pela cristalinidade do amido, e não há indícios de que a amilose participe dessa etapa. Contudo, há evidências de que a amilose seja responsável pela retrogradação do amido, pois existe uma relação entre o comprimento da cadeia de moléculas de amilose e a facilidade em retrogradar (SOUZA, 2011). A retrogradação ocorre após resfriamento da solução onde as moléculas se reaproximam, pontes de hidrogênio se reorganizam e expulsando novamente a água e formando novos cristais.

\subsubsection{Amido termoplástico (TPS)}

O amido quando processado pode desmembrar seus grânulos semicristalinos e formar uma fase de polímero, que se denomina amido termoplástico (TPS), ou amido desestruturado ou, ainda, amido plastificado (EMBRAPA, 2007). O amido termoplástico (TPS) é um dos vários polímeros biodegradáveis que se tornou cada vez mais atraente nos últimos tempos (KAMPANGKAEW et al., 2014).

O amido submetido ao processamento térmico, com temperaturas na faixa de (90 a 180) ํㅡ, e ao processamento mecânico à pressão e cisalhamento na presença de um plastificante, se transforma em um material fundido, tendo a estrutura semicristalina original do seu grânulo destruída (CURVELO et al., 2001; EMBRAPA, 2007; KAMPANGKAEW et al., 2014).

$\mathrm{Na}$ estrutura do amido, as ligações de hidrogênio intra e inter-moleculares entre grupos hidroxila, que representam a sua cristalinidade, prejudicam as propriedades mecânicas finais das embalagens elaboradas por este tipo de material (LU; XIAO; \& XU, 2009; MARTINS; SANTANA, 2016). Para melhorar suas propriedades, vários métodos têm sido desenvolvidos dando características positivas aos amidos, como métodos de modificação física ou química e o uso de plastificantes como o glicerol (CARVALHO; CURVELO; \& GANDINI, 2005; DA RÓZ et al., 2011; MARTINS; SANTANA, 2016; MORÁN; CYRAS; \& VÁZQUEZ, 2013). Há tempos, em muitos trabalhos a adição de plastificantes nos materiais puros à base de amido são incorporados para superar a fragilidade do filme causada pelas altas forças 
intermoleculares (GARCÍA et al., 2000; LOURDIN et al., 1995; MALI et al., 2005; SOUZA; ANDRADE, 2000).

Geralmente, quando os grânulos de amido são aquecidos, a degradação térmica ocorre antes da fusão, por isso o amido não pode ser processado por fusão para qualquer produto diretamente. Em síntese, a adição de plastificantes promove a interação dos grupos hidroxilas do amido, reduzindo as ligações de hidrogênio. Finalmente, a temperatura de fusão do TPS formado após a adição do plastificante ao amido se torna mais baixa do que a temperatura de degradação, podendo então este material ser processado por tecnologias convencionais usadas em plásticos sintéticos (KAMPANGKAEW et al., 2014).

Muitos estudos abordam a modificação química do amido como uma forma alternativa de melhorar a sua propriedade higroscópica. A reação de acetilação é uma das mais aplicadas. Esta reação permite a obtenção de um material termoplástico e hidrofóbico (FRINGANT et al., 1996; GRAAF et al., 1995; LOROTONDA et al., 2005). Parte dos grupos hidroxila dos monômeros de glicose são convertidos em outros grupos químicos, modificando a estrutura molecular e consequentemente as propriedades e aplicações de amido (LOROTONDA et al., 2005).

O TPS tem dureza e resistência, exceto à água. Produzir TPS com superfície hidrofóbica aumenta a resistência à água superficial responsável pela biodegradabilidade (PARDO et al., 2017). Há muitas maneiras de aumentar a resistência à água do TPS, como a seleção do tipo e conteúdo do plastificante, mistura com polímeros sintéticos, ou a adição de cargas de reforço como exemplo as fibras de celulose, que podem também melhorar suas propriedades mecânicas (CURVELO et al., 2001; KAMPANGKAEW et al., 2014).

Para obtenção do TPS, várias técnicas industriais de processamento de plásticos podem ser utilizadas, tais como extrusão, injeção e moldagem por compressão, ou mesmo em misturadores. Existem alguns fatores que exercem grande influência no comportamento reológico durante o processamento do amido, como o teor de plastificante, temperatura de processo, velocidade de rotação dos rotores, bem como a natureza do próprio amido (EMBRAPA, 2007). 


\subsubsection{Plastificação do amido}

Segundo a International Union of Pure and Applied Chemistry (IUPAC), plastificantes são substâncias incorporadas a plásticos ou elastômeros com a finalidade de aumentar sua flexibilidade, processabilidade ou capacidade de alongamento (SOUZA, 2011).

Os plastificantes são moléculas pequenas, pouco voláteis e são adicionados aos polímeros de alto peso molecular para amolecê-los ou abaixar seu ponto de fusão durante o processamento, ou para Ihe conferir flexibilidade ou extensibilidade muito semelhante à da borracha (EMBRAPA, 2007).

Sabemos que o amido natural apresenta ponto de fusão acima de sua temperatura de degradação, sendo necessário adicionar um plastificante para diminuir sua temperatura de fusão para realizar seu processamento. Os plastificantes mais usados para o amido são: a água e o glicerol (EMBRAPA, 2007).

O glicerol é um composto orgânico pertencente à função álcool, presente em todos os óleos de origem vegetal e animal em sua forma combinada, ou seja, ligado a ácidos graxos, tais como, ácido esteárico, palmítico e láurico, para formar a molécula de triacilglicerol. Seu uso justifica-se tanto pelo seu poder plastificante quanto pela enorme quantidade na qual está sendo produzido, por se tratar de um subproduto da produção do biodiesel, o que contribui para seu baixo custo. Por ser o glicerol uma molécula hidrofílica relativamente pequena, pode ser introduzida entre as cadeias poliméricas adjacentes, resultando em decréscimo da atração intermolecular e, portanto, em aumento da mobilidade molecular. Este efeito melhora a flexibilidade e a extensibilidade dos filmes (ALVES et al., 2007; REIS, 2011; SOUZA, 2011; SOUZA et al., 2012), promove a elongação e diminui a resistência à tração (RODRíGUEZ et al., 2006; SOUZA, 2011).

Em geral, a adição de plastificantes ao amido é um método estabelecido para reduzir a transição vítrea $\left(T_{\mathrm{g}}\right)$ do amido abaixo de sua temperatura de decomposição e converter o amido em um amido termoplástico, que facilita o seu processamento (ZHANG et al., 2013). 


\subsection{EXTRUSÃO}

A extrusão é o método mais importante no processamento de materiais poliméricos com aplicação em diversos setores industriais como: embalagens, automotivo, aeroespacial, construção civil, elétrica e eletrônica, incluindo até áreas médicas (ABEYKOON et al., 2012).

Diferentes tipos de extrusoras de processamento de polímeros estão disponíveis na indústria: extrusora de rosca simples (um parafuso), extrusora de rosca múltipla (dois ou mais parafusos), extrusora de disco, entre outras, sendo que a extrusora de parafuso simples é a mais utilizada na indústria de plásticos (ABEYKOON et al., 2012).

A primeira máquina extrusora para termoplásticos surgiu em 1935, criada por Paul Troester na Alemanha. Antes do surgimento eram usadas para produzir borracha, aquecidas por vapor, tanto com rosca, como com pistão. Depois de 1935 começaram a aparecer máquinas com aquecimento elétrico (RAUWENDAAL, 2001).

Enquanto isso, o fundamento básico de extrusoras com duas roscas foi concebido na Itália por Roberto Colombo, onde todas as máquinas eram alimentadas com matéria-prima já fundida, mas a partir da década de 50 começaram a aparecer estudos científicos sobre o transporte e plastificação de material sólido (RAUWENDAAL, 2001).

Normalmente a matéria-prima do polímero sólido, em grãos, pó ou flocos é colocada na máquina (alimentação), seguida por aquecimento, plastificação e por fim pressionado pela extrusora para dentro do canal de uma matriz (transporte), cuja parte frontal possui uma abertura no formato da seção transversal do produto desejado (RAUWENDAAL, 2001).

A máquina extrusora possui vários componentes, que podem variar dimensão, função entre outros, conforme o tipo de processo, geometria e especificações do produto, tamanho de produção e etc. (RAUWENDAAL, 2001).

Pode-se dizer, então, que as extrusoras têm a função de homogeneizar, plastificar e transportar o plástico até a matriz, forçando o material a passar por sua abertura, tomando assim sua forma. A Figura 5 a seguir mostra os principais componentes da extrusora. 
Figura 5 - Componentes básicos de uma extrusora de parafuso único

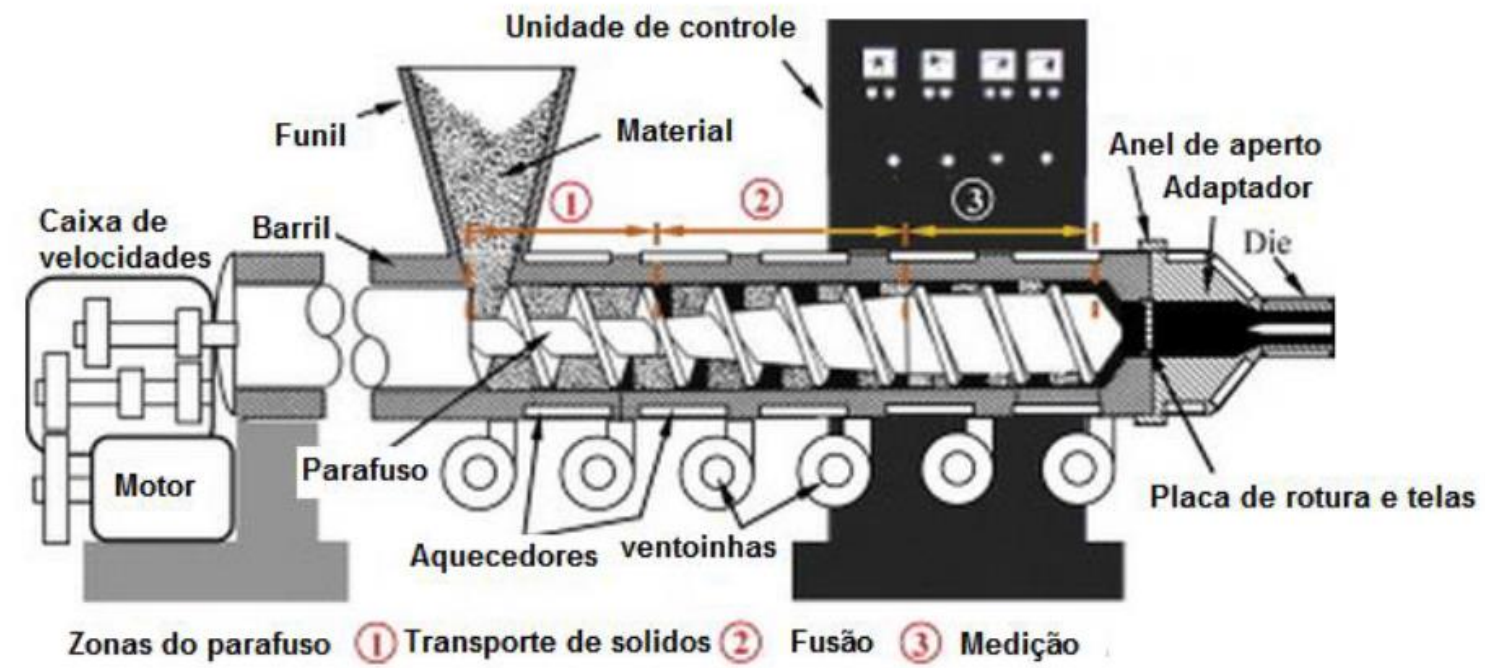

Fonte: Adaptado: ABEYKOON (2012); LLANOS (2018).

Diversas pesquisas têm sido desenvolvidas com o objetivo de produzir amido termoplástico para obtenção de materiais biodegradáveis, com ampla aplicação na indústria de alimentos, química, entre outras, além de verificarem a estabilidade térmica de matérias que melhoram ou dão alguma característica ao produto extrusado.

Ghanbari et al. (2018) produziram amido termoplástico (TPS) a partir de 2,7 g/100 g de amido de milho não modificado (amilose: $25 \mathrm{~g} / 100 \mathrm{~g}$; amilopectina $75 \mathrm{~g} / 100 \mathrm{~g}$ ) adicionado de massa sólida gel de nanofibras de celulose (NFC) como agente de reforço em várias proporções que vão desde $(0,5$ a 1,5) g/100 g. Glicerina foi utilizada como plastificante para preparar o TPS. Foram produzidos: TPS puro e nanocompósitos TPS/NFC (foram preparadas três formulações de filmes nanocompósitos TPS/NFC 0,5, TPS/NFC 1,0 e TP/NFC 1,5, contendo diferentes teores de NFC de $(0,5,1,0$ e 1,5) $\mathrm{g} / 100 \mathrm{~g}$ em massa, respectivamente). Todas as misturas foram feitas com uma razão de massa de amido para glicerol de 70/30 (g/g). A extrusão foi realizada com uma extrusora de parafuso duplo co-rotativa (ZSK-25, Alemanha), com uma velocidade de parafuso de $80 \mathrm{rpm}$. As temperaturas da extrusora foram controladas $\left(80,100,110,115\right.$ e 120) ${ }^{\circ} \mathrm{C}$ para as zonas $1,2,3,4$ e 5 , respectivamente, enquanto a temperatura do die foi de $125^{\circ} \mathrm{C}$. Na segunda etapa, os grânulos resultantes foram subsequentemente moldados (temperatura de $190^{\circ} \mathrm{C}$, a pressão durante o aquecimento de $3,5 \mathrm{MPa}$, tempo de aquecimento $10 \mathrm{~min}$ e tempo de arrefecimento $5 \mathrm{~min}$ ) por compressão para produzir as amostras de acordo com o 
padrão ASTM. Concluiu- se que o uso de extrusão para produção de TPS/NFC é um procedimento que pode ser aplicado ao setor comercial e que fornece materiais com boas características, sendo uma boa alternativa para a preparação de produtos biodegradáveis.

Gilfillan et al. (2016) produziram filmes de amido de milho com alto teor de amilose, glicerol, água, e foram adicionadas combinações de álcool com as seguintes concentrações: $(0,5,1,0$ e 1,5) g/100 g. A mistura foi adicionada na extrusora de parafuso duplo rotativo Prism (Eurolab, Inglaterra), sob as seguintes condições operacionais: o perfil de temperatura da extrusora foi de $(35,70,100,130,130,120$, $110,80,80,90)^{\circ} \mathrm{C}$ do alimentador até o final da matriz. Este perfil de temperatura prontamente volatiliza o álcool usado no processo; a velocidade de rotação do parafuso foi de (110 e 120) rpm, o que deu um tempo de residência de $(1,75$ e 2,25) min e pressão de (14 a 17) bar. Os parafusos com um diâmetro de $16 \mathrm{~mm}$, relação L/D de 40 foram equipados com três seções de elementos de amassamento. A última seção do parafuso tem espessura suficiente para desenvolver a pressão necessária para expulsar o amido plastificado através de dois furos de $3 \mathrm{~mm}$ na matriz (seção final). Na saída (die) foram produzidos dois fios cilíndricos extrudados de plástico com $3 \mathrm{~mm}$. Os resultados deste trabalho mostraram que o processo de extrusão térmica de amido não modificado na presença de álcool pode ser usado para melhorar as propriedades mecânicas do filme e reduzir o seu teor de umidade.

Durge et al. (2013) avaliaram a estabilidade da coloração das antocianinas préextrusadas, fazendo uma mistura de farinha de arroz com antocianinas. A porcentagem de antocianina variou de (1 a 3) g/100 g em relação a mistura de farinha de arroz com teor de umidade de 14 \%. Os parâmetros de extrusão foram mantidos constantes, no die a temperatura foi de $160^{\circ} \mathrm{C}$, a velocidade de parafuso de $150 \mathrm{rpm}$, e uma taxa de alimentação de $70 \mathrm{~g} / \mathrm{min}$. O cozimento por extrusão de farinha condicionada foi realizado na extrusora de parafuso único Brabender (modelo n.. 823500, Alemanha), com 20:1 barril de comprimento para relação de diâmetro e um parafuso com compressão com proporção de 2:1. A extrusora foi equipada com um bocal de matriz de $5 \mathrm{~mm}$ diâmetro. Os autores concluíram que a amostra extrusada com $2 \mathrm{~g} / 100 \mathrm{~g}$ de antocianina foi mais aceitável em termos de aparência, cor e aceitabilidade geral, e, portanto, foi usada para estudos posteriores. 


\subsection{NANOCOMPÓSITOS}

Nanocompósitos são definidos como materiais compostos de dois ou mais componentes, sendo que pelo menos um deles possui dimensões em escala nanométrica. Nanocompósitos têm atraído atenção considerável da indústria e da área acadêmica, porque eles geralmente herdam vantagens dos materiais componentes, ou mesmo são capazes de produzir materiais multifuncionais com propriedades superiores (QI et al., 2018).

Nanocompósitos poliméricos, geralmente, contêm uma matriz orgânica na qual os nanomateriais inorgânicos são dispersos. Os componentes inorgânicos incluem tipicamente nanopartículas, nanotubos, nanofolhas, nanofios, nanoargila e assim por diante, enquanto a matriz orgânica refere-se principalmente a polímeros sintéticos ou biomacromoléculas (LI et al., 2015, Ql et al., 2018).

Esses nanocompósitos poliméricos podem exibir recursos ópticos, térmicos, propriedades mecânicas, entre outras, melhorados devido ao sinergismo da característica dos componentes inorgânicos (como: grande área superficial, alta reatividade superficial, excelente estabilidade térmica, alta resistência mecânica) como as dos polímeros orgânicos (incluindo: baixo peso molecular, flexibilidade, boa processabilidade) (KUMAR, JOUAULT, 2013; QI et al., 2018).

\subsubsection{Nanofibras de Celulose}

O Brasil é um dos líderes mundiais de produção de celulose e as inovações tecnológicas feitas a partir de derivados de fontes renováveis (FERREIRA, 2017).

Segundo a Indústria Brasileira de Árvores (IBÁ) o Brasil ocupa o quarto lugar no ranking dos países produtores de celulose de todos os tipos e está como primeiro produtor mundial de celulose de eucalipto. As duas principais fontes de madeira utilizadas para a produção de celulose são as árvores plantadas de pinus e de eucalipto, responsáveis por mais de $98 \%$ do volume produzido. A celulose também pode ser obtida de outros tipos de plantas, não madeiras, como bambu, babaçu, sisal e resíduos agrícolas (por exemplo: bagaço de cana-de-açúcar). São 7,8 milhões de hectares de árvores plantadas de eucalipto, pinus e demais espécies, sendo que 34 \% são destinadas ao segmento de celulose e papel (IBÁ, 2015). 
A celulose é o componente mais abundante da parede celular dos vegetais, conferindo rigidez e firmeza às plantas. É o entrelaçamento dessas fibras que origina diversos produtos para aplicações em indústrias de papel: papel toalha, papel higiênico, guardanapos, cadernos, livros; embalagens para alimentos e bebidas, para indústrias farmaceuticas e de produtos de limpeza, entre outros (IBÁ, 2015).

Consoante à origem da celulose, as nanofibras apresentam características distintas. Isto tem a ver com as dimensões das fibras e com a composição e estrutura da parede celular, bem com a proporção de celulose, hemicelulose e lignina presentes. As proporções destes três últimos constituintes diferem de acordo com a planta ser folhosa, resinosa ou não madeireira e, dentro destas, varia também entre espécies (ISOGAI; SAITO; FUKUZUMO, 2011).

Nos últimos anos, as nanofibras de celulose (NCF) têm sido amplamente estudadas para muitas aplicações científicas e tecnológicas, devido às suas características únicas, como estabilidade térmica, biodegradabilidade, abundância, renovabilidade, resistência mecânica e propriedades ópticas (de CARVALHO BENINI et al., 2017). Atualmente, NFC é um dos materiais de reforço mais promissores para melhorar as propriedades mecânicas e a absorção de umidade do amido termoplástico (TPS) devido aos pontos relevantes citados acima, além do seu baixo peso, baixo custo e o fato de serem obtidas a partir de fontes naturais renováveis altamente abundantes (GHANBARI et al., 2018).

O uso de diferentes plantas para extração de nanofibras de celulose (NFC) tem sido apresentado na literatura por muitos pesquisadores. E a exploração de diferentes recursos é importante, considerando que as características dos materiais celulósicos podem ser alteradas de acordo com a idade e localização da planta, condições climáticas sazonais e processos de purificação (reagentes químicos, temperatura) (GHANBARI et al., 2018).

Celulose microfibrilada (CMF), tais como nanofibras de celulose (NFC) são normalmente extraídas de plantas lignocelulósicas, como madeira e culturas agrícolas, utilizando tratamentos mecânicos e químicos, ao contrário a celulose nanocristalina, tais como os nanowhiskers de celulose, os quais são extraídos de diversas fontes e preparados por hidrólise ácida. NFC contém tanto as regiões amorfas e cristalinas da celulose como podem apresentar redes embaralhadas. Além disso, é também um polissacarídeo contendo unidades de repetição de glicose 
semelhante ao amido (GHANBARI et al., 2018; KAMPANGKAEW et al., 2014; MA et al., 2008). Um dos maiores cuidados que se deve tomar ao processar esses materiais lignocelulósicos é sua temperatura de processamento que é limitada a $200{ }^{\circ} \mathrm{C}$, devido à hemicelulose presente nas fibras que começa a degradar em $230^{\circ} \mathrm{C}$ (GHANBARI et al., 2018).

O estudo das nanofibras de celulose como agentes reforçadores, iniciou-se há mais de 20 anos e desde então pesquisadores têm-se dedicado a estudar formas de extração, caracterização, isolamento e aplicação desses materiais altamente purificados.

Várias terminologias aparecem na literatura para esses materiais, porém genericamente, materiais celulósicos isolados que possuam uma dimensão na escala nanométrica são referidos como nanoceluloses e os interesses dos pesquisadores da área de nanotecnologia são pelo fato delas serem altamente cristalinas, abundantes de plantas naturais, terem propriedades únicas e diferentes tamanhos. Estes cientistas acreditam que as nanoceluloses têm elevado potencial para serem utilizadas em filmes transparentes e extremamente fortes (KLEMM et al., 2011).

De acordo com Klemm et al. (2011), as nomenclaturas dos tipos de celulose são classificadas em três subcategorias, que variam de acordo com suas funções, métodos de preparação, que por sua vez dependem principalmente da fonte de celulose e condição de processamento que são mostradas na Tabela 2. 
Tabela 2 - Nomenclaturas para nanoceluloses á partir de principais fontes e obtenção

\begin{tabular}{cccc}
\hline $\begin{array}{c}\text { Tipo de } \\
\text { Celulose }\end{array}$ & Sinônimos & Principais Fontes & Obtenção \\
\hline $\begin{array}{c}\text { Celulose } \\
\text { Microfibrilada }\end{array}$ & $\begin{array}{c}\text { Celulose Nanofibrilada, } \\
\text { Vicrofibras de Celulose, } \\
\text { Nanofibras de celulose }\end{array}$ & $\begin{array}{c}\text { Madeira, beterraba, } \\
\text { tubérculos de batata, } \\
\text { cânhamo, linho. }\end{array}$ & $\begin{array}{c}\text { Delaminação da } \\
\text { polpa de madeira por } \\
\text { pressão mecânica, } \\
\text { antes e/ou depois de } \\
\text { um tratamento } \\
\text { químico ou } \\
\text { enzimático. }\end{array}$ \\
$\begin{array}{c}\text { Celulose } \\
\text { Nanocristalina }\end{array}$ & $\begin{array}{c}\text { Microcristais, Whiskers } \\
\text { e Nanowhiskers }\end{array}$ & $\begin{array}{c}\text { Madeira, algodão, } \\
\text { palha de trigo, celulose } \\
\text { a partir de bactérias e } \\
\text { algas. }\end{array}$ & $\begin{array}{c}\text { Hidrólise ácida de } \\
\text { celulose a partir de } \\
\text { diversas fontes. }\end{array}$ \\
$\begin{array}{c}\text { Nanocelulose } \\
\text { Bacteriana }\end{array}$ & $\begin{array}{c}\text { Celulose Microbiana, } \\
\text { Celulose Bacteriana e } \\
\text { Biocelulose }\end{array}$ & $\begin{array}{c}\text { Açúcares de baixo } \\
\text { peso molecular e } \\
\text { álcoois. }\end{array}$ & Síntese Bacteriana. \\
\hline
\end{tabular}

Fonte: Klemm et al. (2011).

\subsection{MODIFICADORES QUÍMICOS}

O uso da técnica de extrusão reativa (REX) para a obtenção de novos materiais a partir do amido termoplástico (TPS), é a realização de reações durante o processamento. São dois os objetivos principais; i) estudo da compatibilização reativa do amido com outros polímeros e ii) modificação do amido no estado fundido (TPS) por meio de extrusão reativa (REX) envolvendo a sua despolimerização seguida de reações com diisocianatos ou poliisocianatos e com glicerol (repolimerização). A compatilização pode ser com o ácido polilático (PLA), polihidroxialcanoatos (PHB e PHBV) e poliésteres alifáticos (Ecoflex $\AA)$, empregando como agentes compatibilizantes diisocianatos, poliisocianatos bloqueados e/ou ácidos orgânicos (NOSSA, 2014).

O objetivo final da técnica é a obtenção de novos materiais com características distintas do TPS convencional, em especial como maior permanência do plastificante, maior compatibilidade com outros polímeros, maior resistência à água e menor tendência à cristalização. O glicerol poderá atuar como monômero na repolimerização ou então poderá ser enxertado à cadeia do amido funcionando como um plastificante interno (NOSSA, 2014). 
Outro potencial do uso de modificadores é a sua capacidade de agir como protetores térmicos que são substâncias responsáveis por preservar o material do efeito nocivo quando submetido à altas temperaturas de processamento, como estabilizar suas propriedades físicas e químicas. Neste quesito, o uso de ácidos carboxílicos para este fim tem sido interessante por ser uma fonte renovável.

Os ácidos carboxílicos, como os ácidos cítrico e esteárico, possuem um grupo polar $(\mathrm{COOH})$ que pode reagir com os grupos hidroxila do amido através de forças de ligação secundárias, diminuindo a hidrofilicidade do amido e aumentando a compatibilidade com o TPS (MARTINS; SANTANA, 2016; SALOMÃO et al., 2014; SELIGRA et al., 2016).

\subsection{1 Ácido cítrico e ácido esteárico}

Substâncias multifuncionais, como o ácido cítrico, são adicionadas para promover reações de esterificação/transesterificação (reticulação) na interface entre cadeias poliméricas para melhorar sua compatibilidade. Este fato, segundo Zhang e Sun (2004), tem sido efetivo para o controle da morfologia em diversos sistemas poliméricos.

"O ácido cítrico (CA), também conhecido como citrato de hidrogênio, é um ácido orgânico fraco, encontrado no estado sólido em temperatura ambiente, de cor branca ou translúcida, inodoro, de sabor azedo, completamente solúvel em água, biodegradável, de baixo ponto de fusão, atóxico, não inflamável, presente nos frutos cítricos (Tabela 3), como por exemplo, limão, laranja, tangerina, cidra, bergamota e toranja (MARTINS; SANTANA 2016).

O ácido cítrico é um ácido policarboxílico de base biológica, comercialmente disponível a baixo custo, que tem natureza atóxica, uma vez que é produzido como um produto metabólico do corpo (ciclo de Krebs) em todas as células vivas que usam oxigênio como parte da respiração celular (ROCHA-GARCIA et al., 2017; URANGA et al., 2018). Além do caráter antimicrobiano que tem sido relatado em alguns trabalhos recentes (DENGHANI; HOSSEINI; \& REGENSTEIN, 2018; KIM E RHEE, 2015; OLAIMAT et al., 2017; URANGA et al., 2018).

O ácido cítrico pode ser um bom candidato para melhorar algumas propriedades do material em que é adicionado. Vários autores relataram que o ácido cítrico forma uma ligação éster com o amido (SHI et al., 2007; WANG et al., 2007a, 
2009). A esterificação ocorre entre os grupos carboxila no ácido cítrico e os grupos hidroxila no amido. No entanto, com a presença do glicerol, ele reage preferencialmente com os grupos hidroxila do glicerol (CHABRAT et al., 2012; WANG et al., 2007a).

Mesmo se não houver ligação éster entre o ácido cítrico e o amido, foi relatado que o ácido cítrico pode formar fortes interações de ligação de hidrogênio com o amido, mais forte que com o glicerol, melhorando a sensibilidade térmica à água do amido termoplástico (TPS) e inibindo a retrogradação (CHABRAT et al., 2012; HOLSER, 2008; SHI et al., 2007; YU et al., 2005).

A reticulação é um processo que ocorre quando cadeias poliméricas lineares ou ramificadas são interligadas por ligações covalentes. Esse processo aplicado em filmes de amido foi realizado usando ácido cítrico contendo três grupos carboxílicos, e um catalisador (hipofosfito de sódio) (CHABRAT et al., 2012; REDDY E YANG, 2010). O ácido cítrico livre, que não estava envolvido em nenhuma interação de reticulação, pode atuar como plastificante (CHABRAT et al., 2012; SHI et al., 2008). O CA também foi adicionado ao TPS para modificar seu desempenho físico por degradação controlada do amido através de uma hidrólise catalisada por ácido das ligações éster nas cadeias polissacarídicas (CARVALHO et al., 2005; CHABRAT et al., 2012; HIRASHIMA et al., 2005; WU et al., 2010).

O ácido cítrico, em concentração inferior a $20 \mathrm{~g} / 100 \mathrm{~g}$, não apresenta efeito de toxicidade significativo na proliferação celular (CHABRAT et al., 2012; SHI et al., 2008).

O ácido esteárico (SA) (ácido octadecanóico) é um dos tipos úteis de ácidos graxos saturados que vem de muitas gorduras e óleos animais e vegetais. É um ácido sólido branco com odor suave (Tabela 3) (MARTINS; SANTANA, 2016).

Tabela 3 - Propriedades físico-químicas dos ácidos carboxílicos com temperatura de fusão $T_{m}$ e temperatura de ebulição $T_{b}$ de decomposição

\begin{tabular}{ccccc}
\hline Ácido & $\begin{array}{c}\text { Fórmula } \\
\text { molecular }\end{array}$ & Fórmula estrutural & $T_{\mathbf{m}}\left({ }^{\circ} \mathbf{C}\right)$ & $T_{\mathbf{b}}\left({ }^{\circ} \mathbf{C}\right)$ decomposição \\
Cítrico & $\mathrm{C}_{6} \mathrm{H}_{8} \mathrm{O}_{7}$ & 153 & 175 \\
Esteárico & $\mathrm{C}_{18} \mathrm{H}_{36} \mathrm{O}_{2}$ & &
\end{tabular}

Fonte: Adaptado: MARTINS; SANTANA (2016). 
O efeito de diferentes tipos de ácidos carboxílicos no comportamento da gelatinização do amido tem sido descrito na literatura. O estudo de Exarhopoulos e Raphaelides (2012) mostra a adição de três diferentes ácidos (esteárico, mirístico e palmítico) utilizando três tipos de amido (milho, ervilha e amilomilho) com diferentes teores de amilose. Dois modos diferentes de aquecimento dos sistemas de amido foram empregados: adição do ácido nas dispersões aquosas de amido antes ou após aquecimento com as temperaturas predeterminadas $(75,85 \text { ou } 98)^{\circ} \mathrm{C}$. A análise de microscopia eletrônica de varredura (MEV), indicou que interações amilose-ácido ocorridas durante a gelatinização do amido retardaram a destruição do grânulos, dependendo da temperatura de aquecimento. Estudos de difração de raios - X (DRX) revelaram que o grau de cristalinidade das amostras de amido foi dependente do teor de amilose, do comprimento da cadeia dos ácidos e dos métodos de aquecimento empregados.

O ácido esteárico quando foi adicionado ao amido antes do aquecimento, retardou a ruptura dos grânulos. Por outro lado, no caso de adicionar o ácido esteárico após aquecimento, indica que a porção de amilose que permaneceu dentro do grânulo não interage com o ácido (EXARHOPOULOS; RAPHAELIDES, 2012).

\subsection{EMBALAGENS INTELIGENTES}

As tecnologias empregadas nas embalagens inteligentes estão se tornando a solução para satisfazer a resposta às demandas do consumidor e às tendências do setor. No mercado de tecnologias inteligentes, a embalagem de alimentos representa uma fração muito pequena, quase totalmente concentrada no Japão (DAINELLI et al., 2008; CALLAGHAN; KERRY, 2016). Sistemas de embalagem inteligentes podem gerar um produto de alto valor agregado, utilizando funções de embalagem não tradicionais para fornecer produtos alimentícios mais seguros, além de serem ecologicamente corretos. Eles também podem contribuir informativamente; proporcionando melhor eficiência logística e recall otimizado de produtos. Além disso, as tecnologias de embalagem inteligente podem ser ainda mais otimizadas pela incorporação da nanotecnologia, que pode ser utilizada de forma ativa ou inteligente (CALLAGHAN; KERRY, 2016). 


\subsubsection{Antocianinas}

As antocianinas são pigmentos derivados de sais flavílicos, solúveis em água, responsáveis pela ampla gama de cores azul, violeta, vermelho e rosa da maioria de flores e frutos. Os mais de 450 tipos de antocianinas que foram isolados e caracterizados também estão presentes em algumas folhas, raízes, bulbos, tubérculos, sementes, caules, cereais e legumes (ARENAS, 2012; BRIDLE; TIMBERLAKE, 1997, FREITAS, 2005). As antocianinas compõem o maior grupo de pigmentos solúveis em água do reino vegetal e são encontradas em maior quantidade nas angiospermas (BRIDLE; TIMBERLAKE, 1997). Quando extraídas do meio natural, apresentam-se na forma de sais de flavilium, normalmente glicosiladas, sendo as mais comuns a $\beta$-D-glicose, $\beta$-D-galactose e a $\alpha$-D-ramnose (RAMOS et al., 2000).

"As antocianinas podem apresentar diferentes formas estruturais, as quais podem assumir diferentes colorações. De fato, essas formas podem sofrer interferências de diversos fatores, destacando-se entre estes a temperatura, o valor do $\mathrm{pH}$ e possíveis ligações com outras substâncias químicas. $\mathrm{O}$ pH é o fator que mais influencia a coloração das antocianinas, visto que, em função de sua acidez ou alcalinidade, estas podem apresentar diferentes estruturas" (BORDIGNON et al., 2009).

A função das antocianinas nas plantas, flores e frutos são de proteção à ação da luz, antioxidantes, possuem mecanismos de defesa e ainda função biológica. As cores vivas e intensas que elas produzem têm um papel importante nos mecanismos reprodutores das plantas, tais como a polinização e a dispersão de sementes (ARENAS, 2012; CASTAÑEDA-OVANDO et al., 2009; FREITAS, 2005).

São solúveis em solventes polares, e normalmente extraídas a partir de materiais vegetais utilizando-se metanol com pequenas quantidades de ácido clorídrico ou ácido fórmico. O ácido reduz o valor de $\mathrm{pH}$ da solução e evita a degradação dos pigmentos antocianinas (KONG et al., 2003).

Diferentemente das clorofilas e dos carotenóides, a absorção eletrônica das antocianinas está distribuída por toda a região visível do espectro eletromagnético (400 - 700) nm (ARENAS, 2012; BRIDLE; TIMBERLAKE, 1997; FREITAS, 2005).

A estrutura química básica da antocianina é baseada em uma estrutura policíclica de quinze carbonos, mostrada na Figura 6: 
Figura 5 - Estrutura química das antocianinas

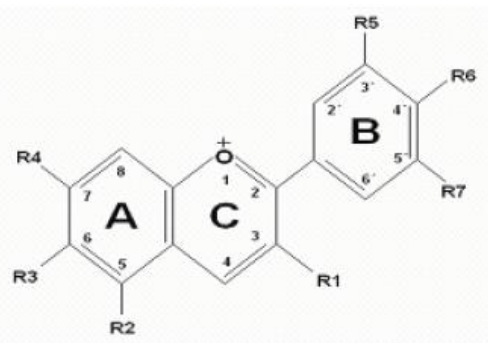

Fonte: ARENAS (2012); LOPÉZ; JIMÉNEZ; VARGAS (2000).

Devido à mudanças nos grupos ligados à sua estrutura fenólica, pode ser encontrada uma enorme diversidade de antocianinas na natureza, que confere diferentes cores que ocorrem em várias frutas, flores e folhas (ARENAS, 2012; TERCI; ROSSI, 2002). As antocianinas podem ser glicosadas por diferentes açúcares nas posições 3, 5 e 7, mas sempre ocorre a glicolisação na posição C-3 (ARENAS, 2012; BRIDLE; TIMBERLAKE, 1997).

\subsubsection{Mudança de cor da antocianina e influência do pH}

A antocianina poderá ter diferentes cores, dependendo do $\mathrm{pH}$, da estrutura e da concentração dos pigmentos, da temperatura de armazenamento e, da presença de oxigênio, luz e co-pigmentos (MAZZA; BROUILLARD, 1987). Com o aumento do número de hidroxilas, a coloração das antocianinas muda de rosa para azul e a presença de grupo metoxila no lugar da hidroxila reverte à tendência anterior (MAZZA; BROUILLARD, 1987).

A variação intensa de cores da antocianina foi estudada por vários autores e, segundo Brouillard e Dubois (1977), em solução aquosa podem existir quatro formas estruturais de antocianinas em equilíbrio: o cátion flavílio $\left(\mathrm{AH}^{+}\right)$, a base quinoidal $(\mathrm{A})$, a pseudobase ou carbinol (B) e a chalcona (C), representadas na Figura 6. Em condições ácidas ( $\mathrm{pH}$ inferior a 3), a antocianina existe primariamente na forma de cátion flavílio $\left(\mathrm{AH}^{+}\right)$de cor vermelha intensa. Com o aumento do $\mathrm{pH}$ ocorre a rápida perda do próton para produzir as formas quinoidais $(A)$, azuis ou violetas. Em paralelo ocorre a hidratação do cátion flavílio $\left(\mathrm{AH}^{+}\right)$, gerando a pseudobase incolor ou carbinol (B) que atinge o equilíbrio lentamente com a chalcona incolor ou amarelo tênue $(C)$, como representado na Figura 7. As quantidades relativas de cátion $\left(\mathrm{AH}^{+}\right)$, formas 
quinoidais $(A)$, pseudobase $(B)$ e chalcona $(C)$ na condição de equilibrio variam conforme o pH e a estrutura da antocianina (IACOBUCCI; SWEENY, 1983).

Portanto o pH do meio exerce um papel muito importante no equilíbrio entre as diferentes formas de antocianinas e, consequentemente, na modificação da cor (ARENAS, 2012).

Figura 6 - Estruturas moleculares encontradas em solução aquosa com diferentes valores de $\mathrm{pH}$. Cátion flavilium $\left(\mathrm{AH}^{+}\right)$, base quinoidal $(\mathrm{A})$; pseudobase incolor ou carbinol $(\mathrm{B})$ e chalcona $(\mathrm{C})$ e sua ampla variaçãoes de cores

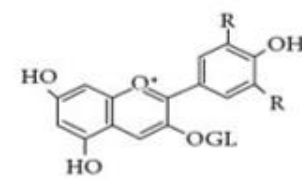

Cátion flavilium $\left(\mathrm{AH}^{+}\right)$

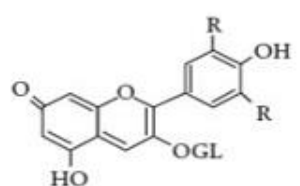

Base quinoidal (A)

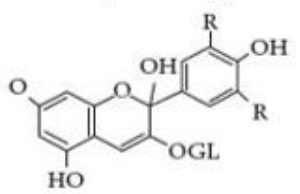

Carbinol (B)

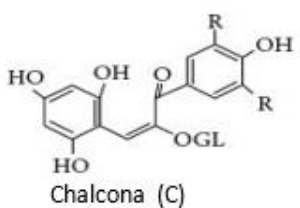

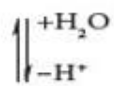
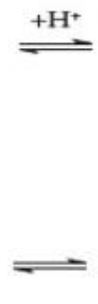<smiles>C1CCC1</smiles> 


\section{MATERIAL E MÉTODOS}

A parte experimental do trabalho foi dividida em cinco etapas:

1) Caracterização do agente reforçador celulose microfibrilada (CMF), quanto à sua morfologia, cristalinidade, classificação granulométrica e estabilidade;

2) Obtenção dos filmes biodegradáveis por extrusão a base de amido de mandioca, contendo glicerol e/ou água como aditivo plastificante, celulose microfibrilada (CMF) como carga de reforço, ácido cítrico e ácido esteárico como modificadores químicos;

3) Caracterização dos filmes quanto às suas propriedades mecânicas e de superfície para seleção do filme ótimo para a adição de antocianina;

4) Adição da antocianina como agente indicador de mudança de $\mathrm{pH}$ no filme ótimo e caracterização de suas propriedades mecânicas, de superfície, cristalinidade e morfologia;

5) Avaliação da mudança de cor da embalagem de amido termoplástico com antocianina.

A primeira etapa foi realizada no Laboratório de Caracterização Tecnológica (LCT), e as demais no Laboratório de Engenharia de Alimentos (LEA). Ambos laboratórios pertencem à Escola Politécnica da Universidade de São Paulo (POLI USP).

\subsection{MATERIAL}

Nesse trabalho foram empregados os seguintes materiais: fécula de mandioca nativa, doada pela Cargill (pureza 83,7 g/100 g; amilose: 19,7 g/100 g; amilopectina: 80,3 g/100 g) usada como matriz de formação dos filmes; Glicerol P.A. - A.C.S. (adquirido da Lab Synth); ácido cítrico anidro P.A. - A.C.S. (adquirido da Lab Synth) e ácido esteárico puro (adquirido da Lab Synth); nanofibras de celulose (NFC) celulose microfibrilada (CMF) em solução aquosa $(3,1 / 100) \mathrm{g}$ concentrada (doada por Suzano Papel e Celulose®); antocianina extraída de casca de uva (doada pela Crh. Hansen), usada como agente indicador de mudança de $\mathrm{pH}$; água Milli $\mathrm{Q}(18,2 \mathrm{M} \Omega \mathrm{cm}$ 
a $25^{\circ} \mathrm{C}$ ); sílica gel (adquirida da Synth) e filtros de papel com diâmetro de $12,5 \mathrm{~cm}$ (Carlschleicher \& Schüll - Alemanha), usados nos ensaios de solubilidade.

\subsection{MÉTODOS}

A seguir os tópicos 4.2.1 a 4.2.3.2 serão descritos os métodos referentes a primeira, segunda e terceira etapas do processo.

\subsubsection{Caracterização da celulose microfibrilada (CMF)}

A celulose microfibrilada usada como agente reforçador dos filmes de amido termoplástico, foi caracterizada quanto ao tamanho de partícula pela técnica de análise granulométrica por espalhamento de luz laser e propriedades morfológicas: microscopia eletrônica de varredura (MEV) e cristalinidade por difração de raios $-X$ (DRX).

\subsubsection{Tamanho e dispersão de partícula}

O tamanho das partículas da celulose microfibrilada, antes do tratamento mecânico de dispersão, foi medido em meio aquoso de dispersão. A função do dispersante é promover a separação dos aglomerados de partículas, evitando erros. O dispersante mais utilizado é a água e sempre que possível deve ser usado, desde que a amostra não seja solúvel nesse dispersante (FRANÇA; COUTO, 2018).

A técnica de análise granulométrica por espalhamento de luz laser foi escolhida para determinar o tamanho de partícula da celulose microfibrilada (CMF) com concentração de $(3,1 / 100) \mathrm{g}$, através do analisador de tamanho de partículas por espaçamento laser (HYDRO 2000MU, Reino Unido), em meio de dispersão de água deionizada, velocidade da bomba de 2500 rpm e ultrassom 1 min. Não foi necessário utilizar agente para diluir ou aglomerar.

\subsubsection{Morfologia}

Uma quantidade de $50 \mathrm{~g}$ de celulose microfibrilada com concentração de $(3,1 / 100) \mathrm{g}$ foi seca em estufa (Nova ética, Modelo 410 NDR, Brasil), com recirculação de ar a temperatura de $32{ }^{\circ} \mathrm{C}$ com o objetivo de obter um material seco e capaz de 
resistir ao manuseio e permitir a sua caracterização. Corpos de prova secos foram manualmente cortados, de maneira que o corte ocorresse naturalmente, sem o uso de aparatos como tesouras ou lâminas que pudessem prejudicar a estrutura natural do material. Tomou-se o cuidado de colocar os corpos de prova retangulares secos com a superfície exposta à secagem para cima no suporte de alumínio. Em seguida, os materiais foram cobertos com platina por meio de pulverização catódica (Bal-Tec MED 020, Coating System, Holanda). Empregou-se um Microscópio Eletrônico de Varredura (MEV) (FEI, QUANTA FEG 650, Estados Unidos) sob voltagem de aceleração de $5 \mathrm{kV}$ para a análise dos corpos de prova.

\subsubsection{Cristalinidade}

A celulose microfibrilada com concentração de $(3,1 / 100) \mathrm{g}$ foi seca em estufa (Nova ética, Modelo 410 NDR, Brasil) com recirculação de ar a temperatura de $32{ }^{\circ} \mathrm{C}$, e armazenada em sílica gel por sete dias (para a retirada da umidade). O estudo foi efetuado através do método do pó, mediante o emprego de difratômetro de raios- $X$ (DRX) (PANalytical, X'Pert PRO, Reino Unido) com detector X'Celerator. As condições de análise para a obtenção dos difratogramas foram: radiação de $\mathrm{Cu}$, corrente de $5 \mathrm{~mA}$ e voltagem de $40 \mathrm{kV}$, sendo a velocidade de varredura de 0,02 \% com tempo/passo de $200 \mathrm{~s}$, com ângulo $2 \theta$ variando de (2 a 90) ${ }^{\circ}$.

Os índices de cristalinidade $(I C)$ da CMF, foram estimados de acordo com a metodologia proposta por Sega, Creely, Martin e Conrad (1959), conforma a equação 1:

$$
I C(\%)=\left(\frac{I_{200}-I_{a m}}{I_{200}}\right) \times 100
$$

Em que $l_{200}$ é a intensidade da difração do plano (200) em $2 \theta=22,8^{\circ}$ (cristalina), e lam é a difração da intensidade em $2 \theta=18^{\circ}$ (amorfa).

\subsubsection{Obtenção do amido termoplástico}

\subsubsection{Formulações das pré-misturas}

Para obtenção do amido termoplástico, foram testadas diferentes formulações que estão descritas na Tabela 4 e observadas no esquema da Figura 8. 
Cada pré-mistura foi homogeneizada em uma batedeira (Philips Walita Daily RI7000/41, Brasil) na velocidade de 80 rpm, por 20 min. Em seguida, armazenada a 25 ํ em sacolas plásticas termo seláveis até sua utilização.

A celulose microfibrilada foi dispersa no plastificante (água e/ou glicerol) em ultra dispersor (Gehaka, HU - 30, Brasil), velocidade de 13.000 rpm, por 15 min e em seguida imersa em banho de ultrassom (UNIQUE, Brasil: $25 \mathrm{kHz}$ e $154 \mathrm{~W}$ ) por um período de $30 \mathrm{~min}$. 
Tabela 4 - Descrição das formulações para obtenção do amido termoplástico

\begin{tabular}{|c|c|c|c|c|}
\hline Formulações & Filmes & Plastificante & $\begin{array}{l}\text { Protetor } \\
\text { Térmico }\end{array}$ & $\begin{array}{c}\text { Agente } \\
\text { Reforçador }\end{array}$ \\
\hline F1 & TPS_Wt & Wt & - & \\
\hline F1_CMF & TPS_Wt_CMF & Wt & - & CMF \\
\hline F2 & TPS_Wt_SA & $\mathrm{Wt}$ & SA & - \\
\hline F2_CMF & TPS_Wt_SA_CMF & Wt & SA & CMF \\
\hline F3 & TPS_Wt_CA & Wt & CA & - \\
\hline F3_CMF & TPS_Wt_CA_CMF & $\overline{W t}$ & $\mathrm{CA}$ & $\mathrm{CMF}$ \\
\hline F4 & TPS_WtGly & Wt + Gly & - & - \\
\hline F4_CMF & TPS_WtGly_CMF & Wt + Gly & - & $\mathrm{CMF}$ \\
\hline F5 & TPS_WtGly_SA & Wt + Gly & SA & - \\
\hline F5_CMF & TPS_WtGly_SA_CMF & Wt + Gly & SA & CMF \\
\hline F6 & TPS_WtGly_CA & Wt + Gly & $\mathrm{CA}$ & - \\
\hline F6_CMF & TPS_WtGly_CA_CMF & Wt + Gly & $\mathrm{CA}$ & CMF \\
\hline F7 & TPS_Gly & Gly & - & - \\
\hline F7_CFM & TPS_Gly_CMF & Gly & - & CMF \\
\hline F8 & TPS_Gly_SA & Gly & SA & - \\
\hline F8_CMF & TPS_Gly_SA_CMF & Gly & SA & $\mathrm{CMF}$ \\
\hline F9 & TPS_Gly_CA & Gly & $\mathrm{CA}$ & - \\
\hline F9_CMF & TPS_Gly_CA_CMF & Gly & $\mathrm{CA}$ & CMF \\
\hline
\end{tabular}

Fonte: Do autor (2018). 
Figura 7 - Esquema do processo de obtenção do amido termoplástico (TPS)

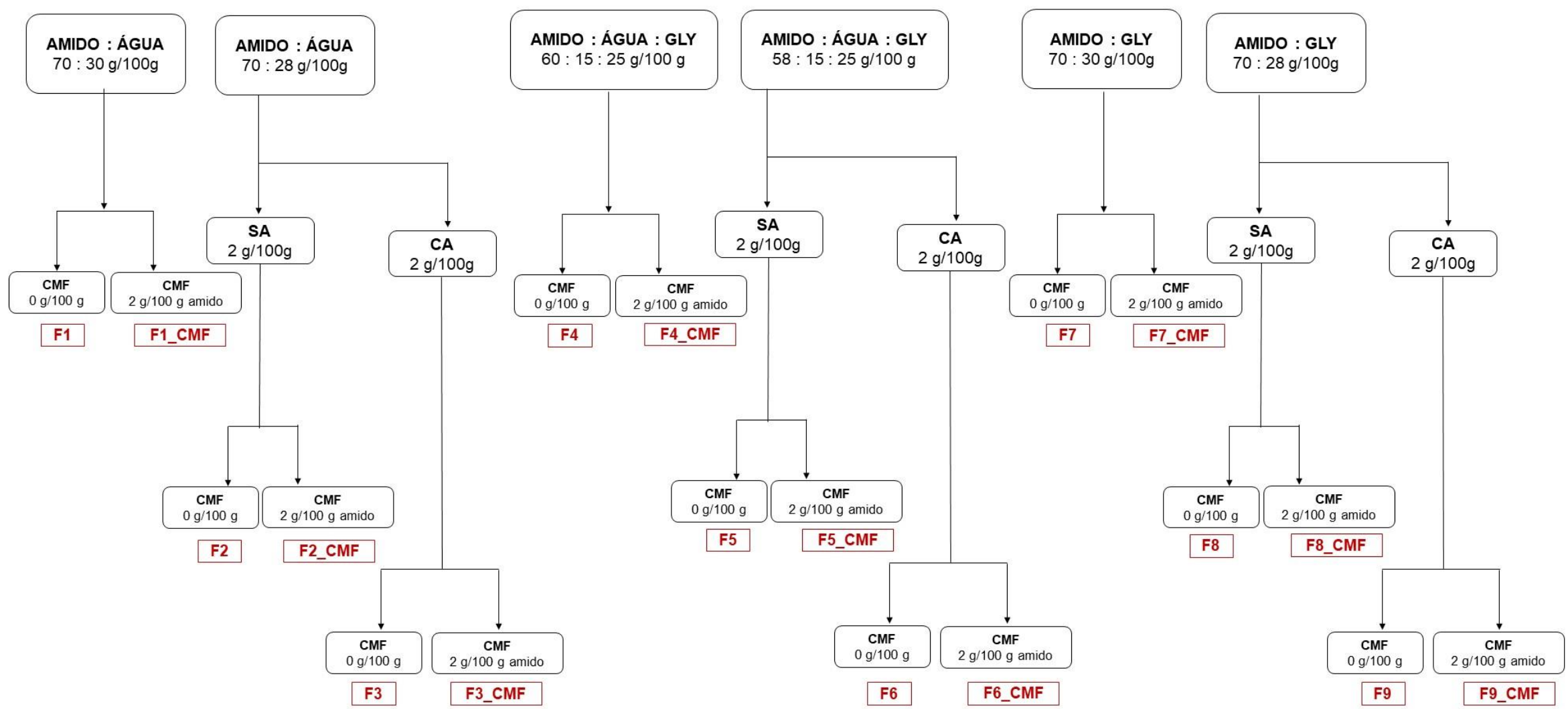

Legenda: (Wt) água; (Gly) glicerol; (SA) ácido esteárico; (CA) ácido cítrico; (CMF) microfibrilas de celulose. Fonte: Do autor (2018). 


\subsubsection{Produção dos pellets}

A pré-mistura foi extrudada em extrusora de dupla rosca co-rotativa (Process 11, ThermoElectron - Alemanha), L/D 40 e diâmetro de $11 \mathrm{~mm}$ dos parafusos equipada com oito zonas de aquecimento e uma matriz de saída (die) de $3 \mathrm{~mm}$. As pré-misturas foram introduzidas a extrusora por um alimentador de dupla rosca (Volumetric Minitwin Process 11, Brabender, Alemanha) a uma taxa de alimentação de 0,5 kg/h. O perfil de temperatura variou de acordo com a formulação, as pré-misturas com glicerol foram processadas desde a zona de alimentação (1) até a zona 8 (desde o alimentador até a saída do extrudado) com o seguinte perfil de temperatura: (80, 90, 90, 100, 110, $110,105,100)^{\circ} \mathrm{C}$ e o die a $100^{\circ} \mathrm{C}$. A velocidade das roscas foi de $100 \mathrm{rpm}$. Já as prémisturas sem glicerol foram processadas desde a zona de alimentação (1) até a zona 8 (desde o alimentador até a saída do extrudado) com o seguinte perfil de temperatura: $(50,50,60,80,75,75,70,70)^{\circ} \mathrm{C}$ e o die a $80^{\circ} \mathrm{C}$. A velocidade das roscas foi de 80 rpm. O TPS extrudado foi peletizado usando uma peletizadora automática Varicut Pelletizer, $16 \mathrm{~mm}$, (Thermo Scientific, Alemanha) produzindo pellets de $2 \mathrm{~mm}$ de comprimento.

\subsubsection{Produção dos filmes de amido}

Os filmes foram obtidos pelo processo de extrusão em extrusora de dupla rosca co-rotativa (Process 11, ThermoElectron - Alemanha), L/D 40 e diâmetro dos parafusos de $11 \mathrm{~mm}$ equipada com oito zonas de aquecimento e um perfil de saída (die) para produção de filmes. Os pellets foram introduzidos a partir de um alimentador do tipo cônico (Kulturstrasse 55-73, Brabender, Alemanha), com um fluxo de alimentação de $0,23 \mathrm{~kg} / \mathrm{h}$. O perfil de temperatura utilizado foi o mesmo usado para obter os pellets. Todos os filmes foram condicionados a uma umidade relativa controlada de $75 \%$ durante no mínimo $48 \mathrm{~h}$ a temperatura de $25 \stackrel{\circ}{\circ}$, antes dos testes de caracterização. O ambiente de alta umidade foi escolhido para avaliar o desempenho do filme em uma condição típica de clima tropical (SOUZA et al., 2012).

No processo de extrusão, a estrutura dos grânulos de amido é quebrada pela combinação de pressão, calor e altas tensões de cisalhamento para fundir o amido usando uma extrusora de parafuso simples ou duplo. Sob energia termomecânica, os grânulos de amido são fragmentados, reestruturados, plastificados e fundidos para 
produzir TPS, como mostrado na Figura 9. Este processo torna-se mais difícil na presença de nanopartículas, porque elas tendem a se agrupar facilmente dentro da matriz de amido. Ou seja, todos os componentes (amido, celulose microfibrilada, modificadores químicos e plastificantes) foram alimentados em uma única etapa na extrusora com ou sem água (ABDULLAH, DONG, 2018; DONG et al., 2015; GARCíA et al., 2015; MADHUMITHA et al., 2018; MEDEIROS, DUFRESNE, ORTS, 2010).

Figura 8 - Processo de produção dos filmes de amido termoplástico (TPS) na extrusora

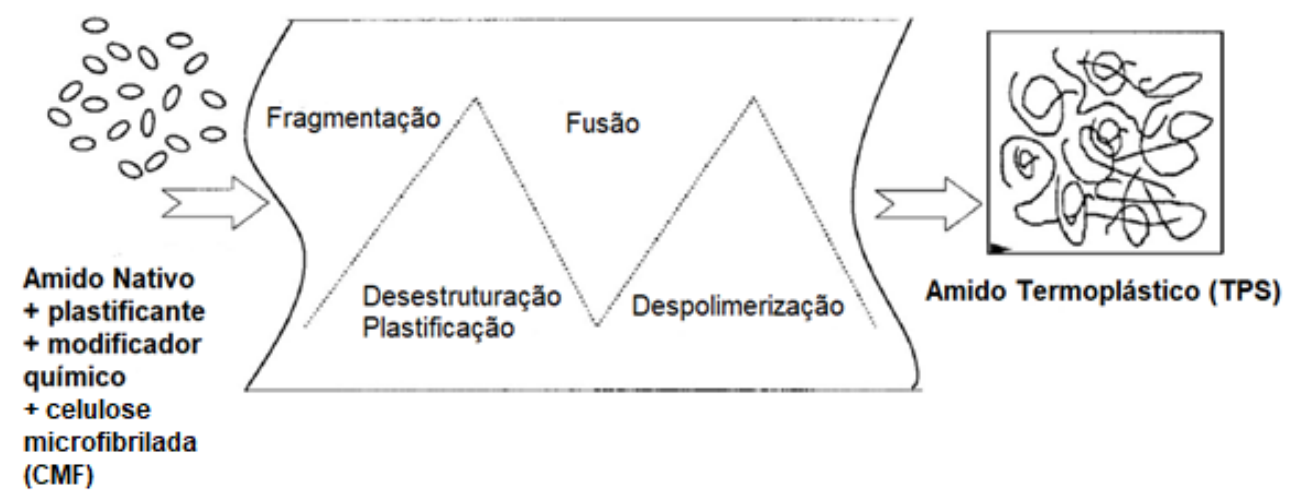

Fonte: Adaptado: ABDULLAH, DONG (2018).

\subsubsection{Solução de Antocianina}

Em $100 \mathrm{~mL}$ de água destilada, foi adicionada $0,384 \mathrm{~g}$ de antocianina, obtendo uma solução com concentração de $3,84 \mathrm{~g} / \mathrm{L}$. A solução sob agitação em agitador magnético (Gehaka, AA-2050, Brasil) foi bombeada na zona seis da extrusora a partir de uma bomba a vácuo (Easy-Load Pump Heads, MasterFlex L/S, U.S.A).

\subsubsection{Produção dos filmes de amido com antocianina (ATH)}

Os filmes com antocianina foram obtidos pelo processo de extrusão utilizando uma extrusora de dupla rosca co-rotativa (Process 11, ThermoElectron - Alemanha), L/D 40 e diâmetro dos parafusos de $11 \mathrm{~mm}$ equipada com oito zonas de aquecimento e um perfil de saída (die) para produção de filmes. Os pellets da formulação ótima (TPS_Wt:Gly_SA) foram alimentados a partir de um alimentador do tipo cônico (Kulturstrasse 55-73, Brabender, Alemanha), com taxa de alimentação de 0,23 kg/h. O perfil de temperatura e a velocidade da rosca utilizados foram os mesmos aplicados para a produção de pellets (TPS_Wt:Gly_SA). A vazão de saída do filme foi de 3,84 $\mathrm{g} / \mathrm{min}$. As vazões de alimentação da solução de antocianina foram $(5,10$ e 20$) \mathrm{mL} / \mathrm{min}$ 
que são correspondentes aos filmes ATH_0,005, ATH_0,010 e ATH_0,020 com (5, 10 e 20) $\mathrm{mg}$ de antocianina/100 g de filme, respectivamente. Todos os filmes foram condicionados a uma umidade relativa controlada de 75 \% durante no mínimo 48 h a temperatura de $25^{\circ} \mathrm{C}$, antes dos testes de caracterização. O ambiente de alta umidade foi escolhido para avaliar o desempenho do filme em uma condição típica de clima tropical (SOUZA et al., 2012).

\subsubsection{Caracterização dos filmes de amido}

Os filmes pré-condicionados $\left(75 \% \cup R, 25^{\circ} \mathrm{C}\right)$ foram caracterizados quanto às suas propriedades mecânicas e de superfície, conforme os métodos descritos a seguir.

\subsubsection{Propriedades mecânicas e de superfície}

\subsection{Espessura}

A espessura dos filmes extrudados pré-condicionados foi avaliada através da espessura média resultante de 5 medições em posições aleatórias usando um micrômetro digital Zaas- Precision de ponta plana (resolução de 1 ㅆm).

\subsection{Propriedades mecânicas}

Para a realização dos testes mecânicos dos filmes extrudados, foi utilizado o texturômetro TA TX Plus (Stable Micro Systems, Inglaterra) e avaliados no software Texture Exponent (versão 4.0.13.0) de acordo com o método ASTM D882-12 (ASTM, 2012). Os corpos de prova com comprimento de $10 \mathrm{~cm}$ e largura de 2,7 cm foram previamente acondicionados em ambiente de umidade relativa controlada de $75 \%$, por no mínimo 48 h. A tensão na ruptura (MPa) e a deformação na ruptura (\%) foram obtidas diretamente das curvas de tensão versus deformação (Figura 10). O módulo elástico ou módulo de Young (MPa) foi determinado calculando-se o coeficiente angular da parte linear da curva de tensão versus elongação. A distância inicial de aderência e a velocidade do teste foram $50 \mathrm{~mm}$ e $0,9 \mathrm{~mm} / \mathrm{s}$, respectivamente. 
Figura 9 - Analisador de textura com probe A/TGT (Stable Micro Systems)

Fonte: Do autor (2018).

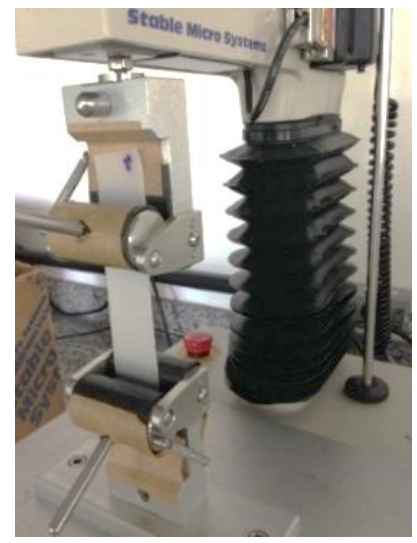

\subsection{Solubilidade e conteúdo de umidade}

A solubilidade em água dos filmes extrudados foi calculada da quantidade de matéria seca do filme solubilizado após imersão durante $24 \mathrm{~h}$ em água a $(25 \pm 2){ }^{\circ} \mathrm{C}$ (GONTARD, et al. 1992), como descrito por Maniglia (2017). Três discos de cada corpo de prova de filme, com $2 \mathrm{~cm}$ de diâmetro, previamente pesados, foram imersos em $50 \mathrm{~mL}$ de água Milli-Q e mantidos por 24 h a $25^{\circ} \mathrm{C}$, sob agitação mecânica (C24 Incubator Shaker), com rotação de 150 rpm, após o qual, foi determinado o conteúdo de matéria seca não solubilizada. A matéria sólida insolúvel foi determinada utilizando-se o método de filtração segundo a técnica no 971.09 da AOAC (1995). A solubilidade foi calculada conforme a Equação 2:

$$
\text { Solubilidade }(\%)=\left(1-\frac{m_{f}}{m_{i}}\right) \times 100
$$

Sendo:

$m_{i}$ : massa inicial dos filmes $(\mathrm{g}) ; \mathrm{m}_{\mathrm{f}}$ : massa final os filmes $(\mathrm{g})$

O teor de umidade foi determinado a partir da perda de massa dos corpos de prova depois de secá-los em estufa (Fabbe-Primar, 219/5, Brasil) a $105^{\circ} \mathrm{C}$ por $24 \mathrm{~h}$, segundo a técnica da ASTM D644-04 (ASTM, 2004). As medidas foram feitas em triplicata. A umidade dos filmes extrudados foi calculada segundo a Equação 3.

$$
\text { Umidade }(\%)=\left(1-\frac{m_{f}}{m_{i}}\right) \times 100
$$


Sendo:

$m_{i}$ : massa inicial dos filmes antes da secagem $(\mathrm{g}) ; \mathrm{m}_{\mathrm{f}}$ : massa final dos filmes após a secagem $(\mathrm{g})$.

\subsection{Molhabilidade (higroscopicidade)}

Determinou-se a molhabilidade dos filmes extrudados por medições de ângulo de contato utilizando o equipamento OCA -20 Dataphysiscs (OCA 20, Dataphysiscs, Alemanha) equipado com uma câmera USB (máx. 123 imagens $\mathrm{s}^{-1}$ ). As medidas do ângulo de contato foram feitas em equilíbrio após deposição de $14 \mu \mathrm{L}$ de água Milli-Q em forma de gota na superfície de cada película. As imagens de uma gota de água (tensão superficial $72,9 \mathrm{mN} / \mathrm{m}$ ) foram tomadas a cada $3 \mathrm{~s}$ em ar, à temperatura ambiente. O software de processamento de imagem SCA-20U foi utilizado para medir o ângulo de contato, que foi identificado tangente à borda de queda, na interseção dos meios líquido, sólido e gasoso (Figura 11).

Os valores dos ângulos de contato foram obtidos em triplicata - ângulos de contato foram medidos com deposição de gotas de água deionizada em diferentes regiões dos filmes (MANIGLIA, 2017).

Figura 10 - Ilustração do ângulo de contato formado pela gota depositada sobre a superfície do filme

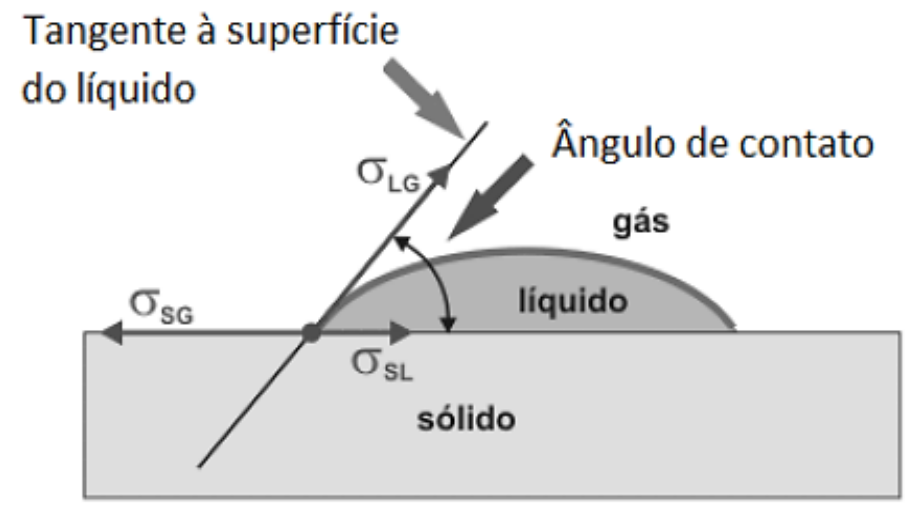

Fonte: LAl et al. (2016); MANIGLIA (2017). 


\subsubsection{Propriedades ópticas (Cor e Opacidade)}

A cor dos filmes extrudados foi expressa como diferença total de cor $\left(\Delta E^{\star}\right)$, determinada de acordo com a norma ASTM D7251 (2011) e Hunterlab (1997), utilizando o espectrofotômetro ColorQuest XE (HunterLab, USA), D65/10 ${ }^{\circ}$. Para a determinação da cor foram obtidas as coordenadas da escala CIElab conforme podem ser vistas na Figura $12\left(L^{*}, a^{*}, b^{*}\right)$ : parâmetros de claridade $L^{*}\left(L^{*}=0\right.$ preto e $L^{*}=100$ branco) e da cromaticidade definida por $a\left(+a^{*}=\right.$ vermelho e $-a^{*}=$ verde $)$ e $b^{*}\left(+b^{*}=\right.$ amarelo e $-b^{*}=$ azul), pelo modo de transmitância total. As medidas foram feitas em triplicata.

A cor foi expressa pela diferença de cor $\left(\Delta E^{*}\right)$, a qual foi calculada pela seguinte Equação 4:

$$
\Delta E^{*}=\sqrt{\left(\Delta L^{*}\right)^{2}+\left(\Delta a^{*}\right)^{2}+\left(\Delta b^{*}\right)^{2}}
$$

Sendo:

$\Delta L^{*}, \Delta a^{*}$, e $\Delta b^{*}$ : diferenças entre os parâmetros dos corpos de prova e do padrão um filme de PVC $\left(L^{*}=92,55, a^{*}=-1,18, b^{*}=0,41\right)$.

Figura 11 - Diagrama CIELab para os parâmetros de cor $L^{*}, a^{*} e b^{*}$

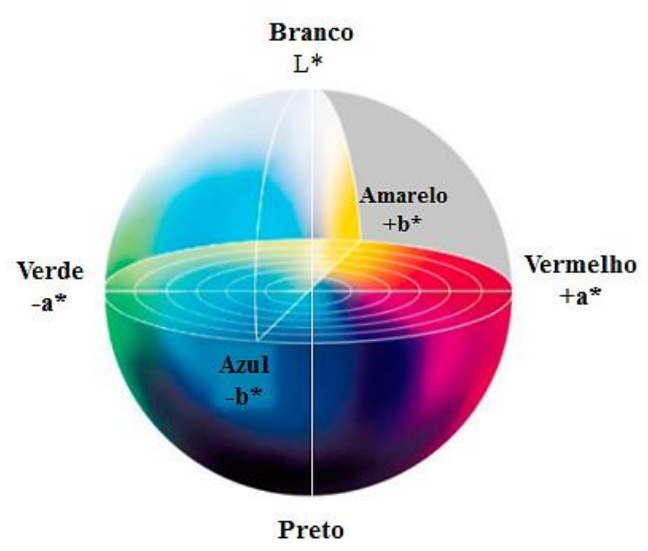

Fonte: AGUDO et al. (2014); MANIGLIA (2017).

A opacidade também foi determinada segundo a norma ASTM D7251 (2011) e o método Hunterlab (1997), utilizando o espectrofotômetro ColorQuest XE (HunterLab, USA), D65/10 ${ }^{\circ}$. O método consistiu na determinação da opacidade do filme sobreposto ao padrão preto $(Y p)$ e sobreposto ao branco $(Y b)$, que foi calculada pela razão entre 
esses dois valores segundo a Equação 5. A opacidade assim medida apresenta escala arbitrária entre (0 e 100) \%.

$$
\text { Opacidade }(\%)=\frac{Y p}{Y b} \times 100
$$

A seguir nos tópicos 4.2.4 a 4.2.5.3 serão descritos os métodos referentes a quarta e quinta etapas do processo.

\subsubsection{Caracterização dos filmes de amido com antocianina (ATH)}

Os métodos empregados para avaliar as propriedades mecânicas, de superfície e óticas dos filmes foram os mesmos empregados para caracterização dos filmes de amido termoplástico preparados na primeira parte do trabalho (item 4.2.3).

\subsubsection{Morfologia}

A morfologia foi determinada empregando um Microscópio Eletrônico de Varredura (MEV) (FEI, QUANTA FEG 650, Estados Unidos) sob voltagem de aceleração de $5 \mathrm{kV}$ para a análise dos corpos de prova que foram cortados em pedaços retangulares cobertos com platina por meio de pulverização catódica (BalTec MED 020, Coating System, Holanda).

\subsubsection{Cristalinidade}

A cristalinidade foi determinada utilizando o difratômetro de raios-X (DRX) (PANalytical, X'Pert PRO, Reino Unido) com detector X'Celerator. As condições de análise para a obtenção dos difratogramas foram: radiação de $\mathrm{Cu}$, energia: corrente de $5 \mathrm{~mA}$ e voltagem de $40 \mathrm{kV}$, sendo a velocidade de varredura de $0,02^{\circ}$ por segundo, com tempo/passo de $200 \mathrm{~s}$, com ângulo $2 \theta$ variando de (2 a 60) ${ }^{\circ}(2 \theta)$. $O$ índice de cristalinidade (\%) dos materiais foi quantitativamente estimado como a razão entre a área cristalina para a área total do difratograma, seguindo o método de Nara \& Komiya (1983) e usando o software Origin 8.1 (OriginLab Corporation, Massachusetts, EUA). 


\subsubsection{Avaliação da atividade indicadora de mudança de $\mathrm{pH}$ dos filmes de amido}

A propriedade mais relevante para a avaliação de embalagens inteligentes indicadoras de $\mathrm{pH}$ relaciona-se com sua capacidade de mudança de cor, sendo considerada ideal àquela cuja mudança seja facilmente visível à olho nu. Dessa forma, é desejado que a mudança de $\mathrm{pH}$ do meio seja acompanhada pela mudança de cor do material indicador.

Para avaliação da atividade indicadora de mudança de $\mathrm{pH}$ foram elaborados filmes de amido termoplástico obtidos a partir das formulações adicionadas com (5, 10 e 20) $\mathrm{mg}$ de antocianina/100 g de filme.

\subsubsection{Preparo da amostra}

Foram preparadas porções de $2 \mathrm{~g}$ de peixe do tipo cação (Carcarhinus spp) em estado fresco e cru, adquirido em um supermercado local (São Paulo - SP, Brasil). As porções foram adicionadas em tubos Falcon que foram tampados com o filme de amido, de modo que este ficasse a $7 \mathrm{~cm}$ de distância do peixe. $O$ mesmo procedimento foi realizado com carne bovina moída do tipo acém adquirida também em supermercado local (São Paulo - SP, Brasil). Foram avaliadas duas temperaturas de acondicionamento das amostras: em temperatura ambiente $(22 \pm 2){ }^{\circ} \mathrm{C}$ e sob refrigeração $(6 \pm 2){ }^{\circ} \mathrm{C}$. Tubos com o filme de amido sem ATH foram usados como controle e todos os testes foram realizados em triplicata.

\subsubsection{Determinação da alteração de cor dos filmes biodegradáveis inteligentes}

A análise de cor e opacidade foram determinadas, em triplicata, a cada $24 \mathrm{~h}$ durante três dias, a fim de avaliar a mudança de cor após o efeito da alteração de $\mathrm{pH}$ da carne bovina e de peixe. Os testes foram feitos no filme utilizado como tampa do tubo Falcon e foram analisados pelo Colorímetro ColorQuest XE previamente calibrado, usando a escala Cielab, como explicado no item 4.2.3.2.

\subsubsection{Determinação do pH das amostras de carne bovina e peixe}


$\mathrm{O} \mathrm{pH}$ das amostras de carne bovina e de peixe foi determinado pelo método eletrométrico segundo a metodologia do INSTITUTO ADOLFO LUTZ (1985). A cada $24 \mathrm{~h}$, foram dispostos $2 \mathrm{~g}$ de amostra das carnes em sacolas plásticas zip e diluídas em $20 \mathrm{~mL}$ de água destilada. O conteúdo foi agitado e triturado (Mastigador, CE 2000, IUL Instrumentos) até que as partículas do alimento ficassem uniformemente suspensas. Em seguida, foi medido diretamente o pH da solução com o pHmetro Tec3MP (TECNAL, Brasil).

\subsubsection{Análise estatística - tratamento de dados}

A análise de variância (ANOVA) e teste de Tukey de comparações múltiplas com um nível de significância de 5 \% foram realizados usando o software StatSoft Statistica 12.0 para comparação das propriedades dos filmes de amido extrudados. 


\section{RESULTADOS E DISCUSSÃO}

A seguir, nos tópicos 5.1 a 5.2.2 serão descritos os resultados e discussões referentes a primeira, segunda e terceira etapas desse trabalho.

\subsection{CARACTERIZAÇÃO DA CELULOSE MICROFIBRILADA (CMF)}

\subsubsection{Tamanho e dispersão de partículas}

Para a determinação do tamanho das partículas da celulose microfibrilada (CMF), construiu-se a curva granulométrica acumulativa (fração passante versus diâmetro) para medir a granulometria do material e obter o diâmetro característico D10, D50 e D90 (diâmetro em que 10, 50 e 90 \%, respectivamente, das partículas possuem diâmetros iguais ou inferiores a este).

A Figura 13 apresenta um exemplo da curva de (Fração passante versus diâmetro), com a representação do $D 90$.

Figura 12 - Curva de passagem granulométrica da celulose microfibrilada (CMF)

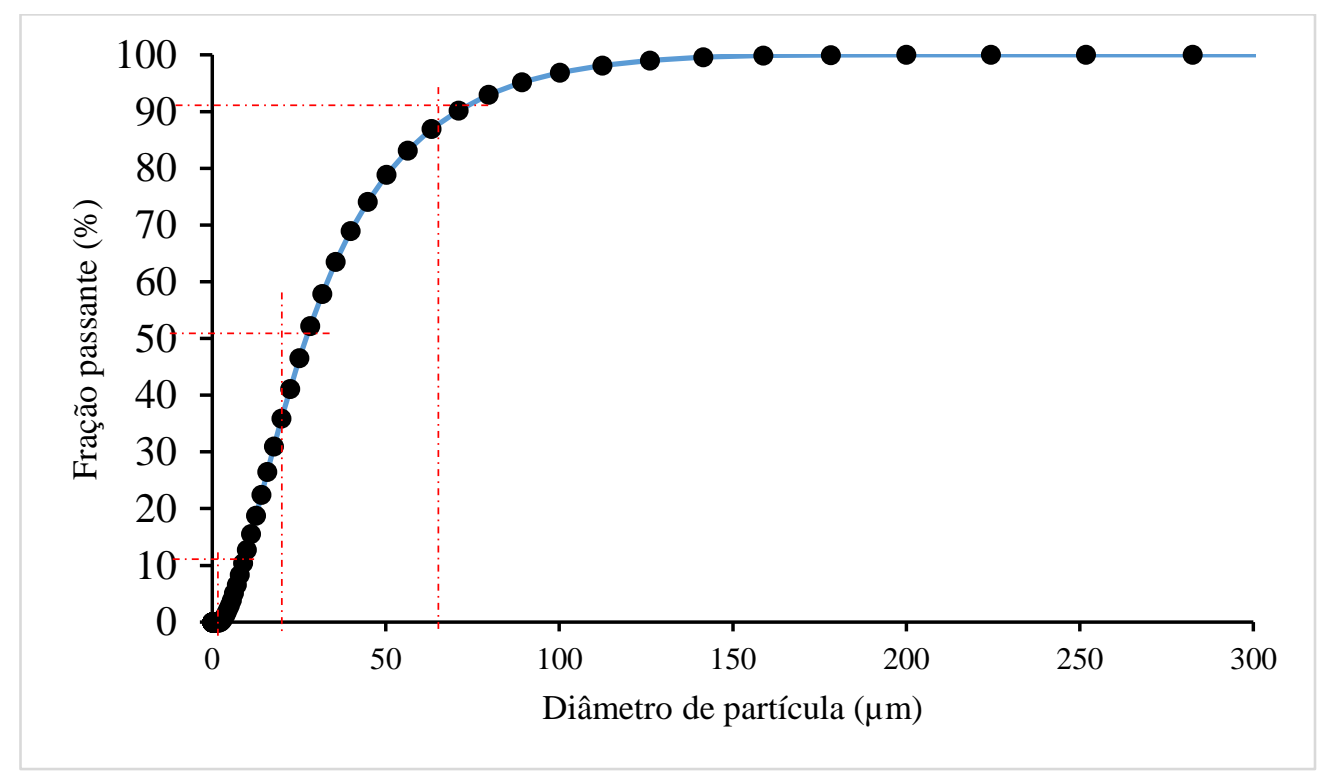

Fonte do autor (2018).

De acordo com a Figura 13, pode-se confirmar que o processo de análise granulométrica por espalhamento de luz a laser foi efetivo.

Com $D 10=8,76 \mu \mathrm{m}$, o que informa que $10 \%$ das partículas apresentam diâmetro inferior a este. Com $D 50=27,01 \mu \mathrm{m}$, portanto, $50 \%$ das partículas 
apresentam diâmetro inferior a este; geralmente considerado como tamanho médio das partículas da amostra. E $D 90=70,36 \mu \mathrm{m}$, o que informa que $90 \%$ das partículas apresentam diâmetro inferior a este

A Figura 14 apresenta a distribuição do tamanho de partícula da celulose microfibrilada (CMF).

Figura 13 - Distribuição do tamanho de partícula de celulose microfibrilada (CMF)

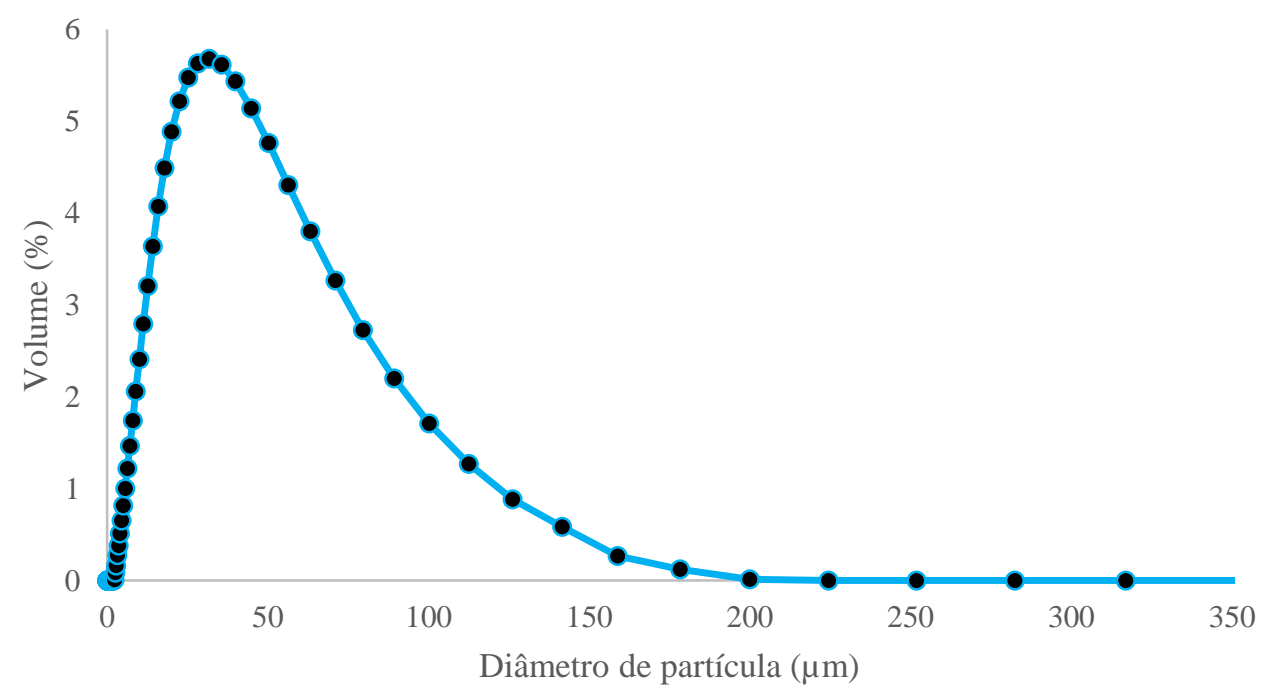

Fonte do autor, 2018.

Pela Figura 14 nota-se que a celulose microfibrilada (CMF) apresenta distribuição monomodal com uma ampla faixa de tamanho entre (1,5 e 200) $\mu \mathrm{m}$. O pico no qual se situa o maior volume de partículas (5,6 \%) corresponde ao diâmetro de $36 \mu \mathrm{m}$. Este valor é próximo ao diâmetro 23,6 $\mu \mathrm{m}$ encontrado por AndradeMahecha (2012) para a celulose microcristalina comercial (MCC) AvicelC PC 105 (FMC Biopolymer).

O diâmetro de partícula do material inicial (sem processamento) encontrado apresenta-se em escala "micro". Porém, a utilizada para produzir os filmes de amido termoplástico (TPS) foi processada mecanicamente. No entanto, é preciso salientar que nanofibras podem ser consideradas como um termo tecnológico usado para descrever estruturas secundárias, podendo conter dimensões de vários micrômetros e ao menos uma dimensão em escala nanométrica (SYVERUD et al., 2011).

Já os métodos enzimático e mecânico (por exemplo, alta pressão homogeneizador), podem fornecer feixes de fibras fortemente emaranhados com 
diâmetro em nanoescala (5 - 110) nm e comprimento de alguns micrômetros (de CAMPOS et al., 2013; KAUSHIK; SINGH; \& VERMA, 2010; MARTELLI-TOSI et al., 2016; MARTELLI-TOSI et al., 2018; PAAKKO et al., 2007).

Acredita-se que pela proximidade do resultado da literatura a CMF não passou por nenhum tratamento ou método para redução do tamanho de sua fibra.

\subsubsection{Morfologia}

A Figura 15 (a, b e c) apresenta as micrografias da celulose microfibrilada (CMF), com maior aumento (15.000 x). A Figura 15 (d e e) apresenta as micrografias $(30.000 \mathrm{x})$ e a Figura 15 (f) $(60.000 \mathrm{x})$.

$\mathrm{Na}$ Figura 15, nota-se a presença de redes emaranhadas, formadas pelo entralaçamento dessas fibras como pode-se observar na Figura 15 (d) (indicados por uma seta). Na Figura 15 (c) é possivel observar nitidamente uma enorme e grossa fibra de celulose com o entrelaçamento de outras mais finas. Estas estruturas observadas por MEV condizem com as micrografias observadas em trabalhos de outros autores.

Hassanpour et al. (2016) apresentaram micrografias de nanofibra de celulose (NFC) pura e modificada organicamente (Cloisite 30B). A NFC pura é constituída por uma típica rede entrelaçada de estrutura filamentar, com uma alta densidade de poros espalhados sobre a superfície da NFC. A fixação do composto químico na superfície da NFC não demonstrou qualquer efeito significativo na forma filamentar da NFC, mas resultou na formação de uma rede nanofibrilar densamente emaranhada com menor porosidade aparente na amostra modificada, em comparação com a NFC pura.

As NFCs, resultantes do tratamento enzimático, apresentaram comprimentos não uniformes e dispostos como nanofibras aglomeradas, enquanto a celulose nanocristalina (NCC), derivado da hidrólise ácida, formam comprimentos mais curtos variando de (100 a 600) $\mathrm{nm}$. Estes resultados confirmam que o comprimento da nanocelulose depende do método de extração, isto é, tratamento químico ou enzimático. Observa-se que as NFCs são mais longas e têm comprimentos em dimensões em microescala (de CAMPOS et al., 2013, MARTELLI-TOSI et al.; 2018). 
Pode-se notar nas micrografias a presença de estruturas amorfas, sem dimensões definidas, podendo associar a presença de açúcares gerados durante o processo de hidrólise (MARTELLI-TOSI et al.; 2018).

Figura 14 - Microscopia eletrônica (MEV) da celulose microfibrilada (CMF), com aproximação de $15.000 \mathrm{x}$ (a), (b) e (c), $30.000 \times$ (d) e (e) e de 60.000x (f)
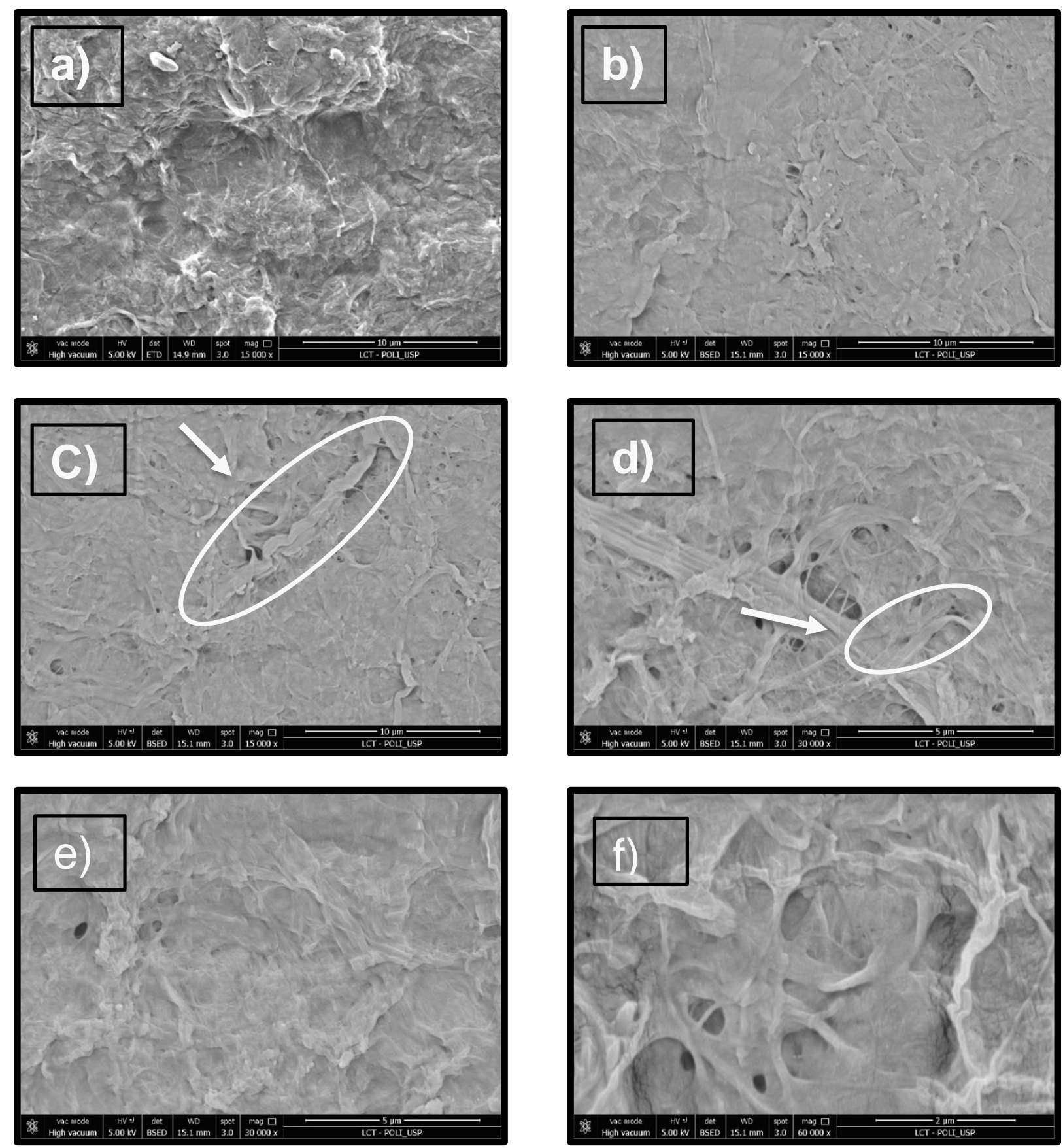

Fonte do autor (2018). 


\subsubsection{Cristalinidade}

A Figura 16 apresenta o difratograma de raios- $X$ da celulose microfibrilada (CMF). Os picos do difratograma possuem intensidade semelhante ao de amido, por ser também um polissacarídeo, contendo unidades de repetição de glicose, com característica de material semi-cristalino (presença de zonas amorfas e cristalinas) (GHANBARI et al., 2018; KAMPANGKAEW et al., 2014; MA et al., 2008).

Figura 15 - Difratograma de raios-X da CMF, com o respectivo índice de cristalinidade (I.C. \%)

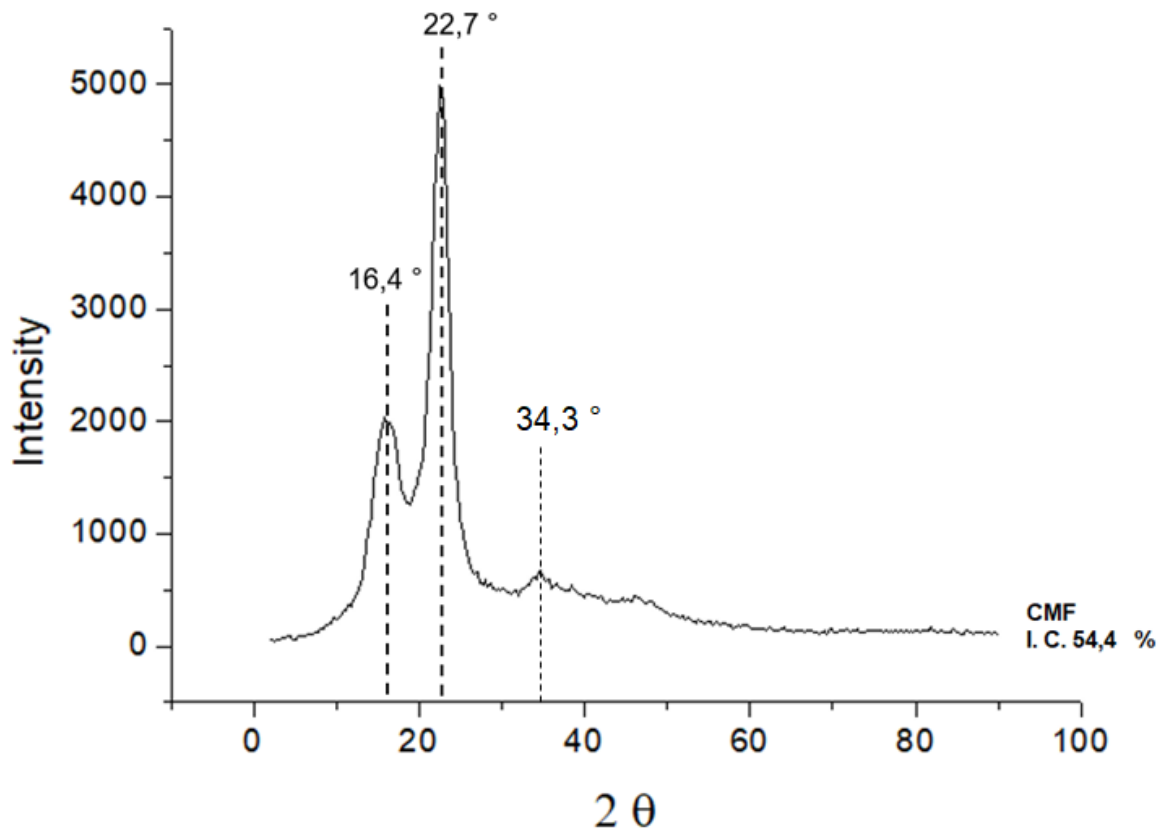

Fonte: Do autor (2018).

Na Figura 16, observa-se a presença de dois principais picos: $16,4^{\circ}$ e $22,7^{\circ}$

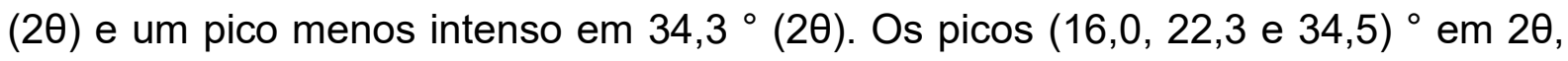
são típicos de celulose tipo I (KAFLE et al., 2014; MARTELLI-TOSI et al.; 2018).

QUERO et al. (2018) caracterizaram a cristalinidade da celulose microfibrilada (CMF) e notaram picos sobrepostos posicionados nos ângulos de difração $2 \theta$ de $(14,8 \text { e } 16,3)^{\circ}$ e outro pico de difração posicionado num ângulo de difração $2 \theta$ de $22,3^{\circ}$. Estes três picos de Bragg já haviam sido relatados anteriormente para CMF obtida de celulose extraída de eucalipto (que contém predominantemente a forma cristalina de celulose la). Os picos correspondem, respectivamente, aos planos de 
difração (101), (101), (002) (BESBES; ALILA; \& BOUFI 2011; QING et al., 2013; TONOLI et al., 2012).

Hassanpour et al. (2016) analisaram os difratogramas (DRX) de NFC pura e NFC modificada quimicamente, e observaram que o difratograma da NFC pura exibiu o padrão típico de celulose tipo I, com os picos de difração em valores de $2 \theta$ de $(14,6$, $16,6,22,4$ e 34,5$)^{\circ}$ que supostamente representam os planos de difração (1-10), (110), (200) e (004), que são considerados da celulose Iß (FRENCH, 2014; LU et al., 2016). Pode-se, portanto, afirmar que a amostra de CMF também apresenta os picos referentes aos planos de difração (1-10), (110), (200) e (004), indicando a presença da celulose I $\beta$.

De acordo com o método de Sega, Creely, Martin e Conrad (1959), foi calculado o índice de cristalinidade (I.C.) da amostra de CMF, a partir dos difratogramas de DRX (Figura 16). Foi obtido o valor índice de cristalinidade de $(54,4 \pm 3,5) \%$.

Martelli et al. (2018) apresentaram valores próximos ao obtido neste trabalho para as nanofibras de celulose produzidas a partir de hidrólise química com I.C. = 50 \% e a partir de hidrolise enzimática com I.C. = 57 \%. Os autores atribuíram que a presença remanescente de açúcares redutores (glicose, maltose e lactose) em amostras de NFC liofilizadas, provavelmente, contribuíram para a presença de mais fases amorfas na estrutura das fibras, reduzindo o I.C.

A partir desse padrão, Quero et al. (2018) estimaram o I.C., e foram encontrados valores de $(43 \pm 3) \%$ e $(69 \pm 2) \%$, respectivamente, pelos métodos de integração e altura do pico. Estes valores estão dentro do intervalo de (40 a 80) \% tipicamente relatado na literatura para o I.C. da CMF obtido a partir de métodos de fibrilação mecânica e determinado por DRX em pó usando o método de intensidade (ABDUL KHALIL et al., 2014; LAVORATTI; SCIENZA; \& ZATTERA, 2016; PARK ET al., 2010; QING et al., 2013).

\subsection{CARACTERIZAÇÃO DOS FILMES DE AMIDO}

\subsubsection{Aspecto visual}

De acordo com as formulações testadas (Figura 8), pode-se observar o aspecto visual dos filmes biodegradáveis de amido termoplástico (TPS) na Figura 17. 
Figura 16 - Fotos dos filmes extrudados de amido termoplástico (TPS)

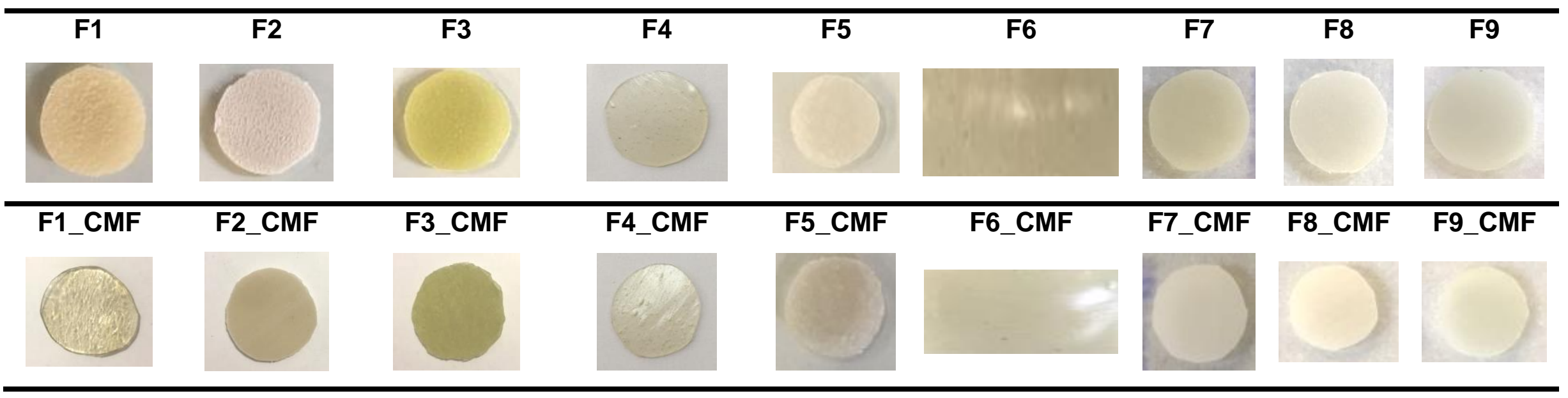

Legenda:

Wt: água; Gly: glicerol; CMF: celulose microfibrilada; SA: ácido esteárico; CA: ácido cítrico

F1 => amido : wt (70:30 g/100 g); F1 CMF => amido : wt (70:30 g/100 g com adição de CMF $2 \mathrm{~g} / 100 \mathrm{~g}$ amido);

F2 => amido : $w t:$ SA (70:28:2 g/100 g); F2_CMF => amido : $w t: S A(70: 28: 2 \mathrm{~g} / 100 \mathrm{~g}$ com adição de CMF $2 \mathrm{~g} / 100 \mathrm{~g}$ amido);

F3 => amido : $w t:$ : CA (70:28:2 g/100 g); F3_CMF => amido : $w t:$ CA (70:28:2 g/100 g com adição de CMF $2 \mathrm{~g} / 100 \mathrm{~g}$ amido);

F4 => amido : wt : gly (60:15:25 g/100 g); F4_CMF => amido $:$ wt $:$ gly $(60: 15: 25 \mathrm{~g} / 100 \mathrm{~g}$ com adição de CMF $2 \mathrm{~g} / 100 \mathrm{~g}$ amido);

F5 => amido : wt : gly : SA (58:15:25:2 g/100 g); F5_CMF => amido : wt : gly : SA (58:15:25:2 g/100 g com adição de CMF 2 g/100 g amido);

F6 => amido : wt: gly : CA (58:15:25:2 g/100 g); F6_CMF => amido : wt : gly : CA (58:15:25:2 g/100 g com adição de CMF 2 g/100 g amido);

F7 => amido : gly (70:30 g/100 g); F7_CMF => amido : gly (70:30 g/100 g com adição de CMF 2 g/100 g amido);

F8 => amido : gly : SA (70:28:2 g/100 g); F8 CMF => amido : gly : SA (70:28:2 g/100 g com adição de CMF $2 \mathrm{~g} / 100 \mathrm{~g}$ amido);

F9 => amido : glyl : CA (70:28:2 g/100 g); F9_CMF => amido : gly : CA (70:28:2 g/100 g de celulose com adição de CMF $2 \mathrm{~g} / 100 \mathrm{~g}$ amido).

Fonte: Do autor (2018). 
Quanto aos aspectos visuais dos TPS, pôde-se observar que, em sua maioria, os mesmos se apresentaram translúcidos, flexíveis e de superfície contínua. Porém, dependendo do agente plastificante e do modificador químico, observou-se superfície rugosa, ou filmes adesivos.

Como exemplo, os filmes F1, F2, F3 se apresentaram quebradiços, com superfície rugosa, os filmes F4 e F5 translúcidos com superfície mais lisa, e os filmes F7, F8 e F9 apresentaram superfície contínua, o mesmo pode ser observado nos TPS incorporados com CMF. Os filmes F6 e F6_CMF apresentaram superfícies adesivas, pegajosas e extremamente elásticas, impossibilitando a sua caracterização.

Pode-se observar que a incorporação de CMF em todas as pré-misturas permitiu a obtenção de filmes com uma intensidade maior de cor. $E$ os filmes incorporados com ácido esteárico (F2, F5 e F8), visualmente, apresentam cores rosadas e pastéis, e os com ácido cítrico (F3, F6 e F9) filmes esverdeados e/ou tons de cinza. Somente os filmes que não continham os modificadores químicos (F1, F4 e F7) apresentaram a coloração branca, característica do amido. Porém, trata-se de uma análise qualitativa, pois uma análise quantitativa de cor será apresentada no item 5.2.4.

Foram descartados todos os filmes que continham bolhas, por serem inviáveis para a utilização nos testes de caracterização.

Em relação à caracterização das propriedades mecânicas, de superfície e ópticas, os resultados permitiram a obtenção de informações sobre os novos materiais elaborados neste trabalho. Dessa forma, foi possível entender o comportamento dos mesmos quando sob ação de esforços externos e de condições de armazenamento controlada.

Vale a pena lembrar que o principal requisito na escolha de uma formulação de embalagem é saber qual será seu uso final. Apesar do objetivo principal ser a obtenção de um material como indicador de mudança de $\mathrm{pH}$, o conhecimento de suas propriedades permite seu uso mais adequado.

\subsubsection{Propriedades mecânicas e de superfície}

A Tabela 5, apresenta as propriedades mecânicas e de superfície dos filmes de amido termoplástico (TPS) incorporados com o agente plastificante e modificador químico. A Tabela 6 apresenta as mesmas propriedades, porém com incorporação 
adicional de celulose microfibrilada (CMF). Ambas as tabelas apresentam resultados com média e desvio padrão das respectivas propriedades medidas. 
Tabela 5 - Propriedades mecânicas e de superfície dos filmes extrudados de amido termoplástico (TPS)

\begin{tabular}{|c|c|c|c|c|c|c|c|c|c|}
\hline \multirow[t]{2}{*}{ Filmes } & \multirow{2}{*}{$\begin{array}{c}\text { Amido } \\
\text { Qtde. }\end{array}$} & \multicolumn{2}{|c|}{ Plastificante } & \multicolumn{2}{|c|}{$\begin{array}{l}\text { Modificador } \\
\text { químico }\end{array}$} & \multirow[t]{2}{*}{$\begin{array}{c}\text { Espessura } \\
(\mathrm{mm})\end{array}$} & \multirow[t]{2}{*}{$\begin{array}{c}\text { Tensão } \\
\text { (MPa) }\end{array}$} & \multirow[t]{2}{*}{$\begin{array}{c}\text { Elongação } \\
(\%)\end{array}$} & \multirow[t]{2}{*}{$\begin{array}{c}\text { Módulo de } \\
\text { Young } \\
\text { (MPa) }\end{array}$} \\
\hline & & Tipo & Qtde. & Tipo & Qtde. & & & & \\
\hline$F 1$ & $70 \mathrm{~g}$ & Wt & $30 \mathrm{~g}$ & - & - & $1,0 \pm 0,0^{\mathrm{aA}}$ & $1,4 \pm 0,1^{\mathrm{aA}}$ & $29,1 \pm 2,5^{\mathrm{bA}}$ & $8,5 \pm 1,2^{\mathrm{aA}}$ \\
\hline$F 2$ & $70 \mathrm{~g}$ & Wt & $28 \mathrm{~g}$ & SA & $2 \mathrm{~g} / 100 \mathrm{~g}$ & $0,9 \pm 0,0^{\mathrm{abA}}$ & $0,5 \pm 0,1^{\mathrm{bB}}$ & $11,6 \pm 2,7^{c C}$ & $8,3 \pm 1,2^{\mathrm{aA}}$ \\
\hline F3 & $70 \mathrm{~g}$ & Wt & $28 \mathrm{~g}$ & $\mathrm{CA}$ & $2 \mathrm{~g} / 100 \mathrm{~g}$ & $1,0 \pm 0,0^{\mathrm{aA}}$ & $1,2 \pm 0,1^{\mathrm{aA}}$ & $21,5 \pm 2,0^{\mathrm{bB}}$ & $8,9 \pm 1,4^{\mathrm{aA}}$ \\
\hline$F 4$ & $60 \mathrm{~g}$ & Wt : Gly & $15 \mathrm{~g}: 25 \mathrm{~g}$ & - & - & $1,2 \pm 0,3^{\mathrm{aA}}$ & $0,9 \pm 0,1^{\mathrm{bB}}$ & $60,7 \pm 9,8^{\mathrm{aA}}$ & $3,4 \pm 0,3^{\mathrm{bB}}$ \\
\hline$F 5$ & $58 \mathrm{~g}$ & Wt : Gly & $15 \mathrm{~g}: 25 \mathrm{~g}$ & SA & $2 \mathrm{~g} / 100 \mathrm{~g}$ & $0,6 \pm 0,3^{\mathrm{bA}}$ & $1,8 \pm 0,3^{\mathrm{aA}}$ & $50,0 \pm 4,2^{\mathrm{bA}}$ & $10,5 \pm 2,6^{\mathrm{aA}}$ \\
\hline F7 & $70 \mathrm{~g}$ & Gly & $30 \mathrm{~g}$ & - & - & $0,8 \pm 0,3^{\mathrm{aA}}$ & $0,8 \pm 0,1^{\mathrm{bA}}$ & $35,8 \pm 2,8^{\mathrm{bB}}$ & $5,2 \pm 1,5^{\mathrm{bA}}$ \\
\hline F8 & $70 \mathrm{~g}$ & Gly & $28 \mathrm{~g}$ & SA & $2 \mathrm{~g} / 100 \mathrm{~g}$ & $1,0 \pm 0,0^{\mathrm{aA}}$ & $0,6 \pm 0,1^{\mathrm{bA}}$ & $78,0 \pm 5,4^{\mathrm{aA}}$ & $3,0 \pm 0,2^{\mathrm{bB}}$ \\
\hline$F 9$ & $70 \mathrm{~g}$ & Gly & $28 \mathrm{~g}$ & $\mathrm{CA}$ & $2 \mathrm{~g} / 100 \mathrm{~g}$ & $1,1 \pm 0,1^{\mathrm{aA}}$ & $0,1 \pm 0,0^{\mathrm{bB}}$ & $107,0 \pm 28,6^{\mathrm{aA}}$ & $0,7 \pm 0,2^{b c}$ \\
\hline
\end{tabular}

Letras minúsculas diferentes entre si, na mesma coluna, indicam diferença significativa entre os diferentes agentes plastificantes empregados para um mesmo tipo de modificador químico, de acordo com o teste de Tukey $(p<0,05)$.

Letras maiúsculas diferentes entre si, na mesma coluna, indicam diferença significativa entre os diferentes modificadores químicos (sem modificador, ácido cítrico e esteárico) empregados para um mesmo agente plastificante, de acordo com o teste de Tukey $(p<0,05)$.

Fonte: Do autor (2018). 
Tabela 6 - Propriedades mecânicas e de superfície dos filmes extrudados de amido termoplástico (TPS), incorporados com $2 \mathrm{~g} / 100 \mathrm{~g}$ de celulose microfibrilada (CMF)

\begin{tabular}{|c|c|c|c|c|c|c|c|c|c|}
\hline \multirow[t]{2}{*}{ Filmes } & \multirow{2}{*}{$\begin{array}{c}\text { Amido } \\
\text { Qtde. }\end{array}$} & \multicolumn{2}{|c|}{ Plastificante } & \multicolumn{2}{|c|}{$\begin{array}{c}\text { Modificador } \\
\text { químico }\end{array}$} & \multirow[t]{2}{*}{$\begin{array}{c}\text { Espessura } \\
(\mathrm{mm})\end{array}$} & \multirow[t]{2}{*}{$\begin{array}{c}\text { Tensão } \\
\text { (MPa) }\end{array}$} & \multirow[t]{2}{*}{$\begin{array}{c}\text { Elongação } \\
(\%)\end{array}$} & \multirow[t]{2}{*}{$\begin{array}{l}\text { Módulo de } \\
\text { Young } \\
\text { (MPa) }\end{array}$} \\
\hline & & Tipo & Qtde. & Tipo & Qtde. & & & & \\
\hline F1_CMF & $70 \mathrm{~g}$ & $\mathrm{Wt}$ & $30 \mathrm{~g}$ & - & - & $1,1 \pm 0,2^{\mathrm{bA}}$ & $1,2 \pm 0,4^{\mathrm{aA}}$ & $46,8 \pm 6,8^{\mathrm{abA}}$ & $10,9 \pm 0,8^{\mathrm{aA}}$ \\
\hline$F 2 \_C M F$ & $70 \mathrm{~g}$ & Wt & $28 \mathrm{~g}$ & SA & $2 g / 100 g$ & $1,0 \pm 0,1^{\mathrm{aA}}$ & $0,6 \pm 0,0^{a b B}$ & $36,9 \pm 1,6^{\mathrm{bB}}$ & $12,2 \pm 0,2^{\mathrm{aA}}$ \\
\hline F3_CMF & $70 \mathrm{~g}$ & Wt & $28 \mathrm{~g}$ & $\mathrm{CA}$ & $2 \mathrm{~g} / 100 \mathrm{~g}$ & $1,2 \pm 0,1^{\mathrm{aA}}$ & $1,0 \pm 0,3^{\mathrm{aA}}$ & $26,0 \pm 3,1^{b c}$ & $12,5 \pm 3,0^{\mathrm{aA}}$ \\
\hline$F 4 \_C M F$ & $60 \mathrm{~g}$ & Wt : Gly & $15 \mathrm{~g}: 25 \mathrm{~g}$ & - & - & $1,7 \pm 0,3^{\mathrm{bA}}$ & $0,6 \pm 0,1^{\mathrm{bA}}$ & $59,9 \pm 11,4^{\mathrm{aA}}$ & $2,6 \pm 0,3^{\mathrm{cA}}$ \\
\hline F5_CMF & $58 \mathrm{~g}$ & Wt : Gly & $15 \mathrm{~g}: 25 \mathrm{~g}$ & SA & $2 \mathrm{~g} / 100 \mathrm{~g}$ & $1,2 \pm 0,2^{\mathrm{aA}}$ & $0,5 \pm 0,1^{\mathrm{bA}}$ & $57,2 \pm 3,9^{\mathrm{aA}}$ & $2,6 \pm 0,4^{\mathrm{cA}}$ \\
\hline F7_CMF & $70 \mathrm{~g}$ & Gly & $30 \mathrm{~g}$ & - & - & $1,0 \pm 0,3^{\mathrm{a} A}$ & $1,0 \pm 0,1^{\mathrm{aA}}$ & $38,5 \pm 2,9^{\mathrm{bB}}$ & $6,1 \pm 1,4^{\mathrm{bA}}$ \\
\hline F8_CMF & $70 \mathrm{~g}$ & Gly & $28 \mathrm{~g}$ & SA & $2 \mathrm{~g} / 100 \mathrm{~g}$ & $1,0 \pm 0,0^{\mathrm{aA}}$ & $0,7 \pm 0,0^{\mathrm{aB}}$ & $58,6 \pm 6,0^{\mathrm{aA}}$ & $4,1 \pm 0,4^{\mathrm{bA}}$ \\
\hline$F 9 \_C M F$ & $70 \mathrm{~g}$ & Gly & $28 \mathrm{~g}$ & $\mathrm{CA}$ & $2 \mathrm{~g} / 100 \mathrm{~g}$ & $1,0 \pm 0,0^{\mathrm{aA}}$ & $0,2 \pm 0,1^{b c}$ & $58,0 \pm 8,5^{\mathrm{aA}}$ & $1,6 \pm 0,5^{\mathrm{cB}}$ \\
\hline
\end{tabular}

Letras minúsculas diferentes entre si, na mesma coluna, indicam diferença significativa entre os diferentes agentes plastificantes empregados para um mesmo tipo de modificador químico, de acordo com o teste de Tukey $(p<0,05)$.

Letras maiúsculas diferentes entre si, na mesma coluna, indicam diferença significativa entre os diferentes modificadores químicos (sem modificador, ácido cítrico e esteárico) empregados para um mesmo agente plastificante, de acordo com o teste de Tukey $(p<0,05)$

Fonte: Do autor (2018). 
Nota-se pela Tabela 5 que não houve diferença significativa entre as espessuras do TPS ao variar o tipo de agente plastificante (água (wt), água e glicerol (wt : gly) ou glicerol (gly)), exceto quando na presença de ácido esteárico. Filmes na presença de SA, plastificados com água ou glicerol apresentaram menor espessura que quando plastificados com somente água ou com glicerol. Em relação aos tipos de modificadores químicos, sem variar o tipo de plastificante, não houve mudanças significativas $(p<0,05)$ para este parâmetro.

Nota-se também pela Tabela 6 que os tipos de modificadores químicos, sem variar o tipo de plastificante, não causou mudanças significativas $(p<0,05)$ para a espessura de filmes com a presença de CMF.

As variações na espessura de um material qualquer implicam em problemas no seu desempenho mecânico e perda de barreira que comprometem o desempenho do material biodegradável. Portanto, o controle da espessura dos filmes é muito importante para se avaliar a uniformidade desses materiais, a repetibilidade da medida de suas propriedades e a comparação dos resultados entre filmes biodegradáveis (ARENAS, 2012).

Com relação a resistência, os filmes TPS apresentaram comportamentos distintos para cada plastificante. Para filmes plastificados com wt, os mais resistentes foram aqueles produzidos sem modificador ou com ácido cítrico. Para filmes plastificados com wt:gly, os mais resistentes foram os elaborados com SA. No entanto, para os filmes plastificados com gly, filmes elaborados com CA foram os menos resistentes.

No caso da elongação, filmes plastificados com wt ou com wt : gly apresentaram maior flexibilidade quando sem a presença de modificador químico. No entanto, filmes plastificados com gly e na presença de modificadores químicos, foram os mais flexíveis. Os filmes plastificados com wt foram menos flexiíveis quando comparados aqueles elaborados com os outros plastificantes.

Não houve diferenças significativas da rigidez (módulo de Young) entre os filmes TPS plastificados com wt com ou sem a presença de modificares químicos para os filmes plastificados com wt. No entanto, na presença de wt : gly, com SA foram obtidos filmes mais rígidos. 
Não houve diferença significativa entre as espessuras do TPS_CMF ao variar o tipo de agente plastificante wt, wt : gly, gly, exceto aquele elaborado com wt:gly sem modificador químico que apresentou a maior espessura.

Os filmes TPS_CMF plastificados com wt apresentaram maior resistência a ruptura elaborados sem modificador ou com CA. Para os filmes plastificados com wt:gly, a presença do modificador não alterou esta propriedade, enquanto que filmes com o plastificante gly apresentaram maior resistência a ruptura quando na ausência de modificador químico. Filmes sem modificador químico apresentaram maior valor de tensão quando plastificados ou só com wt ou só com o gly. Filmes com SA apresentaram maior valor de tensão quando plastificados com o gly e quando na presença de CA, na presença de wt.

Segundo Wang, Yu e Han (2007), a presença de ácido cítrico na matriz polimérica destrói a estrutura do amido e facilita a permeação do plastificante glicerol (ARENAS, 2012). Tal citação justifica os resultados, pois os filmes F9 e F9_CMF com glicerol e ácido cítrico apresentaram os menores valores de tensão.

Em relação a flexibilidade dos filmes TPS_CMF, os plastificados com wt foram mais flexíveis na ausência de modificador químico, no entanto filmes plastificados com wt:gly, e filmes plastificados somente com gly e com os modificadores químicos apresentaram os maiores valores de elongação.

Ning et al. (2009) elaboraram por extrusão amido termoplástico (TPS)/nanocompósitos de montmorilonita modificada com glicerol (GMMT). Estes autores relataram que na presença de ácido cítrico a despolimerização do polissacarídeo era propícia para a melhor plastificação do TPS.

O ácido cítrico é composto de grupos carboxila e hidroxila que aumentam as diferentes interações entre os componentes da mistura (YOON; CHOUGH; PARK, 2006; YUN; NA; YOON, 2006). Quando adicionado às misturas TPS, o ácido cítrico aumentou a plasticização do amido e aumentou as propriedades mecânicas da mistura (WANG et al., 2007b). Na presença de ácido cítrico, grânulos de amido residual não foram detectados. Isto foi atribuído ao fato do ácido, que acelera a fragmentação e a dissolução do grânulo de amido, podendo destruir a estrutura (ARENAS, 2012).

Para um mesmo tipo de plastificante, a presença de CMF não influenciou a rigidez dos filmes, com ou sem modificador químico. No caso do glicerol, os filmes 
sem modificador ou na presença de SA apresentaram maior rigidez. Os filmes TPF_CMF plastificados com apenas água (wt) apresentaram maior rigidez entre todos os filmes elaborados com os demais plastificantes. Nas Figuras 18 e 19, é possível visualizar as diferenças entre os filmes com relação as propriedades mecânicas. 
Figura 17 - Espessura (mm) e Tensão (MPa) dos filmes extrudados de amido termoplástico (TPS) sem e com celulose microfibrilada (CMF)
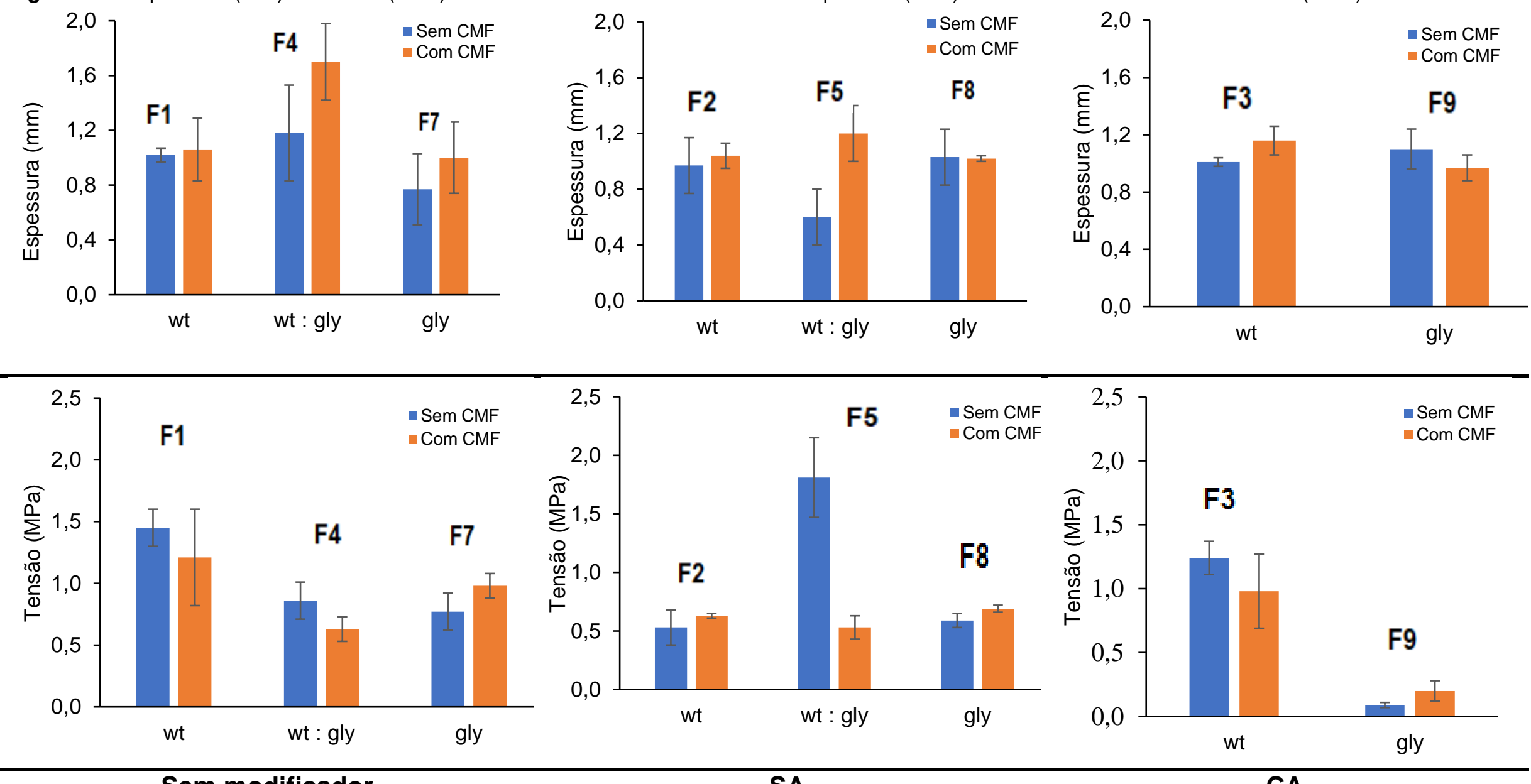

Fonte: Do autor (2018).

SA

CA 
Figura 18 - Elongação (\%) e Módulo de Young (\%) dos filmes extrudados de amido termoplástico (TPS) sem e com celulose microfibrilada (CMF)
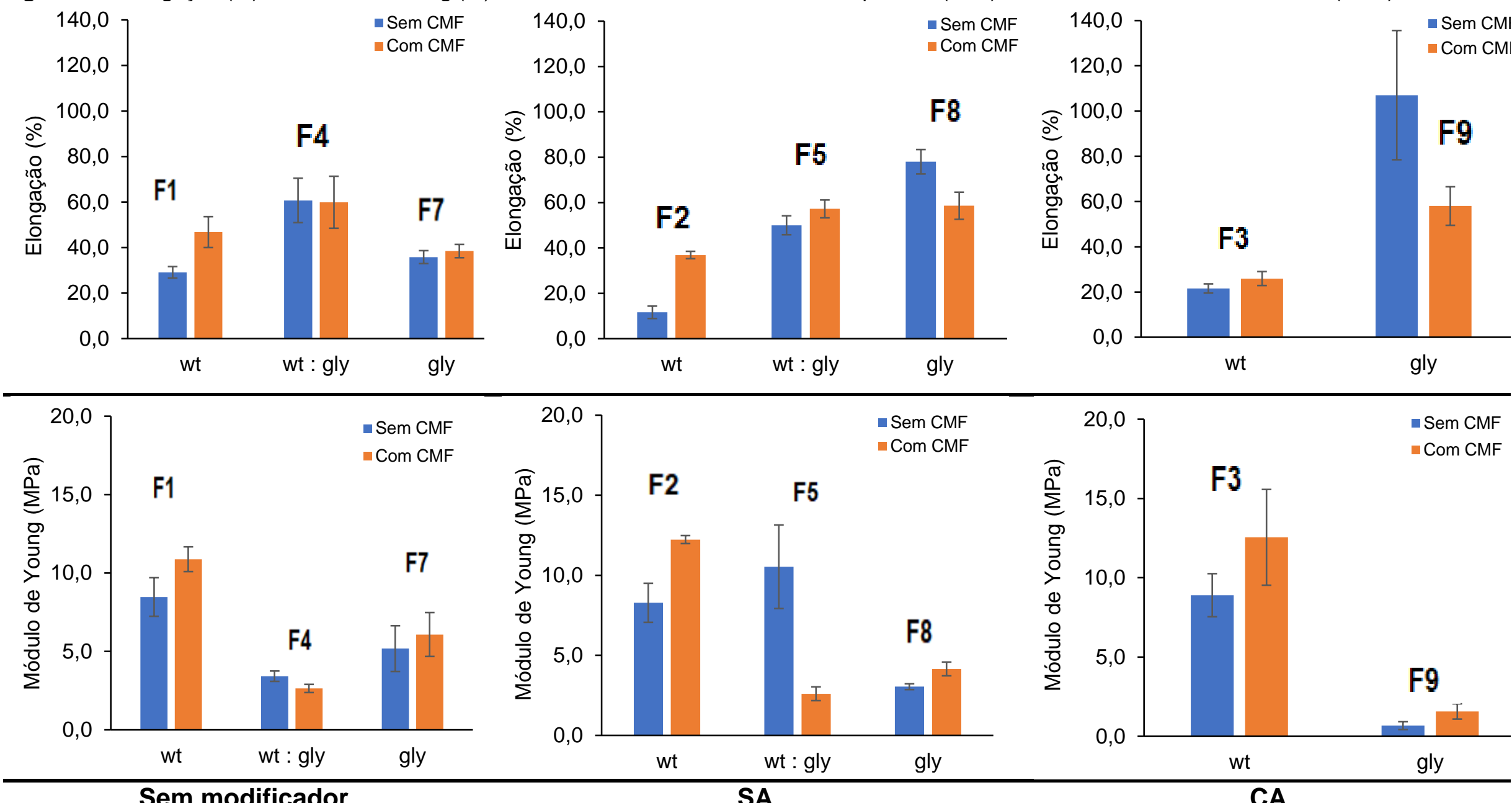

Fonte: Do autor (2018). 
Pela Figura 18 observa-se que a presença do CMF influenciou significativamente apenas a espessura dos filmes plastificados com wt : gly e com SA (aumento de $100 \%$ ).

Resultados semelhantes foram discutidos por Llanos (2018), que notou mudanças significativas $(p<0,05)$ na espessura dos filmes de amido nanoestruturados, com aumentos de $32 \%$ e $52 \%$ na presença de montmorilonita (MMT) e nanofibras de bambu NFBs, respectivamente.

Müller, Laurindo e Yamashita (2011) e Rhim, Hong e Ha (2009) concluíram que a presença de nanopartículas nas matrizes poliméricas aumenta de forma significativa $(p<0,05)$ a espessura dos filmes devido ao espaço ocupado pelos reforçadores (LLANOS, 2018).

A adição de CMF influenciou de forma significativa a tensão apenas dos filmes plastificados com wt e gly e na presença de SA (diminuição de $71 \%$ na resistência do filme). Kampangkaew, Thongpin e Santawtee (2014) também observaram diminuição da tensão dos filmes de TPS com a adição de NFC, e relatam que foi devido a uma agregação de NFC, ou seja, varia de acordo com o maior conteúdo de NFC. Resultado semelhante foi relatado por outros pesquisadores (HIETALA, MATHEW, OKSMAN, 2013; SAVADEKAR, MHASKE, 2012).

A presença de CMF afetou de forma significativa a elongação dos filmes plastificados com wt e sem modificador químico (aumento de $161 \%$ na flexibilidade dos filmes). Para os filmes com ácido esteárico, quando plastificados com wt a presença de CMF aumentou a flexibilidade dos filmes em $317 \%$. No entanto, para este mesmo modificador, mas plastificado com gly, a presença da CMF reduziu a flexibilidade dos filmes (25\%), e para esse mesmo plastificante, mas com o modificador, a CMF reduziu a flexibilidade em $46 \%$.

Em relação ao módulo de Young dos filmes, a CMF promoveu a rigidez dos filmes na presença da água como agente plastificante, sem modificador químico (28 \%) ou com ácido esteárico (48\%), e na presença de glicerol com ácido esteárico (37\%). Porém, os filmes se tornaram menos rígidos com CMF quando plastificados com wt:gly sem (23\%) ou com ácido esteárico (75\%). Para os filmes com ácido cítrico, independentemente do tipo de plastificante, a presença da CMF não alterou significativamente esta propriedade. 
Abdullah \& Dong (2018) determinaram o módulo de Young de TPS puro e com a adição de $10 \mathrm{~g} / 100$ ge NFCs. Os autores observaram um aumento de 749,3\% nesta propriedade e atribuíram este comportamento a presença de estruturas cristalinas e densas dos CNFs, em oposição à do TPS.

Em geral, as fibras de celulose têm a capacidade de formar redes tridimensionais dentro de matrizes poliméricas, a fim de melhorar as propriedades do nanocompósito (ALOUI et al., 2016).

A Tabela 7 apresenta os valores de umidade, solubilidade e molhabilidade (ângulo de contato) dos filmes TPS incorporados com o agente plastificante e modificador químico. A Tabela 8 apresenta as mesmas propriedades, respectivamente, porém de TPS incorporados com celulose microfibrilada (CMF). Ambas as tabelas apresentam resultados com média e desvio padrão das respectivas propriedades. 
Tabela 7 - Umidade $(\mathrm{g} / 100 \mathrm{~g})$, solubulidade $(\%)$ e ângulo de contao $\left(^{\circ}\right)$ dos filmes extrudados de amido termolástico (TPS)

\begin{tabular}{|c|c|c|c|c|c|c|c|c|}
\hline \multirow[t]{2}{*}{ Filmes } & \multirow{2}{*}{$\begin{array}{c}\text { Amido } \\
\text { Qtde. }\end{array}$} & \multicolumn{2}{|c|}{ Plastificante } & \multicolumn{2}{|c|}{$\begin{array}{l}\text { Modificador } \\
\text { químico }\end{array}$} & \multirow[t]{2}{*}{$\begin{array}{l}\text { Umidade } \\
(\mathrm{g} / 100 \mathrm{~g})\end{array}$} & \multirow[t]{2}{*}{$\begin{array}{c}\text { Solubilidade } \\
(\%)\end{array}$} & \multirow[t]{2}{*}{$\begin{array}{l}\text { Ângulo de } \\
\text { contato }\left(^{\circ}\right)\end{array}$} \\
\hline & & Tipo & Qtde. & Tipo & Qtde. & & & \\
\hline$F 1$ & $70 \mathrm{~g}$ & $\mathrm{Wt}$ & $30 \mathrm{~g}$ & - & - & $26,3 \pm 0,2^{a B}$ & $57,8 \pm 2,9^{\mathrm{aB}}$ & $45 \pm 1^{a B}$ \\
\hline$F 2$ & $70 \mathrm{~g}$ & Wt & $28 \mathrm{~g}$ & SA & $2 \mathrm{~g} / 100 \mathrm{~g}$ & $30,3 \pm 0,5^{\mathrm{aA}}$ & $30,1 \pm 1,0^{\mathrm{bC}}$ & $118 \pm 1^{\mathrm{aA}}$ \\
\hline$F 3$ & $70 \mathrm{~g}$ & Wt & $28 \mathrm{~g}$ & $\mathrm{CA}$ & $2 \mathrm{~g} / 100 \mathrm{~g}$ & $26,1 \pm 2,1^{\mathrm{aB}}$ & $83,0 \pm 3,8^{\mathrm{aA}}$ & $37 \pm 5^{\mathrm{aB}}$ \\
\hline$F 4$ & $60 \mathrm{~g}$ & Wt : Gly & $15 \mathrm{~g}: 25 \mathrm{~g}$ & - & - & $28,4 \pm 0,8^{\mathrm{aB}}$ & $43,6 \pm 1,6^{\mathrm{bA}}$ & $33 \pm 6^{\mathrm{bB}}$ \\
\hline$F 5$ & $58 \mathrm{~g}$ & Wt : Gly & $15 \mathrm{~g}: 25 \mathrm{~g}$ & SA & $2 \mathrm{~g} / 100 \mathrm{~g}$ & $21,4 \pm 0,4^{\mathrm{bB}}$ & $41,0 \pm 1,9^{a A}$ & $72 \pm 6^{b A}$ \\
\hline$F 7$ & $70 \mathrm{~g}$ & Gly & $30 \mathrm{~g}$ & - & - & $20,2 \pm 1,5^{a B}$ & $63,8 \pm 2,4^{\mathrm{aB}}$ & $19 \pm 4^{\mathrm{CB}}$ \\
\hline F8 & $70 \mathrm{~g}$ & Gly & $28 \mathrm{~g}$ & SA & $2 g / 100 g$ & $19,0 \pm 0,5^{\mathrm{cA}}$ & $43,7 \pm 2,3^{\mathrm{aC}}$ & $28 \pm 3^{c A}$ \\
\hline$F 9$ & $70 \mathrm{~g}$ & Gly & $28 \mathrm{~g}$ & $\mathrm{CA}$ & $2 \mathrm{~g} / 100 \mathrm{~g}$ & $19,7 \pm 0,6^{\mathrm{bA}}$ & $70,0 \pm 1,4^{\mathrm{bA}}$ & $21 \pm 6^{\mathrm{bB}}$ \\
\hline
\end{tabular}

Letras minúsculas diferentes entre si, na mesma coluna, indicam diferença significativa entre os diferentes agentes plastificantes empregados para um mesmo tipo de modificador químico, de acordo com o teste de Tukey $(p<0,05)$.

Letras maiúsculas diferentes entre si, na mesma coluna, indicam diferença significativa entre os diferentes modificadores químicos (sem modificador, ácido

cítrico e esteárico) empregados para um mesmo agente plastificante, de acordo com o teste de Tukey $(p<0,05)$.

Fonte: Do autor (2018). 
Tabela 8 - Umidade $(\mathrm{g} / 100 \mathrm{~g})$, solubulidade $(\%)$ e ângulo de contato $\left(^{\circ}\right)$ dos filmes extrudados de amido termolástico (TPS), incorporados com $2 \mathrm{~g} / 100 \mathrm{~g}$ de celulose microfibrilada (CMF)

\begin{tabular}{|c|c|c|c|c|c|c|c|c|}
\hline \multirow[t]{2}{*}{ Filmes } & \multirow{2}{*}{$\begin{array}{c}\text { Amido } \\
\text { Qtde. }\end{array}$} & \multicolumn{2}{|c|}{ Plastificante } & \multicolumn{2}{|c|}{$\begin{array}{c}\text { Modificador } \\
\text { químico }\end{array}$} & \multirow[t]{2}{*}{$\begin{array}{l}\text { Umidade } \\
(\mathrm{g} / 100 \mathrm{~g})\end{array}$} & \multirow[t]{2}{*}{$\begin{array}{c}\text { Solubilidade } \\
\text { (\%) }\end{array}$} & \multirow[t]{2}{*}{$\begin{array}{l}\text { Ângulo de } \\
\text { contato }\left(^{\circ}\right)\end{array}$} \\
\hline & & Tipo & Qtde. & Tipo & Qtde. & & & \\
\hline F1_CMF & $70 \mathrm{~g}$ & Wt & $30 \mathrm{~g}$ & - & - & $23,1 \pm 1,3^{a b A}$ & $96,2 \pm 0,6^{\mathrm{aA}}$ & $53 \pm 6^{a B}$ \\
\hline$F 2 \_C M F$ & $70 \mathrm{~g}$ & Wt & $28 \mathrm{~g}$ & SA & $2 \mathrm{~g} / 100 \mathrm{~g}$ & $28,7 \pm 2,9^{a A}$ & $44,7 \pm 2,0^{\mathrm{aC}}$ & $104 \pm 9 \mathrm{aA}$ \\
\hline F3_CMF & $70 \mathrm{~g}$ & Wt & $28 \mathrm{~g}$ & $\mathrm{CA}$ & $2 \mathrm{~g} / 100 \mathrm{~g}$ & $25,4 \pm 2,8^{\mathrm{aA}}$ & $71,3 \pm 2,0^{a B}$ & $24 \pm 3^{a C}$ \\
\hline F4_CMF & $60 \mathrm{~g}$ & Wt : Gly & $15 \mathrm{~g}: 25 \mathrm{~g}$ & - & - & $28,6 \pm 1,8^{a A}$ & $44,0 \pm 3,4^{\mathrm{cA}}$ & $51 \pm 9^{a B}$ \\
\hline F5_CMF & $58 \mathrm{~g}$ & Wt : Gly & $15 \mathrm{~g}: 25 \mathrm{~g}$ & SA & $2 \mathrm{~g} / 100 \mathrm{~g}$ & $23,0 \pm 2,4^{\mathrm{bB}}$ & $45,0 \pm 2,0^{a A}$ & $73 \pm 7^{\mathrm{bA}}$ \\
\hline$F 7 \_C M F$ & $70 \mathrm{~g}$ & Gly & $30 \mathrm{~g}$ & - & - & $20,4 \pm 4,0^{\mathrm{bA}}$ & $63,8 \pm 2,8^{\mathrm{bA}}$ & $26 \pm 7^{b B}$ \\
\hline$F 8 \_C M F$ & $70 \mathrm{~g}$ & Gly & $28 \mathrm{~g}$ & SA & $2 \mathrm{~g} / 100 \mathrm{~g}$ & $18,9 \pm 0,4^{\mathrm{bA}}$ & $43,2 \pm 0,6^{\mathrm{aB}}$ & $67 \pm 5^{\mathrm{bA}}$ \\
\hline F9_CMF & $70 \mathrm{~g}$ & Gly & $28 \mathrm{~g}$ & $\mathrm{CA}$ & $2 \mathrm{~g} / 100 \mathrm{~g}$ & $18,5 \pm 0,2^{\mathrm{bA}}$ & $64,8 \pm 1,3^{\mathrm{bA}}$ & $17 \pm 3^{a B}$ \\
\hline
\end{tabular}

Letras minúsculas diferentes entre si, na mesma coluna, indicam diferença significativa entre os diferentes agentes plastificantes empregados para um mesmo tipo de modificador químico, de acordo com o teste de Tukey $(p<0,05)$.

Letras maiúsculas diferentes entre si, na mesma coluna, indicam diferença significativa entre os diferentes modificadores químicos (sem modificador, ácido cítrico e esteárico) empregados para um mesmo agente plastificante, de acordo com o teste de Tukey $(p<0,05)$.

Fonte: Do autor (2018). 
A umidade e a solubilidade em água são propriedades muito importantes no desenvolvimento de embalagens com aplicações na indústria de alimentos, por isso, requerem muita atenção.

Em relação a umidade na Tabela 7, observa-se que quando foi utilizada wt como plastificante, houve diferença significativa $(p<0,05)$ nos filmes elaborados com ou sem modificadores químicos, sendo que os filmes plastificados com somente wt e na presença de ácido esteárico (SA) apresentaram os maiores valores de umidade. Para filmes plastificados com gly, não houve diferença significativa da umidade dos filmes entre os modificadores químicos testados.

A menor umidade pode ser explicada por uma quebra de cadeias de amilose e amilopectina, de forma que ocorra um entrelaçamento com outras cadeias de amido por pontes de hidrogênio intermoleculares (em oposição à ligação de hidrogênio extramolecular com a água), levando a uma menor capacidade de captação de água (DA RÓZ et al., 2011).

Filmes plastificados com wt ou com gly adicionados de ácido cítrico apresentaram maior solubilidade. Enquanto que a adição de ácido esteárico reduziu a solubilidade. Os filmes plastificados com wt : gly não apresentaram diferença significativa na ausência ou presença dos diferentes agentes modificadores.

Filmes plastificados com wt apresentaram maior ângulo de contato que quando plastificados com wt : gly e com apenas glicerol, independente da ausência ou presença de diferentes agentes modificadores. Ou seja, os filmes plastificados somente com wt apresentaram carácter mais hidrofóbico que os demais.

Considera-se, quando um ângulo de contato com água é menor que $90^{\circ}$ a superfície é considerada hidrofílica. Quando o ângulo de contato com água é maior que 90 a superfície é considerada hidrofóbica (ASTM D7334, 2008; BORGES et al., 2016; RIOS et al., 2007). Segundo os valores obtidos para o ângulo de contato dos filmes TPS (Tabela 7), estes materiais exibem uma superfície hidrofílica com valores menores de $90^{\circ}$, exceto o filme $\mathrm{F} 2$, que possui ângulo de contato de $118^{\circ}$, sendo considerado hidrofóbico. Resultados semelhantes foram encontrados por Llanos, (2018), pois os ângulos de contato dos filmes de amido nanoestruturados com MMT

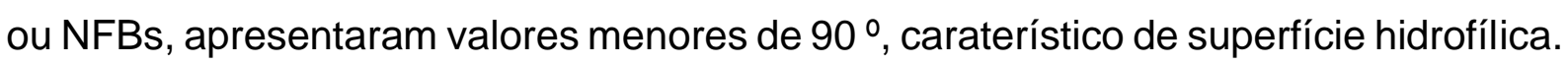


Independentemente do tipo de plastificante, filmes com SA apresentaram caráter mais hidrofóbico que na ausência de modificador químico ou na presença de CA.

Para os filmes TPS adicionados de CMF, foi observado pela Tabela 8 que a umidade não foi influenciada quando plastificados com somente wt ou com somente gly, independente da ausência ou presença dos diferentes tipos de modificadores químicos. No entanto, quando plastificados com wt : gly, a presença do SA reduziu a umidade dos filmes.

Ghanbari et al. (2018) avaliaram a absorção de umidade dos filmes de amido puro e nanocompósitos TPS/NFC em ambiente de umidade relativa de $98 \%$. A absorção de água dos TPS preenchidos com $(1,0$ e 1,5) \% de NFCs foi moderadamente reduzida em comparação com o TPS puro (quantidade de redução foi de $6,4 \%$ para os compósitos TPS/NFC 1,0 e $10 \%$ para os TPS/NFC 1,5 após 24 h).

Svagan et al. (2009) argumentaram que a absorção de água do TPS foi reduzida com o aumento de NFC, porque as NFCs têm um maior grau de ordenação molecular do que o TPS, tornando-o menos higroscópico. É bem conhecido que o amido tem baixa barreira contra umidade e a adição de NFCs é uma maneira eficaz de diminuir sua sensibilidade à umidade e, assim, melhorar as propriedades mecânicas e a estabilidade (BABAEE et al., 2015; GHANBARI et al. 2018).

Os filmes TPS_CMF plastificados com wt apresentaram diferença significativa na solubilidade na presença ou não dos modificadores químicos testados, sendo que filmes elaborados sem modificador químico forma mais solúveis. Já para os filmes com wt : gly, não houve diferença estatística entre filmes elaborados com ou sem SA. Quando plastificados com apenas gly, os filmes TPS com CMF apresentam menor solubilidade que na presença de SA.

Resultados similares foram relatados por Llanos (2018) obtendo um decréscimo de 8,37 \% na solubilidade dos filmes de amido estruturados com montmorilonita (MMT) ou nanofibras de bambu (NFBs) quando a maior concentração de nanopartículas de argila em relação aos filmes controle foi empregada.

Abdullah e Dong (2018) incorporaram nanotubos de haloisita modificados (HNTs) em filmes TPS e notaram que houve uma diminuição significativa da solubilidade, (0,3 e 3,0) \% com a inclusão de (3 e 6) g/100 g de HNTs, 
respectivamente, quando comparado com o de TPS puro. Issa et al. (2018) também apresentaram resultados semelhantes, a solubilidade em água reduziu em 14 \% para o nanocompósito TPS/MMT (3 g de MMT/100 g).

Os filmes TPS_CMF plastificados com wt apresentam maior ou igual solubilidade que os filmes plastificados com os demais plastificantes quando na ausência ou presença dos mesmos modificadores químicos. Os mesmos mostraram maior (são mais hidrofóbicos) ou igual ângulo de contato, nas mesmas condições citadas. O modificador químico SA gerou filmes TPS_CMF mais hidrofóbicos que na ausência de modificadores ou na presença do CA.

Observando a Figura 20, nota-se que a incorporação da CMF nos filmes TPS não causou efeito significativo na umidade dos filmes. No entanto, a presença da CMF aumentou a solubilidade dos filmes TPS plastificados com wt sem modificador químico (66\%) ou com SA (33 \%). No entanto, os filmes TPS na presença de CA e plastificados com somente água ou com somente gly tiveram, com a adição de CMF, uma redução da solubilidade (16\% e $7 \%$, respectivamente).

$\mathrm{Na}$ Figura 21, filmes TPS plastificados com wt : gly e sem a presença de modificador apresentaram aumento do ângulo de contato (55 \%) quando a CMF foi adicionada. Filmes TPS plastificados com gly e na presença de SA apresentaram aumento do ângulo de contato em 58 \% quando a CMF foi adicionada. No entanto, filmes TPS plastificados com wt e na presença de CA apresentaram redução do ângulo de contato 35 \% quando a CMF foi adicionada, tornando-os mais hidrofílicos. 
Figura 19 - Umidade ( $\mathrm{g} / 100 \mathrm{~g})$ e Solubilidade (\%) dos filmes extrudados de amido termoplástico (TPS) sem e com a incorporação de celulose microfibrilada (CMF)
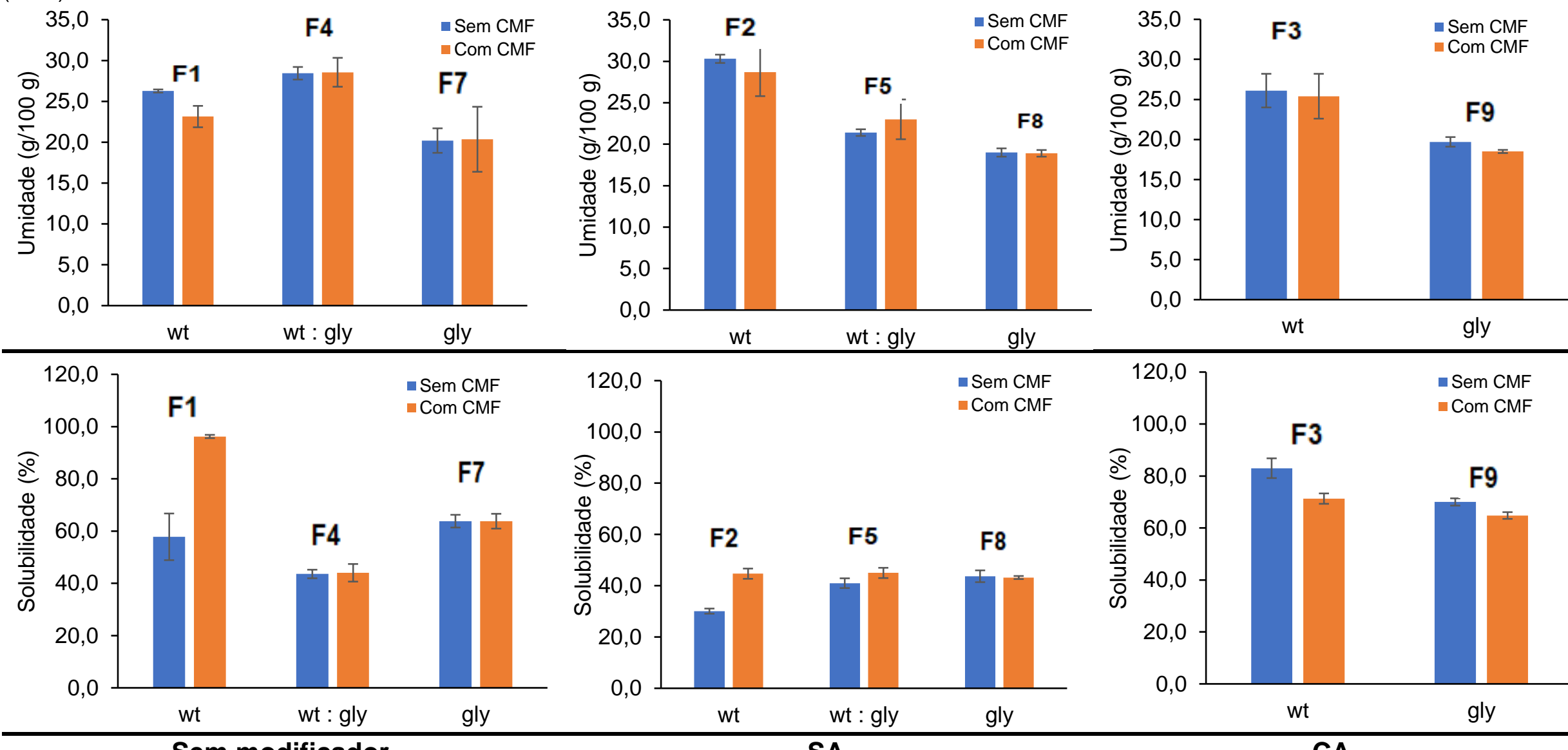

Fonte: Do autor (2018). 
Figura 20 - Ângulo de contato $\left(^{\circ}\right)$ dos filmes extrudados de amido termoplástico (TPS) sem e com a incorporação de celulose microfibrilada (CMF)
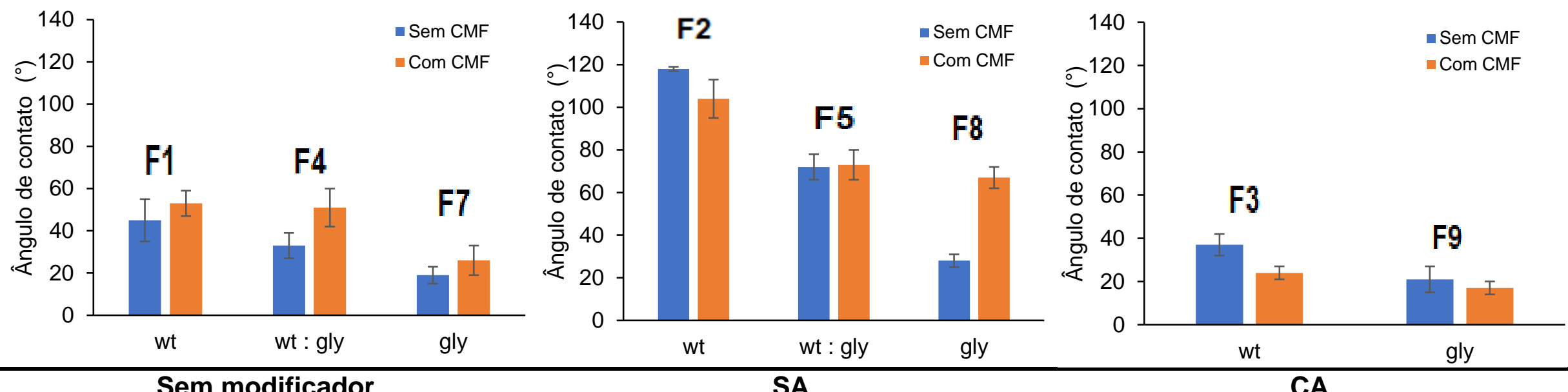

Fonte: Do autor (2018). 
A Tabela 9 mostra as diferenças totais de cor $\left(\Delta E^{*}\right)$ e opacidade dos filmes de amido termoplástico (TPS) incorporados com o agente plastificante e modificador químico. A Tabela 10 apresenta as mesmas propriedades, respectivamente, porém dos filmes incorporados com a celulose microfibrilada (CMF). Ambas as tabelas apresentam resultados com média e desvio padrão das respectivas propriedades. 
Tabela 9 - Diferença total de cor $\left(\Delta E^{\star}\right)$ e opacidade dos filmes extrudados de amido termolástico (TPS)

\begin{tabular}{|c|c|c|c|c|c|c|c|}
\hline \multirow{2}{*}{ Filmes } & \multirow{2}{*}{$\begin{array}{c}\text { Amido } \\
\text { Qtde. }\end{array}$} & \multicolumn{2}{|c|}{ Plastificante } & \multicolumn{2}{|c|}{ Modificador químico } & \multirow{2}{*}{$\begin{array}{c}\text { Diferença Total de } \\
\text { Cor }\left(\Delta E^{\star}\right)\end{array}$} & \multirow{2}{*}{$\begin{array}{c}\text { Opacidade } \\
\text { (\%) }\end{array}$} \\
\hline & & Tipo & Qtde. & Tipo & Qtde. & & \\
\hline$F 1$ & $70 \mathrm{~g}$ & Wt & $30 \mathrm{~g}$ & - & - & $26,1 \pm 1,2^{\mathrm{aB}}$ & $99 \pm 0^{\mathrm{aA}}$ \\
\hline$F 2$ & $70 \mathrm{~g}$ & Wt & $28 \mathrm{~g}$ & SA & $2 \mathrm{~g} / 100 \mathrm{~g}$ & $33,8 \pm 1,2^{\mathrm{aA}}$ & $99 \pm 0^{\mathrm{aA}}$ \\
\hline F3 & $70 \mathrm{~g}$ & Wt & $28 \mathrm{~g}$ & $\mathrm{CA}$ & $2 \mathrm{~g} / 100 \mathrm{~g}$ & $34,4 \pm 0,4^{\mathrm{aA}}$ & $99 \pm 0^{\mathrm{aA}}$ \\
\hline$F 4$ & $60 \mathrm{~g}$ & Wt: Gly & $15 g: 25 g$ & - & - & $16,6 \pm 0,7^{\mathrm{bA}}$ & $61 \pm 4^{\mathrm{bB}}$ \\
\hline$F 5$ & $58 \mathrm{~g}$ & Wt : Gly & $15 \mathrm{~g}: 25 \mathrm{~g}$ & SA & $2 \mathrm{~g} / 100 \mathrm{~g}$ & $4,0 \pm 0,4^{\mathrm{cB}}$ & $96 \pm 1^{\mathrm{bB}}$ \\
\hline$F 7$ & $70 \mathrm{~g}$ & Gly & $30 \mathrm{~g}$ & - & - & $16,1 \pm 1,1^{\mathrm{bA}}$ & $99 \pm 0^{\mathrm{aA}}$ \\
\hline F8 & $70 \mathrm{~g}$ & Gly & $28 \mathrm{~g}$ & SA & $2 \mathrm{~g} / 100 \mathrm{~g}$ & $13,6 \pm 1,8^{\mathrm{bA}}$ & $99 \pm 0^{\mathrm{aA}}$ \\
\hline F9 & $70 \mathrm{~g}$ & Gly & $28 \mathrm{~g}$ & $\mathrm{CA}$ & $2 \mathrm{~g} / 100 \mathrm{~g}$ & $13,7 \pm 1,3^{\mathrm{bA}}$ & $99 \pm 0^{\mathrm{aA}}$ \\
\hline
\end{tabular}

Letras minúsculas diferentes entre si, na mesma coluna, indicam diferença significativa entre os diferentes agentes plastificantes empregados para um mesmo tipo de modificador químico, de acordo com o teste de Tukey $(p<0,05)$

Letras maiúsculas diferentes entre si, na mesma coluna, indicam diferença significativa entre os diferentes modificadores químicos (sem modificador, ácido cítrico e esteárico) empregados para um mesmo agente plastificante, de acordo com o teste de Tukey $(p<0,05)$.

$\Delta E^{*}$ : calculado considerando como padrão um filme $\operatorname{PVC}\left(L^{*}=92,55, a^{*}=-1,18, b^{*}=0,41\right)$

Fonte: Do autor (2018). 
Tabela 10 - Diferença total de cor $\left(\Delta E^{*}\right)$ e opacidade dos filmes extrudados de amido termolástico (TPS), incorporados com $2 \mathrm{~g} / 100 \mathrm{~g}$ de celulose microfibrilada (CMF)

\begin{tabular}{|c|c|c|c|c|c|c|c|}
\hline \multirow[t]{2}{*}{ Filmes } & \multirow{2}{*}{$\begin{array}{l}\text { Amido } \\
\text { Qtde. }\end{array}$} & \multicolumn{2}{|c|}{ Plastificante } & \multicolumn{2}{|c|}{ Modificador químico } & \multirow{2}{*}{$\begin{array}{l}\text { Diferença Total de } \\
\text { Cor }\left(\Delta E^{\star}\right)\end{array}$} & \multirow{2}{*}{$\begin{array}{c}\text { Opacidade } \\
(\%)\end{array}$} \\
\hline & & Tipo & Qtde. & Tipo & Qtde. & & \\
\hline F1_CMF & $70 \mathrm{~g}$ & Wt & $30 \mathrm{~g}$ & - & - & $10,3 \pm 0,4^{\mathrm{bB}}$ & $60 \pm 10^{\mathrm{bB}}$ \\
\hline$F 2 \_C M F$ & $70 \mathrm{~g}$ & Wt & $28 \mathrm{~g}$ & SA & $2 \mathrm{~g} / 100 \mathrm{~g}$ & $24,4 \pm 2,3^{\mathrm{aA}}$ & $99 \pm 1^{\mathrm{aA}}$ \\
\hline F3_CMF & $70 \mathrm{~g}$ & Wt & $28 \mathrm{~g}$ & CA & $2 \mathrm{~g} / 100 \mathrm{~g}$ & $22,9 \pm 1,5^{\mathrm{aA}}$ & $98 \pm 1^{\mathrm{aA}}$ \\
\hline F4_CMF & $60 \mathrm{~g}$ & Wt : Gly & $15 \mathrm{~g}: 25 \mathrm{~g}$ & - & - & $15,3 \pm 0,3^{\mathrm{aA}}$ & $40 \pm 6^{c B}$ \\
\hline F5_CMF & $58 \mathrm{~g}$ & Wt : Gly & $15 \mathrm{~g}: 25 \mathrm{~g}$ & SA & $2 \mathrm{~g} / 100 \mathrm{~g}$ & $8,6 \pm 0,3^{\mathrm{cB}}$ & $97 \pm 1^{\mathrm{aA}}$ \\
\hline F7_CMF & $70 \mathrm{~g}$ & Gly & $30 \mathrm{~g}$ & - & - & $8,9 \pm 0,2^{\mathrm{bA}}$ & $99 \pm 0^{a A}$ \\
\hline F8_CMF & $70 \mathrm{~g}$ & Gly & $28 \mathrm{~g}$ & $\mathrm{SA}$ & $2 \mathrm{~g} / 100 \mathrm{~g}$ & $9,6 \pm 0,1^{\mathrm{bA}}$ & $99 \pm 1^{\mathrm{aA}}$ \\
\hline F9_CMF & $70 \mathrm{~g}$ & Gly & $28 \mathrm{~g}$ & $\mathrm{CA}$ & $2 \mathrm{~g} / 100 \mathrm{~g}$ & $9,8 \pm 0,8^{\mathrm{bA}}$ & $99 \pm 0^{\mathrm{aA}}$ \\
\hline
\end{tabular}

Letras minúsculas diferentes entre si, na mesma coluna, indicam diferença significativa entre os diferentes agentes plastificantes empregados para um mesmo tipo de modificador químico, de acordo com o teste de Tukey $(p<0,05)$.

Letras maiúsculas diferentes entre si, na mesma coluna, indicam diferença significativa entre os diferentes modificadores químicos (sem modificador, ácido cítrico e esteárico) empregados para um mesmo agente plastificante, de acordo com o teste de Tukey $(p<0,05)$.

$\Delta E^{*}$ : calculado considerando como padrão um filme PVC $\left(L^{*}=92,55, a^{*}=-1,18, b^{*}=0,41\right)$.

Fonte: Do autor (2018). 
Todos os filmes plastificados com apenas wt apresentaram maior diferença total de cor, enquanto que filmes TPS plastificados com wt : gly e adicionados de SA apresentaram menor diferença total de cor que todos os demais filmes produzidos.

Se observa que somente filmes plastificados com wt : gly apresentaram opacidade diferentes dos demais com valores menores que $99 \%$.

Filmes TPS_CMF plastificados somente com wt apresentaram maior diferença total de cor quando elaborados com os modificadores químicos. Os modificadores químicos não afetaram a diferença total de cor $\left(\Delta E^{*}\right)$ dos filmes plastificados com apenas gly, no entanto afetaram esta propriedade dos filmes plastificados com somente wt ou com wt : gly. A ausência de modificador químico gerou filmes plastificados com wt com menor diferença total de cor, no entanto comportamento inverso foi observado para os filmes plastificados com wt : gly.

Filmes TPS_CMF plastificados com somente gly não tiveram sua opacidade influenciada na ausência ou presença dos modificadores químicos. No entanto, quando plastificados com somente wt ou com wt : gly, nota-se que a ausência de modificador químico gerou filmes menos opacos.

A diferença total de cor e a opacidade dos filmes de amido termoplástico sem e com a adição de CMF estão apresentadas nas Figuras 22 e 23.

Para os filmes TPS sem ou com os modificadores químicos houve redução na diferença total de cor quando adicionados de CMF, independentemente do tipo de plastificante. A adição de CFM resultou em filmes menos opacos quando elaborados sem os modificadores químicos e plastificados com somente wt ou somente wt : gly. Para os filmes com os demais modificadores químicos, a adição de CFM não afetou a opacidade, independentemente do tipo de plastificante.

Dos resultados obtidos, indica-se que o filme F5_CMF possui menores valores de tensão e módulo de Young, já o filme F5 possui maior valores de tensão, módulo de Young e ângulo de contato, e menores valores de umidade, solubilidade e diferença total de cor, sendo o escolhido para dar continuidade nas etapas quatro e cinco deste trabalho, denominado de filme controle (F5). 
Figura 21 - Diferença total de cor $\left(\Delta E^{*}\right)$ dos filmes extrudados de amido termoplástico (TPS) sem e com a incorporação de celulose microfibrilada (CMF)
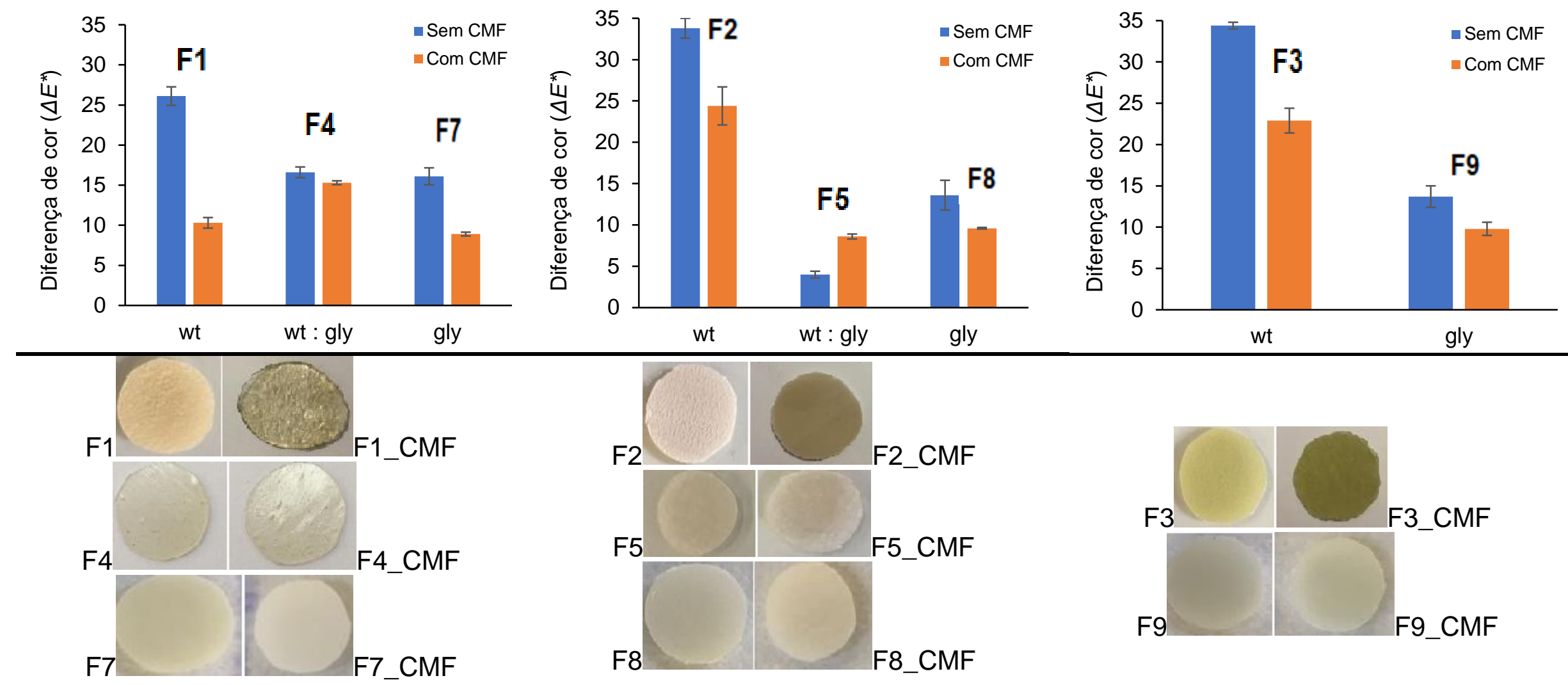

Sem modificador

SA

CA Fonte: Do autor (2018). 
Figura 22 - Opacidade dos filmes extrudados de amido termoplástico (TPS) sem e com a incorporação de celulose microfibrilada (CMF)
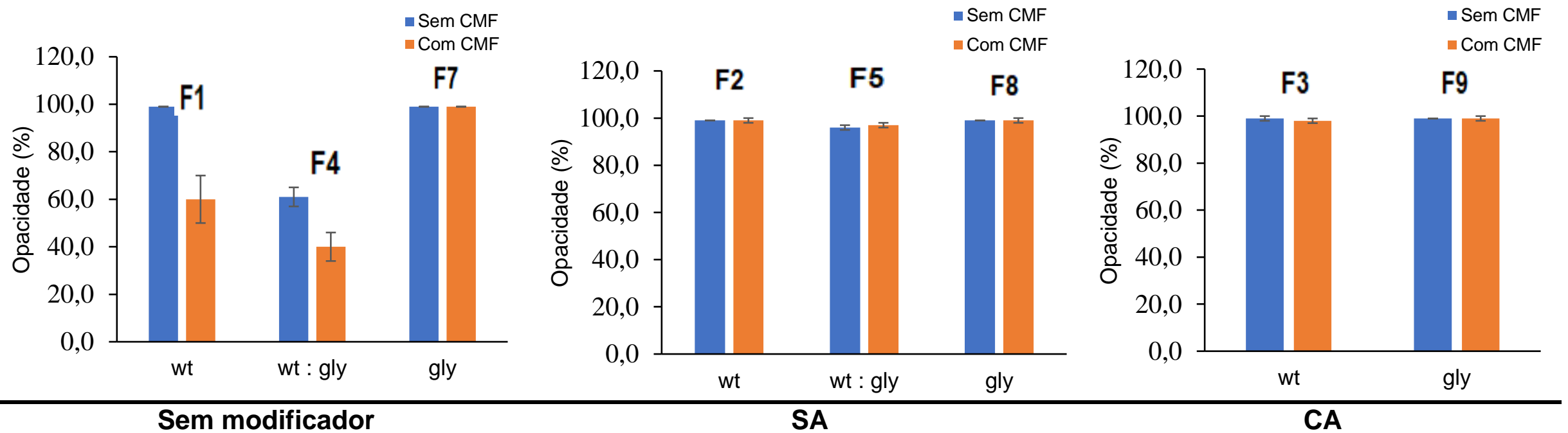

Fonte: Do autor (2018). 
A seguir os tópicos 5.3 a 5.3 .4 serão descritos os resultados e discussões referentes a quarta e quinta etapa desse trabalho.

\subsection{Caracterização dos filmes de amido com antocianina (ATH)}

\subsubsection{Morfologia por microscopia eletrônica de varredura (MEV)}

Na Figura 24 estão apresentadas às micrografias obtidas por MEV da superfície (magnificação de 400 x) e da área transversal (magnificação de 200 x) dos filmes F5 incorporados de antocianina (ATH).

Nas micrografias de superfície apresentadas, se destaca a ausência de visíveis grânulos de amido e micropartículas de ácido esteárico, indicando boa interação entre os componentes da formulação. Martins \& Santana (2016) produziram blendas de polipropileno (PP) com amido e ácidos por extrusão, e observaram mudanças importantes na morfologia das misturas. Os ácidos têm como objetivo aumentar a plastificação do amido, pela acidificação, levando à sua fragmentação e dissociação. Assim como foi concluído pelos autores mencionados, nesse trabalho a formulação contendo o ácido esteárico demostrou ser um excelente agente compatibilizante e protetor térmico, melhorando a adesão interfacial, durante a fusão do amido. A melhora da adesão interfacial pode ser atribuída à forte interação química entre a fase polar dos ácidos e os grupos hidroxila do amido.

Nota-se também que o aumento da concentração de ATH incorporada influenciou no aparecimento de algumas ondulações superficiais, que possam ocorrer devido a maior presença de solução de ATH sendo inserida, ou seja, maior quantidade de água no processo, o que interfere na formação da matriz. Essa observação também pode ser verificada na micrografia da área transversal de todas as imagens.

Pode-se observar também que o aumento da concentração de antocianina sendo adicionada reduziu a uniformidade dos filmes. Zhang et al. (2018) também observaram as imagens de MEV obtidas dos filmes de amido/PVA, amido/quitosana e PVA/quitosana (1:1). Os autores notaram que a adição de antocianina provocou uma redução da homogeneidade da superfície e a presença de uma estrutura mais rugosa nos filmes. A inserção de antocianinas pode destruir o arranjo ordenado da estrutura do amido tornando-o fraco (TALÓN et al.; 2016; ZHANG et al.; 2018). 
Figura 23 - Microscopia eletrônica (MEV), (a. e b.) se refere as micrografias dos filmes ATH_0,005, (c. e d.) dos filmes ATH_0,010, e (e. e f.) dos filmes ATH_0,020. Superfície com aproximação de 400 x, e da área transversal com aproximação de $200 \mathrm{x}$
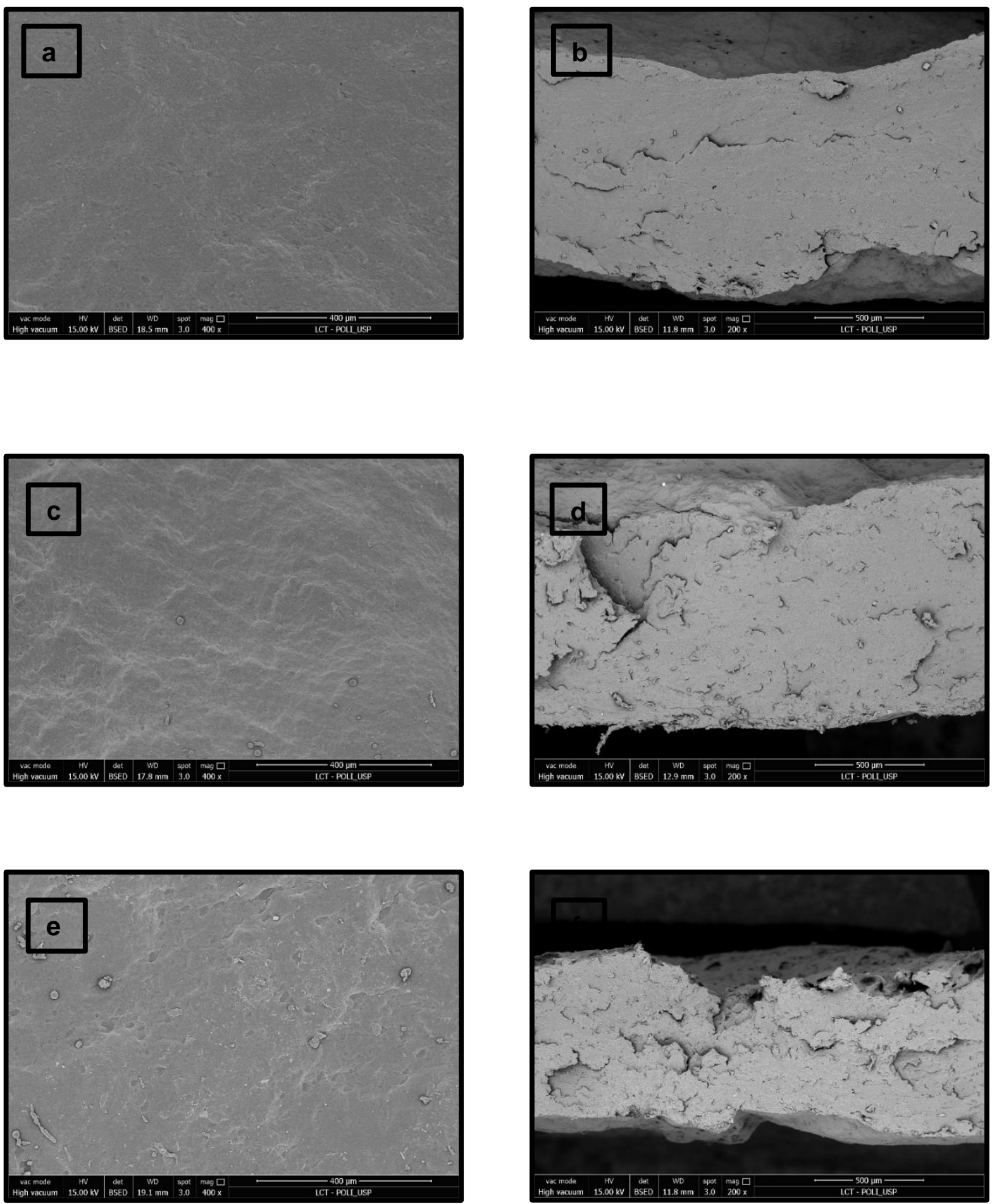

Fonte: Do autor, 2018. 


\subsubsection{Cristalinidade}

A difração de raios - X é uma das várias maneiras empregadas para identificar e classificar os amidos nativos. Três tipos de amido, designados como tipo A, B e C, podem ser identificados com base nos padrões de difração de raios - X (TEIXEIRA et al., 2018). Estes dependem em parte dos comprimentos da cadeia que compõem a rede de amilopectina, a densidade do empacotamento dentro dos grânulos e a presença de água. Embora o tipo A e tipo B sejam modificações cristalinas reais, o tipo C é uma forma mista. A estrutura do amido tipo A tem amilopectina de comprimento de cadeia de 23 a 29 unidades de glicose. A ligação de hidrogênio entre os grupos hidroxila das cadeias de moléculas de amilopectina resultam na formação de estrutura helicoidal externa dupla. Entre estas micelas, as cadeias lineares das porções de amilose são embaladas pela formação de ligações de hidrogênio com cadeias lineares externas de amilopectina. Este padrão é muito comum em cereais. $A$ estrutura do tipo B consiste em amilopectina de comprimento de cadeia de 30 a 44 moléculas de glicose com água inter-disseminada. Este é o padrão usual de amidos em batata crua e banana. A estrutura do tipo C é composta de amilopectina de comprimento de cadeia de 26 a 29 moléculas de glicose, uma combinação de tipo $A$ e tipo B, típica de tubérculos, ervilhas e feijões. Uma forma adicional, chamada tipo $\mathrm{V}$, ocorre em grânulos inchados (TEIXEIRA et al., 2018).

A Figura 25, apresenta o difratograma de raios - $X$ dos filmes de amido de mandioca termoplástico controle (F5) e com diferentes concentrações de ATH. 
Figura 24 - Difratograma de raios - X dos filmes de amido termoplástico controle e com concentrações diferentes de ATH

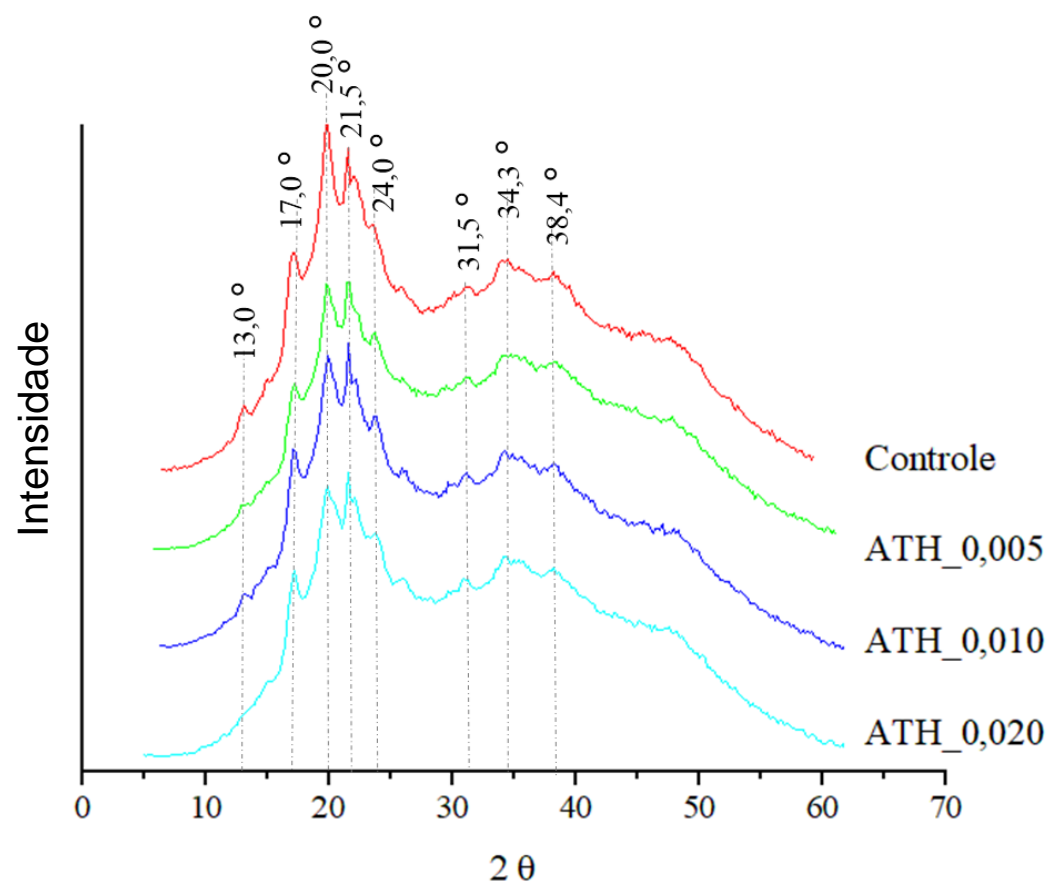

Fonte: Do autor (2018).

$\mathrm{Na}$ Figura 25, observa-se a presença dos picos em $2 \theta=(13 ; 17 ; 20 ; 21,5 ; 24$; $31,5 ; 34,3 ; 38,4)^{\circ}$. Os picos mais intensos são em $2 \theta=(17,20 \text { e } 21,5)^{\circ}$, onde há forte predomínio do amido tipo $\mathrm{A}$ e o tipo $\mathrm{V}$, que se é esperado, pois a formação do amido termoplástico é sob ação de calor e tensão mecânica do processo de extrusão sendo também característica do amido tipo V.

Teixeira et al. (2018) analisaram o difratograma de raios - $X$ do amido de mandioca e o classificaram como sendo do tipo $C$, devido a presença de picos característicos de amido tipo $A$ em $2 \theta=(15,3 \text { e } 23)^{\circ}$ e tipo $B$ em $(17 \text { a 17,6 })^{\circ}$.

Zhang et al. (2017) analisaram padrões de difração de raios - $X$ de amido nativo de milho em diferentes temperaturas. Amido de milho nativo com estrutura polimórfica cristalina tipo $A$ atípica foi caracterizada por picos de difração nítidos em torno de $2 \theta$ $=(15,17,18,23)^{\circ}$. A intensidade do pico de difração diminuiu com o aumento da temperatura porque o tratamento térmico fundiu gradualmente a estrutura cristalina dupla helicoidal. Os resultados também sugerem que a perda de cristalinidade pode ser devida à ruptura do amido granular, que na presença de água juntamente com o tratamento por aquecimento causou a quebra de moléculas e de ligação química. 
Amaral et al. (2015) apresentaram os difratogramas de raios $-X$ do amido de milho granular (AN) e de amido hidratado com glicerol e ácido cítrico $(\mathrm{H}-34)$ produzido em extrusora dupla-rosca, antes e após o processo de recozimento. Os grânulos de amido nativo apresentaram uma cristalinidade tipicamente $A$, evidenciada por picos de difração característicos em $2 \theta=\left(15,0 ; 17,2 ; 18,0\right.$ e 23,2) ${ }^{\circ}$. A formação de estruturas cristalinas no amido termoplástico é influenciada pela razão amilose/amilopectina além das condições de armazenamento, como tempo, temperatura e umidade das amostras.

Existem dois tipos diferentes de cristalinidade que podem ser distinguidos após o processamento do amido: (i) Cristalinidade residual: oriunda das formas cristalinas A, B ou C, devido à incompleta fusão dos grânulos durante o processamento; (ii) Cristalinidade induzida pelo processamento: oriunda da cristalinidade do tipo $\mathrm{V}$ formada sob ação de calor e tensão mecânica. Os complexos do tipo V são formados pela cristalização da amilose com lipídios, com picos máximos em aproximadamente $2 \theta=(13,5 ; 18,03 ; 19,1 \text { e } 20,7)^{\circ}$. A estrutura cristalina do tipo $B$, com pico máximo característico em $2 \theta=17,4^{\circ}$, está associada à cristalização da amilose devido à sua estrutura linear (AMARAL et al., 2015).

A partir dos difratogramas de raios - $X$ foram calculados os índices de cristalinidade (I.C.) dos filmes obtendo os seguintes valores: Controle (F5) com 16,83 $\%$, ATH_0,005 com 16,94\%, ATH_0,010 com 16,81\%, ATH_0,020 com 16,95\%.

Foi calculado por Teixeira et al. (2018) o valor de $23,1 \%$ doe índice de cristalinidade para o amido de mandioca. Este valor é superior ao encontrado para os filmes. De acordo com Zhang et al. (2017), a presença de água juntamente com o tratamento térmico funde gradualmente a estrutura cristalina, causando perda de cristalinidade devido à ruptura do amido granular e quebra de moléculas e de ligações químicas.

\subsubsection{Propriedades mecânicas e de superfície}

A Tabela 11, e a Figura 26 apresentam as propriedades físicas e de superfície dos filmes de amido termoplástico (TPS) controle (F5) e com a incorporação de diferentes concentrações de antocianina (ATH). A tabela apresenta resultados com média a desvio padrão das respectivas propriedades. 
Tabela 11 - Propriedades mecânicas e de superfície dos filmes de amido termoplástico (TPS) sem (controle) e com a presença de antocianina (ATH) armazenados a (25 \pm 2 ) ${ }^{\circ} \mathrm{C}$ e $75 \%$ UR

\begin{tabular}{ccccc}
\hline Filmes & $\begin{array}{c}\text { Espessura } \\
(\mathbf{m m})\end{array}$ & $\begin{array}{c}\text { Tensão } \\
\mathbf{( M P a})\end{array}$ & $\begin{array}{c}\text { Elongação } \\
(\%)\end{array}$ & $\begin{array}{c}\text { Módulo de Young } \\
(\mathbf{M P a})\end{array}$ \\
\hline Controle & $0,6 \pm 0,3^{\mathrm{b}}$ & $1,8 \pm 0,3^{\mathrm{a}}$ & $50,0 \pm 4,2^{\mathrm{a}}$ & $10,5 \pm 2,6^{\mathrm{a}}$ \\
ATH_0,005 & $1,7 \pm 0,2^{\mathrm{a}}$ & $0,4 \pm 0,1^{\mathrm{b}}$ & $39,1 \pm 3,6^{\mathrm{ab}}$ & $2,5 \pm 0,4^{\mathrm{b}}$ \\
ATH_0,010 & $1,4 \pm 0,2^{\mathrm{a}}$ & $0,3 \pm 0,0^{\mathrm{b}}$ & $32,4 \pm 6,0^{\mathrm{b}}$ & $2,4 \pm 0,5^{\mathrm{b}}$ \\
ATH_0,020 & $1,5 \pm 0,2^{\mathrm{a}}$ & $0,4 \pm 0,0^{\mathrm{b}}$ & $33,6 \pm 4,6^{\mathrm{b}}$ & $2,2 \pm 0,5^{\mathrm{b}}$ \\
\hline
\end{tabular}

Letras diferentes entre si, na mesma coluna, indicam diferença significativa entre os filmes, de acordo com o teste de Tukey $(p<0,05)$.

Fonte: Do autor (2018).

Nota-se pela Tabela 11, que o filme controle possui menor espessura $(\mathrm{mm})$ quando comparado aos filmes com antocianina (ATH), que por sua vez não apresentaram diferenças significativas entre si. A espessura média dos filmes com ATH é de $1,50 \mathrm{~mm}$, ou seja, em torno de $250 \%$ maior que o controle, conforme apresentado na Figura 26. Zhang et al. (2018) observaram que a incorporação de antocianina em filmes de amido/PVA e amido/quitosana não alterou a espessura dos filmes. Por outro lado, Park \& Zhao (2004) observaram o aumento da espessura em filmes de quitosana adicionados de compostos bioativos.

O mesmo comportamento foi encontrado para a tensão (MPa) e módulo de Young (MPa), a adição de antocianina reduziu a resistência à ruptura e a rigidez dos filmes, porém a variação da quantidade de antocianina utilizada não afetou significativamente estas propriedades. Em relação a elongação (\%), nota-se que a antocianina reduziu a flexibilidade dos filmes. Podemos observar que a incorporação de antocianina reduz a tensão, a elongação e o módulo de Young em 532 \%, 142 \% e $454 \%$, respectivamente, quando comparado ao controle, sendo uma redução considerável. A adição de antocianina pode ter promovido a redução das interações das moléculas de água com a matriz dos filmes, que diminuiu a flexibilidade dos filmes (YOSHIDA et al.; 2014; ZHANG et al., 2018).

Zhang et al. (2018) avaliaram o efeito da adição de antocianina em diferentes matrizes (amido com álcool polivinil - PVA, amido com quitosana e mistura PVA com quitosana (1:1)). Os autores notaram comportamento diferente do observado neste trabalho, pois a antocianina promoveu efeito apenas nos filmes de amido com quitosana, causando aumento de sua resistência à quebra e aumento de flexibilidade 
dos filmes de mistura PVA e quitosana (1:1). Estes comportamentos podem ser devido às suas diferentes estruturas cristalinas e ao tipo de interação da matriz com a antocianina (PICONE \& CUNHA, 2011, ZHANG et al., 2018).

A Tabela 12, e a Figura 27 apresentam resultados com média e desvio padrão de umidade, solubilidade e ângulo de contato dos filmes de amido termoplástico (TPS) controle e com a incorporação de diferentes concentrações de antocianina (ATH).

Nota-se pela Tabela 12, que a umidade dos filmes com antocianina foi superior ao do filme controle (aumento de aproximadamente $40 \%$ ). Zhang et al. (2018) observaram diferente comportamento com a adição de antocianina. Filmes de amido/PVA, amido/quitosana não apresentaram alteração nesta propriedade com a adição de antocianina, no entanto filmes de PVA/quitosana apresentaram redução de umidade com a incorporação de $2,5 \%$ de antocianina ao controle. Os autores explicaram que isto ocorreu, possivelmente, porque a interação entre 0 álcool polivinílico (SPVA) e antocianina (ATH) poderia reduzir a disponibilidade de grupos hidroxila do composto amido hidro gel de álcool polivinílico (SPVA), o que reduziria as interações da água (Wang et al., 2013). 
Figura 25 - Espessura (mm), tensão (MPa), elongação (\%) e módulo de Young (MPa) dos filmes de amido termoplástico (TPS) controle e com diferentes concentrações de antocianina

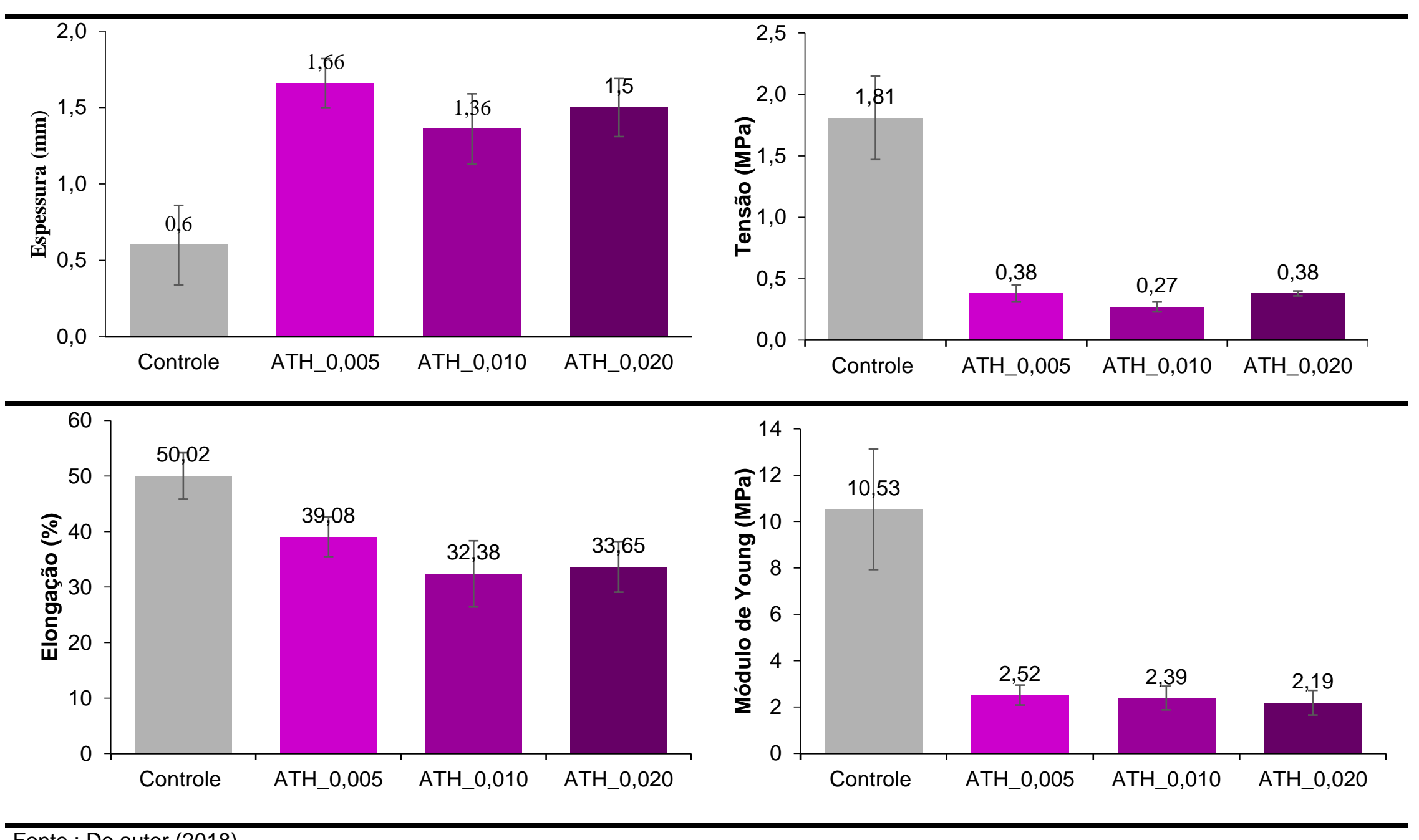

Fonte : Do autor (2018). 
Arenas (2012) elaborou filmes de amido pelo método casting, com 0,75 g de glicerol e $0,10 \mathrm{~g}$ de argila montmorilonita sódica (MMT-Na)] $/ 5 \mathrm{~g}$ de amido de mandioca, incorporados com antocianina e ácido cítrico, e observou que a umidade de todas as formulações dos filmes apresentaram valores médios muito próximos de $(14,46$ a $14,67) \mathrm{g} / 5 \mathrm{~g}$ de amido (b.s.), e quanto maior a concentração de antocianina, maior foi a umidade.

Zhai et al. (2017) produziram filmes de amido/PVA (2 :1), com álcool polivinílico (SPVA). Foi incorporado no filme 30, 60 e $120 \mathrm{mg}$ de antocianina/100 $\mathrm{g}$ de amido na matriz de SPVA, e pode-se notar valores de $(25,50$ a 18,50$) \mathrm{g} / 100 \mathrm{~g}$ de umidade. A incorporação de antocianina reduziu significativamente a umidade. A solubilidade em água, também aumentou com o aumento da concentração de ATH, porém apenas 5 $\%$ do controle.

Quando se observa a molhabilidade por meio da medida do ângulo de contato dos filmes de amidos TPS incorporados com ATH, verificamos que todos são hidrofílicos, com ângulo de contato menor que $90^{\circ}$. Quanto maior a concentração de ATH, notou-se mais hidrofóbica a superfície do filme.

Tabela 12 - Propriedades de superfície dos filmes de amido termoplástico (TPS) sem (controle) e com a presença de antocianina (ATH) armazenados a $(25 \pm 2) \stackrel{\circ}{\circ}$ e $75 \%$ UR

\begin{tabular}{cccc}
\hline Filmes & Umidade $(\mathbf{g} / \mathbf{1 0 0} \mathbf{g})$ & Solubilidade (\%) & $\begin{array}{c}\text { Ângulo de contato } \\
\left({ }^{\circ}\right)\end{array}$ \\
\hline Controle & $21,4 \pm 0,4^{\mathrm{c}}$ & $41,0 \pm 1,9^{\mathrm{b}}$ & $72 \pm 6^{\mathrm{ab}}$ \\
ATH_0,005 & $29,2 \pm 0,6^{\mathrm{b}}$ & $40,7 \pm 0,9^{\mathrm{b}}$ & $58 \pm 6^{\mathrm{b}}$ \\
ATH_0,010 & $31,4 \pm 0,6^{\mathrm{a}}$ & $42,2 \pm 0,6^{\mathrm{b}}$ & $70 \pm 4^{\mathrm{ab}}$ \\
ATH_0,020 & $30,2 \pm 0,1^{\mathrm{ab}}$ & $45,6 \pm 0,5^{\mathrm{a}}$ & $81 \pm 6^{\mathrm{a}}$ \\
\hline
\end{tabular}

Letras diferentes entre si, na mesma coluna, indicam diferença significativa entre os filmes, de acordo com o teste de Tukey $(\mathrm{p}<0,05)$.

Fonte: Do autor (2018). 
Figura 26 - Umidade $(\mathrm{g} / 100 \mathrm{~g})$, solubilidade $(\%)$ e ângulo de contato $\left(^{\circ}\right)$ dos filmes de amido termoplástico (TPS) controle e com diferentes concentrações de antocianina

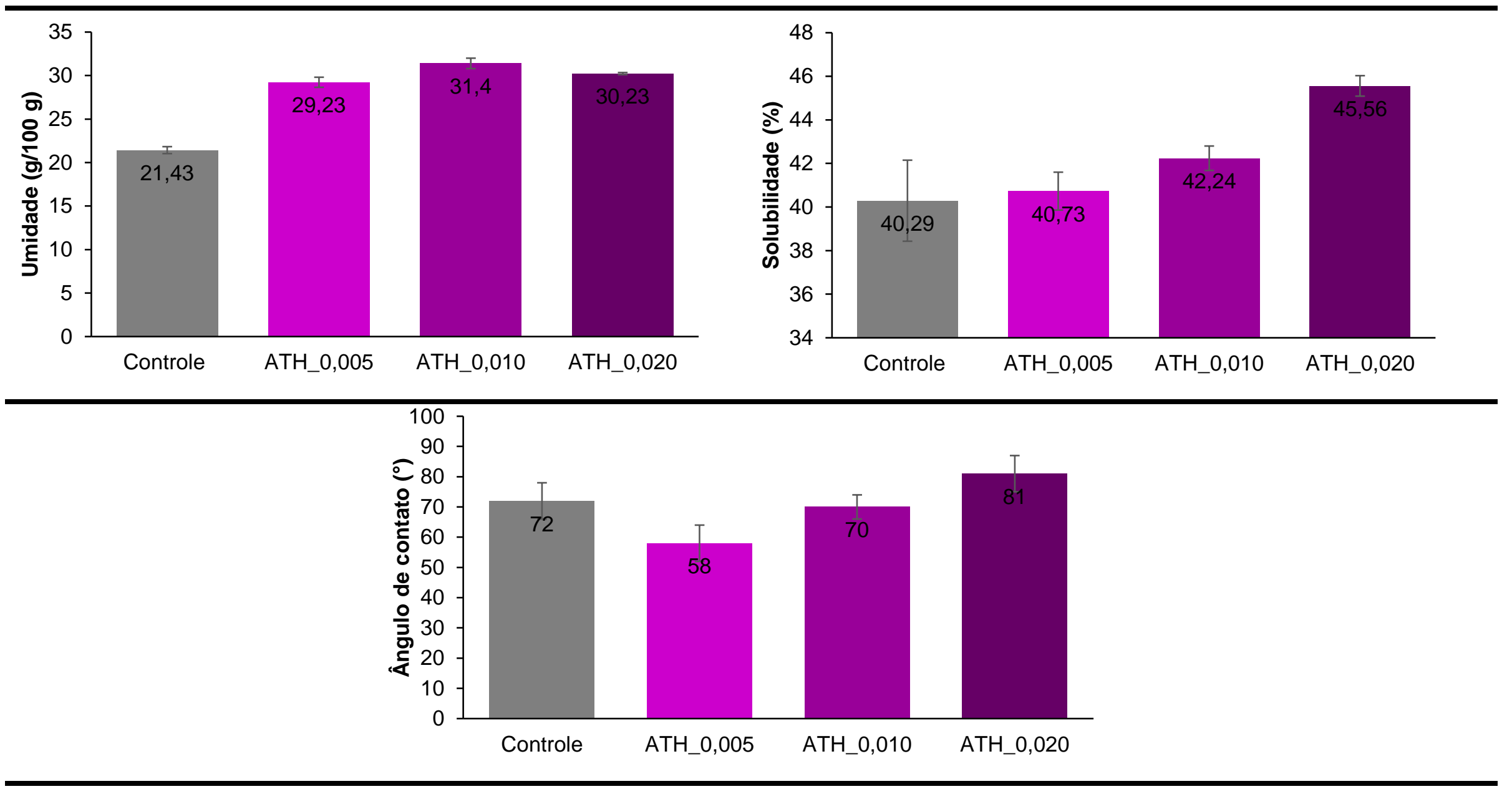

Fonte : Do autor (2018). 
A Tabela 13, e a Figura 28 apresentam os valores médios e os desvios padrão das medidas de diferença total de cor $\left(\Delta E^{*}\right)$ e opacidade (\%) dos filmes de amido termoplástico (TPS) controle, e com incorporação de diferentes concentrações de ATH, obtidos da análise de cor descrita no item 4.2.6.

Tabela 13 - Propriedades de diferença total de cor $\left(\Delta E^{*}\right)$ e opacidade $(\%)$ dos filmes de amido termoplástico (TPS) sem (controle) e com a presença de antocianina (ATH) armazenados a (25 \pm 2$)$ $\stackrel{\circ}{\circ}$ e $75 \%$ UR

\begin{tabular}{ccc}
\hline Filmes & Cor $\left(\Delta \boldsymbol{E}^{*}\right)$ & Opacidade $(\%)$ \\
\hline Controle & $4,0 \pm 0,4^{\mathrm{a}}$ & $96 \pm 1^{\mathrm{a}}$ \\
ATH_0,005 & $34,8 \pm 4,8^{\mathrm{b}}$ & $98 \pm 1^{\mathrm{a}}$ \\
ATH_0,010 & $32,3 \pm 3,8^{\mathrm{b}}$ & $98 \pm 0^{\mathrm{a}}$ \\
ATH_0,020 & $92,6 \pm 0,6^{\mathrm{c}}$ & $98 \pm 0^{\mathrm{a}}$ \\
\hline
\end{tabular}

Letras diferentes entre si, na mesma coluna, indicam diferença significativa entre os filmes, de acordo com o teste de Tukey $(p<0,05)$.

$\Delta \mathrm{E}^{*}$ : calculado considerando como padrão um filme PVC $\left(L^{*}=92,55, a^{*}=-1,18, b^{*}=0,41\right)$.

Fonte: Do autor (2018).

$\mathrm{Na}$ Tabela 13 e Figura 28, é estatisticamente comprovada a diferença total de $\operatorname{cor}\left(\Delta E^{*}\right)$ e fica evidente à olho nu que quando é incorporado antocianina (ATH) no filme de amido termoplástico controle há a predominância da coloração rosa. Os filmes que foram adicionados 0,005 e 0,010 g/100 g do indicador de cor são estatisticamente iguais, e ambos estatisticamente diferentes do filme $A T H \_0,020$. A opacidade de todos os filmes produzidos com ou sem ATH são estatisticamente iguais, quase $100 \%$ opacos. A seguir no item 5.3.4 será descrito e discutido com mais detalhes a influência da diferença total de cor e opacidade desses filmes com ATH, visto que essa propriedade é de extrema importância neste trabalho, pois espera-se que a embalagem produzida apresente alteração da cor ao variar o $\mathrm{pH}$ dos voláteis emitidos pelo alimento condicionado por esta embalagem. 
Figura 27 - Diferença total de cor $\left(\Delta \mathrm{E}^{\star}\right)$ e opacidade (\%) dos filmes de amido termoplástico (TPS) controle e com diferentes concentrações de antocianina

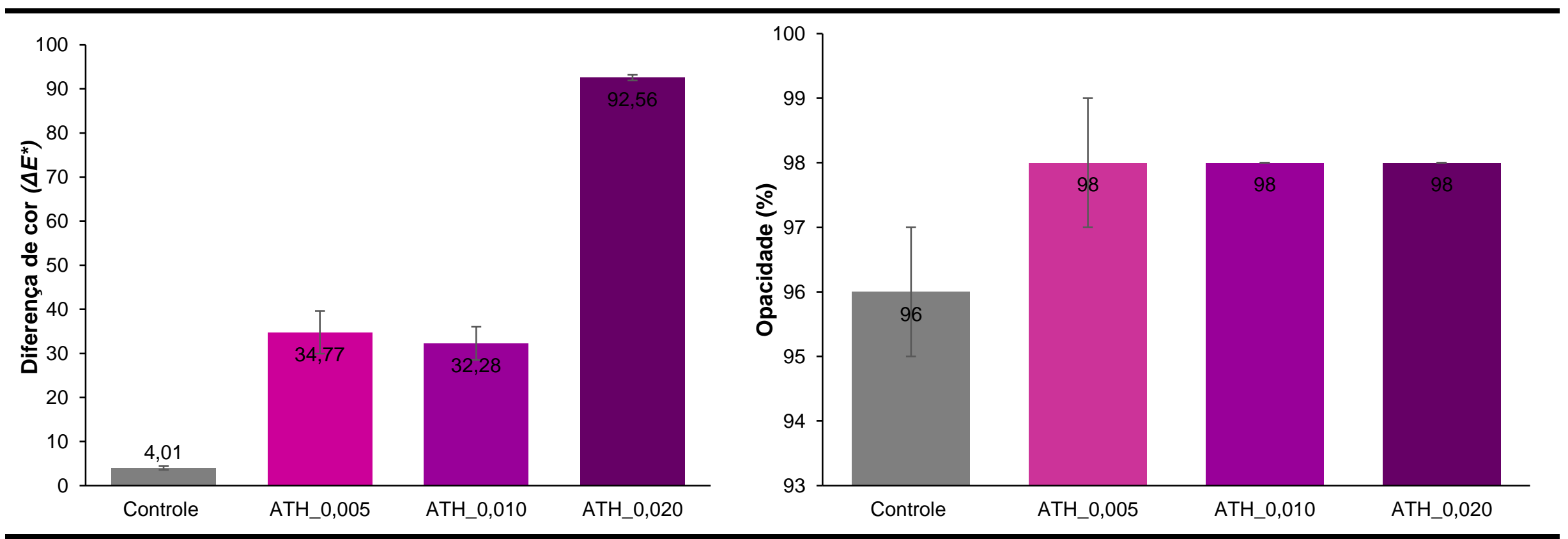

Fonte: Do autor (2018). 


\subsubsection{Avaliação da atividade indicadora de mudança de pH dos filmes de amido termoplástico}

Notou-se que houve alteração da cor dos filmes adicionados com os três teores diferentes de antocianina (ATH), armazenados em duas diferentes temperaturas ao longo do tempo, com mudança visual e nos parâmetros de cor $L^{*}, a^{*}, b^{*}$ e $\Delta E^{*}$ do material, indicando correlação entre alterações de coloração e a deterioração do produto.

As Figuras 29 e 30 mostram as imagens dos filmes de amido termoplástico incorporados com antocianina, durante sua estocagem sob refrigeração $\left(6^{\circ} \mathrm{C}\right)$ e em temperatura ambiente, respectivamente, por três dias, utilizados como embalagem de carne bovina e peixe. Em todas as imagens também é observada a mudança de cor à olho nu.

$\mathrm{O} \mathrm{pH}$ da formulação durante o preparo do filme foi medido e o valor encontrado foi 4,93, influenciando aa cor inicial (dia 0) de todas as formulações (Figuras 29 e 30). Ao decorrer dos dias, independente do filme estar em contato com carne bovina ou de peixe, eles seguem a mesma tendência de cor. Notamos que nos valores de $\mathrm{pH}$ iguais a 6, 7 e 8, a base quinoidal da ATH começam a ficar evidente, mostrando uma tendência de mudança para a cor violeta.

Observando as paletas de cores obtidas para ambas as formulações e comparando-as, percebe-se que a formulação ATH_0,005 apresentou uma maior mudança de cor, levando-nos a concluir que a incorporação de $5 \mathrm{mg}$ de antocianina por $100 \mathrm{~g}$ de filme fornece um material indicador de mudança de $\mathrm{pH}$ mais efetivo. 
Figura 28 - Imagens dos filmes de amido termoplástico incorporados com antocianina, durante sua estocagem sob refrigeração $\left(6{ }^{\circ} \mathrm{C}\right)$, propostos como embalagem de carne bovina e de peixe

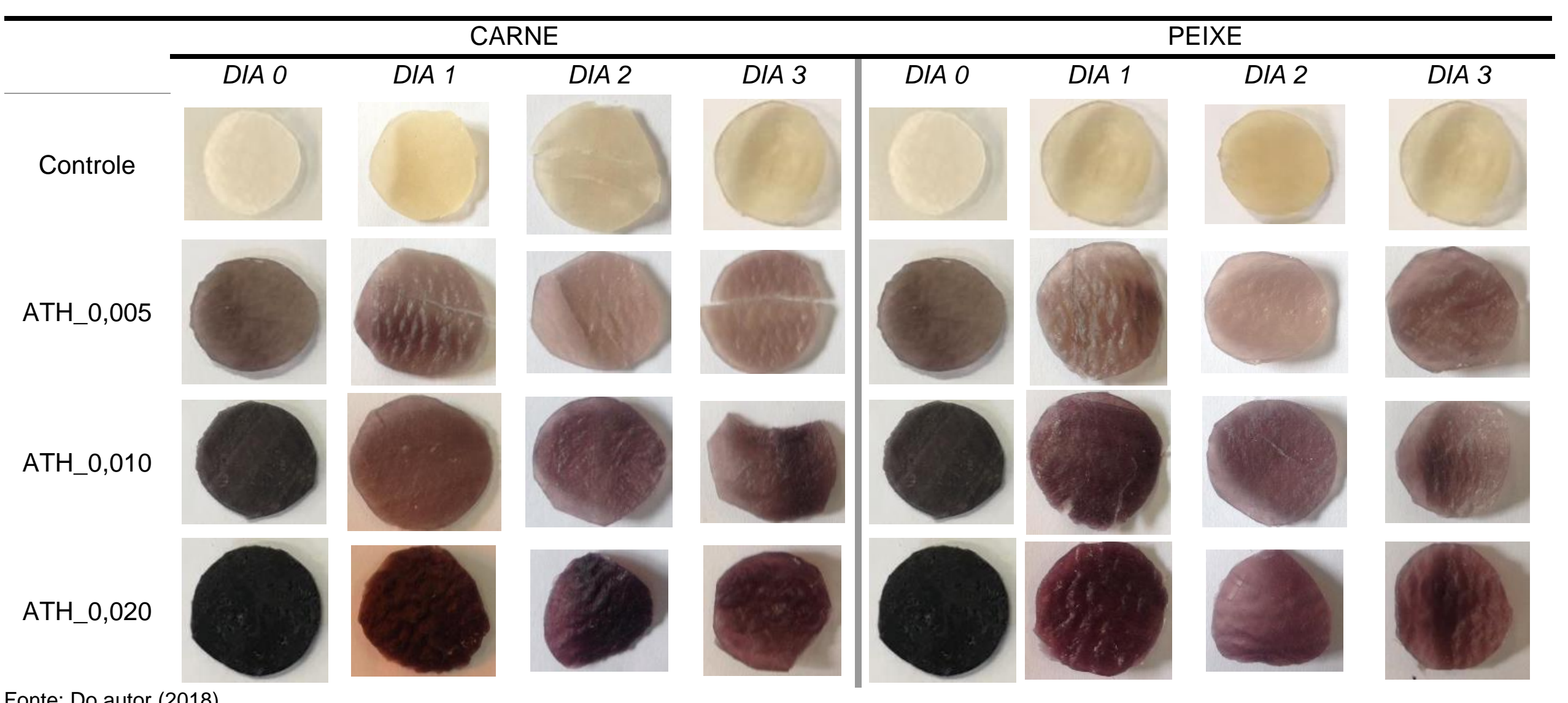

Fonte: Do autor (2018). 
Figura 29 - Imagens dos filmes de amido termoplástico incorporados com antocianina, durante sua estocagem em temperatura ambiente $\left(22{ }^{\circ} \mathrm{C}\right)$, propostos como embalagem de carne bovina e de peixe

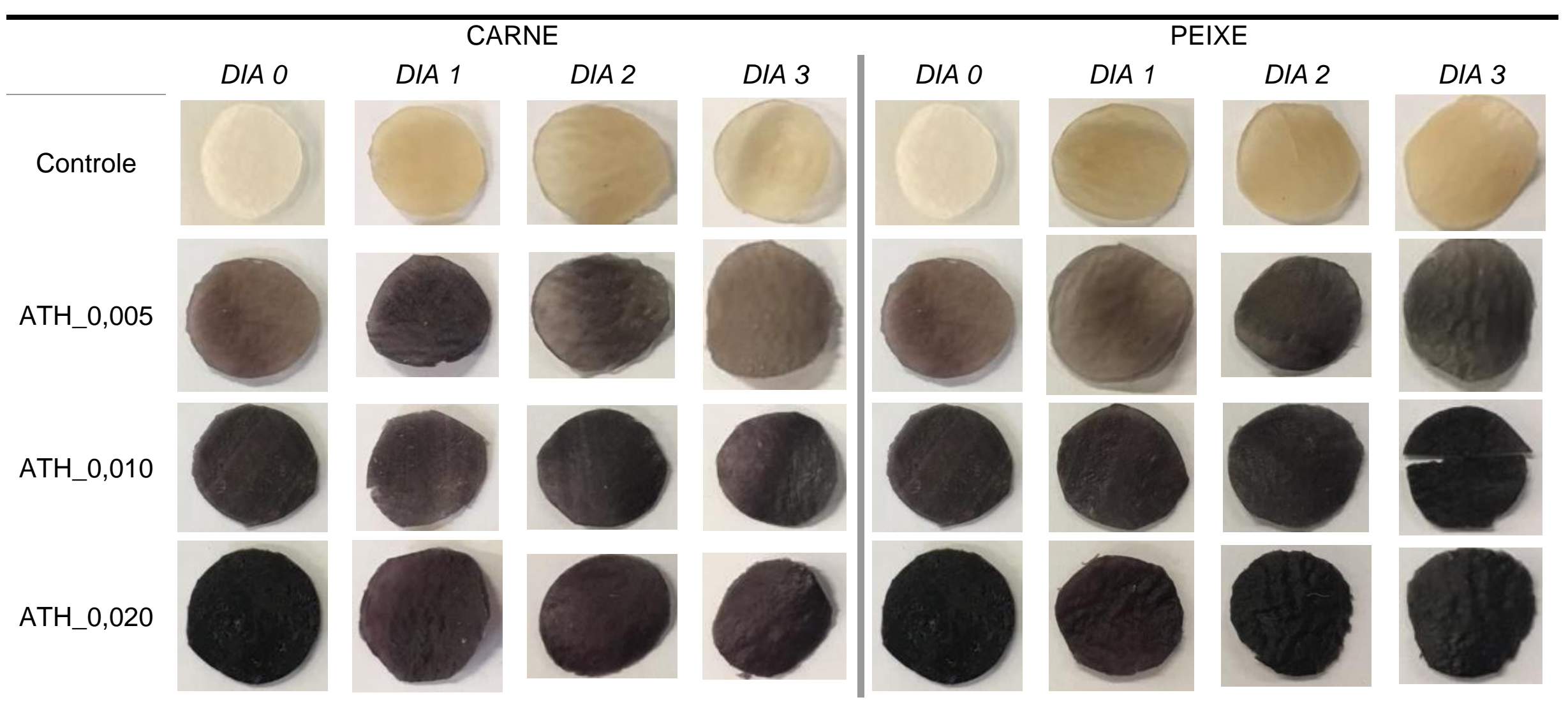

Fonte: Do autor (2018). 
As Tabelas 14 e 15 apresentam o comportamento da diferença total de cor $\Delta E^{*}$, opacidade (\%) e pH dos filmes de amido de mandioca termoplástico sem (controle) e com antocianina (ATH) na presença de carne bovina e de peixe, respectivamente.

A análise de variancia e teste de Tukey indicaram que a concentração de antocinanina dos filmes $A T H \_0,005$ e $A T H \_0,010$ são iguais estatisticamente ao decorrer dos dias, mas os filmes ATH_0,020 e controle diferem entre si e dos demais. $O$ aumento da temperatura de estocagem e do tempo de armazenamento de todos os filmes incrementou significativamente a diferença total de color $\Delta E^{\star}$, quando comparado a do filme controle.

A Tabela 14, que apresenta os dados dos filmes armazenados com carne bovina, evidencia que o filme controle manteve sua cor, como esperado. Já no filme ATH_0,005, o parâmetro $\Delta E^{\star}$ apresentou um declínio significativo a partir do segundo dia e um aumento no terceiro dia, e esta variação é perceptível visualmente nos filmes armazenados em ambas as temperaturas. Para o filme $A T H \_0,010$, o aumento ocorre significamente somente no terceiro dia de estocagem nas mesmas condições, entretanto para o filme $A T H \_0,020$ ocorre um declínio significativo ao decorrer do tempo, para ambas as temperaturas.

Zhang et al. (2018) produziram filmes de amido com antocianina para a detecção de frescura de produtos à base de carne, baseado na mudança de cor do filme. As variações de cor de três diferentes filmes indicadores em duas temperaturas (4 e 25) ${ }^{\circ} \mathrm{C}$ foram analisadas. Os resultados mostraram claramente que os filmes indicadores armazenados a $4{ }^{\circ} \mathrm{C}$ tiveram pequenas mudanças de cor, no entanto, os filmes armazenados a $25^{\circ} \mathrm{C}$ apresentaram maiores mudanças de cor em um prazo de 16 dias. Neste estudo, Zhang et al. (2018) observaram que o valor de $\Delta E^{\star}$ aumentou continuamente com o aumento do período de armazenamento, o filme apresentou uma cor púrpura no início, depois cor marrom às $48 \mathrm{~h}$ e finalmente cor amarela após $72 \mathrm{~h}$. A cor dos filmes indicadores era púrpura, indicando que a carne de porco estava em período fresco às $24 \mathrm{~h}$, com o valor de $\Delta E^{\star}$ de 8,08. Em $48 \mathrm{~h}$, mudou para marrom $\left(\Delta E^{*}=25,42\right)$. Quando a carne começou a deteriorar, a mudança de cor do filme foi vista a olho nu, e o valor de $\Delta E^{\star}$ aumentou para 29,61 com os filmes consistentemente amarelados às $60 \mathrm{~h}$. Os autores concluíram que o filme possui boa capacidade de indicar a frescura da carne de porco. 
Tabela 14 - Diferença total de cor $\left(\Delta E^{*}\right)$, opacidade (\%) e pH dos filmes de amido de mandioca sem (controle) e com a presença de antocianina (ATH) na presença de carne bovina

\begin{tabular}{|c|c|c|c|c|c|c|c|c|c|c|c|c|c|}
\hline \multicolumn{2}{|c|}{ Amostras } & \multicolumn{3}{|c|}{ Dia 0} & \multicolumn{3}{|c|}{ Dia 1} & \multicolumn{3}{|c|}{ Dia 2} & \multicolumn{3}{|c|}{ Dia 3} \\
\hline & $\begin{array}{c}\mathbf{T} \\
{ }^{\circ} \mathbf{C}\end{array}$ & $\Delta E^{*}$ & $\begin{array}{l}\text { Op. } \\
(\%)\end{array}$ & $\mathrm{pH}$ & $\Delta E^{*}$ & Op. (\%) & $\mathrm{pH}$ & $\Delta E^{*}$ & Op. (\%) & $\mathrm{pH}$ & $\Delta E^{*}$ & Op. (\%) & $\mathrm{pH}$ \\
\hline \multirow{2}{*}{ Controle } & 6 & $4,0 \pm 0,4^{\mathrm{aA}}$ & $98 \pm 1^{a}$ & $5,9 \pm 0,1^{\mathrm{aA}}$ & $4,0 \pm 0,4^{\mathrm{aA}}$ & $301-1$ & $6,0 \pm 0,1^{\mathrm{aA}}$ & $4,0 \pm 0,4^{\mathrm{aA}}$ & $99 \pm 1^{\text {aA }}$ & $6,8 \pm 0,1^{\mathrm{aA}}$ & $4,0 \pm 0,4^{\mathrm{aA}}$ & $99 \pm 1^{\mathrm{aA}}$ & $7,2 \pm 0,2^{\mathrm{a} A}$ \\
\hline & 22 & $4,0 \pm 0,4^{\mathrm{aA}}$ & $98 \pm 1^{a}$ & $5,9 \pm 0,1^{\mathrm{aA}}$ & $4,0 \pm 0,4^{\mathrm{aA}}$ & $98 \pm 1^{\mathrm{aA}}$ & $6,9 \pm 0,1^{\mathrm{bB}}$ & $4,0 \pm 0,4^{\mathrm{aA}}$ & $99 \pm 1^{\text {aA }}$ & $8,5 \pm 0,1^{\mathrm{aA}}$ & $4,0 \pm 0,4^{\mathrm{aA}}$ & $98 \pm 1^{\mathrm{aA}}$ & $7,4 \pm 0,1^{\mathrm{aA}}$ \\
\hline \multirow{2}{*}{ ATH_0,005 } & 6 & $34,8 \pm 4,8^{\mathrm{bB}}$ & $98 \pm 1^{a}$ & $5,9 \pm 0,1^{1 \mathrm{~A}}$ & $34,9 \pm 3,9^{\mathrm{bB}}$ & $98 \pm 0^{\mathrm{aA}}$ & $6,0 \pm 0,1^{\mathrm{aA}}$ & $22,6 \pm 4,3^{\mathrm{bB}}$ & $99 \pm 1^{\text {aA }}$ & $6,0 \pm 0,0^{\mathrm{aA}}$ & $33,1 \pm 7,6^{\mathrm{bB}}$ & $97 \pm 4^{\mathrm{aA}}$ & $6,1 \pm 0,2^{\mathrm{bB}}$ \\
\hline & 22 & $34,8 \pm 4,8^{\mathrm{bB}}$ & $98 \pm 1^{a}$ & $5,9 \pm 0,1^{\mathrm{aA}}$ & $34,0 \pm 5,7^{\mathrm{bB}}$ & $98 \pm 0^{\mathrm{aA}}$ & $7,1 \pm 0,4^{\mathrm{bB}}$ & $25,6 \pm 6,8^{\mathrm{bB}}$ & $99 \pm 1^{\text {aA }}$ & $6,7 \pm 0,5^{\mathrm{aA}}$ & $29,2 \pm 2,9^{\mathrm{bB}}$ & $98 \pm 0^{\mathrm{aA}}$ & $7,2 \pm 0,3^{\mathrm{a} A}$ \\
\hline \multirow{2}{*}{ ATH_0,010 } & 6 & $32,3 \pm 3,8^{\mathrm{bB}}$ & $98 \pm 1^{a}$ & $5,9 \pm 0,1^{1} \mathrm{AA}$ & $39,1 \pm 12,8^{\mathrm{cC}}$ & $98 \pm 1^{\mathrm{aA}}$ & $5,9 \pm 0,1^{\mathrm{aA}}$ & $35,1 \pm 7,1^{\mathrm{bC}}$ & $97 \pm 3^{\mathrm{aA}}$ & $6,0 \pm 0,1^{\mathrm{aA}}$ & $48,5 \pm 9,2^{\mathrm{bB}}$ & $98 \pm 1^{\mathrm{aA}}$ & $6,0 \pm 0,2^{\mathrm{bE}}$ \\
\hline & 22 & $32,3 \pm 3,8^{\mathrm{bB}}$ & $98 \pm 1^{a}$ & $5,9 \pm 0,1 \mathrm{aA}$ & $36,7 \pm 1,6 \mathrm{bcB}$ & $97 \pm 1^{\mathrm{aA}}$ & $7,1 \pm 0,6^{\mathrm{abB}}$ & $40,9 \pm 3,5^{\mathrm{bcc}}$ & $98 \pm 1^{\mathrm{aA}}$ & $6,0 \pm 0,9 \mathrm{aA}$ & $43,6 \pm 1,6^{\mathrm{bB}}$ & $97 \pm 4^{\mathrm{aA}}$ & $7,6 \pm 0,2^{a A}$ \\
\hline \multirow{2}{*}{ ATH_0,020 } & 6 & $92,6 \pm 0,6^{\mathrm{cC}}$ & $98 \pm 1^{a}$ & $5,9 \pm 0,1^{\mathrm{aA}}$ & $79,7 \pm 3,0 \mathrm{dD}$ & $99 \pm 0^{a A}$ & $5,9 \pm 0,0^{a A}$ & $67,7 \pm 6,3^{\mathrm{dD}}$ & $98 \pm 1^{\mathrm{aA}}$ & $6,1 \pm 0,3^{\mathrm{a} A}$ & $55,7 \pm 9,8^{\mathrm{bcB}}$ & $98 \pm 1^{\mathrm{aA}}$ & $6,3 \pm 0,1 \mathrm{bE}$ \\
\hline & 22 & $92,6 \pm 0,6^{\mathrm{cc}}$ & $98 \pm 1^{a}$ & $5,9 \pm 0,1^{\mathrm{aA}}$ & $52,5 \pm 5,6^{\mathrm{dD}}$ & $100 \pm 4^{\mathrm{aA}}$ & $6,6 \pm 0,3^{\mathrm{bB}}$ & $52,8 \pm 12,6^{\mathrm{bdC}}$ & $92 \pm 10^{\text {aA }}$ & $7,0 \pm 0,4^{\mathrm{aA}}$ & $56,8 \pm 17,1^{\mathrm{bcB}}$ & $100 \pm 4^{\mathrm{aA}}$ & $6,5 \pm 0,2^{\mathrm{bB}}$ \\
\hline
\end{tabular}

Letras minúsculas diferentes entre si, na mesma coluna, indicam diferença significativa entre os filmes, de acordo com o teste de Tukey ( $p<0,05$ ).

Letras maiúsculas diferentes entre si, na mesma coluna, indicam diferença significativa entre as temperaturas, de acordo com o teste de Tukey $(p<0,05)$.

$\Delta E^{*}$ : calculado considerando como padrão o filme controle $\left(L^{*}=93,70, a^{*}=0,66, b^{*}=3,73\right)$.

Fonte: Do autor (2018). 
Tabela 15 - Diferença total de cor $\left(\Delta E^{\star}\right)$, opacidade (\%) e pH dos filmes de amido de mandioca sem (controle) e com a presença de antocianina (ATH) na presença de peixe

\begin{tabular}{|c|c|c|c|c|c|c|c|c|c|c|c|c|c|}
\hline \multicolumn{2}{|c|}{ Amostras } & \multicolumn{3}{|c|}{ Dia 0} & \multicolumn{3}{|c|}{ Dia 1} & \multicolumn{3}{|c|}{ Dia 2} & \multicolumn{3}{|c|}{ Dia 3} \\
\hline & $\begin{array}{l}\mathbf{T} \\
{ }^{\circ} \mathrm{C}\end{array}$ & $\Delta E^{*}$ & $\begin{array}{l}\text { Op. } \\
\text { (\%) }\end{array}$ & pH & $\Delta E^{*}$ & $\begin{array}{l}\text { Op. } \\
\text { (\%) }\end{array}$ & pH & $\Delta E^{*}$ & $\begin{array}{l}\text { Op. } \\
\text { (\%) }\end{array}$ & pH & $\Delta E^{*}$ & $\begin{array}{l}\text { Op. } \\
\text { (\%) }\end{array}$ & pH \\
\hline \multirow{2}{*}{ Controle } & 6 & $4,0 \pm 0,4^{\mathrm{aA}}$ & $98 \pm 1^{\mathrm{aA}}$ & $6,7 \pm 0,2^{\mathrm{aA}}$ & $4,0 \pm 0,4^{\mathrm{aA}}$ & $\underset{\mathrm{aA}}{99 \pm 1}$ & $6,6 \pm 0,2^{a} \mathrm{~A}$ & $4,0 \pm 0,4^{\mathrm{aA}}$ & $99 \pm 1^{a A}$ & $6,7 \pm 0,2^{\mathrm{aA}}$ & $4,0 \pm 0,4^{\mathrm{aA}}$ & $99 \pm 1^{\mathrm{aA}}$ & $6,7 \pm 0,1^{\mathrm{aA}}$ \\
\hline & 22 & $4,0 \pm 0,4^{\mathrm{aA}}$ & $98 \pm 1^{\mathrm{aA}}$ & $6,7 \pm 0,2^{\mathrm{aA}}$ & $4,0 \pm 0,4^{\mathrm{aA}}$ & $99 \pm 1^{a}$ & $7,6 \pm 0,1^{\mathrm{bB}}$ & $4,0 \pm 0,4^{\mathrm{aA}}$ & $99 \pm 1^{a A}$ & $8,5 \pm 0,1^{\mathrm{bB}}$ & $4,0 \pm 0,4^{\mathrm{aA}}$ & $99 \pm 1^{\mathrm{aAA}}$ & $8,7 \pm 0,1^{\mathrm{bB}}$ \\
\hline \multirow{2}{*}{ ATH_0,005 } & 6 & $34,8 \pm 4,8^{\mathrm{bB}}$ & $98 \pm 1^{\mathrm{aA}}$ & $6,7 \pm 0,2^{\mathrm{aA}}$ & $34,0 \pm 4,7^{\mathrm{bB}}$ & $99 \pm 1^{\mathrm{aA}}$ & $6,6 \pm 0,0^{a} \mathrm{~A}$ & $26,1 \pm 4,6^{\mathrm{bB}}$ & $98 \pm 0^{\mathrm{a} A}$ & $6,6 \pm 0,0^{\mathrm{aA}}$ & $34,6 \pm 0,7^{\mathrm{bB}}$ & $99 \pm 1^{a}$ & $6,7 \pm 0,9^{a A}$ \\
\hline & 22 & $34,8 \pm 4,8^{\mathrm{bB}}$ & $98 \pm 1^{\mathrm{aA}}$ & $6,7 \pm 0,2^{\mathrm{aA}}$ & $27,2 \pm 1,6^{\mathrm{bB}}$ & $99 \pm 1^{\text {aA }}$ & $7,5 \pm 0,1^{\mathrm{bB}}$ & $28,8 \pm 5,5^{\mathrm{bB}}$ & $98 \pm 0^{\mathrm{aA}}$ & $8,3 \pm 0,1^{\mathrm{bB}}$ & $34,5 \pm 6,8^{\mathrm{bB}}$ & $99 \pm 1^{\mathrm{aA}}$ & $8,4 \pm 0,1^{1 \mathrm{BB}}$ \\
\hline \multirow{2}{*}{ ATH_0,010 } & 6 & $32,3 \pm 3,8^{\mathrm{bB}}$ & $98 \pm 1^{\mathrm{aA}}$ & $6,7 \pm 0,2^{\mathrm{aA}}$ & $40,5 \pm 1,0^{\mathrm{bcc}}$ & $99 \pm 1^{\mathrm{aA}}$ & $6,7 \pm 0,0^{\mathrm{a} A}$ & $39,3 \pm 4,4^{\mathrm{bcc}}$ & $97 \pm 0^{\mathrm{aA}}$ & $6,6 \pm 0,0^{\mathrm{aA}}$ & $31,7 \pm 2,0^{\mathrm{bB}}$ & $98 \pm 0^{\mathrm{aA}}$ & $6,7 \pm 0,0^{a A}$ \\
\hline & 22 & $32,3 \pm 3,8^{\mathrm{bB}}$ & $98 \pm 1^{\mathrm{aA}}$ & $6,7 \pm 0,2$ aA & $40,7 \pm 4,6^{\mathrm{bcc}}$ & $98 \pm 1^{\text {aA }}$ & $7,6 \pm 0,0^{\mathrm{bB}}$ & $48,9 \pm 8,2^{\mathrm{bcc}}$ & $97 \pm 0^{\mathrm{a} A}$ & $8,4 \pm 0,1^{\mathrm{bB}}$ & $73,8 \pm 3,9^{\mathrm{cD}}$ & $98 \pm 1^{\mathrm{aA}}$ & $8,3 \pm 0,1^{\mathrm{bB}}$ \\
\hline \multirow{2}{*}{ ATH_0,020 } & 6 & $92,6 \pm 0,6^{\mathrm{cc}}$ & $98 \pm 1^{\mathrm{aA}}$ & $6,7 \pm 0,2$ aA & $52,7 \pm 4,7^{\mathrm{bcD}}$ & $98 \pm 1^{\mathrm{aA}}$ & $6,6 \pm 0,0^{\mathrm{aA}}$ & $40,9 \pm 1,9^{\mathrm{bcc}}$ & $98 \pm 1^{\mathrm{aA}}$ & $6,6 \pm 0,0^{\mathrm{aA}}$ & $42,8 \pm 3,6^{b c}$ & $99 \pm 1^{\mathrm{aA}}$ & $6,7 \pm 0,1^{\mathrm{aA}}$ \\
\hline & 22 & $92,6 \pm 0,6^{\mathrm{cC}}$ & $98 \pm 1^{\mathrm{aA}}$ & $6,7 \pm 0,2^{\mathrm{aA}}$ & $56,9 \pm 16,6 \mathrm{bcCD}$ & $99 \pm 1^{\mathrm{aA}}$ & $7,7 \pm 0,1^{\mathrm{bB}}$ & $85,0 \pm 5,8^{\mathrm{dD}}$ & $98 \pm 1^{\mathrm{aA}}$ & $8,5 \pm 0,1^{\mathrm{bB}}$ & $55,1 \pm 13,3^{\mathrm{bcD}}$ & $98 \pm 1^{\text {aA }}$ & $8,2 \pm 0,0^{\mathrm{bB}}$ \\
\hline
\end{tabular}

Letras minúsculas diferentes entre si, na mesma coluna, indicam diferença significativa entre os filmes, de acordo com o teste de Tukey $(p<0,05)$.

Letras maiúsculas diferentes entre si, na mesma coluna, indicam diferença significativa entre as temperaturas, de acordo com o teste de Tukey $(p<0,05)$. $\Delta E^{*}$ : calculado considerando como padrão o filme controle $\left(L^{*}=93,70, a^{*}=0,66, b^{*}=3,73\right)$.

Fonte: Do autor (2018). 
$\mathrm{Na}$ Tabela 15, nota-se que no filme $A T H \_0,005$ com carne de peixe, armazenado a $6{ }^{\circ} \mathrm{C}$ o parâmetro $\Delta E^{*}$ reduziu no segundo dia e aumentou no terceiro, armazenado a $22^{\circ} \mathrm{C}$ apresentou redução do parâmetro $\Delta E^{\star}$ no primeiro dia e aumento no terceiro. O filme $A T H \_0,010$ armazenado a $6{ }^{\circ} \mathrm{C}$ apresentou inicial aumento do parâmetro $\Delta E^{\star}$ no primeiro dia seguido por redução significativa a partir do terceiro dia, e esta variação é perceptível visualmente nos filmes armazenados em ambas as temperaturas. Para o filme $A T H \_0,010$ armazenado a $22{ }^{\circ} \mathrm{C}$, houve aumento significativo do parâmetro $\Delta E^{\star}$ no terceiro dia de estocagem, entretanto para o filme ATH_0,020 ocorreu um declínio significativo ao decorrer do tempo, para ambas as temperaturas.

Arenas (2012) produziu filme de amido com antocianina e ácido cítrico, para avaliar a frescura de peixe. O autor observou que o aumento da temperatura de estocagem e do tempo de armazenamento de ambos os filmes com pH $(2,8$ e 4,3) aumentou significativamente a diferença total de coloração $\Delta E^{*}$. Em filmes com pH 2,8, o parâmetro $\Delta E^{*}$ apresentou um incremento significativo de 3,60 para 17,95, porém esta variação só foi perceptível visualmente nos filmes com pH 2,8 armazenados a $12{ }^{\circ} \mathrm{C}$ após o segundo dia de estocagem. Em filmes com pH 4,3 o parâmetro $\Delta E^{*}$ aumentou significativamente de 1,16 para 13,58. Os demais estudados apresentaram um comportamento similar. Por outro lado, filmes com pHs $2,8 \_6{ }^{\circ} \mathrm{C}$ não apresentaram uma clara tendência, como alguns dos apresentados neste trabalho.

As mudanças na coloração destes filmes foram confirmadas visualmente pela nítida alteração de cor nos sistemas ao longo do tempo e quantitativamente pelo parâmetro $\Delta E^{*}$ das diferentes formulações e temperaturas de estocagem dos filmes (Figuras 29 e 30). Não foi encontrada na literatura filmes de amido termoplástico produzidos via extrusão e incorporados com antocianina e ácido esteárico.

As Figuras 31 e 32 abaixo, apresentam o comportamento $\Delta E^{*}$ das Tabelas 14 e 15 , respectivamente. 
Figura 30 - Variação da diferença total de cor $\Delta \mathrm{E}^{*}$, dos filmes de amido de mandioca sem (controle) e com a presença de antocianina (ATH) na presença de carne bovina

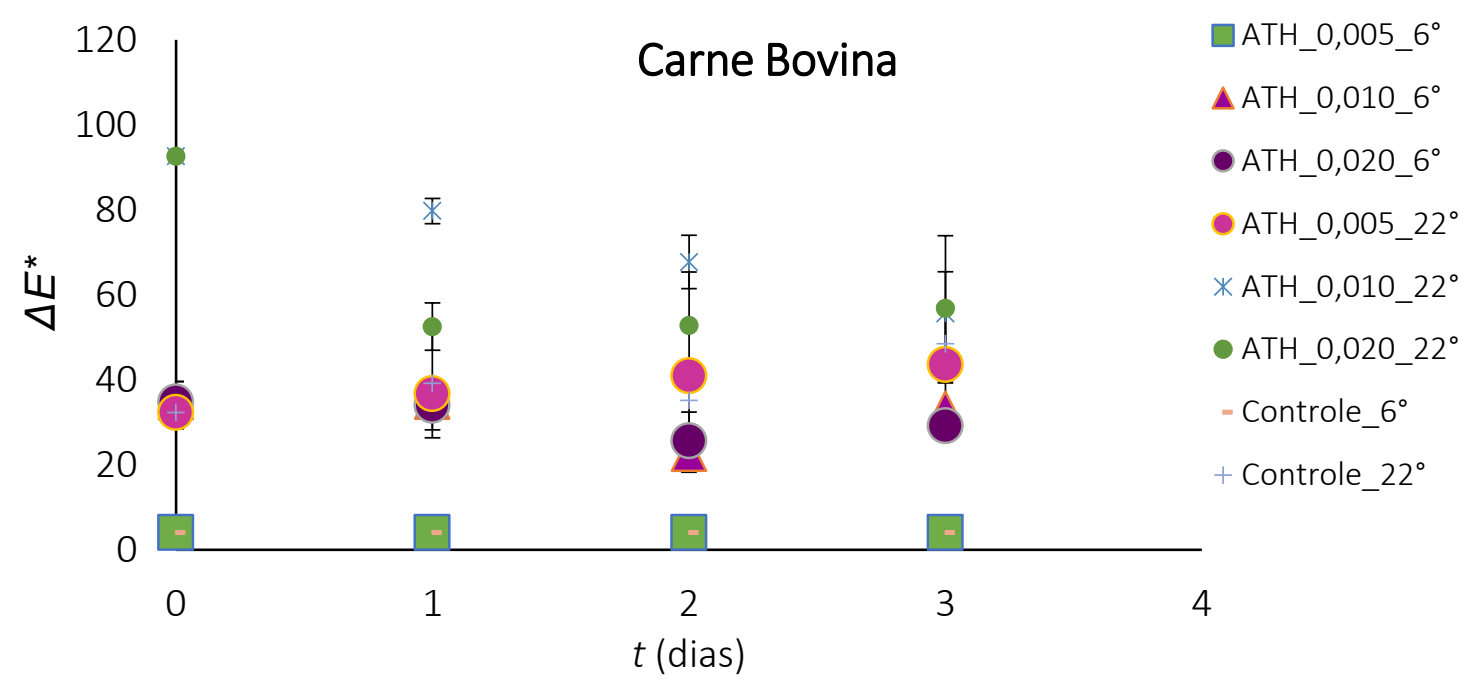

Fonte: Do autor (2018).

Figura 31 - Variação da diferença total de cor $\Delta \mathrm{E}^{*}$, dos filmes de amido de mandioca sem (controle) e com a presença de antocianina (ATH) na presença de peixe

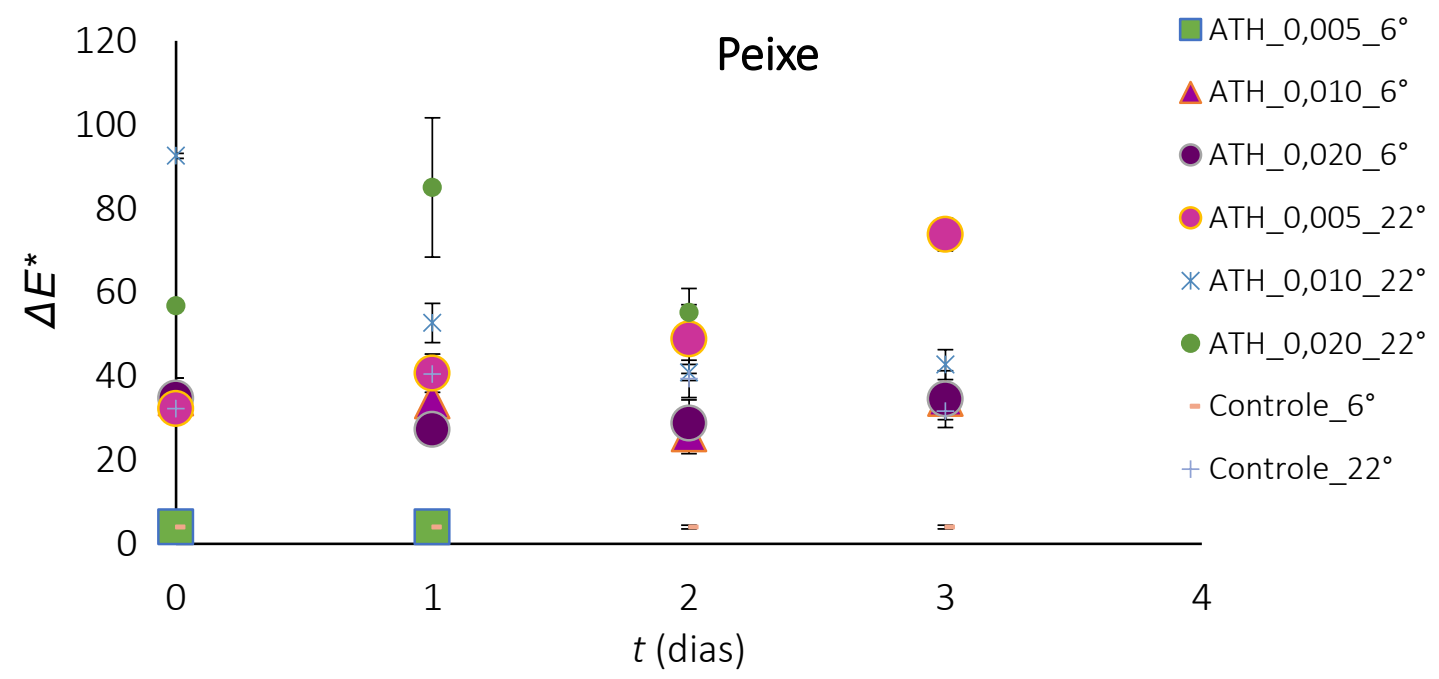

Fonte: Do autor (2018).

Quanto à opacidade, não houve diferença significativa entre as concentrações de antocinanina e temperatura de armazenamento, independentemente do alimento presente, carne bovina ou de peixe. Todos os filmes termoplásticos apresentaram caráter extremamente opaco (em torno de $99 \%$ ). 
Ao avaliar o efeito da temperatura e tempo de armazenamento sobre o $\mathrm{pH}$ da carne bovina, o teste de Tukey mostrou que o incremento de ambos os fatores ocasionaram um acréscimo do pH do mesmo (Tabelas 14 e 15).

A Figura 33 apresenta as mudanças no $\mathrm{pH}$ da carne bovina ao longo do tempo, nas diferentes temperaturas de estocagem. Pode-se observar que o valor médio encontrado de $\mathrm{pH}$ em ambas as temperaturas de estocagem no dia 0 foi de 5,93, os quais mudaram para 6,38 e 7,16 , em temperaturas de $6{ }^{\circ} \mathrm{C}$ e $22{ }^{\circ} \mathrm{C}$, respectivamente, no terceiro dia de armazenamento.

$\mathrm{O} \mathrm{pH}$ da carne é um importante parâmetro de qualidade, já que pode influenciar a cor, a capacidade de retenção de água, a maciez, dentre outros fatores. O valor do $\mathrm{pH}$, após 24 horas do abate ( $\mathrm{pH}$ final), está em torno de 5,80 a 5,50. Quando o pH atinge esses valores ocorre à inibição enzimática e a glicólise anaeróbica cessa (FORREST et al., 1979; PARDI et al., 1993; OSORIO et al., 1998).

A proteína é um dos componentes principais da carne, tornando-a suscetível a bactérias e bolores. Durante a deterioração, vários compostos nitrogenados voláteis, como amônia e aminas, podem ser produzidos (XIAOBO, 2008; ZHANG et al., 2018). A legislação brasileira considera deteriorado e, portanto, impróprio para o consumo carne com pH entre 6,0 e 6,4, segundo o decreto - Lei n. 939.688 , artigo 138, paráfrafo 2 do RIISPOA (BRASIL, 1999). Portanto, podemos concluir por esse parâmetro de $\mathrm{pH}$, que a carne bovina armazenada após três dias na geladeira à temperatura de 6 oC ainda está propria para o consumo.

Figura 32 - pH dos filmes de amido de mandioca sem (controle) e com a presença de antocianina (ATH) na presença de carne bovina

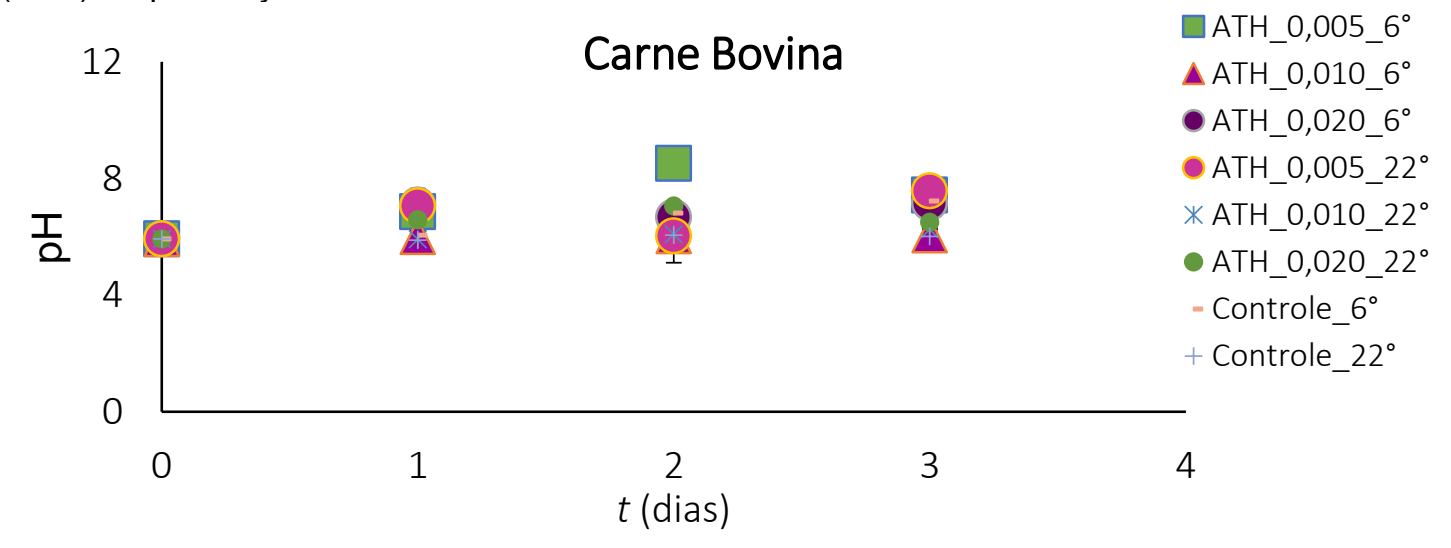

Fonte: Do autor (2018). 
A Figura 34 apresenta as mudanças no $\mathrm{pH}$ do peixe ao longo do tempo, nas diferentes temperaturas de estocagem.

Choi et al. (2017) produziram filmes indicadores de mudança de pH com ágar, amido de batata e antocianina, e verificaram as alterações de cor dos filmes correlacionando com o pH da carne suína. A mudança de $\mathrm{pH}$ das amostras de suínos foi medida à temperatura ambiente $\left(25^{\circ} \mathrm{C}\right.$ ). No início (dia 0 ), o $\mathrm{pH}$ da carne de porco fresca foi de 5,82. Este valor de $\mathrm{pH}$ aumentou para o ponto de deterioração de 6,28 após $20 \mathrm{~h}$ de armazenamento. Quando o ponto de deterioração completo foi alcançado, o pH foi de 7,42 após $48 \mathrm{~h}$ de armazenamento. Um relatório de Huang e Liu (2010) afirma que carne suína é fresca quando o valor do pH está entre 5,18 e 6,12, sub fresco em valores de pH entre 6,13 e 6,16, e o início da deterioração em valores de $\mathrm{pH}$ acima de 6,17. $\mathrm{O}$ aumento dos valores de $\mathrm{pH}$ durante $\mathrm{o}$ armazenamento de carne suína é devido a formação de compostos de deterioração, como amônia e amino complexos com açúcares resultantes da decomposição de substâncias tais como proteínas e lipídeos (Jay \& Shelef, 1978).

Como observado na Figura 34, o valor médio encontrado do $\mathrm{pH}$ em ambas as temperaturas de estocagem no dia 0 foi de 6,75, os quais mudaram para 6,70 e 8,43, em temperaturas de $6{ }^{\circ} \mathrm{C}$ e $22^{\circ} \mathrm{C}$, respectivamente, no terceiro dia de armazenamento.

Figura 33 - pH dos filmes de amido de mandioca sem (controle) e com a presença de antocianina (ATH) na presença de peixe

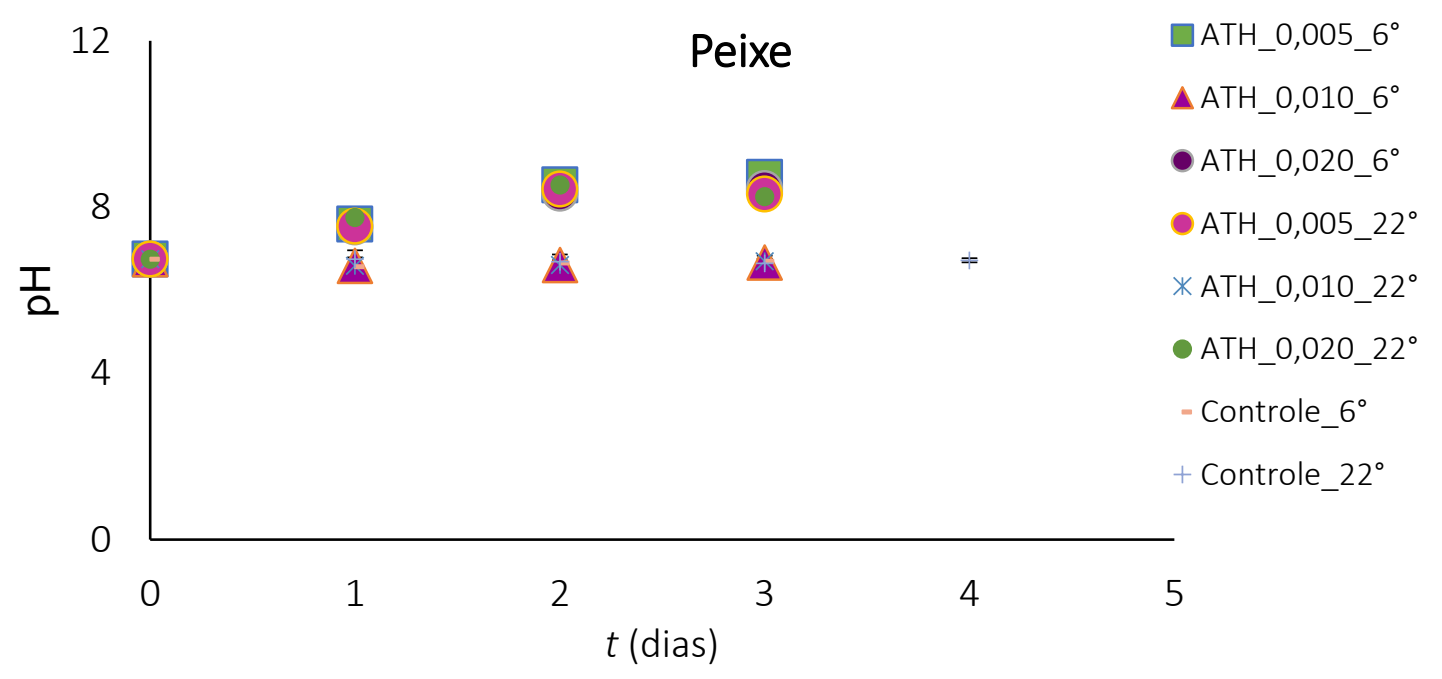

Fonte: Do autor (2018). 
Arenas (2012) encontrou o valor médio de $\mathrm{pH}$ em ambas as temperaturas de estocagem no dia 0 foi de 6,43, os quais mudaram para 7,82 e 8,09, em temperaturas de $6{ }^{\circ} \mathrm{C}$ e $12 \stackrel{\circ}{\circ}$, respectivamente, no terceiro dia de armazenamento

Estes resultados já eram esperados, uma vez que a deterioração do peixe aumenta o pH para níveis mais elevados devido à decomposição de aminoácidos e da ureia e à disseminação oxidativa da creatina (ARENAS, 2012; LEITÃO, 1988).

A conservação do peixe apresenta muitos problemas, uma vez que a decomposição ocorre rapidamente, fazendo com que o peixe seja considerado um dos produtos de origem animal mais susceptível a deterioração (ARENAS, 2012; LEITÃO, 1984).

A legislação brasileira considera deteriorado e, portanto, impróprio para o consumo do peixe com pH da carne externa superior ou igual a 6,8, e da carne interna superior ou igual a 6,5, segundo o decreto - Lei n. -30.691 , artigo 443, parágrafo 2 do RIISPOA (BRASIL, 1952). Em geral, como descrito na legislação brasileira, valores de pH próximo a 6,8 são indicativos de decomposição, à medida que os valores passam de neutros $(\mathrm{pH}=7,0)$, para alcalinos $(\mathrm{pH}>7,0)$, o produto torna-se impróprio para o consumo.

Podemos concluir, que o peixe armazenado após três dias na geladeira à temperatura de $6 \stackrel{\circ}{\circ} \mathrm{C}$ ainda está próprio para o consumo.

Outros fatores importantes a serem considerados, são os parâmetros $L^{*}, a^{*}, b^{*}$ pois são os que influenciam o cálculo do $\Delta E^{*}$.

As Tabelas 16 e 17 mostram os parâmetros de cor $L^{*}, a^{*}, b^{*}$ dos filmes de amido termoplástico incorporados com antocianina, durante sua estocagem sob refrigeração $\left(6^{\circ} \mathrm{C}\right)$ e temperatura ambiente $\left(22^{\circ} \mathrm{C}\right)$, utilizados como embalagem de carne bovina.

A análise estatística indicou que tanto o teor de antocianina quanto o tempo de armazenamento influenciaram significativamente a luminosidade $L^{*}$ de todos os filmes usados na embalagem de carne, que diminuiu conforme aumentou o teor de antocianina, visto que a sua presença, visivelmente, deixou os filmes mais escuros.

A temperatura não alterou significativamente os valores de $L^{*}$ dos filmes, uma vez que armazenados sob refrigeração $\left(6^{\circ} \mathrm{C}\right)$ o valor médio de $L^{*}$ a cada tempo de estocagem se mostrou próximo para os filmes armazenados à temperatura ambiente $\left(22^{\circ} \mathrm{C}\right)$ como mostra a Figura 35. 
Figura 34 - Luminosidade $\left(L^{*}\right)$ dos filmes de amido termoplástico com ATH, ao longo do armazenamento na presença de carne bovina

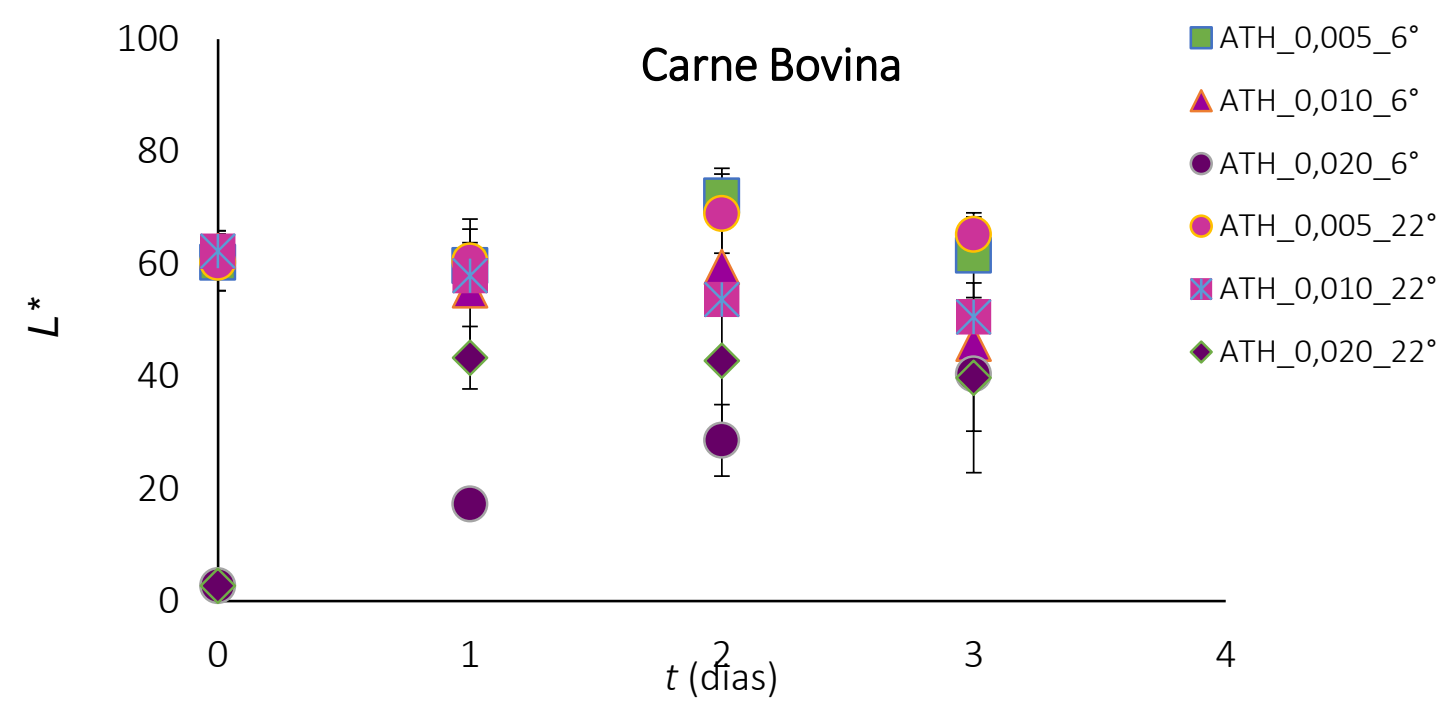

Fonte: Do autor (2018).

Tabela 16- Parâmetros de cor $L^{*}, a^{*}, b^{*}$ dos filmes de amido termoplástico incorporados com antocianina, durante sua estocagem sob refrigeração $\left(6^{\circ} \mathrm{C}\right)$, utilizados como embalagem de carne bovina

\begin{tabular}{|c|c|c|c|c|}
\hline Filme & Fator & $L^{*}$ & $a^{*}$ & $b^{*}$ \\
\hline Controle & $\frac{T\left({ }^{\circ} \mathrm{C}\right)}{6}$ & $93,7 \pm 0,4^{a}$ & $0,7 \pm 0,1^{a}$ & $3,7 \pm 0,7^{a}$ \\
\hline ATH_0,005 & $\begin{array}{c}\text { T (dias) } \\
0 \\
1 \\
2 \\
3 \\
\end{array}$ & $\begin{array}{l}60,3 \pm 5,0^{\mathrm{b}} \\
59,7 \pm 4,1^{\mathrm{b}} \\
72,7 \pm 5,0^{\mathrm{b}} \\
61,5 \pm 7,5^{\mathrm{b}}\end{array}$ & $\begin{array}{l}9,4 \pm 1,7^{a} \\
6,9 \pm 0,4^{a} \\
5,6 \pm 1,1^{a} \\
7,2 \pm 1,2^{a}\end{array}$ & $\begin{array}{l}6,8 \pm 1,5^{\mathrm{a}} \\
7,9 \pm 1,6^{\mathrm{b}} \\
7,8 \pm 1,8^{\mathrm{b}} \\
8,3 \pm 0,2^{\mathrm{b}}\end{array}$ \\
\hline ATH_0,010 & $\begin{array}{c}\mathrm{t} \text { (dias) } \\
0 \\
1 \\
2 \\
3 \\
\end{array}$ & $\begin{array}{c}62,2 \pm 3,7^{\mathrm{b}} \\
55,3 \pm 2,7^{\mathrm{b}} \\
59,5 \pm 8,3^{\mathrm{b}} \\
45,8 \pm 6,3^{\mathrm{bc}}\end{array}$ & $\begin{array}{l}7,9 \pm 0,9^{a} \\
8,2 \pm 1,8^{a} \\
8,5 \pm 1,6^{a} \\
8,4 \pm 1,7^{a}\end{array}$ & $\begin{array}{l}3,4 \pm 0,5^{a} \\
4,5 \pm 0,0^{a} \\
4,3 \pm 0,2^{a} \\
4,4 \pm 0,1^{a}\end{array}$ \\
\hline ATH_0,020 & $\begin{array}{c}\mathrm{t} \text { (dias) } \\
0 \\
1 \\
2 \\
3\end{array}$ & $\begin{array}{c}2,7 \pm 2,2^{\mathrm{d}} \\
17,2 \pm 2,5^{\mathrm{e}} \\
28,6 \pm 6,4^{\mathrm{e}} \\
40,4 \pm 10,1^{\mathrm{bc}}\end{array}$ & $\begin{array}{c}14,3 \pm 11,0^{\mathrm{ab}} \\
23,1 \pm 1,9^{\mathrm{b}} \\
19,3 \pm 0,6^{\mathrm{b}} \\
16,4 \pm 1,5^{\mathrm{ab}}\end{array}$ & $\begin{array}{r}-0,1 \pm 1,2^{\mathrm{ac}} \\
2,4 \pm 2,2^{\mathrm{a}} \\
2,6 \pm 0,5^{\mathrm{a}} \\
3,3 \pm 1,7^{\mathrm{a}}\end{array}$ \\
\hline
\end{tabular}

Letras diferentes entre si, na mesma coluna, indicam diferença significativa entre os filmes ao decorrer dos dias, de acordo com o teste de Tukey $(p<0,05)$.

Fonte: Do autor (2018). 
Tabela 17 - Parâmetros de cor $L^{*}, a^{*}, b^{*}$ dos filmes de amido termoplástico incorporados com antocianina, durante sua estocagem em temperatura ambiente $\left(22^{\circ} \mathrm{C}\right)$, utilizados como embalagem de carne bovina

\begin{tabular}{|c|c|c|c|c|}
\hline Filme & Fator & $L^{*}$ & $a^{*}$ & $\boldsymbol{b}^{\star}$ \\
\hline Controle & $\begin{array}{c}T\left({ }^{\circ} \mathrm{C}\right) \\
22\end{array}$ & $93,7 \pm 0,4^{a}$ & $0,7 \pm 0,1^{a}$ & $3,7 \pm 0,7^{a}$ \\
\hline ATH_0,005 & $\begin{array}{c}\mathrm{t} \text { (dias) } \\
0 \\
1 \\
2 \\
3 \\
\end{array}$ & $\begin{array}{l}60,3 \pm 5,0^{\mathrm{b}} \\
60,5 \pm 5,7^{\mathrm{b}} \\
68,9 \pm 7,0^{\mathrm{b}} \\
65,2 \pm 3,1^{\mathrm{b}} \\
\end{array}$ & $\begin{array}{c}9,4 \pm 1,7^{\mathrm{b}} \\
7,4 \pm 0,9^{\mathrm{b}} \\
5,8 \pm 1,0^{\mathrm{b}} \\
6,1 \pm 1,8^{\mathrm{b}} \\
\end{array}$ & $\begin{array}{l}6,8 \pm 1,5^{\mathrm{b}} \\
5,0 \pm 1,8^{\mathrm{b}} \\
7,3 \pm 1,6^{\mathrm{b}} \\
6,1 \pm 1,6^{\mathrm{b}} \\
\end{array}$ \\
\hline ATH_0,010 & $\begin{array}{c}\mathrm{t} \text { (dias) } \\
0 \\
1 \\
2 \\
3 \\
\end{array}$ & $\begin{array}{l}62,2 \pm 3,7^{\mathrm{b}} \\
57,9 \pm 1,6^{\mathrm{bc}} \\
53,7 \pm 3,0^{\mathrm{c}} \\
50,6 \pm 1,2^{\mathrm{c}} \\
\end{array}$ & $\begin{array}{c}7,9 \pm 0,9^{\mathrm{b}} \\
8,3 \pm 0,1^{\mathrm{b}} \\
8,7 \pm 2,9^{\mathrm{b}} \\
5,5 \pm 3,0^{\mathrm{b}}\end{array}$ & $\begin{array}{c}3,4 \pm 0,5^{a} \\
2,3 \pm 0,8^{a} \\
2,4 \pm 0,5^{\mathrm{a}} \\
0,82 \pm 0,5^{\mathrm{c}}\end{array}$ \\
\hline ATH_0,020 & $\begin{array}{c}\mathrm{t} \text { (dias) } \\
0 \\
1 \\
2 \\
3\end{array}$ & $\begin{array}{c}2,7 \pm 2,2^{\mathrm{d}} \\
43,3 \pm 5,6^{\mathrm{e}} \\
42,8 \pm 12,1^{\text {be }} \\
39,7 \pm 16,9^{\text {be }}\end{array}$ & $\begin{array}{c}14,3 \pm 11,0^{\mathrm{c}} \\
15,4 \pm 0,9^{\mathrm{cd}} \\
14,4 \pm 3,8^{\mathrm{d}} \\
18,2 \pm 4,4^{\mathrm{c}}\end{array}$ & $\begin{array}{c}-0,3 \pm 0,9^{c d} \\
3,0 \pm 0,7^{a} \\
1,4 \pm 0,3^{c} \\
2,70,3^{c}\end{array}$ \\
\hline
\end{tabular}


Nas Figuras 36 e 37, é possível observar a variação dos parâmetros $a^{*}$ e $b^{*}$ dos filmes ao longo do período de armazenamento.

O parâmetro $a^{*}$ é um dos fatores mais importantes neste trabalho de avaliação da atividade indicadora de $\mathrm{pH}$ dos filmes biodegradáveis incorporados com antocianina, devido à evidente componente vermelha presente nos mesmos, valores positivos desse parâmetro foram medidos para todas as formulações com diferentes concentrações de antocianina.

Nota-se que a única formulação que ocorre um aumento gradual do parâmetro $a^{*}$ (eixo verde - vermelho) ao decorrer dos dias de armazenamento é a ATH_0,010 em temperatura de $6{ }^{\circ} \mathrm{C}$, para as demais formulações independentemente da temperatura de armazenamento, não houve alteração do parâmetro $a^{*}$. Com relação ao parâmetro $b^{*}$, todas as formulações apresentaram valores positivos indicando a presença de tons amarelos, com exceção da formulação $A T H \_0,020$ que no dia 0 armazenada a temperatura de $22{ }^{\circ} \mathrm{C}$ apresentou valores negativos de $b^{*}$, indicando a presença de tons azuis e que com o passar dos dias apresentou tons amarelos.

Figura 35 - Parâmetro $a^{*}$ dos filmes de amido termoplástico com ATH, ao londo do armazenamento na presença de carne bovina

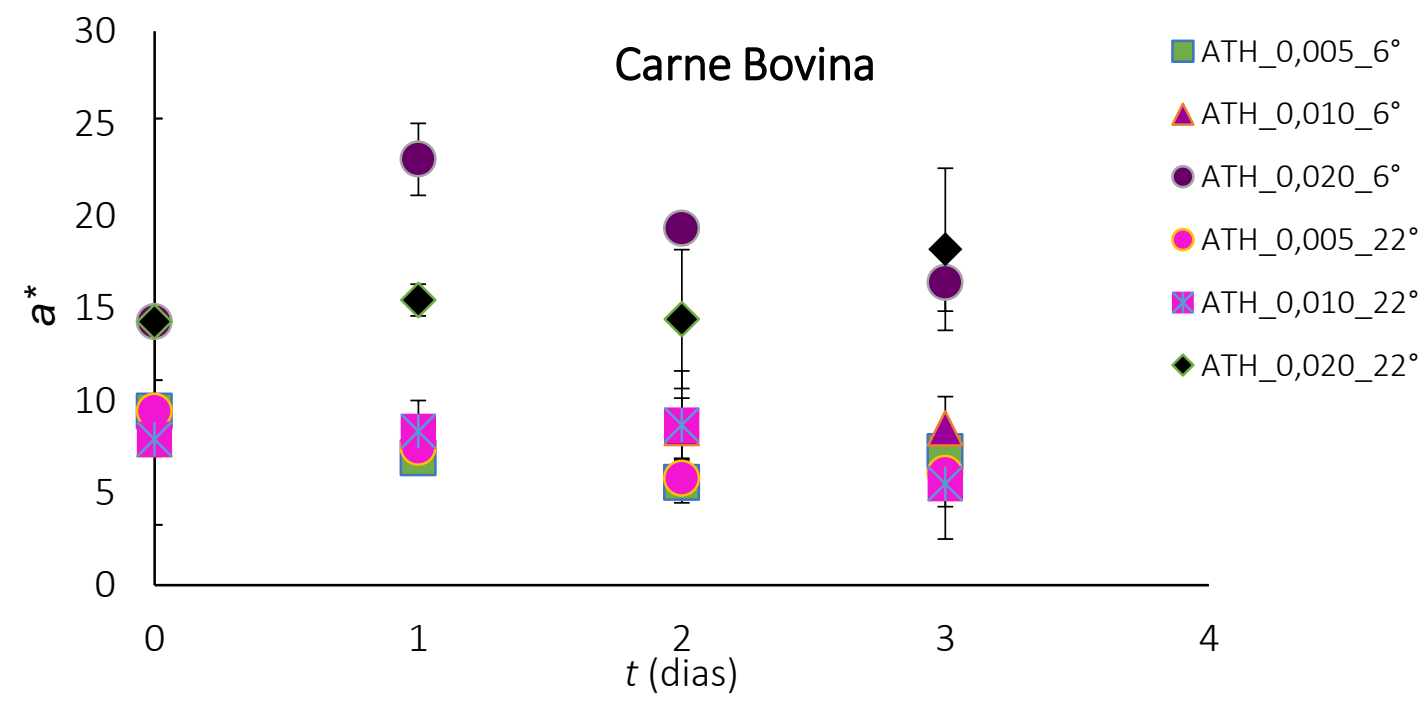

Fonte: Do autor (2018). 
Figura 36 - Parâmetro $b^{*}$ dos filmes de amido termoplástico com ATH, ao longo do armazenamento na presença de carne bovina

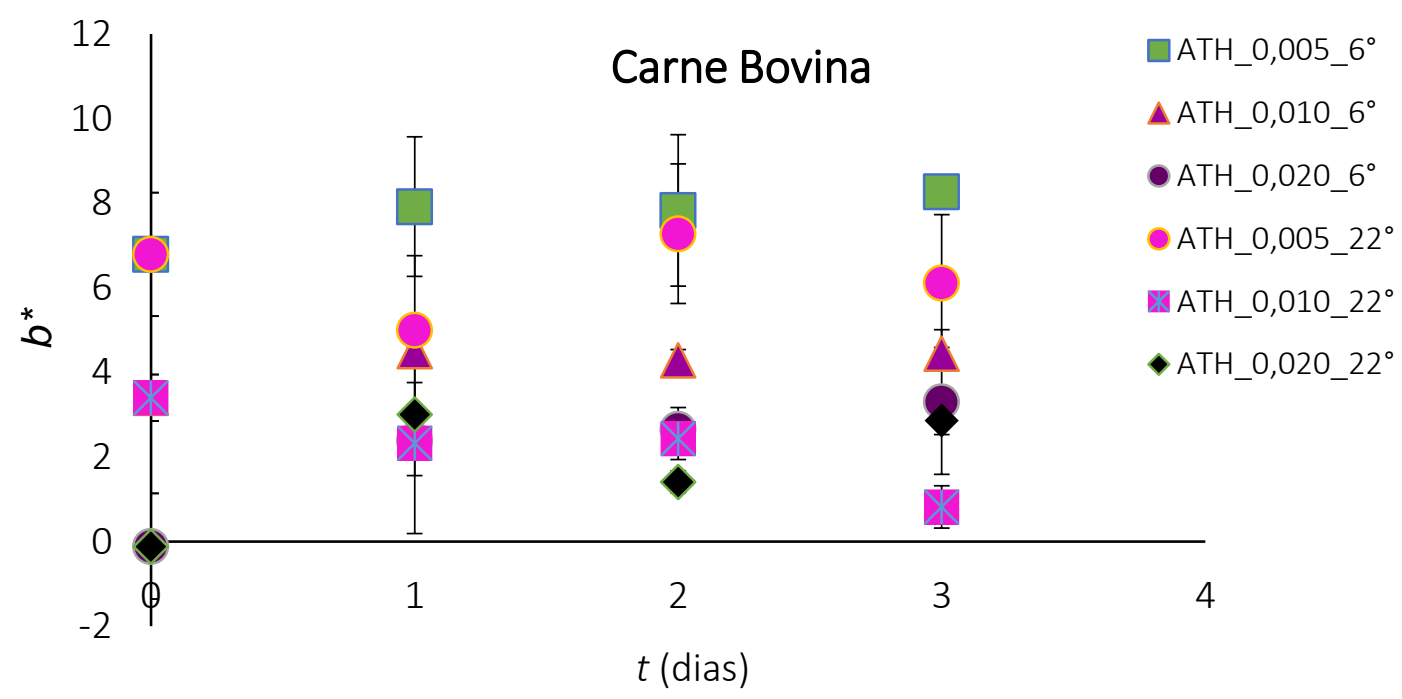

Fonte: Do autor (2018).

Choi et al. (2017) mediram os paramentos $L^{*}, a^{*}$ e $b^{*}$ dos filmes indicadores de mudança de $\mathrm{pH}$ com ágar, amido de batata e antocianina correlacionando o $\mathrm{pH}$, e obtiveram variações mais drásticas nestes parâmetros que os obtidos neste trabalho. Inicialmente os filmes apresentaram a coloração vermelha e quando a carne de porco era fresca, com um valor de $\mathrm{pH}$ de $5,78\left(L^{*}=64,25, a^{*}=12,23\right.$ e $\left.b^{*}=6,72\right)$. A cor do filme indicador de $\mathrm{pH}$ mudou de vermelho para rosa com o tempo de armazenamento. No entanto, o filme indicador de $\mathrm{pH}$ não teve mudanças drásticas de cor quando o valor do $\mathrm{pH}$ aumentou para 6,1 em $12 \mathrm{~h},\left(L^{*}=69,84, a^{*}=7,77\right.$, e $\left.b^{*}=11,81\right)$. Posteriormente, a cor do filme drasticamente mudou de rosa para verde quando o $\mathrm{pH}$ da carne de porco atingiu 6,28 após 20 h. Finalmente, mudou completamente para verde no $\mathrm{pH} 7,5$, sugerindo assim o ponto completo de deterioração da carne suína $\left(L^{*}=81,55, a^{*}=1,50\right.$ e $\left.b^{*}=8,29\right)$.

As Tabelas 18 e 19 apresentam os parâmetros de cor $L^{*}, a^{*}, b^{*}$ dos filmes de amido termoplástico incorporados com antocianina, durante sua estocagem sob refrigeração $\left(6^{\circ} \mathrm{C}\right)$ e temperatura ambiente $\left(22^{\circ} \mathrm{C}\right)$, utilizados como embalagem para peixe.

Nesse caso, a análise estatística também indicou que tanto o teor de antocianina quanto a temperatura e o tempo de armazenamento influenciaram significativamente aa luminosidade $\left(L^{*}\right)$ de todos os filmes usados na embalagem de peixe. $O$ valor de $L^{*}$ diminuiu com o aumento do teor de antocianina, visto que a sua presença deixa os filmes mais escuros, como observado a olho nu. 
A temperatura de estocagem não alterou significativamente a luminosidade $\left(L^{*}\right)$ dos filmes com as seguintes concentrações: $A T H \_0,005$ e $A T H \_0,010$, uma vez que armazenados sob refrigeração $\left(6^{\circ} \mathrm{C}\right)$ o valor médio de $L^{*}$ se mostrou próximo para os filmes armazenados à temperatura ambiente $\left(22^{\circ} \mathrm{C}\right)$. Para o filme $A T H \_0,020$, na temperatura de armazenamento de $6{ }^{\circ} \mathrm{C}$ o valor da luminosidade diminuiu, ou seja, o filme ficou mais escuro, ao longo do armazenamento seu valor aumentou significativamente tornando-o mais claro. O mesmo ocorreu a temperatura de $22{ }^{\circ} \mathrm{C}$, porém instavelmente, pois aumentou (dias 1 e 3) e diminuiu (dia 2). Na Figura 38 é possível observar o valor do parâmetro $L^{*}$ dos filmes ao longo do tempo de estocagem à temperatura ambiente e sob refrigeração.

Figura 37 - Luminosidade $L^{*}$ dos filmes de amido termoplástico com ATH, ao longo do armazemanteo na presença de peixe

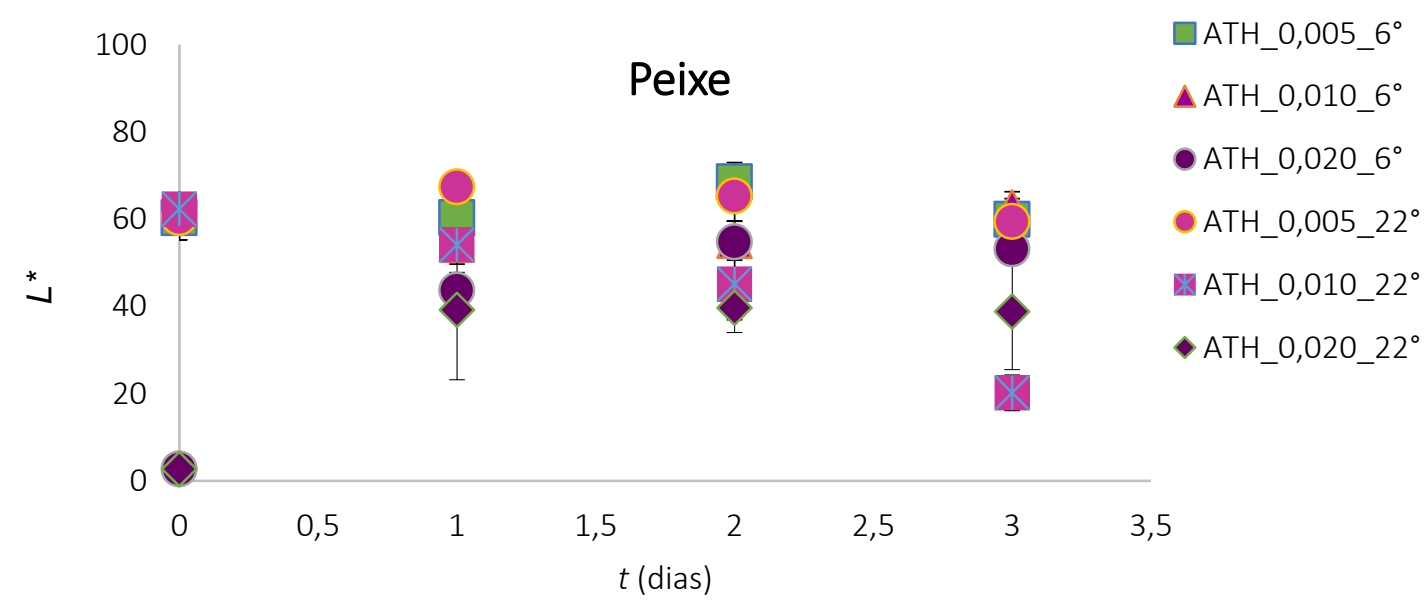

Fonte: Do autor (2018). 
Tabela 18- Parâmetros de cor $L^{*}, a^{*}, b^{*}$ dos filmes de amido termoplástico incorporados com antocianina, durante sua estocagem sob refrigeração $\left(6^{\circ} \mathrm{C}\right)$, utilizados como embalagem de peixe

\begin{tabular}{|c|c|c|c|c|}
\hline Filme & Fator & $L^{*}$ & $a^{*}$ & $b^{*}$ \\
\hline Controle & $\frac{T\left({ }^{\circ} \mathrm{C}\right)}{6}$ & $93,7 \pm 0,4^{a}$ & $0,7 \pm 0,1^{a}$ & $3,7 \pm 0,7^{a}$ \\
\hline ATH_0,005 & $\begin{array}{c}\mathrm{t} \text { (dias) } \\
0 \\
1 \\
2 \\
3 \\
\end{array}$ & $\begin{array}{c}60,3 \pm 5,0^{\mathrm{b}} \\
60,3 \pm 4,6^{\mathrm{b}} \\
68,5 \pm 4,4^{\mathrm{b}} \\
59,9 \pm 0,9^{\mathrm{bc}}\end{array}$ & $\begin{array}{l}9,4 \pm 1,7^{b} \\
6,4 \pm 0,9^{c} \\
5,8 \pm 0,9^{c} \\
7,7 \pm 0,4^{b}\end{array}$ & $\begin{array}{l}6,8 \pm 1,5^{\mathrm{b}} \\
7,8 \pm 1,2^{\mathrm{b}} \\
8,5 \pm 1,0^{\mathrm{b}} \\
6,2 \pm 1,0^{\mathrm{b}} \\
\end{array}$ \\
\hline ATH_0,010 & $\begin{array}{c}\mathrm{t} \text { (dias) } \\
0 \\
1 \\
2 \\
3 \\
\end{array}$ & $\begin{array}{l}62,2 \pm 3,7^{\mathrm{b}} \\
54,1 \pm 1,1^{\mathrm{c}} \\
55,1 \pm 4,4^{\mathrm{c}} \\
62,7 \pm 2,0^{\mathrm{b}} \\
\end{array}$ & $\begin{array}{l}7,9 \pm 0,9^{b} \\
9,3 \pm 0,9^{b} \\
8,1 \pm 0,4^{b} \\
7,1 \pm 0,5^{b}\end{array}$ & $\begin{array}{l}3,4 \pm 0,5^{a} \\
3,5 \pm 1,2^{a} \\
4,8 \pm 0,6^{a} \\
4,9 \pm 0,3^{a}\end{array}$ \\
\hline ATH_0,020 & $\begin{array}{c}T \text { (dias) } \\
0 \\
1 \\
2 \\
3\end{array}$ & $\begin{array}{c}2,7 \pm 2,2^{\mathrm{d}} \\
43,6 \pm 4,2^{\mathrm{e}} \\
54,8 \pm 1,5^{\mathrm{c}} \\
53,1 \pm 2,2^{\mathrm{c}}\end{array}$ & $\begin{array}{l}14,3 \pm 11,0^{\mathrm{d}} \\
17,1 \pm 2,5^{\mathrm{ed}} \\
13,0 \pm 1,6^{\mathrm{ed}} \\
14,0 \pm 2,0^{\mathrm{ed}}\end{array}$ & $\begin{array}{l}-0,1 \pm 1,2^{c} \\
4,0 \pm 0,2^{a} \\
5,4 \pm 0,7^{b} \\
5,3 \pm 0,5^{b}\end{array}$ \\
\hline
\end{tabular}

Letras diferentes entre si, na mesma coluna, indicam diferença significativa entre os filmes, de acordo com o teste de Tukey $(p<0,05)$.

Fonte: Do autor (2018). 
Tabela 19 - Parâmetros de cor $L^{*}, a^{*}, b^{*}$ dos filmes de amido termoplástico incorporados com antocianina, durante sua estocagem em temperatura ambiente $\left(22^{\circ} \mathrm{C}\right)$, utilizados como embalagem de peixe

\begin{tabular}{|c|c|c|c|c|}
\hline Filme & Fator & $L^{*}$ & $a^{*}$ & $b^{*}$ \\
\hline Controle & $\frac{T\left({ }^{\circ} \mathrm{C}\right)}{22}$ & $93,7 \pm 0,4^{\mathrm{a}}$ & $0,7 \pm 0,1^{\mathrm{a}}$ & $3,7 \pm 0,7^{\mathrm{a}}$ \\
\hline ATH_0,005 & $\begin{array}{c}\mathrm{t} \text { (dias) } \\
0 \\
1 \\
2 \\
3\end{array}$ & $\begin{array}{l}60,3 \pm 5,0^{\mathrm{b}} \\
67,3 \pm 1,5^{\mathrm{b}} \\
65,2 \pm 5,7^{\mathrm{b}} \\
59,4 \pm 6,8^{\mathrm{b}}\end{array}$ & $\begin{array}{c}9,4 \pm 1,7^{b} \\
6,4 \pm 0,2^{c} \\
3,9 \pm 0,6^{d} \\
3,6 \pm 0,5^{d}\end{array}$ & $\begin{array}{l}6,8 \pm 1,5^{\mathrm{b}} \\
7,2 \pm 1,0^{\mathrm{b}} \\
6,3 \pm 1,7^{\mathrm{b}} \\
6,7 \pm 0,6^{\mathrm{b}}\end{array}$ \\
\hline ATH_0,010 & $\begin{array}{c}\mathrm{t} \text { (dias) } \\
0 \\
1 \\
2 \\
3 \\
\end{array}$ & $\begin{array}{c}62,2 \pm 3,6^{\mathrm{b}} \\
54,1 \pm 4,4^{\mathrm{b}} \\
45,0 \pm 8,1^{\mathrm{cb}} \\
20,2 \pm 4,0^{\mathrm{d}}\end{array}$ & $\begin{array}{c}7,9 \pm 0,9^{\mathrm{bc}} \\
9,8 \pm 1,1^{\mathrm{b}} \\
3,7 \pm 0,8^{\mathrm{d}} \\
5,2 \pm 1,6^{\mathrm{d}} \\
\end{array}$ & $\begin{array}{l}3,4 \pm 0,5^{\mathrm{a}} \\
1,2 \pm 1,0^{\mathrm{c}} \\
0,3 \pm 1,8^{\mathrm{c}} \\
0,2 \pm 1,5^{\mathrm{c}} \\
\end{array}$ \\
\hline ATH_0,020 & $\begin{array}{c}\mathrm{t} \text { (dias) } \\
0 \\
1 \\
2 \\
3\end{array}$ & $\begin{array}{c}2,7 \pm 2,2^{\mathrm{e}} \\
39,1 \pm 16,0^{\mathrm{bc}} \\
39,6 \pm 5,6^{\mathrm{bc}} \\
38,8 \pm 13,3^{\mathrm{bc}}\end{array}$ & $\begin{array}{c}14,3 \pm 11,0^{\mathrm{e}} \\
15,4 \pm 4,4^{\text {ef }} \\
10,7 \pm 4,0^{\text {bf }} \\
5,9 \pm 0,5^{\mathrm{d}}\end{array}$ & $\begin{array}{c}-0,1 \pm 1,2^{c} \\
2,5 \pm 2,3^{c} \\
-2,7 \pm 1,2^{c d} \\
2,5 \pm 0,8^{c}\end{array}$ \\
\hline
\end{tabular}

Letras diferentes entre si, na mesma coluna, indicam diferença significativa entre os filmes, de acordo com o teste de Tukey $(p<0,05)$.

Fonte: Do autor (2018). 
A Figura 39 apresenta uma tendência de queda no valor do parâmetro $a^{*}$ ao longo do tempo de estocagem à temperatura ambiente e geladeira.

Figura 38 - Parâmetro $a^{*}$ dos filmes de amido termoplástico com ATH, ao londo do armazenamento na presença de peixe

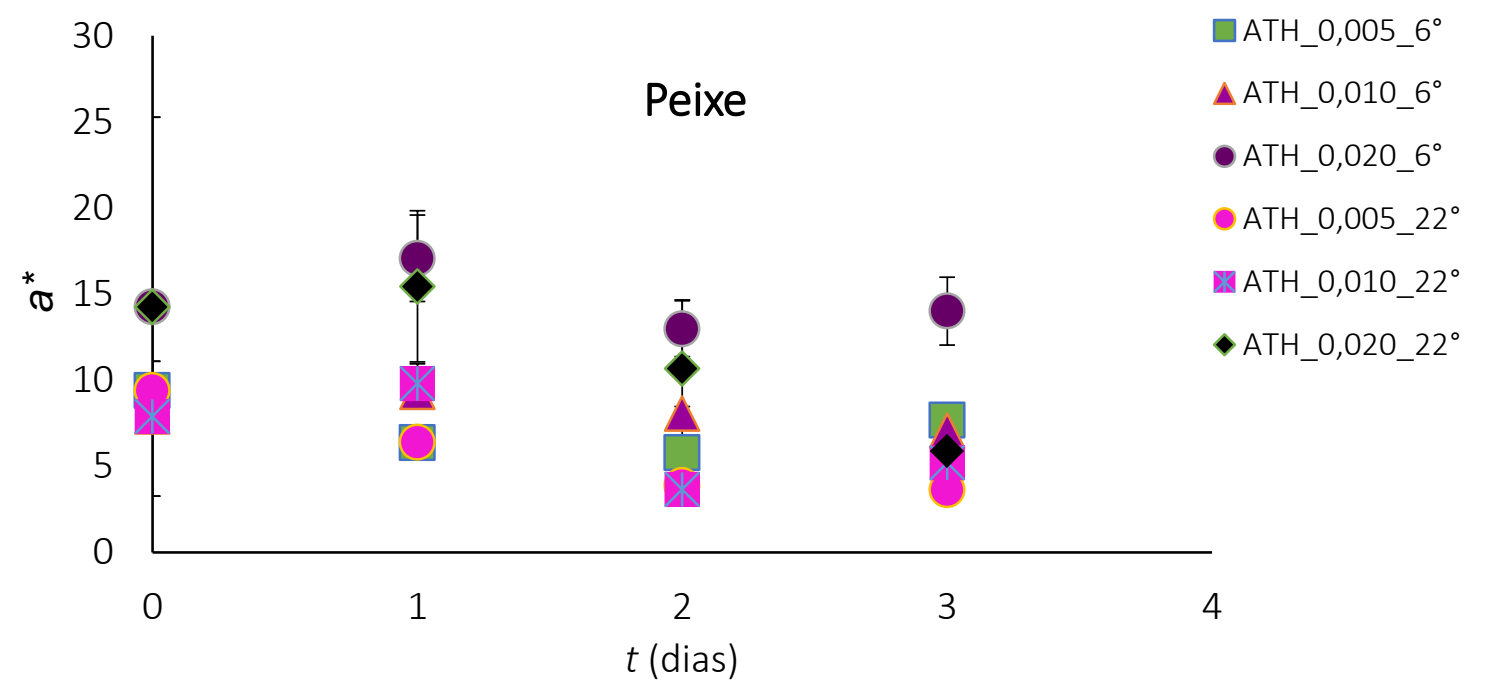

Fonte : Do autor (2018).

Este comportamento era esperado, uma vez que quando o peixe se deteriora, aminas voláteis básicas como trimetilamina (TMA), amônia $\left(\mathrm{NH}_{3}\right)$ e dimetilamina (DMA) conhecidas como nitrogênio básico volátil total (TVB-N, do inglês Total Volatile Basic Nitrogen) são liberadas indicando que o peixe passou da sua fase inicial de frescura (PACQUIT et al., 2006). Essas substâncias apresentam um $\mathrm{pH}$ básico detectado pelas antocianinas contidas na embalagem, obtendo como resposta a mudança de cor das mesmas, com perda significativa da sua componente vermelha (ARENAS, 2012).

A Figura 40 apresenta a variação do parâmetro $b^{*}$ ao longo do tempo de estocagem à temperatura ambiente e geladeira.

No início dos testes, somente para a formulação $A T H \_0,020$ os valores de $b^{*}$ são negativos (eixo azuis) e com o tempo mudam para valores positivos (eixo amarelos). Isto ocorreu possivelmente devido a presença de nitrogênio básico volátil total (TVB-N) em decorrência da deterioração do peixe, tornando o meio alcalino. 
Como citado na revisão bibliográfica, com o aumento do $\mathrm{pH}$ ocorre a desprotonação do cátion flavílio da antocianina que resulta na formação da base quinoidal, azul ou violeta, e em paralelo ocorre a hidratação do cátion flavílio, gerando a pseudobase incolor ou carbinol que atinge o equilíbrio lentamente com a chalcona incolor ou amarelo pálido (BROUILLARD; DUBOIS, 1977).

Figura 39 - Parâmetro $b^{*}$ dos filmes de amido termoplástico com ATH, ao longo do armazenamento na presença de peixe

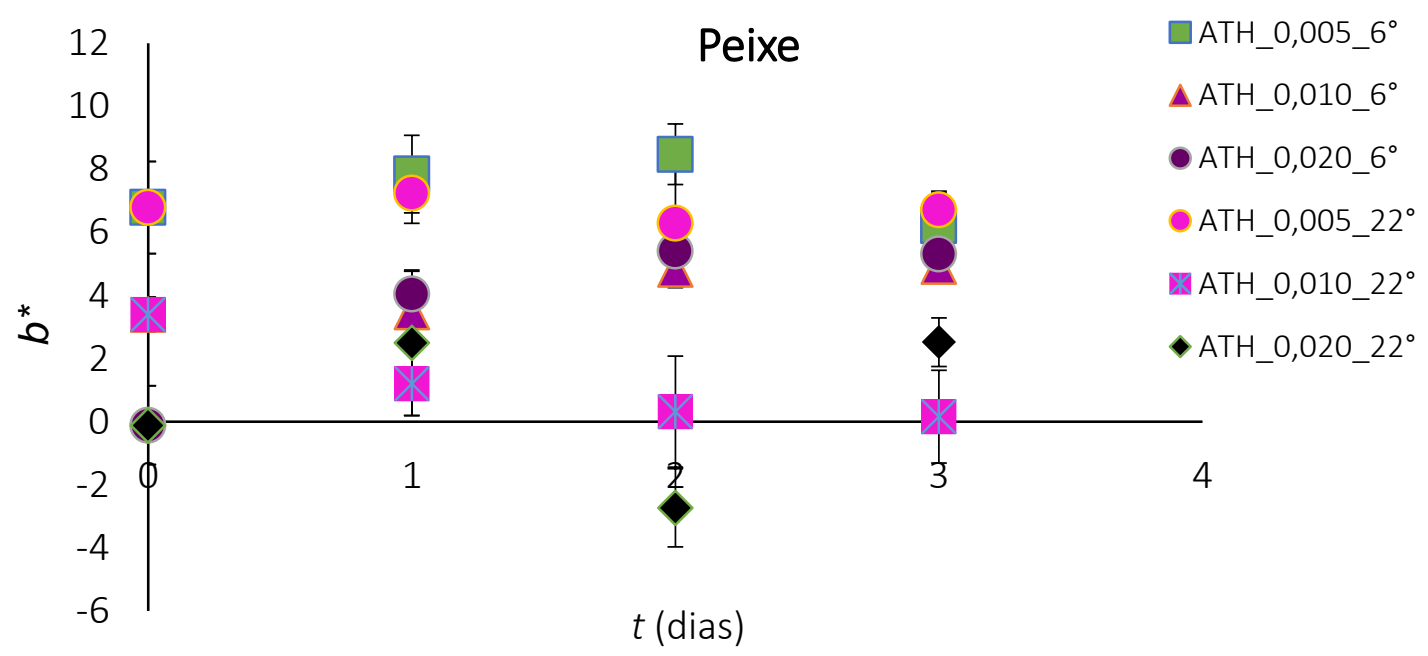

Fonte : Do autor (2018).

Arenas (2012), já citado neste trabalho, produziu filmes de amido com antocianina com pH $(2,8$ e 4,3) e ácido cítrico, para avaliar a deterioração de determinado peixe, e mediu os mesmos parâmetros $L^{*}, a^{*}, b^{*}$. Com relação ao parâmetro $a^{*}$, os valores dos filmes foram positivos para ambos os teores de antocianina sendo significativamente maiores quando incorporada a maior concentração do pigmento na matriz polimérica, assim como os produzidos neste trabalho. Ao decorrer do tempo de estocagem dos filmes usados na embalagem do peixe, todos os valores de $a^{*}$ diminuíram, evidenciando a perda do componente vermelho do filme. Com relação ao parâmetro $b^{*}$ (eixo azul - amarelo), houve comportamento diferente do apresentado neste trabalho, pois os filmes apresentaram valores negativos o que indica a presença de tons azulados. Observou-se que no maior teor de antocianina $(0,010 \mathrm{~g})$, e na menor temperatura de estocagem ( $4{ }^{\circ} \mathrm{C}$ ), o parâmetro $b^{*}$ apresentou os menores valores. Assim como ocorreu no filme $A T H \_0,020 \_22^{\circ}$, foi possível observar oscilações no parâmetro $b^{*}$ 
de todas as amostras ao longo do tempo de estocagem, especialmente a partir do segundo dia, excetuando a formulação $\left(0,010 \mathrm{~g}\right.$ antocianina a $\left.4{ }^{\circ} \mathrm{C}\right)$ que sofreu uma queda neste parâmetro entre o primeiro e segundo dia de armazenamento, seguido de seu aumento.

Por fim, diante das avaliações de todas as formulações e as suas respostas frente a deterioração do alimento condicionado, conclui-se que o filme de amido termoplástico $A T H \_0,005$ foi o mais interessante para o desenvolvimento de embalagens biodegradáveis indicadores de mudança de $\mathrm{pH}$, atingindo, com sucesso, o objetivo proposto para este trabalho. 


\section{CONCLUSÃO}

O processo de extrusão de diferentes formulações da fécula de mandioca com os aditivos (modificadores químicos, agente de reforço e plastificantes) permitiu a obtenção de filmes com características diversificadas e promissoras.

Nesta pesquisa, notou-se que os aditivos podem atuar com sinergismo ou individualmente nas propriedades do filme. No entanto, pode-se observar que a adição de celulose microfibrilada nas condições testadas não foi interessante para as propriedades dos filmes de amido elaborados neste trabalho. E no aspecto geral, os resultados obtidos neste estudo indicam que os filmes de amido extrudados podem ser explorados para o desenvolvimento de filmes biodegradáveis a partir de fontes renováveis com aplicação em diversos setores da indústria de embalagens.

Foi selecionada a formulação ideal (F5), composta por amido:glicerol:ácido esteárico (70:28:2) g/100 g para o estudo posterior com a incorporação de antocianina (ATH) como indicadora de mudança de $\mathrm{pH}$.

Quando se incorpora antocianina no filme TPS notou-se pelas micrografias de superfície, ausência de grânulos de amido e micropartículas de ácido esteárico, indicando boa interação entre os componentes da formulação. Os difratogramas de raios - $\mathrm{X}$ indicaram padrão de amido tipo $\mathrm{A}$ e tipo $\mathrm{V}$ nas formulações independente da adição e concentração de ATH. Por outro lado, a incorporação de ATH influenciou fortemente as propriedades físicas, mecânicas e de superfície.

Os filmes de amido termoplástico incorporados com $10 \mathrm{mg} / 100 \mathrm{~g}$ de antocianina armazenados sob refrigeração a temperatura de $6{ }^{\circ} \mathrm{C}$ representam uma alternativa ecologicamente correta para indicar variações de $\mathrm{pH}$ do alimento acondicionado. Os filmes com ATH expostos a carne bovina ou a carne de peixe apresentaram alteração gradativa da cor roxa para azul/cinza conforme o alimento se degradou.

No caso da avaliação a temperatura de $22^{\circ} \mathrm{C}$, com peixe e carne bovina, os filmes incorporados com $5 \mathrm{mg} / 100 \mathrm{~g}$ apresentaram nítida alteração de cor com a alteração do $\mathrm{pH}$. Nestas condições, o pH do peixe e carne atingiram, no terceiro dia, $\mathrm{pH} 8,4$ e 7,2, respectivamente, considerados impróprios para consumo pela legislação brasileira. 
A formulação sugerida neste trabalho e proposta como embalagem inteligente e indicadora de mudança de $\mathrm{pH}$, seria a do filme F5 ATH_0,005 composto por amido:glicerol: ácido esteárico (70:28:2) g/100 g e adicionado de $5 \mathrm{mg}$ antocianina/100 g filme.

As informações disponibilizadas neste estudo mostram que existe grande potencial de utilização destes materiais biodegradáveis à base de amido de mandioca como embalagem de alimentos. Entretanto, essa aplicação ainda encontra importantes entraves como o problema da alta hidrofilicidade deste tipo de material, o que acarretaria em problemas nas condições de estocagem em ambiente de alta umidade relativa e/ou também na necessidade de maior desenvolvimento de tecnologia para a produção em escala industrial. 


\section{SUGESTÃO PARA TRABALHOS FUTUROS}

$\checkmark$ Caracterizar outras propriedades relevantes dos filmes biodegradáveis como as propriedades de barreira;

$\checkmark$ Adicionar um novo agente reforçador de matriz polimérica;

$\checkmark$ Estudar novas formas de processar CMF para adicionar e comparar novos resultados;

$\checkmark$ Produzir TPS com menor espessura;

$\checkmark$ Avaliar a adição de ATH em diferentes estágios do processo;

$\checkmark$ Estudar a atuação do TPS desenvolvido como indicador de mudança de pH em diferentes alimentos. 


\section{REFERÊNCIAS}

ABDUL KHALIL, H. P. S.; DAVOUDPOUR, Y.; ISLAM, M. N.; MUSTAPHA, A.; SUDESH, K.; DUNGANI, R.; \& JAWAID, M. Production and modification of nanofibrillated celulose using various mechanical processes: $A$ review. Carbohydrate Polymers, v. 99(Supplement C), p. 649-665, 2014.

ABDULLAH, Z. W.; DONG, Y. Recent advances and perspectives on starch nanocomposites for packaging applications. J Mater Sci: Review, 2018.

ABEYKOON, $C$. et al. A review and evaluation of melt temperature sensors for polymer extrusion. Sensors and Actuators, A: Physical, Lausanne, v. 182, p. 16-27, Aug. 2012.

ABRE - Associação Brasileira de Embalagem. ESTUDO MACROECONÔMICO DA EMBALAGEM ABRE / FGV. Apresentação agosto de 2017: fechamento do primeiro semestre e perspectivas para o segundo. São Paulo, 2017. Disponível em: $<$ http://www.abre.org.br/setor/apresentacao-do-setor/a-embalagem/>.Acesso em: 07 fev. 2018.

ACOSTA, S. et al. Mechanical, barrier and microstructural properties of films based on cassava starch gelatin blends: effect of aging and lipid addition. Inside Food Symposium. Anais...Leuven, Belgium: 2013.

AGUDO, J. et al. A Low-Cost Real Color Picker Based on Arduino. Sensors, v. 14, n. 7, p. 11943-11956, 7 jul. 2014.

AHVENAINEN, R.; PULLINEN, T.; HURME, E.; SMULANDER, M.; SIIKA-AHO, M. Package for Decavyble Foodstuffs. PCT International Patent Application WO 98/21120 - VTT Biotechnology and Food Resarch, Espoo. Finland, 1997.

ALVES, V.; COSTA, N.; HILLIOU, L.; LAROTONDA, F.; GONCALVES, M.; \& SERENO, A. Design of biodegradable composite films for food packaging. Desalination, v. 199, n. 1, p. 331-333, 2006.

ALVES, V. D.; MALI, S.; BELÉIA, A.; GROSSMANN, M. V. E. Effect of glycerol and amylose enrichment on cassava starch film properties. Journal of Food Engineering, v. 78, p. 941-946, 2007.

ALOUI, H.; KHWALDIA, K.; HAMDI, M.; FORTUNATI, E.; KENNY, J. M.; BUONOCORE, G. G.; LAVORGNA, M. Synergistic effect of halloysite and cellulose nanocrystals on the functional properties of PVA based nanocomposites. ACS Sustain Chem Eng, v. 4, n. 3, p. 794-800, 2016.

AMARAL, L. J. D.; DIAS, F. T. G.; ZORZI, J. E.; CRUZ, R. C. D. Obtenção de amidos termoplásticos para a extrusão de pós cerâmicos. Polímeros, 2015. http://dx.doi.org/10.1590/0104-1428.2001

AMERICAN SOCIETY FOR TESTING AND MATERIALS - ASTM. ASTM D7251 Standard Specification for Color and Appearance Retention of Variegated Color Plastic. West Conshohocken, PA, ASTM International, 2011. 
AMERICAN SOCIETY FOR TESTING AND MATERIALS - ASTM. ASTM D7334 Standard Practice for Surface Wettability of Coatings, Substrates and Pigments by Advancing Contact Angle Measurement. West Conshohocken, PA, ASTM International, 2008.

ANDRADE - MAHECHA, M. M. Microcompósitos, nanocompósitos e coberturas a base de materiasi biodegradáveis obtidos a partir do Biri (Canna indica L.). Doutor em Engenharia de Alimentos. Faculdade de Engenharia de Alimentos UNICAMP, Campinas, 2012.

AOAC. METHOD 971.09. Official methods of analysis of AOAC International. Association of Official Analytical Chemists, Chapter 49, Gaithersburg, Maryland, v. II, 1995.

APLEVICZ, K. S., DEMIATE, I. M. Caracterização de amidos de mandioca nativos e modificados e utilização em produtos panificados. Ciênc. Tecnol. Aliment., v. 27, n. 3, p. 478-484, 2007.

ARENAS, A. M. Z. Filme Biodegradável á base de fécula de mandioca como potencial indicador de mudança de pH. São Paulo, p.29, 2012. (Mestrado em Engenharia) Escola Politécnica - USP.

ASTM STANDARD D644-04 - Standard test methods for moisture content of paper and paperboard by oven drying, Anais. West Conshohocken, PA: ASTM International, 2004.

ASTM STANDARD D882-12. Standard test method for tensile properties of thin plastic sheeting. Anais. West Conshohocken, PA: ASTM International, 2012.

AZEREDO, $\mathrm{H}$. et al. Nanocomposite edible films from mango puree reinforced with cellulose nanofibers. Journal of food science, v. 74, n. 5, p. N31-N35, 2009.

BABAEE, M.; JONOOBI, M.; HAMZEH, T.; ASHORI, A. Carbohydr. Polym, v. 132, p. $1-8,2015$.

BELIBI, P. C.; DAOU, j.; NDJAKA, J. M. B.; MICHELIN, L.; BRENDLÉ, J.; NSOM, B.; DURAND, B. - Tensile and water barrier properties of cassava starch composite films reinforced by synthetic zeolite and beidellite. Journal of Food Engineering, v 115, p 339-346, 2013.

BELIBI, P. C.; NDJAKA, J. M. B.; NSOM, B.; DURAND, B. - A Comparative Study of Some Properties of Cassava and Tree Cassava Starch Films. Phisics Procedia, v. 55, p 220-226, 2014.

BESBES, I.; ALILA, S.; \& BOUFI, S. Nanofibrillated cellulose from TEMPO-oxidized eucalyptus fibres: Effect of the carboxyl content. Carbohydrate Polymers, v. 84, n. 3, p. $975-983,2011$.

BEZERRA, V. S. Alterações na composição química e cocção de raízes de mandioca (Manihot esculenta Crantz) minimamente processadas. Lavras - Minas Gerais, 2000. Dissertação Mestrado. Universidade Federal de Lavras. 
BORDIGNON Jr. C. L.; FRANCESCATTO.V.; NIENOW. A. A.; CALVETE. E.; REGINATTO. F. H. Influência do $\mathrm{pH}$ da solução extrativa no teor de antocianinas em frutos de morango. Ciência e Tecnologia de Alimentos, v. 29 n. 1, 2009.

BORGES, J. G. et al. Lecithin, gelatin and hydrolyzed collagen orally disintegrating films: functional properties. International Journal of Biological Macromolecules, Guildford, v. 86, p. 907-916, 2016.

BRASIL. Ministério da Agricultura. Decreto $n .$. 30.691, de 29 de mar. de 1952. Regulamento da inspeção industrial e sanitária de produtos de origem animal. (RIISPOA). 1952.

BRASIL. Ministério da Agricultura. Decreto n. 39.688, de 30 de ago. de1999. Regulamento Da Inspeção Industrial E Sanitária Dos Produtos De Origem Animal (RIISPOA). 1999.

BRASIL. Resolução, n. 263 de setembro 2005. Comissão Nacional de Normas e Padrões para Alimentos. Diário Oficial da União, Brasília, p. 368-369.

BRIDLE, P.; TIMBERLAKE, C. F. Anthocyanins as natural food colours - selected aspects. Food Chemistry, v. 58, n.1-2, p.103-109, 1997.

BROUILLARD, R.; DUBOIS, J. E. Mechanism of the structural transformations of anthocyanins in aqueous media. Journal of American Chemistry Society, v. 99, p. 1359-1363, 1977

BULEÓN, A.; COLONNA, P.; PLANCHOT, V.; \& BALL, S. Starch granules: structure and biosynthesis. International Journal of Biological Macromolecules, v. 23, p. 85-112, 1998.

CALLAGHAN, K. A. M. O'.; KERRY, J. P. Consumer attitudes towards the application of smart packaging technologies to cheese products. Food Packaging and Shelf Life, v. 9, p. 1-9, 2016.

CAMPOS, A. D. Modificações após colheita no grau de deterioração fisiológica e composição química das raízes de 3 cultivares de Mandioca (Manihot Sculenta Crantz). Lavras - Minas Gerais,1987. Dissertação (Mestrado em ciências de alimentos) - Escola Superior de Agricultura de Lavras (ESAL).

CARVALHO, A. J. F.; CURVELO, A. A. S.; \& GANDINI, A. Surface chemicalmodification of thermoplastic starch: Reactions with isocyanates, epoxyfunctions and stearoyl chloride. Industrial Crops and Products, v. 21, n. 3, p. 331-336, 2005.

CARVALHO, A. J.; ZAMBON, M. D.; DA SILVA, C. A.; GANDINI, A. Thermoplastic starch modification during melt processing: Hydrolysis catalyzed by carboxylic acids. Carbohydrate Polymers, v. 62, n. 4, p. 387-390, 2005.

CASTAÑEDA-OVANDO, A. et al. Chemical studies of anthocyanins: a review. Food Chemistry, v. 113, n. 4, p. 859-871, 2009. 
CHABRAT, E.; ABDILLAHI, H.; ROUILLY, A.; RIGAL, L. Influence of citric acid and water on thermoplastic wheat flour/poly (lactic acid) blends. I: Thermal, mechanical and morphological properties. Industrial Crops and Products, Elsevier, vol. 37, p. 238246, 2012.

CHIVRAC, F.; POLLET, E.; AVÉROUS, L. Progress in nano-biocomposites based on polysaccharides and nanoclays. Materials Science and Engineering R, v. 67, p.1-17, 2009.

CHOI, I.; LEE, J. Y.; LACROIX, M.; HAN, J. Intelligent pH indicator film composed of agar/potato starch and anthocyanin extracts from purple sweet potato. Food Chemistry, v. 218, p. 122-128, 2017.

CORRADINI, E.; LOTTI, C.; MEDEIRO, E. S.; CARVALHO, A. J. F.; CURVELO, A. A. S.; MATTOSO L. H. C. - Estudo comparativo de Amidos Termoplásticos Derivados do Milho com Diferentes Teores de Amilose, Polímeros: Ciência e Tecnologia, v. 15, n. 4, p. 268-273, 2005.

CROISIER, F.; JÉRÔME, C. Chitosan-based biomaterials for tissue engineering. European Polymer Journal, v. 49, n. 4, p. 780-792, 2013.

CURVElO, A. A. S.; de CARVALHO, A. J. F.; AGNELLI, J. A. M. Thermoplastic starch-cellulosic fibers composites: preliminary results. Carbohydrate Polymers, v. 45, n. 2, p. 183-8, 2001.

DA RÓZ, A. L., ZAMBON, M. D., CURVELO, A. A. S., \& CARVALHO, A. J. F. Thermoplastic starch modified during melt processing with organic acids: Theeffect of molar mass on thermal and mechanical properties. Industrial Cropsand Products, v. 33, n. 1, p. 152-157, 2011.

DAINELLI, D., GONTARD, N., SPYROPOULOS, D., ZONDERVAN-VAN DEN BEUKEN, E., \& TOBBACK, P. Active and intelligent food packaging: legal aspects and safety concerns. Trends in Food Science and Technology, v. 19, p. 103-112, 2008.

DATAMARK - Marketing Intelligence Brazil. Matéria Prima. Share for Material. Disponível em: <http://www.datamark.com.br/dados-gerais/>.Acesso em: 07 fev. 2018.

de CAMPOS, A.; CORREA, A. C.; CANNELLA, D.; TEIXEIRA, E. D.; MARCONCINI, J. M.; DUFRESNE, A., et al. Obtaining nanofibers from curaua and sugarcane bagasse fibers using enzymatic hydrolysis followed by sonication. Cellulose, v. 20, n. 3, p. 1491-1500, 2013.

de CARVALHO BENINI, K. C. C., PEREIRA, P. H. F., CIOFFI, M. O. H., \& Cornelis Voorwald, H. J. (2017). Effect of acid hydrolysis conditions on the degradation properties of cellulose from Imperata brasiliensis fibers. Procedia Engineering, 200, 244-251. https://doi.org/10.1016/J.PROENG.2017.07.035.

DEMIATE, I. M. et al. Características de qualidade de polvilho azedo. Parte 3 - Rio Grande do Sul, 1998. Publicatio UEPG - Ciências Exatas e da Terra. v. 4, n. 1, p. 97112. 
DEMIATE, I. M.; CEREDA, M. P. Some physico-chemical characteristics of modified cassava starches presenting baking property. Energia na Agricultura, v. 15, n. 3, p. 3646, 2000.

DENGHANI, S.; HOSSEINI, S. V., \& REGENSTEIN, J. M. Edible films and coatings in seafood preservation: A review. Food Chemistry, v. 240, p. 505-513, 2018.

DÍAZ, A., DINI, C., VIÑA, S. Z., GARCÍA, M. A. Technological properties of sour cassava starches: Effect of fermentation and drying processes. LWT, v. 93, p. 116123, 2018.

DITCHFIELD, C.; TADINI, C. C. Filme biodegradável com base de amido e/ou fécula e uso do mesmo. INPI n. C10704589-1E2, 12 abril 2009.

DURGE, A. C. et al. Stability of anthocyanins as pre-extrusion colouring of rice extrudates. Food Research International, v.50, p. 641-646, 2013.

DONG, P.; PRASANTH, R.; XU, F.; WANG, X.; LI, B.; SHANKAR, R. Eco-friendly polymer nanocomposite-properties and processing. In: Thakur VK, Thakur MK (eds) Advanced structured materials eco-friendly polymer nanocomposites. Springer, New Delhi, p. 1-15, 2015.

EMBRAPA - Empresa Brasileira de Pesquisa Agropecuária. Documentos 30. Amido Termoplástico. ISSN 1518-7179 São Carlos, novembro de 2007.

EXARHOPOULOS, S.; RAPHAELIDES, S. N. Morphological and structural studies of thermally treated starch-fatty acid systems. Journal of Cereal Science. v. 55, p.139 152, 2012.

FAO/WHO. FAO Food and Nutrition Paper. Carbohydrates in human nutrition, v. 66, 1998.

FAOSTAT Food and Agriculture Organization of the United Nations. StatisticalDatabases. Agricultural data 2013. Disponível em: http://faostat.fao.org/faostat/. Acesso em: 05 de janeiro de 2017.

FERREIRA, Ivanir. Ciências Exatas e da Terra. Pesquisa produz plástico e acrílico com nanofibras de celulose. Jornal da Usp. São Paulo, 12 set. 2017. Disponível em:<https://jornal.usp.br/ciencias/ciencias-exatas-e-da-terra/pesquisa-produzplastico-e-acrilico-com-nanofibras-de-celulose/>. Acesso em: 15 maio 2018.

FMC planeja ter $100 \%$ de embalagens ecológicas até 2018. Revista embalagem Marca, São Paulo, 1 junho 2017. Disponível em: <https://www.embalagemmarca.com.br/2017/06/fmc-planeja-ter-100-de-embalagensecologicas-ate-2018/>. Acesso em: 10 jun. 2018.

FORREST, J.C.; et al. Fundamentos de ciencia de la carne. Traduzido por BERNABÉ SANZ PÉREZ. Zaragoza: Acribia, p. 364, 1979.

FRANCO, C. M. L.; DAIUTO, E. R.; DEMIATE, I. M.; CARVALHO, L. J. C. B.; LEONEL, M.; VILPOUX, O. F.; SARMENTO, S. B. S. Propriedades do Amido, In: Propriedades 
Gerais do Amido, Série Culturas de Tuberosas Amiláceas Latino Americanas. Campinas: Fundação Cargill, v. 1, p. 141-184, 2002.

FRANÇA, S. C. A.; COUTO, H. J. B. CAPÍTULO 5 - ANÁLISE MICROGRANULOMÉTRICA - MALVERN E SEDIGRAPH Disponível em: $<$ http://mineralis.cetem.gov.br/bitstream/cetem/1030/1/Cap\%205\%20Microgranulom \%C3\%A9trica_modif..pdf>. Acesso em 18 de jul. 2018.

FREITAS, A. Reatividade Química e Fotoquímica de Antocianinas em Sistemas Organizados 2005. 210 f. Tese (Doutorado em Química) - Instituto de Química, Universidade de São Paulo, São Paulo, 2005.

FRENCH, A. D. Idealized powder diffraction patterns for cellulose polymorphs. Cellulose, v. 21, n. 2, p. 885-896, 2014.

FRINGANT, C., DESBRIÈRES, J., \& RINAUDO, M. Physical properties of acetylated starch-based materials: Relation with their molecular characteristics. Polymer, v. 37, p. 2663-2673, 1996.

GARCÍA, M. A., MARTINO, M. N., \& ZARITZKY, N. E. Microstructural characterization of plasticized starch-based films. Starch/Starke, v. 52, n. 4, p.118-124, 2000.

GARCÍA, N. L.; FAMA, L.; D'ACCORSO, N. B.; GOYANES, S. Biodegradable starch nanocomposites. In: Thakur VK, Thakur MK (eds) Advanced structured materials ecofriendly polymer nanocomposites. Springer, New Delhi, p. 17-77, 2015.

GHANBARI, A.; TABARSA, T.; ASHORI, A.; SHAKERI, A.; MASHKOUR, M. Preparation and characterization of thermoplastic starch and cellulose nanofibers as green nanocomposites: Extrusion processing. International Journal of Biological Macromolecules, v.112, p. 442-447, june 2018.

GHANBARZADEH, B.; ALMASI, H.; ENTEZAMI, A. A. Physical properties of edible modified starch/carboxymethyl cellulose films. Innovative Food Science and Emerging Technologies, v. 11, p. 697-702, 2010.

GILFILLAN, W. N. Thermal extrusion of starch film with alcohol. Journal of Food Engineering, v. 170, p. 92-99, 2016.

GRAAF, R. A., BROEKROELOFS, G. A., JANSSEN, L. P. B. M., \& BEENACKERS, A. A. C. M. The kinetics of the acetylation of gelatinised potato starch. Carbohydrate Polymers, v. 28, p. 137-144, 1995.

HASSANPOUR, A.; ASGHARI, S.; LAKOURAJ, M. M.; MOHSENI, M. Preparation and characterization of contact active antibacterial surface based on chemically modified nanofibrillated cellulose by phenanthridinium silane salt. Biomac (2017), doi:10.1016/j.ijbiomac.2018.03.141.

HIETALA, M.; MATHEW, A. P.; OKSMAN, K. Bionanocomposites of thermoplastic starch and cellulose nanofibers manufactured using twin-screw extrusion. European Polymer Journal, v. 49, n. 4, p. 950-6, 2013. 
HIRASHIMA, M., TAKAHASHI, R., NISHINARI, K. Effects of adding acids before and after gelatinization on the viscoelasticity of cornstarch pastes. Food Hydrocolloids, v. 19, p. 909-914, 2005.

HOLSER, R.A. Thermal analysis of glycerol citrate/starch blends. J. Appl. Polym. Sci. v. 110, p. 1498-150, 2008.

HONEYBOURNE, C. L. Food Spoilage Detection Method. PCT International Patent Application WO 93/15403, 1993.

IACOBUCCI, G. A.; SWEENY, J. G. The chemistry of anthocyanins, anthocyanidins, and related flavilium salts. Tetrahedron Letters, Elmsford, v. 39, n. 19, p. 3005-3012, 1983.

HUANG, R., \& LIU, D. Freshness evaluation of pork as well as its problems and counter measures. Meat Industry, v. 6, p. 43-46, 2010.

IBÁ - Indústria Brasileira de Àrvores. Ibá Celulose, 16 de abril de 2015. Disponível em: http://iba.org/pt/produtos/celulose. Acesso em 02 abril de 2018.

INSTITUTO ADOLFO LUTZ. Normas analíticas do Instituto Adolfo Lutz: métodos químicos e físicos de composição de alimentos. 3. ed. São Paulo, 1985.

ISSA, A. T.; SCHIMMEL, K. A.; WORKU, M.; SHAHBAZI, A.; IBRAHIM, S. A.; TAHERGORABI, R. Sweet potato starch-based nanocomposites: development, characterization, and biodegradability. Starch-Starke 1700273, p. 1-8, 2018.

ISOGAI A., SAITO T., FUKUZUMI H. (2011). TEMPO-oxidized cellulose nanofibers. Nanoscale.3:71-85.

JACOMETTI, G. A. et al. The physicochemical properties of fibrous residues from the agro industry. LWT - Food Science and Technology, v. 62, n. 1, p. 138-143, 2015.

JANTANASAKULWONG, K.; LEKSAWASDI, N.; SEESURIYACHAN, P.; WONGSURIYASAK, S.; TECHAPUN, C.; OUGIZAWA, T. Reactive blending of thermoplastic starch, epoxized natural rubber and chitosan. European Polymer Journal, p. 292-299, 22 sept 2016.

JAY, J. M., \& SHELEF, L. A. Microbial modifications in raw and processed meats and poultry at low-temperatures. Food Technology, n.32, v.5, p. 186-187, 1978.

KAFLE, K.; GREESON, K.; LEE, C.; \& KIM, S. H. Cellulose polymorphs and physical properties of cotton fabrics processed with commercial textile mills for mercerization and liquid ammonia treatments. Textile Research Journal, v. 84, n.16, p. 1692-1699, 2014.

KAMPANGKAEW, S.; THONGPIN, C.; SANTAWTEE, O. The synthesis of Cellulose nanofibers from Sesbania Javanica for filler in Thermoplastic starch. Energy Procedia, v. 56, p. 318-325, 2014. 
KAUSHIK, A.; SINGH, M.; \& VERMA, G. Green nanocomposites based on thermoplastic starch and steam exploded cellulose nanofibrils from wheat straw. Carbohydrate Polymers, v. 82, n. 2, p. 337-345, 2010.

KAYA, S.; MASKAN, A. Water vapor permeability of pestil (a fruit leather) made from boiled grape juice with starch. Journal of food engineering, v. 57, n. 3, p. 295-299, 2003.

KIM, S. A., \& RHEE, M. S. Synergistic antimicrobial activity of caprylic acid in combination with citric acid against both Escherichia coli O157:H7 and indigenous microflora in carrot juice. Food Microbiology, v. 49, p. 166-172, 2015.

KLEMM, D. et al. Nanocelluloses: A New Family of Nature-Based Materials. Angewandte Chemie International Edition, v.50, p.5438-5466, 2011.

KONG, J. M.; CHIA, L.S.; GOH, N. K.; CHIA, T. F.; BROUILLARD. R. Analysis and biological activities of anthocyanins. Elsevier Ltd. All rights reserved, 2003.

KUMAR, S. K.; JOUAULT, N. Nanocomposites with polymer grafted nanoparticles. Macromolecules, v. 46, n. 3, p. 199-214, 2013.

LAI, S. et al. A thin transition film formed by plasma exposure contributes to the germanium surface hydrophilicity. Journal of Semiconductors, v. 37, n. 9, p. 93004, set. 2016.

LOROTONDA, F. D. S., MATSUI, K. N., SOBRAL, P. J. A., \& LAURINDO, J. B. Hygroscopicity and water vapor permeability of Kraft paper impregnated with starch acetate. Journal of Food Engineering, v. 71, p. 394-402, 2005.

LAVORATTI, A.; SCIENZA, L. C.; \& ZATTERA, A. J. Dynamic-mechanical and thermomechanical properties of cellulose nanofiber/polyester resin composites. Carbohydrate Polymers, v. 136(Supplement C), p. 955-963, 2016.

LEITÃO, M. F. F. Deterioração microbiológica do pescado e sua importância em Saúde Pública. Higiene Alimentar, v. 3, p. 143-152, 1984.

LEITÃO, M. F. F. Microbiologia e deterioração do pescado fresco e refrigerado de origem fluvial ou marinha. In: KAI, M.; RUIVO, U.E. Controle de Qualidade do Pescado. Santos: Leopoldianum, p. 40-58, 1988.

LI, Q.; CHEN, L.; GADINSKI, M. R.; ZHANG, S.; ZHANG, G.; LI, H. U.; IAGODKINE, E.; HAQUE, A.; CHEN, L. Q.; JACKSON, T. N.; WANG, Q. Flexible high-temperature dielectric materials from polymer nanocomposites. Nature; v. 523: p. 276-580, 2015.

LLANOS, J. H. R. Desenvolvimento e caracterização de bionanocompósitos pelo método de extrusão. Pirassununga, 2018. (Doutor em Ciências do programa de pósgraduação em Engenharia e Ciência de Materiais), Faculdade de Zootecnia e Engenharia de Alimentos da Universidade de São Paulo.

LÓPEZ, O. P.; JIMÉNEZ, A. R.; VARGAS, F. D. Natural pigments: carotenoids, anthocyanins, and betalains - characteristics, biosynthesis, processing, and stability. Critical Reviews Food Science Nutrition, v. 40, n. 3, p. 173 -389, 2000. 
LOURDIN, D., DELLA VALLE, G., \& COLONNA, P. Influence of amylose content on starch films and foams. Carbohydrate Polymers, v. 27, p. 275-280, 1995.

LU, D. R., XIAO, C. M., \& XU, S. J. Starch-based completely biodegradablepolymer materials. Express Polymer Letters, v. 3, n. 6, p. 366-375, 2009.

LU, Q.; CAI, Z.; LIN, F.; TANG, L.; WANG, S.; HUANG, B. Extraction of cellulose nanocrystals with a high yield of $88 \%$ by simultaneous mechanochemical activation and phosphotungstic acid hydrolysis. ACS Sustainable Chemistry \& Engineering, v. 4, n. 4, p. 2165-2172, 2016.

MA, X.; CHANG, P. R.; YU, J. Properties of biodegradable thermoplastic pea starch/carboxymethyl cellulose and pea starch/microcrystalline cellulose composites. Carbohydrate Polymers, v. 72, n.3, p. 369-75, 2008.

MACHADO, B.A.S.; NUNES, I. L.; PEREIRA, F. V.; DRUZIAN, J.I. Processo para a preparação de nanobiocompósitos tipo filmes flexíveis reforçados com nanopartículas de celulose tipo nanowhiskers. Patenteprotocolizada no INPI, 2010, Br.

MADHUMITHA, G.; FOWSIYA, J.; ROOPAN, S. M.; THAKUR, V. K. Recent advances in starch-clay nanocomposites. Int J Polym Anal Charact, v. 5, p. 1-15, 2018.

MAGALHÃES, M. A. Tempo de degradação dos materiais descartados no meio ambiente. Disponível em: <http://redeambiente.org.br/Opiniao.asp?artigo=147>. Acesso em fev. 2018.

MALI, S., SAKANAKA, L. S., YAMASHITA, F., \& GROSSMANN, M. V. E. Water sorption and mechanical properties of cassava starch films and their relation to plasticizing effect. Carbohydrate Polymers, v. 60, p. 283-289, 2005.

MANOEL, A. F.; CLARO, P. I. C; MATTOSO, L. H. C.; MARCONCINI, J. M.; MANTOVANI, G. L. Thermoplastic Waxy Starch Films Processed by Extrusion and Pressing: Effect of Glycerol and Water Concentration. Materials Research, n. 20, p. 353-357, 2017.

MANIGLIA, B. C. Aproveitamento de resíduos agroindustriais para elaboração de filmes biodegradáveis. Ribeirão Preto, 2017 (Tese Doutorado em Ciência, Área: Química), Faculdade de Filosofia, Ciências e Letras de Ribeirão Preto da Universidade de São Paulo.

MANIGLIA, B. C. et al. Development of bioactive edible film from turmeric dye solvent extraction residue. LWT - Food Science and Technology, v. 56, n. 2, p. 269-277, maio 2014.

MANIGLIA, B. C. et al. Turmeric dye extraction residue for use in bioactive film production: Optimization of turmeric film plasticized with glycerol. LWT - Food Science and Technology, v. 64, n. 2, p. 1187e1195, 2015.

MARTELLI-TOSI, M.; MASSON, M. M.; SILVA, N. C.; ESPOSTO, B. S.; BARROS, T. T.; ASSIS, O. B. G.; TAPIA-BLÁCIDO, D. R. Soybean straw nanocellulose produced by enzymatic or acid treatment as a reinforcing filler in soy protein isolate films. Carbohydrate Polymers, v. 198, p. 61-68, 2018. 
MARTELLI-TOSI, M.; TORRICILLAS, M. S.; MARTINS, M. A.; ASSIS, O. B. G.; \& TAPIA-BLÁCIDO, D. R. Using commercial enzymes to produce cellulose nanofibers from soybean straw. Journal of Nanomaterials, v. 10, 2016.

MARTINS, A. B.; SANTANA, R. M. C. Effect of carboxylic acids as compatibilizer agent on mechanicalproperties of thermoplastic starch and polypropylene blends. Carbohydrate Polymers, v. 135, p. 79-85, 2016.

MAZZA G., BROUILLARD R. Recent developments in the stabilization of anthocyanins in food products. Food Chemistry, v. 25, p. 207-225, 1987.

MEDEIROS, E. S.; DUFRESNE, A.; ORTS, W. J. Starch-based nanocomposites. In: Bertolini AC (ed) Starches: characterization, properties, and applications. Taylor \& Francis,Boca Raton, p. 205-251, 2010.

MILLERS, D. W.; WILKES, J. G.; CONTE, E. D. Food Quality Indicator Device. PCT International Patent Application WO 99/0456, 1999.

MONTERO, B.; RICOA, M.; RODRÍGUEZ-LLAMAZARESB, S.; BARRALA, L.; BOUZA, R. Effect of nanocellulose as a filler on biodegradable thermoplastic starch films from tuber, cereal and legume. Carbohydrate Polymers, p. 1094-1104, 23 oct 2016.

MORAES, J. O.; SCHEIBE, A. S.; SERENO, A.; LAURINDO, J. B. - Scale-up the production of cassava starch based films using tape-casting. Journal of Food Engineering, v. 119, p. 800-808, 2013.

MORÁN, J. I., CYRAS, V. P., \& VÁZQUEZ, A. Preparation and characterization ofthree different derivatized potato starches. Journal of Polymers and the Environment, v. 21, n. 2, p. 395-404, 2013.

MÜLLER, C. M. O.; LAURINDO, J. B.; YAMASHITA, F. Effect of nanoclay incorporation method on mechanical and water vapor barrier properties of starchbased films. Industrial Crops and Products, Amsterdam, v. 33, n. 3, p. 605-610, 2011.

NARA, S.; KOMIYA, T. Studies on the relationship between water-satured state and crystallinity by the diffraction method for moistened potato starch. Starch - Stärke, v. 35, n. 12, p. 407-410, 1983.

NING, W.; XINGXIANG, X.; NA, H.; SHIHE, B. Effect of citric and processing on the performance of thermoplastic starch/montmorillonite nanocompósitos. Carbohydrate Polymers, v. 76, p. 68-73, 2009.

NOSSA, de S. T. Modificação do amido termoplástico por extrusão reativa (REX): compatibilização reativa e modificação química via despolimerização/polimerização. São Carlos, 2014 (Tese Doutorado em Ciência, Área: Desenvolvimento, Caracterização e Aplicação de Materiais), Ciência e Engenharia de Materiais da Universidade de São Paulo.

OLAIMAT, A. N., AL-NABULSI, A. A., OSAILI, T. M., AL-HOLY, M., AYYASH, M. M., MEHYAR, G. F., JARADAT, Z. W., \& GHOUSH, M. A. Survival and inhibition of 
Staphylococcus aureus in commercial and hydrated tahini using acetic and citric acids. Food Control, v. 77, p. 179 -186, 2017.

OSÓRIO, J. C. S; et al. Produção de Carne Ovina, Alternativa para o Rio Grande do Sul. Editora da Universidade Federal de Pelotas, Pelotas, p. 166, 1998.

PAAKKO, M.; ANKERFORS, M.; KOSONEN, H.; NYKANEN, A.; AHOLA, S.; OSTERBERG, M.; et al. Enzymatic hydrolysis combined with mechanical shearing and high-pressure homogenization for nanoscale cellulose fibrils and strong gels. Biomacromolecules, v. 8, n. 6, p. 1934-1941, 2007.

PACQUIT A., FRISBY J., DIAMOND D., LAU K., FARRELL A., QUILTY B., DIAMOND

$D$. Development of a smart packaging for the monitoring of fish spoilage. Food Chemistry, 2006.

PARDI, M.C., et al. Ciência, higiene e tecnologia da carne: tecnologia da sua obtenção e transformação. Goiânia: Centro Editorial e Gráfico Universidade de Goiás, v.1, p. 586, 1993.

PARDO, M. et al. Thermoplastic starch-nanohybrid films with polyhedral oligomeric silsesquioxane. Carbohydrate Polymers, v. 173, p. 170-177, fev 2017.

PARK, S.; BAKER, J. O.; HIMMEL, M. E.; PARILLA, P. A.; \& JOHNSON, D. K. Cellulose crystallinity index: measurement techniques and their impact on interpreting cellulase performance. Biotechnology for Biofuels, v. 3, n. 1, p. 10, 2010.

PARK, S.; ZHAO, Y. Incorporation of a high concentration of mineral or vitamin into chitosan-based films. Journal of Agricultural and Food Chemistry, v. 52, p. 1933-1939, 2004

PARKER, R.; RING, S. G. Aspects of the physical chemistry of starch. Journal of Cereal Science, v. 34, p. 1-17, 2001.

PERONI, F. H. G. Características estruturais e físico-químicas de amidos obtidos de diferentes fontes botânicas. 2003. 118f. Dissertação (Mestrado em Engenharia e Ciência de Alimentos) - Faculdade de Engenharia de Alimentos, Universidade Estadual Paulista Júlio de Mesquita Filho (UN.ESP), São José do Rio Preto, 2003

PICONE, C. S. F.; \& CUNHA, R. L. Influence of $\mathrm{pH}$ on formation and properties of gellan gels. Carbohydrate Polymers, v. 84, n. 1, p. 662-668, 2011.

QI, W.; ZHANG, X.; WANG, H. Self-assembled polymer nanocomposites for biomedical application. Current Opinion in Colloid \& Interface Science, v. 35, p. 36-41, 2018.

QING, Y.; SABO, R.; ZHU, J. Y.; AGARWAL, U.; CAI, Z.; \& WU, Y. A comparative study of cellulose nanofibrils disintegrated via multiple processing approaches. Carbohydrate Polymers, v. 97, n. 1, p. 226-234, 2013.

QUAN, C. STEVENS, R. Protein Coupled Colorimetric Analyte Detectors. PCT International Patent Apllication WO 95/33991, 1998. 
QUERO, F.; PADILLA, C.; CAMPOS, V.; LUENGO, J.; CABALLERO, L.; MELO, F.; LI, Q.; EICHHORN, S. J.; \& ENRIONE, J. Stress transfer and matrix-cohesive fracture mechanism in microfibrillated cellulose-gelatin nanocomposite films. Carbohydrate Polymers , 2018. https://doi.org/10.1016/j.carbpol.2018.04.059.

RAMOS, L. A.; LUPETTI, K. O.; CAVALHEIRO, E. T. G.; FATIBELLO-FILHO, O. Utilização Do Extrato Bruto De Frutos De Solanum Nigrum L No Ensino De Química. Eclética Química, v. 25, p. 229-240, 2000.

RAUWENDAAL, C. Polymer extrusion. Munich: Hanser, 2001.

REDDY, N., YANG, Y. Citric acid cross-linking of starch films. Food Chem. v, 118, p. 702-711, 2010.

REIS, L. C. B. Formulação e caracterização de filmes biodegradáveis de fécula de mandioca incorporados com polpa de manga e extrato de erva-mate, e seu efeito na preservação de alimentos. Salvador, 2011. (Mestrado em Ciência de Alimentos), Faculdade de Farmácia - UFBA.

Revista Saúde, Mandioca. Disponível em:< https://saude.abril.com.br/edicoes/399/>. Acesso em 15 de junho 2018.

RHIM, J. W.; HONG, S. I.; HA, C. S. Tensile, water vapor barrier and antimicrobial properties of PLA/nanoclay composite films. LWT - Food Science and Technology, Amsterdam, v. 42, n. 2, p. 612-617, 2009.

RIBEIRO, E.P.; SERAVALLI, A. G. Química de Alimentos. Instituto Mauá de Tecnologia, Ed. Edgard Blûcher Ltda. 1ª Edição, p. 58-63, 2004.

RIOS, P. et al. The effect of polymer surface on the wetting and adhesion. Journal of Adhesion Science and Technology, Zeist, v. 21, n. 3, p. 227-241, 2007.

ROCHA-GARCÍA, D., GUERRA-CONTRERAS, A., REYES-HERNÁNDEZ, J., \& PALESTINO, G. Thermal and kinetic evaluation of biodegradable thermo-sensitive gelatin/poly (ethylene glycol) diamine crosslinked citric acid hydrogels for controlled release of tramadol. European Polymer Journal, v. 89, p. 42-56, 2017.

RODRÍGUEZ, M.; OSÉS, J.; ZIANI, K.; MATÉ, J. I. Combined effect of plasticizers and surfactants on the physical properties of starch based edible films. Food Research International, v. 39, p. 840-846, 2006.

SALOMÃO, G. P.; GROSSMANN, M. V. E.; SHIRAI, M. A.; LAZARETTI, M. M.; YAMASHITA, F.; MULLERA, C. M. O et al., Ind Crop Prod, v. 52, p. 305-312, 2014.

SAVADEKAR, N. R.; MHASKE, S.T. Synthesis of nano cellulose fibers and effect on thermoplastics starch based films. Carbohydrate Polymers, v. 89, n. 1, p. 146-51, 2012.

SEGA, L., CREELY, J. J., MARTIN, A. E., Jr, \& CONRAD, C. M. An empirical method for estimating the degree of crystallinity of native cellulose using the $X$-ray diffractometer. Textile Research Journal, v. 29, n.10, p. 786-794, 1959. 
SELIGRA, P. G.; MOURA, L. E.; FAMÁ, L.; DRUZIAN, J. I.; GOYANESA, S. Influence of incorporation of starch nanoparticles in PBAT/TPS composite films. Research Article, Society of Chemical Industry, Polym Int; v. 65, p. 938-945, 2016.

SHI, R., ZHANG, Z., LIU, Q., HAN, Y., ZHANG, L., CHEN, D., TIAN, W. Characterization of citric acid/glycerol co-plasticized thermoplastic starch prepared by melt blending. Carbohydr. Polym. v. 69, p. 748-755, 2007.

SHI, R., Bi, J., ZHANG, Z., ZHU, A., CHEN, D., ZHOU, X., ZHANG, L., TIAN, W. The effect of citric acid on the structural properties and cytotoxicity of the polyvinyl alcohol/starch films when molding at high temperature. Carbohydr. Polym. v. 74, p. 763-770, 2008.

SILVA, L.T. Desenvolvimento e avaliação de embalagens biodegradáveis com ação antioxidante contendo café e cacau, 2009. Dissertação (Mestrado em Ciência de Alimento) - Faculdade de Farmácia, Universidade Federal da Bahia, Ba.

SOBRAL, P. J. DO A. Propriedades funcionais de biofilmes de gelatina em função da espessura. Ciência \& Engenharia, v. 8, n. 1, p. 60-67, 1999.

SOUZA, A. C. Desenvolvimento de embalagem biodegradável ativa a base de fécula de mandioca e agentes antimicrobianos naturais. São Paulo, 2011. (Doutorado em Engenharia), Escola Politécnica - USP.

SYVERUD, K.; CARRASCO, G.C.; TOLEDO, J.; TOLEDO, P.G. A comparative study of Eucalyptus and Pinus radiata pulp fibres as raw materials for production of cellulose nanofibrils. Carbohydrate Polymers, v. 84 p. 1033-1038, 2011.

SOUZA, A. C., BENZE, R., FERRÃO, E. S., DITCHFIELD, C., COELHO, A. C. V., \& TADINI, C. C. Cassava starch biodegradable films: Influence of glycerol and clay nanoparticles contents on tensile and barrier properties and glass transition temperature. LWT - Food Science and Technology, 46, 110-117, 2012.

SOUZA, A. C.; DIAS, A. M. A.; SOUSA, H. C.; TADINI, C. C. Impregnation of cinnamaldehyde into cassava starch biocompositefilms using supercritical fluid technology for the development of food active packaging. Carbohydrate Polymers, 102, 830-837, 2014.

SOUZA, A. C.; DITCHFIELD, C.; TADINI, C. C. Biodegradable films based on biopolymers for food industries. In M. L. Passos, \& C. P. Ribeiro (Eds), Innovation in Food Engineering: New techniques and products, Boca Raton, FL: CRC Press, p. 511537, 2010.

SOUZA, R. C. R., \& ANDRADE, C. T. Investigação dos processos de Gelatinização e extrusão de amido de milho. Polímeros: Ciência e Tecnologia, v. 10, n. 1, p. 24-30, 2000.

SOUZA, A. C.; GOTO, G. E. O.; MAINARDI, J. A.; COELHO, A. C. V.; TADINI, C. C. Cassava starch composite films incorporated with cinnamon essential oil: Antimicrobial activity, microstructure, mechanical and barrier properties. LWT - Food Science and Technology, 54, 346-352, 2013. 
SVAGAN, A. J.; HEDENQVIST, M. S.; BERGLUND, L. Reduced water vapour sorption in cellulose nanocomposites with starch matrix. Compos Sci Technol, v. 69, n. 3-4, p. 500-506, 2009.

TALÓN, E.; TRIFKOVIC, K. T.; NEDOVIC, V. A.; BUGARSKI, B. M.; VARGAS, M.; CHIRALT, A.; \& GONZÁLEZ-MARTÍNEZ, C. Antioxidant edible films based on chitosan and starch containing polyphenols from thyme extracts. Carbohydrate Polymers, v. 157, p. 1153-1161, 2016

TEIXEIRA, B. S., GARCIA, R. H. L., TAKINAMI, P. Y. I., \& DEL MASTRO, N. L. Comparison of gamma radiation effects on natural corn and potato starches and modified cassava starch. Radiation Physics and Chemistry, v. 142, p. 44-49, 2018.

TEODORO, A. P.; MALI, S.; ROMERO, N.; CARVALHO, G. M. - Cassava starch films containing starch nanoparticles as reinforcement: Physical and mechanical characterization. Carbohydrate Polymers, v. 126, p. 16, 2015.

TERCI, D.; ROSSI, A. Indicadores naturais de pH: Usar papel ou solução? Química Nova, v. 4, p. 684-688, 2002.

TERNI, Hamilton. Seminário debate as transformações do mercado de embalagens impressas. ExpoPrint Latin America. Barueri - SP, 24 maio 2018. Disponível em: < https://www.expoprint.com.br/es/noticias/seminario-transforma-mercado-

embalagens-aps-feiras-npes>. Acesso em: 03 de jun. 2018.

TETRA PACK. Polímeros de fontes renováveis, 2011. São Paulo Disponível em: < https://www.tetrapak.com/br/sustainability/responsible-sourcing/polymers $>$. Acesso em 10 jun. 2018.

THARANATHAN, R.N. Biodegradable films and composite coatings: past, present and future. Trends in Food Science \& Technology, v.14, p.71-78, 2003.

TININI, R. C. dos R., COELHO, S. R. M., MONTEIRO, V. H., DE FIGUEIREDO, P. R. A. Caracterização Do Teor De Amido Em Raizes De Mandioca Para Agroindustrias De Extração De Fécula. Anais do I Seminário Internacional de Ciência, Tecnologia e Ambiente. UNIOESTE, Cascavel - Paraná - Brasil, 28 a 30 de abril de 2009.

TONOLI, G. H. D.; TEIXEIRA, E. M.; CORRÊA, A. C.; MARCONCINI, J. M.; CAIXETA, L. A., PEREIRADA-SILVA, M. A.; \& MATTOSO, L. H. C. Cellulose micro/nanofibres from Eucalyptus kraft pulp: Preparation and properties. Carbohydrate Polymers, v. 89, n. 1, p. 80-88, 2012.

URANGA, J., PUERTAS, A.I., ETXABIDE, A., DUEÑAS, M.T., GUERRERO, P., DE LA CABA, K., Citric acid-incorporated fish gelatin/chitosan composite films, Food Hydrocolloids (2018), doi: 10.1016/j.foodhyd.2018.02.018.

VANDEPUTTE, G. E.; DELCOUR, J. A. From sucrose to starch granule to starch physical behavior: a focus on rice starch. Carbohydrate Polymers, v. 58: p. 245-266, 2004. 
VEIGA-SANTOS, P.; DITCHIFIELD, C.; TADINI, C. C. Development and evaluation of a novel $\mathrm{pH}$ indicator biodegradable film based on cassava starch. Journal of Applied Polymer Science, v. 120, p. 1069-1079, 2011.

VIEIRA, M. G. A. et al. Natural-based plasticizers and biopolymer films: A Preview. European Polymer Journal, v. 47, n. 3, p. 254-263, mar. 2011b.

WANG, L.; DONG, Y.; MEN, H.; TONG, J.; \& ZHOU, J. Preparation and characterization of active films based on chitosan incorporated tea polyphenols. Food Hydrocolloids, v. 32, n. 1, p. 35-41, 2013.

WANG, N., YU, J., CHANG, P.R., MA, X. Influence of citric acid on the properties of glycerol-plasticized dry starch (DTPS) and DTPS/poly (lactic acid) blends. Starch/Stärke v. 59, p. 409-417, 2007,a.

WANG, N.; YU, J. G.; HAN, C. M. Influence of citric acis on the properties of glycrolplasticised Cornstarch extrusion blends. Polymers \& Polymer Composites, v. 15, p. 545-552, 2007.

WANG, N.; YU, J.; MA, X.; WU, Y. The influence of citric acid on the properties of thermoplastic starch/linear low density polyethylene blends. Carbohydr. Polym. v. 67, p. 446-453, 2007 b.

WANG, N., ZHANG, X., HAN, N., BAI, S. Effect of citric acid and processing on the performance of thermoplastic starch/montmorillonite nanocomposites. Carbohydr. Polym. v. 76, p. 68-73, 2009.

WHISTLER, R. L., \& PASCHALL, E. F. Starch: chemistry and technology (2nd ed.). NY: Academic Press, 1984.

WOSIACKI, G; CEREDA, M. Valorização dos resíduos do processamento de mandioca. Publication UEPG - Ciências Exatas e da Terra, v. 8, n. 1, p. 27-43, 2002.

WU, W.S., TSAI, Y.H., WEI, C.I., SUN PAN, B., HUANG, T.C. Effects of organic acids on the pasting properties of rice flour from waxy and nonwaxy varieties. J. Food Qual. v. 33, p. 137-154, 2010.

XIAOBO, L. I. (2008). Microorganisms and Meat Spoilage. Meat Research, v. 09, p. 41-44, 2008.

YAM, K. L.; TAKHISTOV, P.T.; MILTZ, J. Intelligent packaging: concepts and applications. Journal of food science, v. 70, n. 1, p. R1-R10, 2005.

YOON, S.D.; CHOUGH, S.H.; PARK, H.R. Properties of starchbased blend films using citric acid as additive. II. J. Appl. Polym. Sci., v. 100, p. 2554-2560, 2006.

YOSHIDA, C. M. P.; MACIEL, V. B. V.; MENDONÇA, M. E. D.; \& FRANCO, T. T. Chitosan biobased and intelligent films: Monitoring $\mathrm{pH}$ variations. LWT - Food Science and Technology, v. 55, n. 1, p. 83-89, 2014.

YU, J., WANG, N., MA, X. The effects of citric acid on the properties of thermoplastic starch plasticized by glycerol. Starch/Stärke, v. 57, p. 494-504, 2005. 
YUN, Y.H.; NA, Y.H.; YOON, S.D. Mechanical properties with the functional group of additives for starch/PVA blend film. J. Polym. Environ, v.14, p. 71-78, 2006.

ZHAI, X.; SHI, J.; ZOU, X.; WANG, S.; JIANG, C.; ZHANG, J.; HUANG, X.; ZHANG, W.; HOLMES, M. Novel colorimetric films based on starch/polyvinyl alcohol incorporated with roselle anthocyanins for fish freshness monitoring. Food Hydrocolloids, v. 69, p. 308 - 317, 2017.

ZHANG, B.; LI, X.; XIE, Q.; TAO, H.; WANG, W.; CHEN, H. Q. Preparation and characterization of non-crystalline granular starchand corresponding carboxymethyl starch. International Journal of Biological Macromolecules, v. 103 p. 656-662, 2017.

ZHANG, J.; ZOU, X.; DONG ZHAI, X.; HUANG, X. W.; JIANG, C. P.; HOLMES, M. Preparation of an Intelligent pH Film Based on Biodegradable Polymers and Roselle Anthocyanins for Monitoring Pork Freshness. Food Chemistry (2018), doi: https://doi.org/10.1016/j.foodchem.2018.08.041

ZHANG, Y. R. et al. Influence of oxidized starch on the properties of thermoplastic starch. Carbohydrate Polymers, v. 96, p. 358-364, 2013.

ZHANG, J., \& SUN, X. Mechanical properties of poly(lactic acid)/starch composites compatibilized by maleic anhydride. Biomacromolecules, v. 5, p. 1446-1451, 2004. 